\title{
Secondary Exploits
}

\section{Sustaining the Post-Industrial Landscape of the Booth Street Complex through Architectural Reuse \& Salvage}

by

Kathleen Jillian Coulthart

\begin{abstract}
A thesis submitted to the Faculty of Graduate and Postdoctoral
\end{abstract}
Affairs in partial fulfillment of the requirements

for the degree of

Master

in

Architecture

Carleton University

Ottawa, Ontario

(C) 2019

Kathleen Jillian Coulthart 


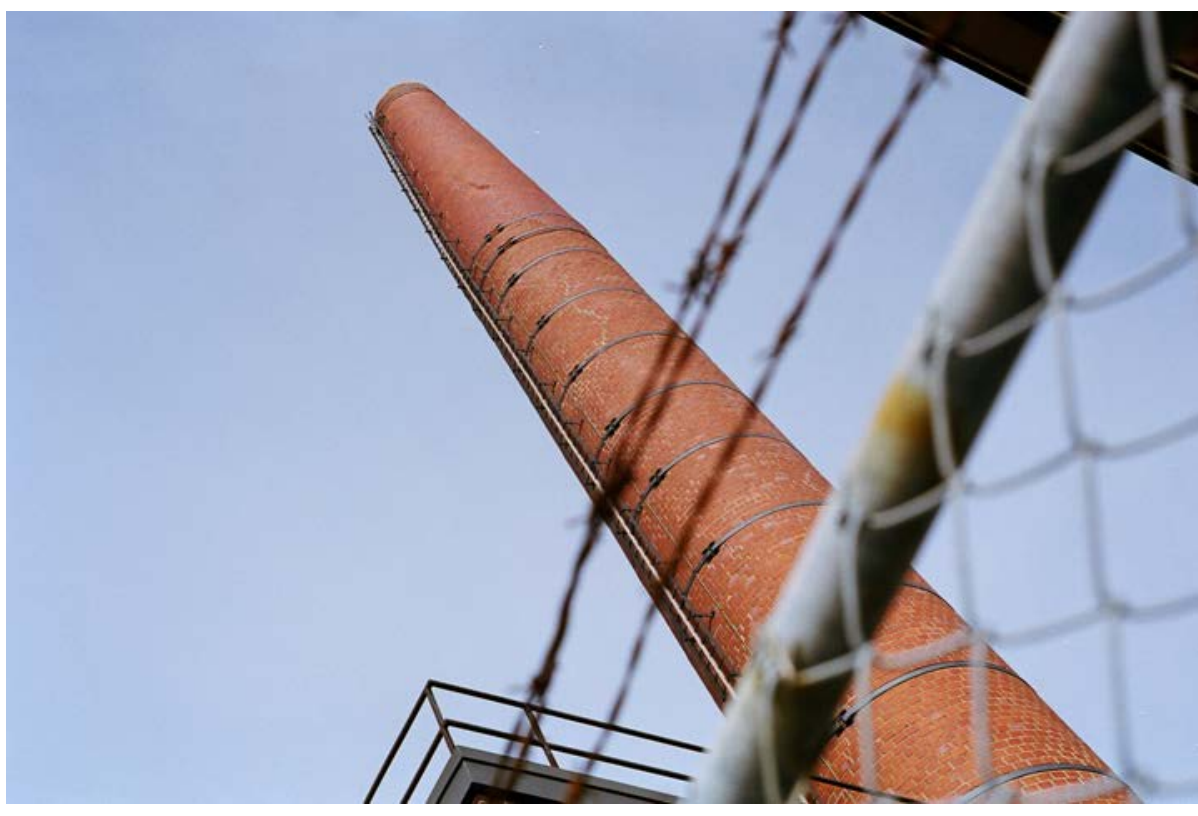

"The exploitation of resources requires three distinct steps - geological exploration and mapping, mining and extraction, and the processing and refining of these materials of geological origin. ${ }^{\prime 1}$

- Alex Ignatieff, 1975 
The contemporary contexts of climate change and urbanization are two which can be characterized by unprecedented change, often accompanied by degradation of built, natural and political landscapes. As a viable solution, the existing architectural building stock provides a wealth of potential for helping to abate the impending crisis. To explore the possibility of sustaining both the integrity of the built environment and of cultural identity, this thesis investigates architectural reuse and salvage as a secondary exploit of resources — resources which are manifest as values and as materials readily found within existing fabrics. How can a post-industrial urban society capitalize on the potential of embodied material and societal wealth found within existing architecture, via secondary sourcing, extracting and processing? To respond to this question, the following exploratory work focuses on Ottawa's Booth Street Complex, its associated network of industrial research and development sites, as well as the materials which comprise both.

Occupied by the federal government's Department of Mines and Natural Resources since its inception, Ottawa's Booth Street Complex is a site which tells stories of local and national significance. Analysis of the complex reveals repercussive impacts onto the greater Canadian landscape, resulting in an increased magnitude of resource extraction as well as an increased presence of current industrial heritage. Through an examination of the status and evolution of a selection of associated sites, a model of cyclical existence is derived, which then informs the interpretation of the local architectural proposal.

A decline in growth of the federal research and development sector has lead to the vacation of numerous buildings within the Booth Street Complex. As a result, the process of federal property disposal is underway and a portion of the site is slated for redevelopment by Canada Lands Corporation. In reaction, this thesis proposes an impactful and sustainable interpretation of the entirety of the Booth Street Complex - one which maintains its value and promotes architectural and environmental longevity through appropriate treatment, reuse and salvage, proposing a model for encouraging the circular economy and comprehensive interpretation. 


\section{Acknowledgments}

I would like to sincerely thank my thesis advisors, Professor Mariana Esponda and Professor Susan Ross, for their unwavering encouragement and support throughout this experience. Your passion for sustainability and heritage has been, and will continue to be, incredibly inspiring.

I would also like to thank the entire faculty and staff within the school of architecture. I have been extremely fortunate to have been surrounded and supported by a such caring, helpful and dedicated group of individuals.

Finally, I would like to thank my parents, family and friends. Your constant support, throughout not only this final thesis year, but my entire architectural education, has made this all possible - thank you. 


\section{Table of Contents}

i Abstract

ii Acknowledgments

iii Table of Contents

vii List of Illustrations

01

10

11

14

17

18

18

Introduction

Chapter I

Chapter II

Part 1: Exploration and Mapping

Defining (Post) Industrial (Cultural) Landscapes

1.1 Cultural Landscapes and Memories of Industry

Defined: Landscapes

Cultural Landscapes

Embedded Memories

1.2 Industrial Heritage and (Post) Industrial Landscapes

Industrial Heritage and The Dublin Principles

Defined: Industrial Landscapes

Defined: Post Industrial Landscapes

1.3 Chapter Conclusions

Secondary Exploits via Reuse, Deconstruction and Salvage

2.1 Reuse of Industrial Heritage

Embodied Energy

Conservation Treatments and Adaptive Reuse

Defined: Interpretation 
Defined: Salvage

Contemporary Need

Historical Practices

Modern Models of Material Reuse

2.3 Precedent Projects

Precedent A: Duisburg Landscape Park

Precedent B: Toronto's Distillery District

Precedent C: Opalis.be

Precedent D: Sunset Park Material Recovery Facility

\section{Chapter III}

The Industrial Heritage of the Booth Street Complex

3.1 Development of Department of Natural Resources

The Birth of the Booth Street Complex

Timeline of the Department of Natural Resources

Part 2: Development and Extraction

\section{Chapter IV}

National Implications: A Network of Industry

4.1 A Landscape of Industrial Extraction

Representing Canada's Landscape of Extraction

Satellite Imagery of Auxiliary Sites

4.2 Auxiliary Site Analysis

Individual Site Descriptions

Catalogue of Evolution Maps

4.3 Spectrum of Existence Matrix and Results

70

4.4 Chapter Conclusions

\section{Chapter V}

Local Implications: The Booth Street Complex Site

5.1 The Recognized and Unrecognized Layers of History

Pre Industrial Histories

Proto Industrial Histories 
Chapter VI

Architectural Status and Redevelopment

6.1 Future Development Plans

Federal Disposal

The Canada Lands Corporation Proposal

Provincial Heritage Designation Proceedings

96

6.2 Complex Documentation

Character Defining Elements

Contamination Overview

6.3 An Extrapolated Future

Part 3: Processing and Refining

Chapter VII

Macro Design Approach: Site as Landscape

$$
\begin{gathered}
\text { 7.1 Classification of the Booth Street Complex Landscape } \\
\text { 7.2 Life-Cycle Phase Application } \\
\text { Existing and Projected Site Phases } \\
\text { Objective and Updates of Terminologies }
\end{gathered}
$$

$$
\text { 7.3 The Macro Site Proposal }
$$

\section{Chapter VIII}

Mezzo Design Approach: Site as Post-Industrial Complex

8.1 Overall Design Objectives and Approaches

8.2 Program Proposal

Alignment of Objectives and Programming

Determining Program Elements

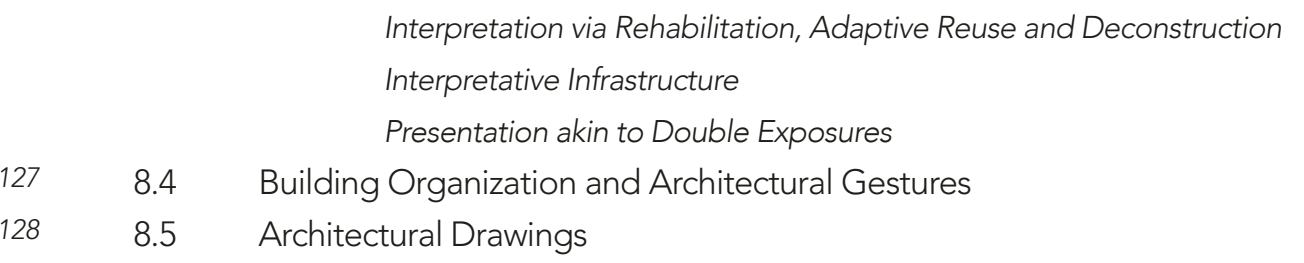


Micro Design Approach: Site as Material Assembly

$1379.1 \quad$ Rationale of Deconstruction

$139 \quad 9.2$ Reclaimed Materials for Salvage

\section{Material Cycles}

Material Treatments: New vs. Old

\section{$148 \quad$ Chapter $\mathrm{X}$}

Conclusions and Post Project Reflections

$$
\begin{aligned}
& \text { Response to Thesis Question } \\
& \text { Reflections upon Methodology } \\
& \text { Reflections upon Approach } \\
& \text { Areas for further Development } \\
& \text { Post-Project Conclusions }
\end{aligned}
$$

\section{$151 \quad$ Appendices}
A. Glossary
B. Site Building Information Tables
C. Photographic Documentation
D. Auxiliary Site Reports
E. The Dublin Principles
F. Thesis Defense Information
G. Reference List 


\section{List of Figures}

Figure $0.01 \quad 03$ Context Map of Booth Street Complex with Quadrants Distinguished By Author

Figure 0.0204 Aerial View of Booth Street Campus c. 2018 Retrieved from: Google Earth Pro

Figure $1.01 \quad 10$ Topographical Surveyors from Geological Survey c. 1922 Retrieved from: Library and Archives Canada - MIKAN No. 4493442

Figure 1.02 20 Embodied Energy compared to Average Building Service Expectancies By Author

Figure 1.03 30 Video Snapshots of New York's Star Theater Building being deconstructed in 1901. Retrieved from: https://www. youtube.com/watch?v=NIU746PLSMC

Figure 1.04 31 Video Snapshots of Ottawa's Sir John Carling Building being demolished in 2014. Retrieved from : https://globalnews.ca/video/1449452/sir-john-carling-building-demolished

Figure 1.05 33 The Delft Ladder showing iterative Life-Cycle Material Flow

Retrieved from: Addis, Bill. Building with Reclaimed Components and Materials: A Design Handbook for Reuse and Recycling. Routledge, 2012.

Figure 1.06 33 Resource Hierarchy Pyramid Retrieved from: Guy, Brad. "Towards a Broader Culture of Reuse: US Perspective." Lecture Heritage in Reverse Symposium, Carleton University, Ottawa, October 27, 2018.

Figure 1.07 $34 \quad$ Aerial Image of Duisburg Landscape Park Retrieved from: https://www.open-iba.de/site/assets/files/1121/dsc_2176.770x770.jpg

Figure 1.08 34 On site Bioremedation at Duisburg Landscape Park Retrieved from: https://s3.eu-central-1.amazonaws.com/locationscoutnet/images/2018-09/ landschaftspark-duisburg-nord-germany_l.jpeg

Figure 1.09 35 Toronto's Distillery District Retrieved from: https://www.open-iba.de/site/assets/files/1121/dsc_2176.770x770.jpg

Figure 1.10 35 Aerial Image of Toronto's Distillery District Retrieved from: https://static.squarespace.com/ static/529fc0c0e4b088b

Figure 1.11 36 Opalis Photography Exhibit Retrieved from: http://archief.z33.be/sites/default/files/imagecache/default/content_images/z33/ atelierahabiter-rotor-opalis04-opening.jpg

Figure 1.12 36 One of the material yards part of Opalis

Retrieved from: http://rotordb.org/works/2012_opalis/IMG_0479202_opalis_rotor.jpg 


\begin{abstract}
Figure 1.13 37 Interior of Sunset Park Material Recovery Facility
Retrieved from: https://images.adsttc.com/media/images/537e/c6d8/c07a/8094/6d00/021f/large_ jpg/05.jpg?1400817346

Figure 1.14 37 Administration vs. Operating Wings of Sunset Park Material Recovery Facility Retrieved from: https://images.adsttc.com/media/images/537e/c6d8/c07a/8094/6d00/021f/large_ jpg/05.jpg?1400817346
\end{abstract}

Figure 1.1543 Timeline of the Department of Natural Resources By Author

Figure 2.01 44 Worker at Jeffrey Mine drilling to remove asbestos ore c.1944

Retrieved from: Retrieved from: Library and Archives Canada - MIKAN No.3197546

Figure 2.02 47 Map of 'Canadian Sites of Extraction c. 2017'

By Author

Figure 2.03 49 Satellite Image of Alfred Bog in Ontario c. 2018

Retrieved from: Google Earth Pro

Figure 2.04 49 Satellite Image of Copper Cliff Mine in Ontario c. 2018

Retrieved from: Google Earth Pro

Figure 2.05 $50 \quad$ Satellite Image of Jeffrey Mine in Quebec c. 2018

Retrieved from: Google Earth Pro

Figure 2.06 $50 \quad$ Satellite Image of Trail Smelter in British Columbia c. 2018

Retrieved from: Google Earth Pro

Figure 2.07 $51 \quad$ Satellite Image of Athabasca Tar Sands c. 2018

Retrieved from: Google Earth Pro

Figure 2.08 51 Satellite Image of Mandy Mine in Manitoba c. 2018

Retrieved from: Google Earth Pro

Figure 2.09 52 Satellite Image of Sydney Coal Fields in Nova Scotia c. 2018

Retrieved from: Google Earth Pro

Figure 2.10 52 Satellite Image of Port Radium in North-West Territories c. 2018

Retrieved from: Google Earth Pro

Figure 2.11 53 Satellite Image of Jericho Diamond Mine in Nunavut c. 2018

Retrieved from: Google Earth Pro

Figure 2.1253 Satellite Image of Dredge No.4 in Yukon c. 2018

Retrieved from: Google Earth Pro

Figure 2.13 58 Mapped Evolution of Alfred Bog, ON

By Author

Figure 2.14 59 Mapped Evolution of Copper Cliff Mine, ON

By Author

Figure 2.15 60 Mapped Evolution of Jeffrey Mine, QC

By Author

Figure 2.16 61 Mapped Evolution of Trail Smelter, BC

Figure 2.17 62 Mapped Evolution of Athabasca Tar Sands, AB

By Author

Figure 2.18 63 Mapped Evolution of Mandy Mine, MB

By Author 
Figure 2.19 64 Mapped Evolution of Sydney Coal Fields, NS

By Author

Figure 2.20 65 Mapped Evolution of Port Radium, NWT

By Author

Figure 2.21 66 Mapped Evolution of Jericho Mine, NU

By Author

Figure 2.22 67 Mapped Evolution of Dredge No. 4, YK

By Author

Figure 2.23 69 Spectrum of Existence Radial Matrix for the Ten Selected Industrial Sites By Author

Figure 2.24 73 Overlaid Ottawa Fire Insurance Plans from 1901

Retrieved from: https://library.carleton.ca/find/gis/geospatial-data/georeferenced-ottawa-fireinsurance-plans

Figure 2.25 $74 \quad$ Overlaid Ottawa Fire Insurance Plans from 1912

Retrieved from: https://library.carleton.ca/find/gis/geospatial-data/georeferenced-ottawa-fireinsurance-plans

Figure 2.26 $75 \quad$ Overlaid Ottawa Fire Insurance Plans from 1948

Retrieved from: https://ibrary.carleton.ca/find/gis/geospatial-data/georeferenced-ottawa-fireinsurance-plans

Figure 2.27 $76 \quad$ Overlaid Ottawa Fire Insurance Plans from 1953

Retrieved from: https://library.carleton.ca/find/gis/geospatial-data/georeferenced-ottawa-fireinsurance-plans

Figure 2.28 77 Original Fuel Testing Station c. 1912

Retrieved from: http://central.bac-lac.gc.ca/.item?app=fondsandco/\&op=img\&id=a013721-v8

Figure 2.29 77 Wooden house, since demolished on site of current complex c. 1930

Retrieved from: http://3.bp.blogspot.com/-00dltyTXNUY/URwhwn7-YLI/AAAAAAAAKAc/ LRzlhhdZnel/s640/e010934887.jpgitem?app=fondsandcol\&op=img\&id=a013721-v8

Figure 2.30 77 The Booth Lumber Yard on site of modern Geological Survey of Canada Building. Unknown Date

Retrieved from: http://3.bp.blogspot.com/-00dltyTXNUY/URwhwn7-YLI/AAAAAAAAKAc/ LRzlhhdZnel/s640/e010935940.jpgitem?app=fondsandcol\&op=img\&id=a013721-v8

Figure 2.31 78 Aerial Imageries from 1928, 1933, 1958, 1965, 1976 and 1991

Retrieved from: maps.ottawa.ca/geoottawa/

Figure 2.32 79 Original Fuel Testing Station and adjacent sheds c. 1912

Retrieved from: Ignatieff, Alex. A Canadian Research Heritage. Ottawa: Canadian Gov. Publ. Centre, Supply and Services Canada, 1981.

Figure 2.33 79 Wooden and Metal Buildings, Unknown Date

Retrieved from: Ignatieff, Alex. A Canadian Research Heritage. Ottawa: Canadian Gov. Publ. Centre, Supply and Services Canada, 1981.

Figure 2.34 79 Quonset Huts, c. 1955

Retrieved from: Ignatieff, Alex. A Canadian Research Heritage. Ottawa: Canadian Gov. Publ. Centre, Supply and Services Canada, 1981.

Figure 2.35 $80 \quad$ Earliest Overall Plan of Booth Complex c. 1925,

Retrieved from: Ricketts, Shannon. FHBRO Building Report 86-61: Four Structures on the EMR Complex, Booth Street, Ottawa. Ottawa, ON: Federal Heritage Buildings Review Office, 1986.

Figure 2.36 80 Proposed Complex Schematic c. 1931 by Noffke,

Retrieved from: Ricketts, Shannon. FHBRO Building Report 86-61: Four Structures on the EMR Complex, Booth Street, Ottawa. Ottawa, ON: Federal Heritage Buildings Review Office, 1986. 


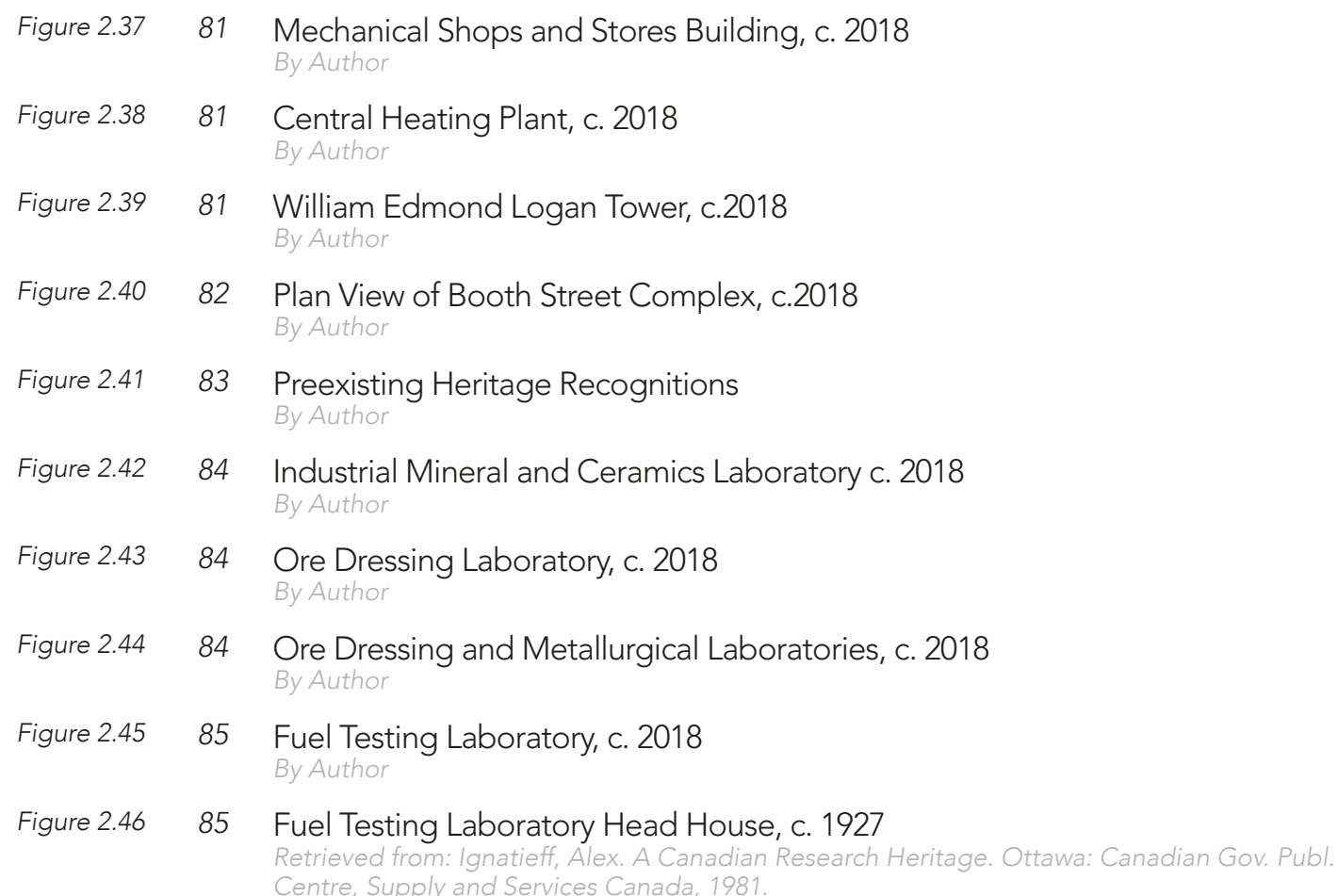

Figure $2.47 \quad 86 \quad$ Physical Metallurgical Laboratories c. 2018

By Author

Figure 2.48 86 Chemical and Radioactive Ores Building, c. 2018

By Author

Figure 2.49 $86 \quad$ Chemical and Radioactive Ores Building, c. 2018

By Author

Figure 2.50 87 Surveys and Mapping Building, c. 2018

By Author

Figure 2.51 87 Geological Survey of Canada Building, c. 1955

Retrieved from: Ignatieff, Alex. A Canadian Research Heritage. Ottawa: Canadian Gov. Publ. Centre, Supply and Services Canada, 1981.

Figure 2.52 88 Geological Survey of Canada Building, c. 2018

By Author

Figure 2.53 88 Administration Building, c. 2018

By Author

Figure 2.54 88 Complex rendering, c. 1954

Retrieved from: http://3.bp.blogspot.com/-00dltyTXNUY/URwhwn7-YLI/AAAAAAAAKAc/ LRzlhhdZnel/s640/e010935940.jpgitem?app=fondsandcol\&op=img\&id=a013721-v13

Figure 2.55 89 Timeline of Booth Street Complex's Development By Author

Figure 2.56 94 Massing Proposal by Canada Lands Corp - Rendering looking North-East Retrieved from: ERA Architecture, Stantec Consulting Ltd., and Hill Knowlton Strategies. "Canada Lands Company Booth Street Redevelopment." City of Ottawa Webcast. March 28, 2018.

Figure 2.57 94 Massing Proposal by Canada Lands Corp-Rendering looking South-West Retrieved from: ERA Architecture, Stantec Consulting Ltd., and Hill Knowlton Strategies. "Canada Lands Company Booth Street Redevelopment." City of Ottawa Webcast. March 28, 2018. 


\begin{tabular}{|c|c|c|}
\hline Figure 2.58 & 97 & $\begin{array}{l}\text { Ontario Heritage Act Recognitions c. } 2019 \\
\text { By Author }\end{array}$ \\
\hline Figure 2.59 & 98 & $\begin{array}{l}\text { Table of Exemplary Character Defining Elements for the B } \\
\text { c. } 2019 \\
\text { By Author }\end{array}$ \\
\hline Figure 2.60 & 99 & $\begin{array}{l}\text { Character Defining Elements of The Industrial Minerals an } \\
\text { at } 405 \text { Rochester St. and The Ore Dressing Laboratories (2 } \\
\text { By Author and Michelle McKenna }\end{array}$ \\
\hline Figure 2.61 & 100 & $\begin{array}{l}\text { Character Defining Elements of The Ore Dressing Labora } \\
\text { and The Ore Dressing and Metallurgical Laboratories (3a- } \\
\text { By Author and Michelle McKenna }\end{array}$ \\
\hline Figure 2.62 & 101 & $\begin{array}{l}\text { Character Defining Elements of The Ore Dressing Laborat } \\
\text { By Author and Michelle McKenna }\end{array}$ \\
\hline Figure 2.63 & 102 & $\begin{array}{l}\text { Character Defining Elements of The Ore Dressing Labora } \\
\text { St., The Fuel Testing Laboratory (6) at } 562 \text { Booth St. and th } \\
\text { at } 558 \text { Booth St. } \\
\text { By Author and Michelle McKenna }\end{array}$ \\
\hline Figure 2.64 & 103 & $\begin{array}{l}\text { Character Defining Elements of The Central Heating Plan } \\
\text { The Mechanical Shops and Stores Building (4) at } 556 \text { Boot } \\
\text { Metallurgy Laboratories (7a-e) at } 568 \text { Booth St. } \\
\text { By Author and Michelle McKenna }\end{array}$ \\
\hline Figure 3.01 & 106 & $\begin{array}{l}\text { Photograph at Corner of Booth St and Lydia St, c.1940 } \\
\text { Retrieved from: Library and Archives Canada - MIKAN No.4170173 }\end{array}$ \\
\hline Figure 3.02 & 111 & $\begin{array}{l}\text { Pre-Disposal Life-Cycle Phase c. } 2011 \\
\text { By Author }\end{array}$ \\
\hline Figure 3.03 & 112 & $\begin{array}{l}\text { Mid-Disposal Life-Cycle Phase c. } 2019 \\
\text { By Author }\end{array}$ \\
\hline Figure 3.04 & 113 & $\begin{array}{l}\text { Projected Post-Disposal Life-Cycle Phase c. } 2030 \\
\text { By Author }\end{array}$ \\
\hline Figure 3.05 & 116 & $\begin{array}{l}\text { Proposed Life-Cycle Phase Landscape Design Approach } \\
\text { By Author }\end{array}$ \\
\hline Figure 3.06 & 124 & $\begin{array}{l}\text { Double Exposure } 1 \text { - Geological Survey of Canada } \\
\text { By Author }\end{array}$ \\
\hline Figure 3.07 & 125 & $\begin{array}{l}\text { Double Exposure } 2 \text { - Fuel Testing Division } \\
\text { By Author }\end{array}$ \\
\hline Figure 3.08 & 126 & $\begin{array}{l}\text { Double Exposure } 3 \text { - Ore Lifting and Dressing } \\
\text { By Author }\end{array}$ \\
\hline Figure 3.09 & 128 & $\begin{array}{l}\text { Level -1 Plan - Rochester Frontage } \\
\text { By Author }\end{array}$ \\
\hline Figure 3.10 & 129 & $\begin{array}{l}\text { Level O Plan } \\
\text { By Author }\end{array}$ \\
\hline Figure 3.11 & 130 & $\begin{array}{l}\text { Level } 1 \text { Plan - Booth Frontage } \\
\text { By Author }\end{array}$ \\
\hline Figure 3.12 & 131 & $\begin{array}{l}\text { Level } 2 \text { Plan } \\
\text { By Author }\end{array}$ \\
\hline
\end{tabular}




\begin{tabular}{|c|c|c|}
\hline Figure 3.13 & 132 & $\begin{array}{l}\text { Level } 3 \text { Plan } \\
\text { By Author }\end{array}$ \\
\hline Figure 3.14 & 133 & $\begin{array}{l}\text { Level } 4 \text { Plan } \\
\text { By Author }\end{array}$ \\
\hline Figure 3.15 & 134 & $\begin{array}{l}\text { Roof Plan } \\
\text { By Author }\end{array}$ \\
\hline Figure 3.16 & 135 & $\begin{array}{l}\text { Section Drawing A } \\
\text { By Author }\end{array}$ \\
\hline Figure 3.17 & 136 & $\begin{array}{l}\text { Section Drawing B } \\
\text { By Author }\end{array}$ \\
\hline Figure 3.18 & 140 & $\begin{array}{l}\text { Salvaged Material Quantification and Reuse Graphic } \\
\text { By Author }\end{array}$ \\
\hline Figure 3.19 & 143 & $\begin{array}{l}\text { Mechanical Shops and Stored Building: Level -1 Plan } \\
\text { By Author }\end{array}$ \\
\hline Figure 3.20 & 144 & $\begin{array}{l}\text { Mechanical Shops and Stored Building: Level } 0 \text { Plan } \\
\text { By Author }\end{array}$ \\
\hline Figure 3.21 & 145 & $\begin{array}{l}\text { Mechanical Shops and Stored Building: Level } 1 \text { Plan } \\
\text { By Author }\end{array}$ \\
\hline Figure 3.22 & 146 & $\begin{array}{l}\text { Mechanical Shops and Stored Building: Level } 2 \text { Plan } \\
\text { By Author }\end{array}$ \\
\hline Figure 3.23 & 147 & $\begin{array}{l}\text { Mechanical Shops and Stored Building: Roof Plan } \\
\text { By Author }\end{array}$ \\
\hline
\end{tabular}




\section{Introduction}

During the post-war era, following an influx of technological advancements initiated by the research of the Geological Survey of Canada and the Federal Mines Branch, the sourcing, extracting and processing of Canada's natural resources grew more attainable, resulting in its exploitation by both public and private industries. ${ }^{1}$ Historical industrial endeavors not only allowed for, but spurred nationwide settlement, growth in the national economy and capitalism, and ultimately lead to Canada's development.

As time progresses and technologies evolve, so do the affiliated built physical contexts and resultant civic sentiments towards them. The resource extraction industry is now a controversial issue. While modern-day intrusive industrial actions support the economy, they also have significant impacts upon the surrounding environments. Canada's natural landscape is no longer the pristine and untouched wilderness which so many Canadians would prefer to imagine. I In actuality, scattered across rural and urban terrains, are both operable and abandoned objects, artifacts and markings of our industrial research and development heritage, which not only reveal an environmentally and politically controversial past but potentially scripts an unwanted future. Permanently embedded into not only the physical landscape of the country but also into the social identity of the people, are the tools of primary resource exploitation.

The thesis work explores the potential for sustaining the integrity of our built environment and our cultural identity via architectural reuse and deconstruction as a secondary exploit of resources - resources manifest as values and as materials, now readily found within existing architectures. Can a contemporary and rapidly urbanizing society capitalize on the potential of embodied material and societal wealth via the secondary sourcing, extraction, and processing of the presented resources?

1. Ignatieff, Alex. A Canadian Research Heritage. Ottawa: Canadian Gov. Publ. Centre, Supply \& Services Canada, 1981.

2. Bélanger, Pierre, ed. Extraction Empire. Mit Press, 2018. 
To respond to this question, Ottawa's Booth Street Complex, its associated network of auxiliary sites, and the materials which comprise the associated landscape have been selected for study.

Over time, the Booth Street Complex, which has a history of governmental use dating back to the early twentieth century, has expanded from a single modest building in an industrial sector south of the city, to a complex now occupying some twenty-seven acres of prime urban land. Since 1908, the buildings within the Booth Street Complex have played host to scientists, geologists, cartographers, engineers, and to the Department of Natural Resource's capital workforce. Despite this, the future use of the complex is currently uncertain. Due to a decline in departmental growth, staff cuts and increasing privatization within the sector, the buildings comprising the north-western quadrant of the complex have been vacated. Consequently in 2011, the property was been deemed surplus by the title department, igniting the process of federal property disposal. The remaining federal buildings throughout the remainder of the complex are showing signs of deterioration, and the complex as a whole is in a dire state of need.

The Booth Street Complex is now split in ownership between two bodies; the title of the north-western quarter of the site was transferred to Canada Lands Corporation in October of 2015, while the remainder has been retained by Canada's federal department of Natural Resources. (Figure 0.1) Canada Lands Corporation is a federal crown corporation that specializes in real estate and development. In the case of the Booth Street Complex, the role of the corporation is to facilitate zoning and planning amendments, as well as ensure heritage protection with the city of Ottawa.

Many of the facilities within the Booth Street Complex were originally conceived in response to an increased demand for new research and development pertaining to Canada's growing geological and mining industries. ${ }^{3}$ The many laboratories, workshops and testing facilities, which were state-of-the-art at the time of their construction, were heavily relied upon by burgeoning public and private extraction endeavors. ${ }^{4}$ The research, mapping, and testing undertaken at the complex, resulted in the realization of additional extraction sites as well as in greater efficiencies at established plants; ultimately the complex contributed to the expansion of extraction nationwide in Canada. ${ }^{5}$

3. ERA Architecture, Stantec Consulting Ltd., and Hill Knowlton Strategies. "Canada Lands Company Booth Street Redevelopment." City of Ottawa Webcast. March 28, 2018.

4. Ibid.

5. Ignatieff, Alex. A Canadian Research Heritage. Ottawa: Canadian Gov. Publ. Centre, Supply \& Services Canada, 1981. 


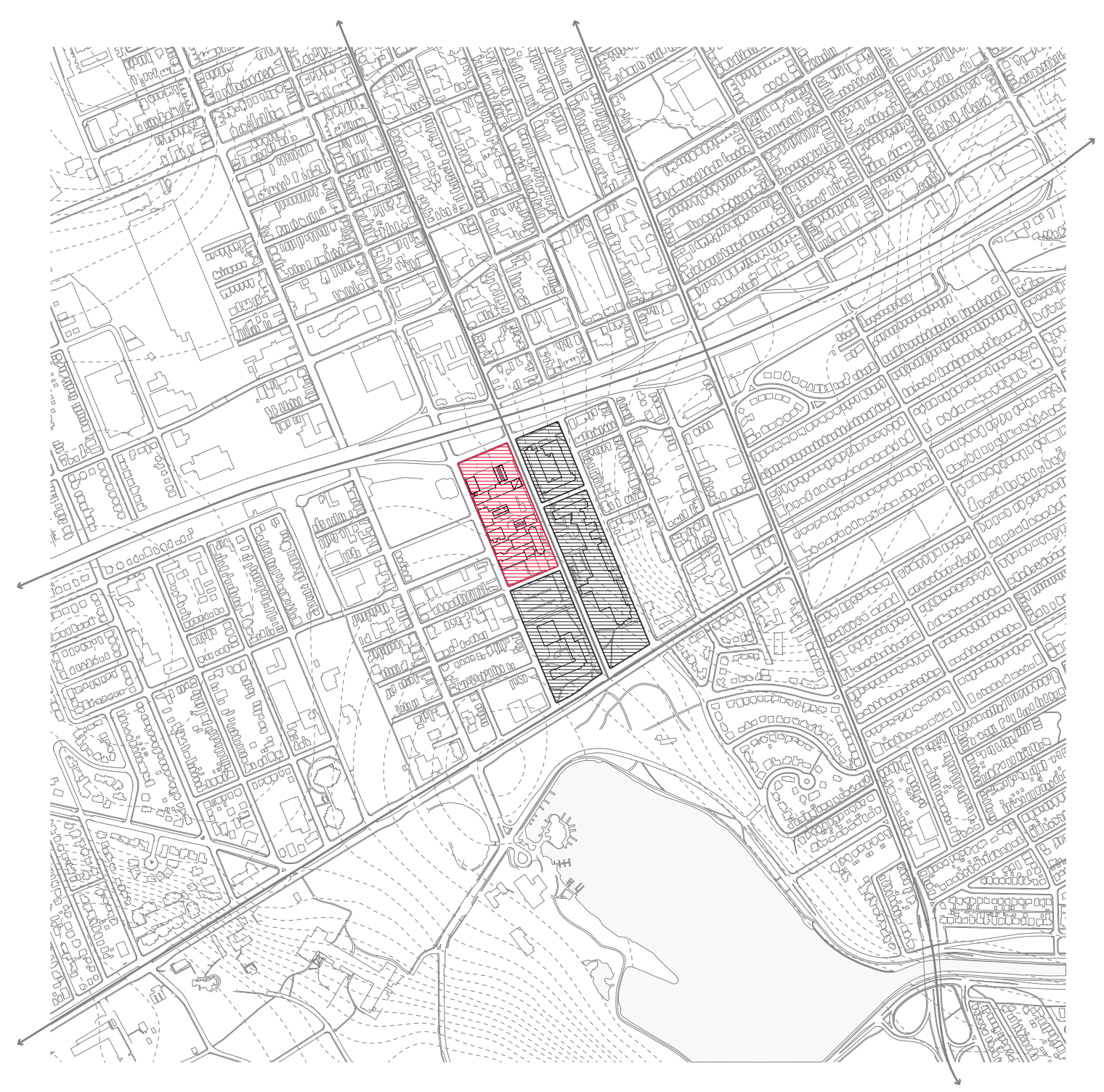

Figure 0.01: Context Map of Booth Street Complex with Quadrants Distinguished. The quadrant hatched red is owned by Canada Lands Corporation. (by Author) 


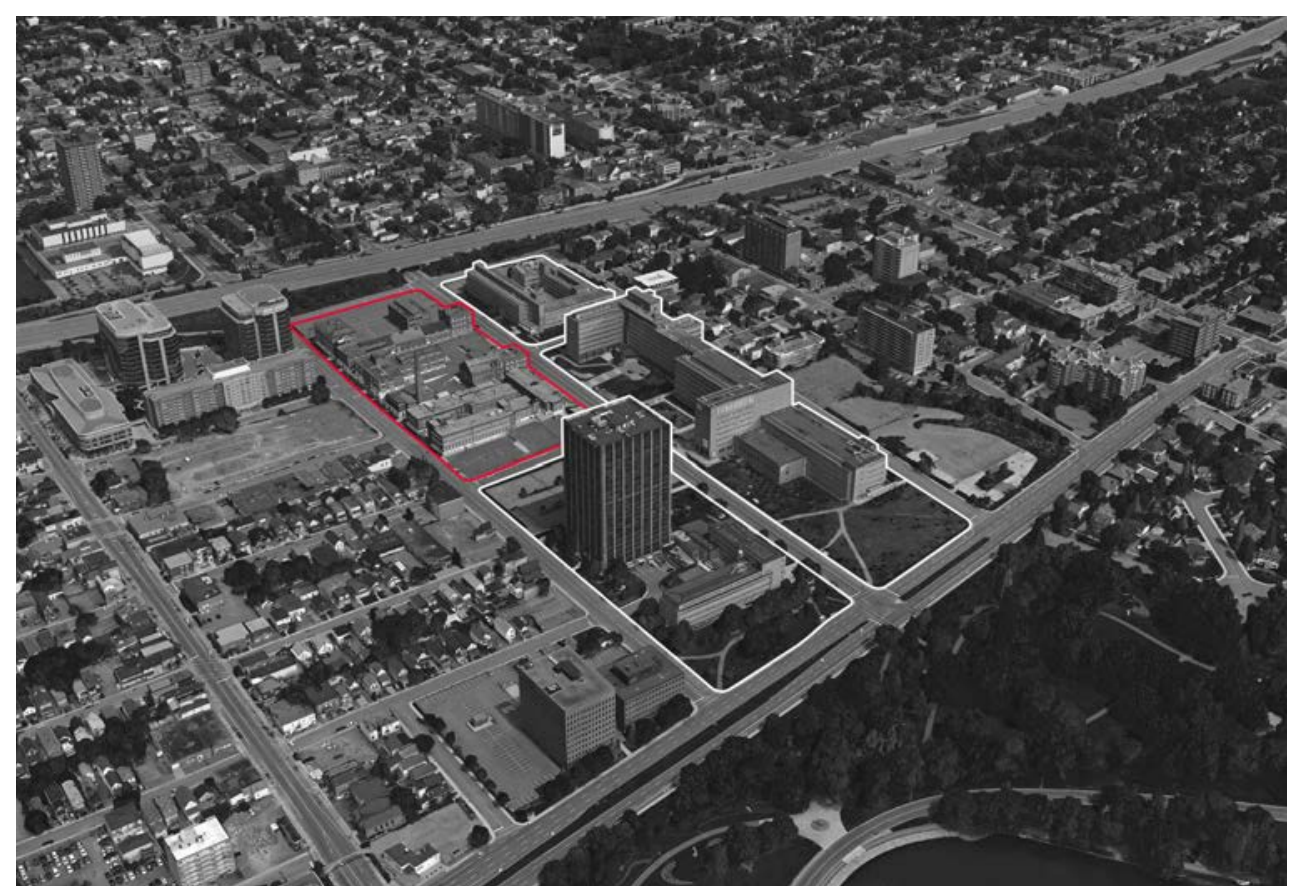

Figure 0.02: Aerial View of Booth Street Campus c.2018 
The reach of the knowledge and technological developments stemming from the Booth Street Complex can be observed through comparison of the site's evolution with that of the extraction industry in Canada. For this reason, the dialogue between the greater, nationwide industrial research landscape and that of the complex is important and perhaps even indicative of the site's future. Are the associated industrial sites undergoing similar transformations? How have they themselves evolved? What are their predicted futures?

Upon both mediums - the physical and social fabrics of our industrial research heritage, each object or artifact of primary exploit is uniquely situated within a spectrum of architectural existence, dynamically positioned between the status of operational and remediated. The operational objects are those which continue to perform in their intended and original manner, whereas artifacts which are remediated have often been reclaimed, erased and forgotten. By addressing Canada's landscape of industrial heritage, it is hoped that a trajectory of site, which addresses the environmental and social setting can be derived in the aim of sustainably conserving the Booth Street Complex.

Objective: Architectural conservation and reuse is capable of sustainably transitioning societal value as well as embodied energy into a medium of future benefit. With this notion as an optimistic ambition, the primary objective of this research and design based thesis is to craft a tri-scaled proposal for the Booth Street Complex and its associated industrial heritage landscape. The architectural subject of this work, and its increasingly controversial history provides the opportunity to make a bold statement about the future of Canadian extraction, the country's historical strategies of territorialization as well as the federal government's role in future environmental stewardship. By applying a macro, mezzo and micro logic to the interpretive architectural proposal, the work is resolved to three co-existing scales: site as landscape, site as complex, and site as materials. This scalar approach allows for speculation at the macro level while also including a degree of technical design on the micro level. Ultimately, the thesis results in an architectural proposal, presented as a model for both sustainable federal and industrial redevelopment and for architectural reuse, deconstruction and material salvage in general.

Scope: As stated within Parks Canada's second edition of 'Standards \& Guidelines: for the Conservation of Historic Places in Canada,' the conservation of architecture "can be seen as a sequence of actions — from understanding the historic place, to planning for its conservation and intervening through projects or maintenance." ${ }^{\prime 6}$ Within this context, the scope of the thesis is all-

6. Standards and Guidelines for the Conservation of Historic Places in Canada. Second ed. Parks Canada. 
encompassing. Through thorough research and fieldwork documentation, an understanding of the Booth Street Complex and its associated auxiliary sites amongst the industrial landscape is achieved. Via subsequent design at the macro and mezzo and levels, a plan for the overall conservation of the sites and of the landscape is proposed, followed by a micro level proposal which explicitly outlines a strategy for working with existing material conditions.

Approach: Early in the research phase of this thesis, a publication by Alex Ignatieff, titled 'A Canadian Research Heritage, 75 years of federal government research in minerals, metals and fuels' was discovered. The publication recounts the history of the Department of Natural Resources, with a focus on the evolution of the Mines Branch specifically. Following is the opening text from this publication:

"The exploitation of mineral resources requires three distinct steps - geological exploration and mapping, mining and extraction ... and the processing and refining of these materials of geological origin. Their association with the geological environment and materials is retained until the degree of purification is reached where man-made products can be manufactured and used. Science and technology that parallel the three steps are used for the complete evaluation of a nation's mineral resources and aids their rational exploitation."7

Can these three steps be used to evaluate and propose a secondary exploit of other resources? What then of re-exploitation?

This question ultimately informed the thesis question and thereafter the approach: Can a contemporary and mainly urban society capitalize on the potential of embodied material and societal wealth via the secondary sourcing, extraction and processing of the presented resources?

Step 1: Sourcing via Exploration and Mapping

Step 2: Mining and Extraction

Step 3: Processing and Refining

7. Ignatieff, Alex. A Canadian Research Heritage. Ottawa: Canadian Gov. Publ. Centre, Supply \& Services Canada, 1981. 
This step by step approach inevitably shaped the development as well as the organization of this thesis. Within the text to follow, the aforementioned steps equate to 'parts' of the thesis, within which, individual Chapters exist based upon their function, objective and essential contributions. Figures within the document are sorted by Part - as found within the list of figures, they are numbered beginning in either 1,2 or 3 .

Part 1 is titled: 'Exploration and Mapping' and is composed of research done during 'Step 1' of the approach. By definition, exploration suggests the act of traveling in or through an unfamiliar area in order to learn about it - for this reason, this first section contains research that is all encompassing and undertaken at a scale once removed from the site specificity of the Booth Street Complex. Guiding architectural theories and concepts of cultural landscapes and conservation, as well as thematic research is included in Part 1, forming Chapters I, II and III respectively.

The mapping aspect of 'Step 1' is less based upon conventional mapping, and rather grounded in mapping as a concept. As described by James Corner,

"Mapping precipitates its more productive effects through finding that is also founding; its agency lies in neither reproduction nor imposition but rather in uncovering realities previously unseen or imagined, even across seemingly exhausted grounds. ${ }^{18}$

Part 1 maps the connections between environmental sustainability and architectural conservation as well as between the federal government and resource extraction.

Part 2: 'Development and Extraction' is much more site-specific than its preceding Part 1. As the title of the section suggests, the work focuses on direct realities of the subject, rather than guiding frameworks. Formed from 'Step 2', the mining and extraction of resources metaphorically equates the culling and defining of value from the Booth Street Complex as well as its associated industrial landscape. Within this section, Chapters IV through VI study the greater industrial heritage landscape of Canada in detail, the history of the Booth Street Complex and the impending redevelopment plans.

Culminating in 'Part 3: Processing and Refining', this last section of the thesis is composed of the design work undertaken within 'Step 3' of the approach. The Chapters included here are titled: Macro, Mezzo and Micro to reflect the three 
scales of design: Landscape, Complex and Material. The architectural design is ultimately generated from a processing of information and from a refinement of space - both crafted and preexisting. The architectural proposals of this Chapter therefore represent the final step in secondary exploitation.

Methodology and Limitations: At the outset of this thesis was a period of exploratory research, followed by site visits and documentation, mapping and then synthesis and design. Although, as suggested by the ordering of Parts 1 through 3 and by the metaphor of extraction, processing and refining, the research, synthesis and design work conducted throughout this thesis was not necessarily done in a chronological ordering but instead was an iterative process. Over the duration of the thesis, thematic research was consistently underway, altering the path and direction of the thesis and the final design proposal.

With the initial objective to better understand the history and associative values of the Booth Street Complex, historic and archival research focused on the 'why' of the site's story. Why was the complex originally designed? Why did the federal Department of Mines and Natural Resources require such a complex? Why has the complex now been partially vacated? The attempt to answer these questions resulted in portions of Chapter III: The Industrial Heritage of the Booth Street Complex, as well as Chapter V: Local Implications: The Booth Street Complex Site, and Chapter VI: Architectural Status and Redevelopment.

Once the 'why' had been answered, the 'what' and 'how' were the followup inquiries. The site's story hinted at a connection to a wider, national landscape which was further investigated within the work of Chapter IV: National Implications: A Network of Industry. Within this Chapter, ten industrial extraction or processing sites across Canada, which were noticeably associated with the Booth Street Complex were selected for further study. Chosen to be representative, with a variation of age, geographical location and resource focus, but also because of their perceived prominence, each site has a unique and important story that not only has implications for the regional landscape, but also the national landscape. In a manner, similar to that of typical architectural precedent studies, the explorations of these sites questioned the form, function, industrial operability and life cycle paths and trajectories. As an output of this study, a series of maps were produced which illustrate physical and associative evolutions of the respective landscapes. From these maps, observations of existence, evolution and termination were made - which were then used to inform the architectural proposal. 
To inform the architectural proposal, a literature review was undertaken which focused on concepts of landscapes, industrial heritage, material reuse culture and deconstruction. It can be found within Chapters I and II.

The resultant design proposal - as illustrated and described within Chapters VII, VIII and IX - represent a distilled and refined response to the work and research undertaken within the preceding Chapters.

A major limitation upon this thesis was imposed by a lack of access to the buildings and the Booth Street Complex site overall. At the outset of the project, it was hoped and understood that Canada Lands Corporation would grant site access to allow for digital documentation and recording but unfortunately this was not permitted. Had the opportunity to visit the north-west quadrant of the complex been given, perhaps the resolution of the architectural proposal would have been higher, the design could have addressed known conditional issues and the overall schematic would have been based on more accurate documentation.

Fortunately, digital photos and historical plan drawings were attained for the complex by a former Masters of Architecture student, Michelle McKenna; however, never have been in any of the building made even working with the exiting drawings a challenge. 


\section{Part 1 : Mapping \& Exploration}

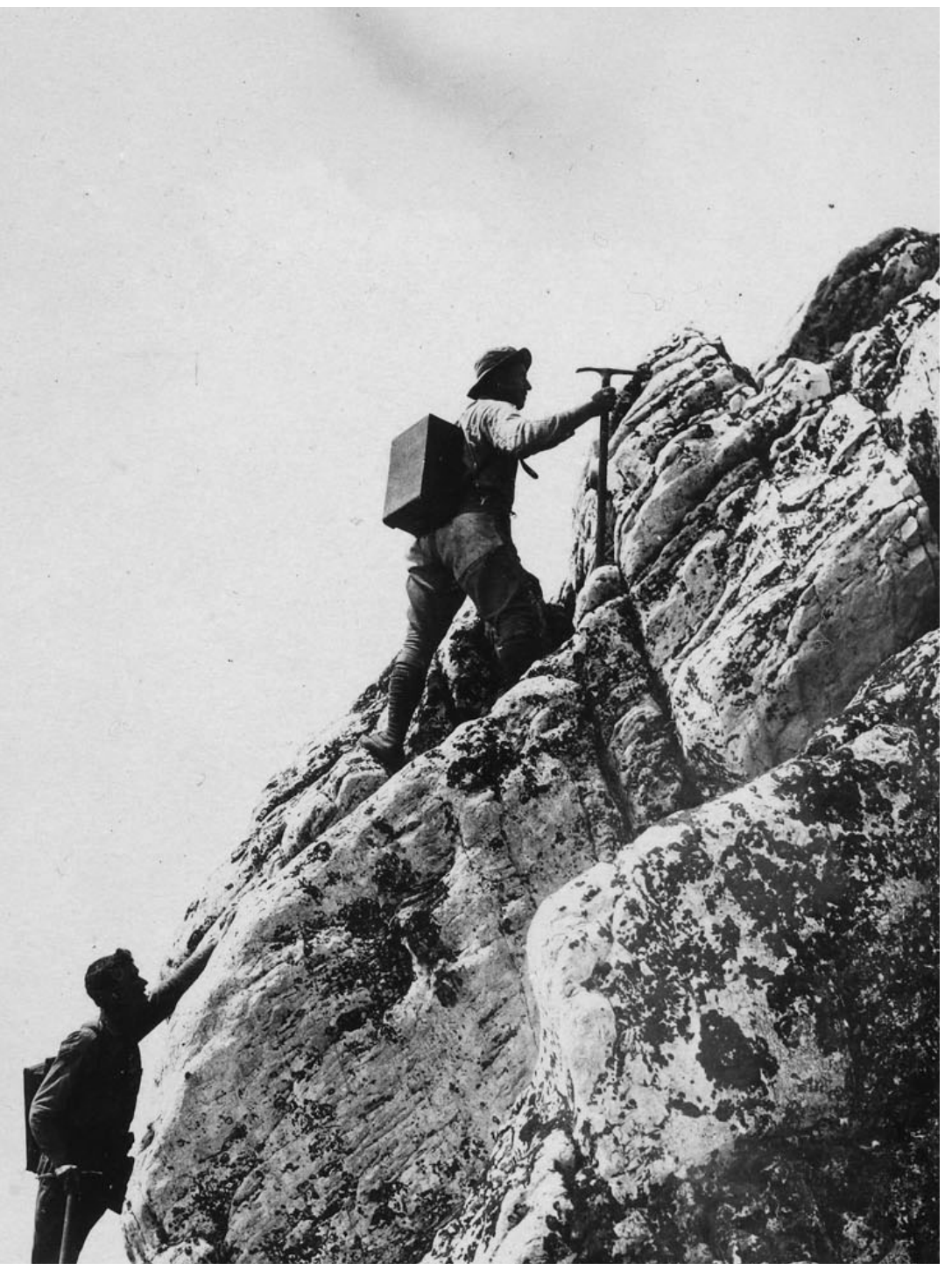

Figure 1.01: Topographical Surveyors from Geological Survey c. 1922 


\section{Chapter I}

\section{Defining (Post) Industrial (Cultural) Landscapes}

Themes: Cultural Landscapes, Industrial Heritage, and Post-Industrial Landscapes

Scattered across Canada's rural and urban terrains, are both operable and static objects, artifacts and markings of industrial heritage upon and within the landscape. These places, which are sometimes celebrated and sometimes purposely forgotten, come in many different forms and styles, respectively reflecting their time of construction and their industrial functions. While some sites continue operating and some are abandoned, others are demolished at the first signs of their industrial obsolescence or when their presence becomes disagreeable with those nearby. What exactly are these places? What connects us to them? What stories can they tell us?

This first Chapter seeks to present and describe the theory, literature, and terminology which provides the contextual setting of this thesis work. By defining the relative concepts of landscape, industrial heritage as well as post-industrial heritage, the Chapter clarifies the meaning of each idea and attempts to respond to the preceding questions.

"To understand ourselves, we need to looksearchingly at our landscapes for they are a clue to culture ${ }^{19}$ (Pierce F. Lewis)

\subsection{Cultural Landscapes and Memories of Industry}

\section{Defined: Landscapes}

In 1979, Donald W. Meinig, an American geographer and author published the essay, 'The Beholding Eye' within which he states that "landscape is an attractive, important, and ambiguous term." ${ }^{10}$ According to his writings, a landscape

8. Taylor, Ken. "Landscape and Memory." Lecture, 16th ICOMOS General Assembly and International Symposium, Quebec. 10. Ibid 
encompasses a wide ensemble of common features which together constitute a rich exhibit of the course and character of society. Meinig states that "landscape is defined by our vision and interpreted by our minds." ${ }^{11}$ By default, individuals project their own beliefs, values, hopes, and fears onto their assessments of a landscape, thereafter crafting an understanding which is subjective, varied and unique - a perception which is socially constructed by the viewer. As time progresses, landscapes have the ability to performatively transform from scene to actor. They become tangibly and intangibly embedded with artifacts, meaning and significance, which along with the succession of generations of peoples, contribute to a community's, and sometimes to a culture's, sense of identity. ${ }^{12}$

\section{Cultural Landscapes}

The landscape of Ottawa's Booth Street Complex as well as that of the greater national industrial network, at the subject of discussion within this thesis, should be defined as cultural landscapes. As defined by UNESCO, cultural landscapes are settings which are the result of the intermingling of man and of nature..$^{13}$ They can be urban or rural. They combine elements of space and time, and as a cumulative whole, represent political as well as social and cultural constructs. Moreover, they contribute to a sense of place and largely to one's identity.

Within his paper presented at the 3rd International Memory and the World Conference in 2008, British Professor, Ken Taylor explains how one's surroundings the landscape - has such a profound influence. He states:

"One of our deepest needs is for a sense of identity and belonging. A common denominator in this is human attachment to [cultural] landscapes and how we find identity in landscape and place. Landscape, therefore, is not simply what we see, but a way of seeing: we see it with our eye but interpret it with our mind and ascribe values to landscape for intangible-spiritual - reasons. ${ }^{\prime \prime 4}$

In other words, the ascribing of values to cultural landscapes is a common denominator for all humans, as the need for a sense of belonging and identity is part of our innate nature. ${ }^{15}$

The Canadian identity is inextricably rooted in, not only the remaining and largely romanticized natural landscape, but also - possibly more importantly, in the realized

\footnotetext{
11. Meinig, D.W, ed. The Interpretation of Ordinary Landscapes: Geographical Essays. New York, NY: Oxford University Press, 1979, 6

12. lbid

13. "Cultural Landscapes." UNESCO World Heritage Centre.

14. Ken Taylor, "Landscape and Memory" (paper presented at 3rd International Memory of the World Conference, Canberra,Australia,

February 19-22 2008), 1

15. Ibid
} 
industrial landscape that has been generated by a result of the nation's extractive industrial activities. Within the Canadian context and with reference to the many artifacts and markings of the country's extraction history, the landscape's influence upon the people is undeniable. Not only has the landscape's various tangible and intangible characteristics dictated many facets of development and use, but the landscape has also created a common setting within which Canadians have encountered life. At the onset, industrial activities and therefore sites, bring with them a level of economic prosperity - which in turn results in increased settlement and density, thus transforming the societal and built landscape in proximity. Between its inherent influence unto the every day, and our industrial extraction activities upon it, there has been a continuous and punctuated dialogue between society and the landscape since industrialization.

\section{Embedded Memories}

The associative values and thereafter memories grafted onto the industrial landscape are significant. Today, the markings and artifacts of the industrial past are representative of a shared experience and of a specific time period of history. Whether the memories which are evoked conjure a place of pride or of shame, their presence ultimately contributes to identity through shared memories.

As Taylor reminds us within his paper, "memory of landscape is not always associated with pleasure. It can be associated sometimes with loss, with pain, with social fracture and [with a] sense of belonging gone." ${ }^{\prime 16}$ Although many Canadians might argue that the industrial activities of the early 20th century and the stories of exploit in the hinterlands bring with it a sense of pride, Taylor's statement sheds light on an irrefutable reality of Canada's industrial landscape - not all memories of these endeavors are positive. For many, they are associated with forceful manipulation of the landscape, cultural loss, fracture, and erasure.

The industrial landscapes of Canada exhibit a palpable and conceptual palimpsestuous existence. With extraction activities, comes a diminished and sometimes a partial erasure of natural resources, of environmental cycles and of land-based cultures. Noting this, there is also, however, a new layer of information added. Through their capturing behavior, cultural landscapes have the ability to reflect and transmit many natural and anthropogenic histories. The resilient and malleable nature of the landscape allows for the expression of embedded memories of hydrologic, topographic and geomorphic transformations, cultural and social practices, economic and demographic processes as well as morphologies of infrastructure and settlement. ${ }^{17}$

16. Ibid, 2

17. New Life for Historic Cities: The Historic Urban Landscape Approach Explained. Paris: UNESCO, 2013, 1 


\subsection{Industrial Heritage and (Post) Industrial Landscapes}

\section{Industrial Heritage and The Dublin Principles}

As defined by the International Committee for the Conservation of the Industrial Heritage $(\mathrm{TICCIH})$, Industrial Heritage is:

"An interdisciplinary method of studying all the evidence, material and immaterial, of documents, artifacts, stratigraphy and structures, human settlements and natural and urban landscapes, created for or by industrial processes. ${ }^{\text {"18 }}$

While also examining its earlier pre-industrial and proto-industrial roots, the field of industrial heritage focuses on the historical period which extends from the date of the beginning of the Industrial Revolution up to and including the present day. ${ }^{19}$ This lengthy time frame results in heritage sites which are diverse in operating purpose, design and built-evolution over time. Many sites are representative of societal processes, technologies as well as regional or historical ecological conditions, whilst others still constitute outstanding achievements of global industrial influence.

"The significance and value of industrial heritage is intrinsic to the structures or sites themselves, their material fabric, components, machinery and setting, expressed in the industrial landscape, in written documentation, and also in the intangible records contained in memories, arts and customs." 20

The need to recognize and protect this significance lead to the creation of the Nizhny Tagil Charter in 2003 - a charter which is now the forefront guiding document regarding the conservation of industrial heritage.

The necessity for the charter is highlighted in the document's preamble and is as follows:

"From the Middle Ages, innovations in Europe in the use of energy and in trade and commerce led to a change towards the end of the 18th century just as profound as that between the Neolithic and Bronze Ages, with developments in the social, technical and economic circumstances of manufacturing sufficiently rapid and profound to be

18. "Dublin Principles." The International Committee for the Conservation of the Industrial Heritage. 2011.

19. Ibid

20. Ibid 
called a revolution. The Industrial Revolution was the beginning of a historical phenomenon that has affected an ever-greater part of the human population, as well as all the other forms of life on our planet, and that continues to the present day. The material evidence of these profound changes is of universal human value, and the importance of the study and conservation of this evidence must be recognized. "21

After the Nizhny Tagil Charter, a further joint agreement between the International Council on Monuments and Sites (ICOMOS) and $\mathrm{TICCIH}$, which defines principles for the Conservation of Industrial Heritage Sites, Structures, Areas, and Landscapes was signed. This document, titled the Dublin Principles, was fundamentally crafted with the aim of assisting in the documentation, protection, conservation, and appreciation of industrial heritage worldwide. ${ }^{22}$ The document includes 14 principles, organized into the following four categories: documenting, ensuring protection, conserving and maintaining, and presenting and communicating. The individual principles are attached in Appendix E.

\section{Defined: Industrial Landscapes}

As defined by lain Stuart within his essay included in 'Industrial Heritage Re-tooled', industrial landscapes are a type of cultural landscape and industrial heritage upon which the dominant cultural process is or has been 'industry'. ${ }^{23}$ The term industry is broadly used within this definition but refers to any economic activity concerned with the processing of raw materials or the manufacturing of goods. The landscape is not limited to a singular spatial region or composition, but rather they are often composed of a series of interrelated sites across a wider region often marked by similarities is geology, hydrology or topography. ${ }^{24}$ Industry in general, and particularly early industrial activity, exhibited a deep integration of site and function. ${ }^{25}$ Economically successful operation of the site usually depended upon some level of natural process or material presence; because of this, industrial endeavors were and typically are geographically located to optimize access to a number of critical variables. As a result, the cultural and industrial landscapes which emerged have often evolved substantially over time, in concert with changes to the panoply of contributing natural and cultural factors and locally to perpetuate favorable geographic conditions. ${ }^{26}$

It is also stated within the $\mathrm{TICCIH}$ guide that, rather than classify industrial landscapes

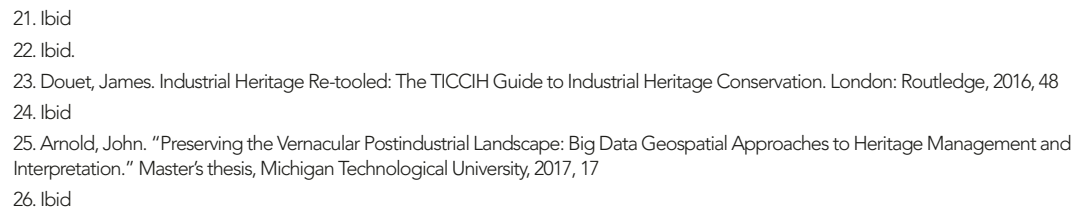


as a category of their own within the large umbrella of cultural landscapes, that they can be categorized into the existing divisions set by the World Heritage Committee. ${ }^{27}$ Within the 'Operational Guidelines for the Implementation of the World Heritage Convention', there are three main types of cultural landscapes: Designed Landscapes, Evolved Landscapes, and Associative Cultural Landscapes. ${ }^{28}$

Designed Cultural Landscapes are described as being "created intentionally by humans," and often include sites such as gardens and parkland areas. ${ }^{29}$ Industrial landscape typologies which might fit into this classification are those such as industrial estates or industrial parks but it is unclear whether a singular industrial site would fit into this category because of its likely dependency on natural preexisting landscape features.

Associative Cultural Landscapes are those where the landscape can be stated as significant due to "powerful religious, artistic, historical, scientific or cultural associations of the natural element rather than material cultural evidence." ${ }^{\prime 30}$ In this case, it is unlikely that the individual site itself bears any industrial activity, but its existence could be important or associated with a greater industrial landscape.

The third classification is labeled Evolved Landscapes. Also referred to as Vernacular Landscapes, these sites are described as those which are "the result of social, economic, administrative or religious activity and have developed their present form by direct or indirect action or association with and in response to the natural environment of the area." ${ }^{131}$ Industrial typologies which might fit into this category are both open-pit and underground mines, in-situ processing plants, refineries or shipping sites.

Within the Evolved Landscape classification, there are two subcategories - which are of relevance to this thesis: Relic Landscapes and Continuing Landscapes. Relic Landscapes are those where the social, economic, administrative and or religious activity has ceased, either abruptly or over a period of time and where the site's distinguishing features may be still visible in material form or may be partially decomposed..$^{32}$ In contrast, a 'continuing landscape' is described as "one that retains an active economic and social role in contemporary society, closely associated with a traditional way of life, and in which an evolutionary process is still in progress." 33

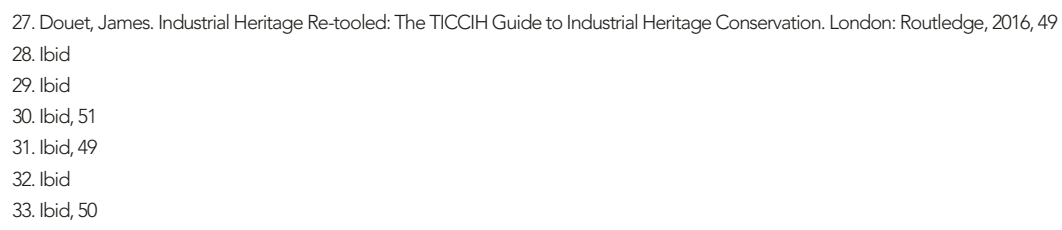




\section{Defined: Post-Industrial Landscapes}

By definition, post-industrial refers that which no longer relies on heavy industry. The concept of post-industrial landscapes therefore refers to sites which at one point were part of an operational industrial landscape but are now functionally and materially obsolete. ${ }^{34}$ They are a physical relic of the preceding operating system and a product of social processes that intimately tethered humans and their enterprise to the natural world. ${ }^{35}$

While the post-industrial landscape often holds substantial historical significance, these sites are unfortunately not widely perceived as valuable contributors to heritage; many times they assume a state of derelict and of inevitable decay as consequence to their technological obsolescence. ${ }^{36}$

\subsection{Chapter Conclusions}

At the outset of this Chapter, a few questions were posed relative to the status of Canada's industrial heritage: What exactly are these Places? What connects us to them? What stories can they tell us?

The artifacts and markings of the industrial heritage upon and within the landscape can be classified into a complex matrix of categories. Within the umbrella category of landscapes, there are subclassifications such as: cultural, designed, evolved, associative, relic, continuing, industrial and post-industrial.

What connects us to them? These Places have informed many aspects of day to day life for Canadians. They inform settlement, travel, economic prosperity, and lifelong professions. They create shared settings via Places of work and Places of residency.

What stories can they tell us? Places of industrial heritage serve as a reminder of shared experiences and act a palimpsest, offering glimpses into history.

34. Arnold, John, and Donald Lafreniere. The Persistence of Time. Historical Environments Spatial Analytics Lab, Michigan Technological University, 2017, 39

35. Ibid, 18

36. Lores, Luis. "Post-Industrial Landscapes: Dereliction or Heritage?" Lecture, WSEAS International Conference on Landscape Architecture, Los Angeles. 


\section{Chapter II}

\section{Secondary Exploits via Reuse, Deconstruction and Salvage}

Themes: Embodied Energy, Carbon, Preservation, Rehabilitation, Restoration, Adaptation, Interpretation, Deconstruction, Demolition, and Salvage

Post-Industrial architectures and landscapes present their own set of unique challenges when it comes to reuse. In many cases, the preceding industrial activities pollute the surrounding landscape, contaminate the extant architecture, create urban brownfields, and the typical transition from active, to obsolete, to neglected, frequently equates metaphorical diminishment. Cultural sustenance via the retention of memory, traditional setting and practices, as well as environmental sustainability through a reduced or negligible energy footprint however is possible through conscious and thoughtful reuse, remediation and interpretation. What resources - both material and immaterial - await secondary exploit in existing sites? How can they be accessed and reused?

Chapter II is written with the intention to introduce the concepts which contribute to the pragmatics of architectural reuse, salvage and deconstruction. By discussing the environmental drivers of sustainability, the impacts of the building industry and potentials of architectural reuse, Chapter II presents the rationale for building retention and reuse.

\subsection{Reuse of Industrial Heritage}

\section{Embodied Energy}

Of all of the rationales which support the reuse and active conservation of post-industrial architectures, one argument stands out as the most universally recognizable and likely to be supported within today's environmental climate: a need for environmental stewardship.

As stated by Jean Carroon, within 'Sustainable Preservation: Greening Existing 
Buildings', "The need for immediate action to address climate change and the related environmental degradation is increasingly urgent. The major role that the building industry must take in abating the crisis is unequivocal. ${ }^{137}$

The impact of the building and construction sector upon both greenhouse gas emissions and the depletion of natural resources is staggeringly high. With respect to the associated land use and the required material extraction, this industry has the most significant impact of any sector by far.

The urgent and immediate need to reduce carbon emissions makes the reuse of all existing structures and architecture an imperative. The energy expenditure associated with the construction and the acquisition of new raw materials which comprise existing buildings, has already been spent within existing buildings - so why create a redundancy? The initial expenditure is referred to as the embodied energy, which as defined by Carroon, is the energy used directly and indirectly in raw material acquisition, production of materials, and the assemblage of those materials into a structure. ${ }^{38}$ From this outlook, the erection of every building and every structure begins with a significant environmental energy debt - culminating from associated resource depletion, energy use and manufacturing. Over time, the embodied energy becomes justified as the building operates but this justification is strictly dependent upon the degree of initial energy requirements.

In 2010, the United Nations Energy Programme estimated that the embodied energy of a building equates approximately 20 percent of the operating energy if the building is able to remain operational for 100 years. ${ }^{39}$ Extrapolated, this statistic means that at 125 years, the average building justifies the initial embodied energy through sheer operational existence. Unfortunately, 125 years, is an age which the majority of buildings in North America have yet to reach, let alone exceed. ${ }^{40}$

As the service life of a structure increases, the ratio between embodied energy and operating energy decreases. ${ }^{41}$ Based on the assumption that there are equal amounts of masonry, wood, concrete and steel buildings currently in the North American building stock, the average life expectancy of a building is 73 years - meaning that the estimated embodied energy at a building's end of life still proportionately represents 42 percent of the operating energy. ${ }^{42}$

37. Carroon, Jean. Sustainable Preservation: Greening Existing Buildings. Hoboken: Wiley, 2010. 3

38. Ibid, 7

39. Ibid

40. O'Connor, Jennifer. Survey on Actual Service Lives for North American Buildings. Vancouver, BC: Forintek Canada, 2004, 5

41. Carroon, Jean. Sustainable Preservation: Greening Existing Buildings. Hoboken: Wiley, 2010. 7

42. O'Connor, Jennifer. Survey on Actual Service Lives for North American Buildings. Vancouver, BC: Forintek Canada, 2004, 5 


\section{Expected Building Service Life (Years)}

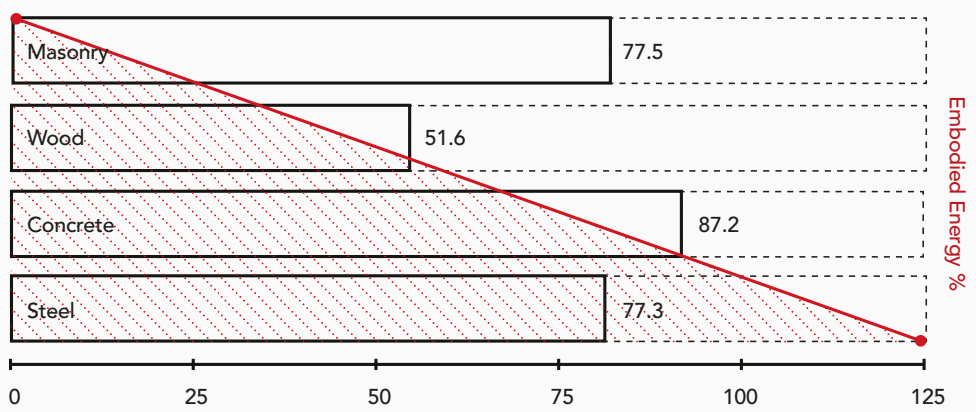

Figure 1.02: Embodied Energy compared to Average Building Service Expectancies (by Author)

Due to the rapid program turn over associated with industrial sites as a result of continual technological advancements, and the typical pattern of eventual obsolescence, abandonment and demolition which results, the likelihood of an industrial building justifying its embodied energy is very slim. Given the under representation of industrial heritage amongst formal heritage designations, this energy imbalance makes the case for the conservation and reuse of industrial heritage that much stronger. Due to the current conditions of climate change and the energy irresponsibility which fuels it, the wasteful loss of post-industrial buildings needs to be managed.

\section{Conservation Treatments and Adaptive Reuse}

To combat the loss of heritage and of value in the existing landscapes, the primary responsive action is heritage conservation - a method of architectural intervention that can manifest in several forms and through a variety of approaches, but which has the ultimate goal of extending the physical and intangible lifespan of a site.

As presented in the second edition of Canada's 'Standards \& Guidelines for the Conservation of Historic Places', "Conservation activities can be seen as a sequence of actions - from understanding the historic place, to planning for its conservation and intervening through projects or maintenance." ${ }^{43}$ In turn, the guide depicts three distinct treatment approaches, commonly accepted as part of the responsible and proper model for accomplishing this: preservation, restoration and rehabilitation. ${ }^{44}$

43. Standards and Guidelines for the Conservation of Historic Places in Canada. 2nd ed. Canada's Historic Places and Parks Canada, 2010, 3 44. Ibid 
To summarize, the guideline describes the action of preservation as "protecting, maintaining and stabilizing the existing form, material and integrity of an historic place or individual component." 45 It describes rehabilitation as the "sensitive adaptation of an historic place or individual component for a continuing or compatible contemporary use." ${ }^{46}$ Lastly, restoration is described as an "accurate revealing, recovering or representing the state of an historic place or individual component as it appeared at a particular period in its history. ${ }^{\prime \prime 7}$

Depending on the proposed program, the existing site conditions, and the value associated with the place, either individual parts or portions of the existing site may undergo any one or a variety of the treatments. As suggested within 'Standards \& Guidelines for the Conservation of Historic Places', it is ideal to select a primary treatment. "A clear idea of the project's primary focus or objective, as provided in a conservation plan, and the heritage values of the historic place will contribute to the success of a consistent and coherent conservation project." ${ }^{48}$

Each respective treatment favors different site values and varies in appropriateness, dependent upon site conditions, historical use and context. 'Standards \& Guidelines for the Conservation of Historic Places' suggests to consider preservation as an approach when materials, features and spaces of the historic place are essentially intact and convey the historic significance, without extensive repair or replacement. ${ }^{49}$ Alternatively, rehabilitation is the suggested treatment when repair or replacement of deteriorated features is necessary and when alterations or additions to the historic place are planned for a new or continued use. ${ }^{50}$ Lastly, the guide suggests restoration, only when the place's significance during a particular period in its history significantly outweighs the potential loss of existing, non character-defining materials, features and spaces from other periods. ${ }^{51}$ For restoration, substantial physical and documentary or oral evidence must exist to accurately carry out the work.

The primary architectural treatment applied within this thesis is rehabilitation - a treatment which can revitalize historical relationships and settings. It is the most appropriate treatment when heritage values related to the context of the historic place dominate but there is a planned or required change of use.

\footnotetext{
45. lbid

46. Ibid

47. Ibid

48. Ibid, 15

49. Ibid

50. Ibid, 16

$51 \mathrm{lbid}$
} 
Rehabilitation is more flexible when it comes to a site's material and tangible being. In many industrial and research-based historic Places, this is important. The utilitarian nature of industrial sites means that few are initially built with dominating intentionally artistic or precious qualities. From a planning perspective, many industrial sites are highly organized and ordered, but their realization on a material scale is typically practical and value engineered. The sites, in their contemporary state are also often highly adapted already - as technologies change, industrial activities need to adjust and react in response - updating to accommodate changes in machinery, equipment, work flows and even infrastructure.

To build upon the selected rehabilitation treatment, an overarching retention strategy is applied within this thesis: adaptive reuse - a model which intrinsically involves the application of a new programming, and has the capacity to combine each of the just mentioned treatment approaches but which commonly favors rehabilitation.

The ICOMOS Burra Charter of 1981 (revised in 2013), is an internationally recognized conservation doctrine which provides guidelines for cultural heritage management. It defines adaptive reuse as "additions to a place, the introduction of new services, or a new use, or changes to safeguard a place, all of which should have a compatible use." 52 The 2013 version of the charter outlines specific suggestions regarding adaptations in Article 21:

"21.1 Adaptation is acceptable only where the adaptation has minimal impact on the cultural significance of the place. 21.2 Adaptation should involve minimal change to significant fabric, achieved only after considering alternatives. ${ }^{\prime 53}$

\section{Defined: Interpretation}

Article 15 of the 2013 Burra Charter states the following regarding change:

"Change may be necessary to retain cultural significance, but is undesirable where it reduces cultural significance. The amount of change to a place should be guided by the cultural significance of the place and its appropriate interpretation. ${ }^{154}$

52. Pill, Jaan. "Burra Charter Offers a Guideline for Adaptive Reuse of Heritage Buildings." Preserved Stories. June 29, 2013.

53. Ibid

54. Ibid 
What exactly is 'interpretation'? How is its relative appropriateness measured?

The concept of historic interpretation was first theorized by American writer Freeman Tilden in his book "Interpreting Our Heritage" published in 1957. Tilden, referred to today akin to the guru of the United States National Park Service by author Bruce Craig, is most commonly recognized as the author of "through interpretation, understanding; through understanding, appreciation; through appreciation, protection." 55

Within his writing, Tilden describes heritage interpretation as an educational activity that should reveal meanings and relationships to visitors. ${ }^{56}$ Through the use of original objects, using firsthand in-situ experience, and illustrative media, rather than just communicating factual information, a stronger understanding of site may be acquired - thereafter supporting appreciation, followed by a increased desire to protect the place itself.

To accomplish successful interpretation, Tilden established six principles that are meant to provide guidance and facilitate communication: ${ }^{57}$

\footnotetext{
"i. Any interpretation that does not somehow relate what is being displayed or described to something within the personality or experience of the visitor will be sterile.

ii. Information, as such, is not interpretation. Interpretation is revelation based upon information. But they are entirely different things. However, all interpretation includes information.

iii. Interpretation is an art, which combines many arts, whether the materials presented are scientific, historical, or architectural. Any art is in some degree teachable.

iv. The chief aim of interpretation is not instruction, but provocation.

v. Interpretation should aim to present a whole rather than a part and must address itself to the whole man rather than any phase.

vi. Interpretation addressed to children should not be a dilution of the presentation to the adults, but it should follow a fundamentally different approach. To be at its best, it will require a separate program."
}

Although these principles are in no way outdated, more recent principles do exist. In 2008, ICOMOS published 'The ICOMOS Charter for the Interpretation and Presentation of Cultural Heritage Sites' within which both the definitions

55. Tilden, Freeman, and R. Bruce. Craig. Interpreting Our Heritage. Chapel Hill: Univ. of North Carolina Press, 2008, 2

56. Ibid, 17

57. Ibid, 18 
for interpretation and for presentation are stated. Within this document, interpretation refers to the full range of activities intended to heighten public awareness and enhance understanding of the cultural heritage site. Said activities can include print and electronic publications, public lectures, on-site and directly related off-site installations, educational programmes, community activities, and ongoing research, training, and evaluation of the interpretation process itself. ${ }^{58}$ In comparison, the term presentation refers to the carefully planned communication of interpretive content through the arrangement of interpretive information, physical access, and interpretive infrastructure at a cultural heritage site..$^{59}$ It can be conveyed through a variety of technical means, including, yet not requiring, elements such as informational panels, museum-type displays, formalized walking tours, lectures and guided tours, and multimedia applications and websites.

In addition to these two terms, the ICOMOS charter also defines the concept of interpretive infrastructure. The concept refers to physical installations, facilities, and areas at, or connected with a cultural heritage site that may be specifically utilized for the purposes of interpretation and presentation including those supporting interpretation via new and existing technologies. ${ }^{60}$

Regarding rehabilitated industrial sites, especially those which are adaptively reused, the interpretive infrastructure can become a large aspect of the intervention architecture. In making industrial sites publicly accessible and thus, in ensuring visitor safety, many projects require significant tangible intervention such as fencings, railings, walkways, catwalks and other circulatory components.

Notably, while Tilden's principles discuss a somewhat emotional interpretation, the principles presented within 'The ICOMOS Charter for the Interpretation and Presentation of Cultural Heritage Sites' discuss the practicality of interpretation. The seven principles are as follows: ${ }^{61}$

i. Access and Understanding:

Interpretation and presentation programmes should facilitate physical and intellectual access by the public to cultural heritage sites.

ii. Information Sources:

Interpretation and presentation should be based on evidence gathered

through accepted scientific and scholarly methods as well as from living

cultural traditions.

58. The ICOMOS Charter for the Interpretation and Presentation of Cultural Heritage Sites. Quebec, QC: ICOMOS, 2008, 4

59. Ibid

60. Ibid

61. Ibid, 5 


\section{iii. Attention to Setting and Context:}

The Interpretation and Presentation of cultural heritage sites should relate to their wider social, cultural, historical, and natural contexts and settings.

iv. Preservation of Authenticity:

The Interpretation and presentation of cultural heritage sites must respect the basic tenets of authenticity in the spirit of the Nara Document (1994).

v. Planning for Sustainability:

The interpretation plan for a cultural heritage site must be sensitive to its natural and cultural environment, with social, financial, and environmental sustainability among its central goals.

vi. Concern for Inclusiveness:

The Interpretation and Presentation of cultural heritage sites must be the result of meaningful collaboration between heritage professionals, host and associated communities, and other stakeholders.

vii. Importance of Research, Training and Evaluation:

Continuing research, training, and evaluation are essential components of the interpretation of a cultural heritage site.

Drawing from both Tilden's six principles as well as the seven stated by ICOMOS, this thesis considers both in its interpretation scheme. (pg. 130)

\subsection{Deconstruction and Salvage}

Although strongly advocated by individuals those in the conservation and sustainability fields, such as both Jean Carroon and Freeman Tilden, conservation is unfortunately not always a possible undertaking. The reality is that sometimes the up front economic demands for architectural retention and of rehabilitation outweigh the benefits in the eye of the stakeholders or property owners. This is an unfortunate reality, but one that can still be accompanied by positive outputs if managed.

In the face of heritage loss, architectural deconstruction and salvage stands as a positive secondary endeavor - a secondary exploit, aiding to promote the circular economy and acting as a method to manage loss.

In October of 2018, Susan Ross, professor within the Azrieli School of Architecture and Urbanism, and the School of Indigenous and Canadian Studies within Carleton University held a symposium titled: 'Heritage in Reverse: Material Values, Waste and Deconstruction'. The two-day symposium, included presentations from nine professionals, as well as public lecture. 
"The goal of this event [was] to bring together individuals and organizations active in related areas of heritage conservation, urban, architectural and construction history, critical heritage and discard studies, building deconstruction, sustainable materials and waste management, in order to address possibilities for bridging between these areas as part of projects, policies, research or creative practices" ${ }^{\prime \prime 2}$

Speakers at the symposium were asked to speak about three overarching questions: ${ }^{63}$

- What can be learned from deconstruction sites about materials reuse opportunities in heritage work?

- What does recent research tell us about possibilities of connecting heritage conservation with waste?

- Which policies can guide difficult conservation decisions in the context of demolition and salvage?

The responses of the speakers ranged in nature but each speaker spoke from experience. Much of the proceeding text in this Chapter is either directly or indirectly sourced from the Heritage in Reverse Symposium - the symposium stands as one of the few times when ideas of deconstruction and heritage share the spotlight at an academic event.

\section{Deconstruction vs. Demolition}

Deconstruction is by no means a modern concept; however its current resurgence is a reaction to the 20th century. As of late, deconstruction is gaining popularity as an environmentally favorable method to save and reuse building material, offering not only a measurable way to reduce embodied energy but also as a way of preserving the immaterial legacy of threatened architectures. The speed at which today's economy functions has resulted in a demand for sped up construction periods - a demand which encourages demolition over deconstruction.

Deconstruction is often described as 'un-building' as it fundamentally involves taking a building apart, reversing the order of the construction and removing layer by layer. As defined by Brad Guy, the Chair of the USGBC Materials and Resources Technical Advisory Group, deconstruction is ultimately a material

62. Ross, Susan. Heritage in Reverse: Material Values, Waste and Deconstruction. Carleton University, School of Indigenous \& Canadian Studies, 2018,3 63. Ibid 
flow concept and a resource based process. ${ }^{64}$ Formally, Guy defines the term as "the selective dismantlement or removal of materials from buildings for primarily reuse or secondarily recycling." 65

Offering an alternative to traditional demolition, deconstruction is irrefutably the more sustainable option; it involves the conservation of existing materials, negates the acquisition of replacement raw materials and reduces landfill waste. Moreover, deconstruction has the potential to yield high-quality materials from an assortment of building and site typologies. ${ }^{66}$

Demolition on the other hand, is the process of rapidly tearing down a building either via explosives, machinery or manual labor which in its haste limits the material resuability.67

As suggested by Ross within her article 'A Bibliography on Demolition Waste and Deconstruction' published by 'Discard Studies', "despite its promise for reuse and reduction of waste, there are several sources of conceptual and material tensions with deconstruction." ${ }^{68}$ These tensions stem from devaluations of insitu architecture, of building reuse or renovation, of the economic benefits of deconstruction or of material legacies. ${ }^{69}$ Moreover, a lack of infrastructure and model projects which support deconstruction create hesitancy for developers and building owners. ${ }^{70}$

\section{Defined: Salvage}

The tangible products of deconstruction are salvaged materials - the reusable materials saved during the process of dismantlement. These can vary largely, dependent upon the building site, era, style and condition but can be grouped into the following broad categorization: site materials, structural members, cladding, fixtures, equipment, interior finishes, and ornament. ${ }^{71}$ They themselves also sometimes need a degree of refurbishment - actions ranging from stabilization to restoration might be undertaken.

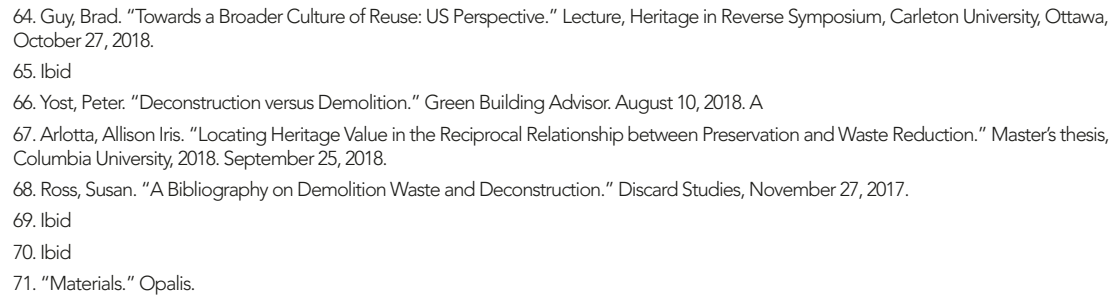




\section{Contemporary Need}

The construction and demolition waste generated by the Canadian construction industry accounts for $27 \%$ of the total municipal solid waste disposed in landfills - a percentage that equates 7 million tonnes of waste per year. ${ }^{72}$ This is a staggeringly alarming statistic but one which is compelling and interesting to analyze.

In 2011, Colin Jeffrey of Dalhousie University's Office of Sustainability published a report titled 'Construction and Demolition Waste Recycling: A Literature Review'. The report provides a comprehensive overview of current methods for reusing and recycling construction and demolition waste materials as well as a thorough summary of the most recent Canadian waste data. As part of the data summary, Jeffrey states that while construction and demolition wastes are usually grouped together under the title 'C\&D' waste, these waste streams are produced by two distinct processes, thus the volume and type of materials produced through each differs. ${ }^{73}$ According to the report, demolition projects often produce 20 to 30 times more waste material per square meter than construction projects. Extrapolated to match the preceding total waste statistic, this percentage suggests that of the 7 million tonne total, between 6.5 to 6.7 million tonnes of C\&D waste is generated from demolition.

Currently, the dominant material flow model for resource consumption in the building sector is linear, following the cradle-to-grave trajectory. ${ }^{74}$ To reduce waste and reconcile spent embodied energies, the ideal solution is a the transition to a closed-loop material flow - the cradle-to-cradle cycle..$^{75}$ This is not only a fundamental requirement of the circular economy but also a major proponent of building deconstruction.

\section{Historical Practices}

Although the past decade has seen growth in the support of deconstruction as a result of increased environmental awareness, the practice is by no means a product of the 20th century - deconstruction practices trace back in history to as early as late antiquity. ${ }^{76}$

Before the mid twentieth century, building demolition equated deconstruction, was a process accomplished through manual labor and was much less wasteful. As explained by Allison Arlotta within her Master of Science Thesis in Historic Preservation, in the nineteenth century, building deconstruction was the norm;

72. "Solid Waste Diversion And Disposal." Canada.ca (Environmental Indicators). December 20, 2018

73. Jeffrey, Colin. Construction and Demolition Waste Recycling: A Literature Review. Halifax, NS: Dalhousie University, 2011, 3

74. Addis, Bill. Building with Reclaimed Components and Materials: A Design Handbook for Reuse and Recycling. Routledge, 2012. 12

75. lbid

76. Guy, Brad. "Towards a Broader Culture of Reuse: US Perspective." Lecture, Heritage in Reverse Symposium, Carleton University, Ottawa, October 27, 2018. 
buildings were demolished manually by crews of laborers over the span of a couple weeks to a couple months. ${ }^{77}$ When a building or property owner wanted to clear the site, house wrecking companies would bid on the opportunity to acquire the project. $^{78}$ At the time, to the advantage of the house wrecker, it was commonly expected that most material from demolished buildings could easily and profitably be resold - making the business of wrecking synonymous with that of salvage. ${ }^{79}$ Fixtures and appliances were sold; wood studs and finishes were removed, and bricks were cleaned. As stated by author Jeff Byles, the process was "Laborious, yes. Wasteful, no. It was an elegant way to wreck." ${ }^{180}$

It was not until the post war period that the shift from manual deconstruction to mechanized demolition became prevalent. The mass industrialization which accompanied increased militarization introduced new practices and equipment. ${ }^{81}$ Following world war two, mechanized tools and methodologies such as bulldozing, wrecking balls and explosives became the go to demolition strategies. ${ }^{82}$ Urban renewal the initial trigger for the shift, but cheaper labor, plentiful machinists and the normalization of clearance escalated the frequency of mechanized demolition. ${ }^{83}$ Where, in the eras pre war, contractors had the opportunity to turn significant profits from the resale of salvaged material, after the war, the materials became less valuable. ${ }^{84}$ A reduced demand in combination with rising labor costs caused rapid demolition to become the favored and economically beneficial practice.

To compare the two processes, the wreckings of two buildings are presented; first, the 1901 deconstruction of New York's Star Theater (Figure 1.3) and second, the 2014 demolition of Ottawa's Sir John Carling Building (Figure 1.4).

The wrecking of both buildings were caught on film so it is interesting to analyze both. New York's Star Theater was deconstructed manually in 1901 over the duration of a month. Within the time lapse video, a variety of deconstruction processes can be observed; workers can be seen first removing roofing, then roof timbers and then wall structure, progressively working their way down, storey by storey. ${ }^{85}$

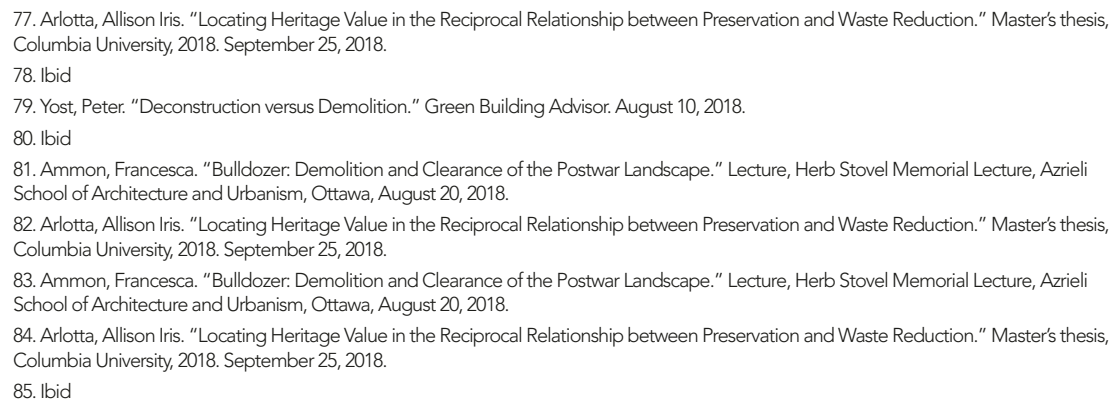




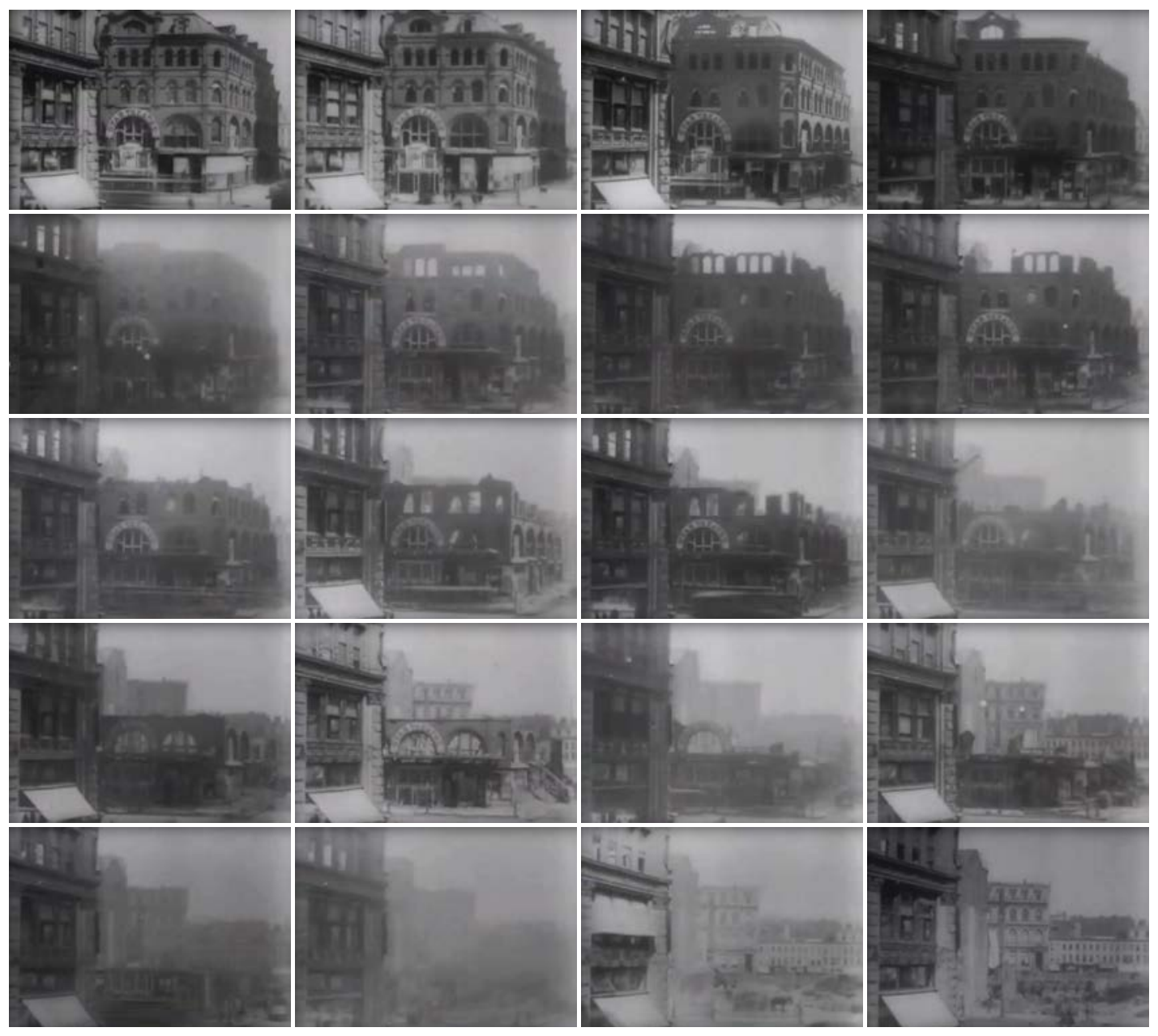

Figure 1.03: Video Snapshots of New York's Star Theater Building being deconstructed in 1901. 

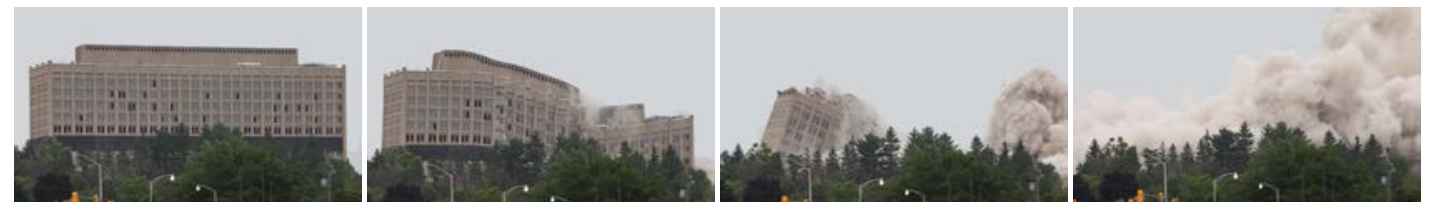

Figure 1.04: Video Snapshots of Ottawa's Sir John Carling Building being demolished in 2014. 
In comparison, Ottawa's Sir John Carling building was demolished using explosives in $2014 .{ }^{86}$ The building went from a piece of prominent modernist architecture to a pile of rubble in a matter of seconds.

The 5:1 ratio of video stills does not do the actual ephemeral difference between the sites justice. Although the demolition of the Sir John Carling Building was highly engineered and planned - there is something curiously disturbing about the speed at which the building legacy and its prominence disappears. If nothing else, the contrast between the two wrecks is provocative. Why has such a wasteful process become the norm?

\section{Modern Models of Material Reuse}

"The very idea of 'waste' is one that belongs to the throwaway society, not to the reuse and recycling society. ${ }^{187}$

As suggested by Bill Addis within his book'Building with Reclaimed Components and Materials', part of the issue surrounding the struggle to reduce waste stems from the fact that early endeavors to reform the ideas treated waste as the problem as opposed to treating the process that creates waste as the issue..$^{88} \mathrm{He}$ explains that while the guidance posed during the environmental movement of the 1990's addressed important concerns about material end life processes, the entire life-cycle of materials was and is the larger issue. ${ }^{89}$

Today, the typical throwaway construction and consumerism practices involve a linear flow of materials - a model which follows the cradle-to-grave ordering. The cradle-to-grave model, traces materials from creation to disposal via extraction, manufacturing, product being, use, demolition, waste and landfill. ${ }^{90}$ Clearly this trajectory is not the ideal pattern and is the main reason why modern society has a waste problem. As explained by Addis and many others in the field of sustainable waste and material management, society needs to strive towards creating a circular economy of materials- a model which is closed-loop rather than linear. ${ }^{91} \mathrm{~A}$ material flow which exemplifies the closed-loop model is the cradle-to-cradle flow. Materials are never disposed of, instead they are recycled, re-manufactured and then reused. The Delft Ladder is an example of a cradle-to-cradle flow. (Figure 1.5)

86. Reevely, David. "Ottawa Hospital Looks for Ways to Salvage Heritage at Sir John Carling Site." Capital Modern. March 06, 2018.

87. Addis, Bill. Building with Reclaimed Components and Materials: A Design Handbook for Reuse and Recycling. Routledge, 2012, 12

88. Ibid

89. Ibid

90. Ibid, 13

91. Ibid 


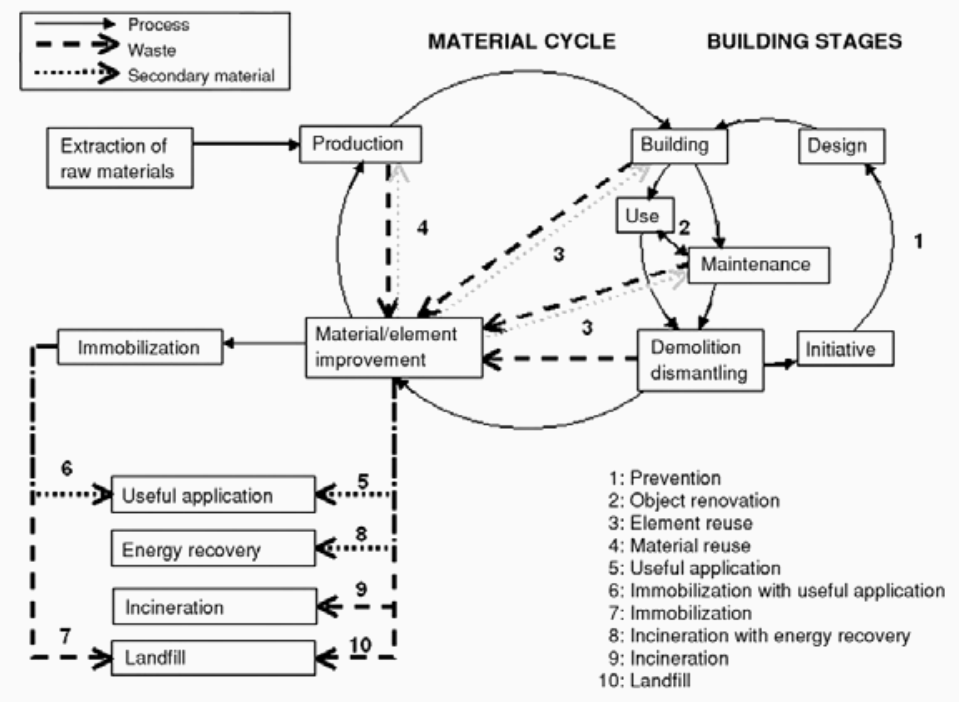

Figure 1.05: The Delft Ladder showing iterative Life-Cycle Material Flow

Resource Hierarchy

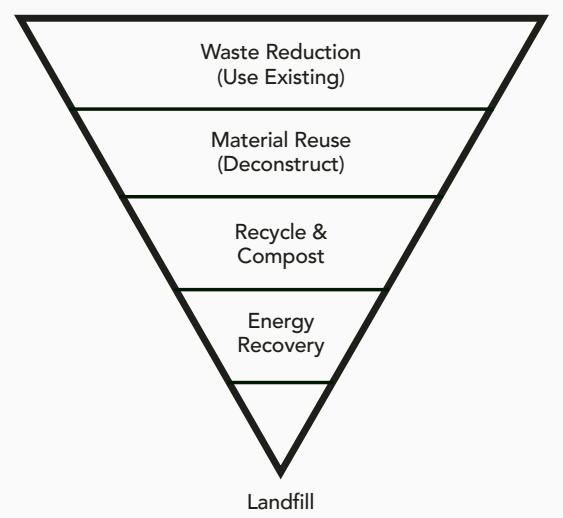

Figure 1.06: Resource Hierarchy Pyramid 
Brad Guy states that deconstruction, salvage and architectural reuse are all critical actions in the circular economy of the built environment. ${ }^{92}$ He presents that there is a hierarchy in resource use and reuse that indicates the level of impact of each action, specifically stating that neither deconstruction nor material recycling are ever the first or most effective strategies, first is waste reduction via the use of existing architectures. ${ }^{93}$ (Figure 1.6) As illustrated within Guy's hierarchy, the reuse of existing architecture as well as the deconstruction of those which cannot be retained, rank as the highest priority in abating waste resources. This, in combination with the potential for sustained memory and associative value brought about by architectural conservation provides the framework for this thesis.

\subsection{Precedent Projects}

To investigate examples of adaptive reuse, deconstruction, and material reuse, four precedent projects were examined. Three of the projects are architectural works while the fourth is an infrastructure for material reuse. Each precedent stands as an example of a potential solution or technique through which the aforementioned issues can be addressed.

\section{Precedent A: Duisburg Landscape Park}

Architects: Latz+Partner

Date of Completion: 2002

Location: Duisburg-Meiderich, Germany

Current Descriptors: Cultural Landscape, Post-Industrial Landscape, Designed Landscape, Rehabilitation (Primary), Adaptive Reuse

Previous Descriptors: Evolved Relic Landscape

Duisburg Landscape Park is selected as a precedent study because of its renowned success as an adaptive reuse project dealing with a post-industrial landscape. The interpretation of the whole landscape, the conservation approach and adaptive reuse as well as remediation treatments are of relevance.

The interpretation strategy of the site drew upon several layers of history and importance within the site: industrial activities, society and ecology. ${ }^{94}$ Memories of each of these concepts was recognized by Latz.

92. Guy, Brad. "Towards a Broader Culture of Reuse: US Perspective." Lecture, Heritage in Reverse Symposium, Carleton University, Ottawa October 27, 2018.

93. Ibid

94. Podner, Alice. "North Duisburg Landscape Park." ALL CHANGE : 'DARC' - Designing the New World: Developing Architectural Education in Response to Climate Change.
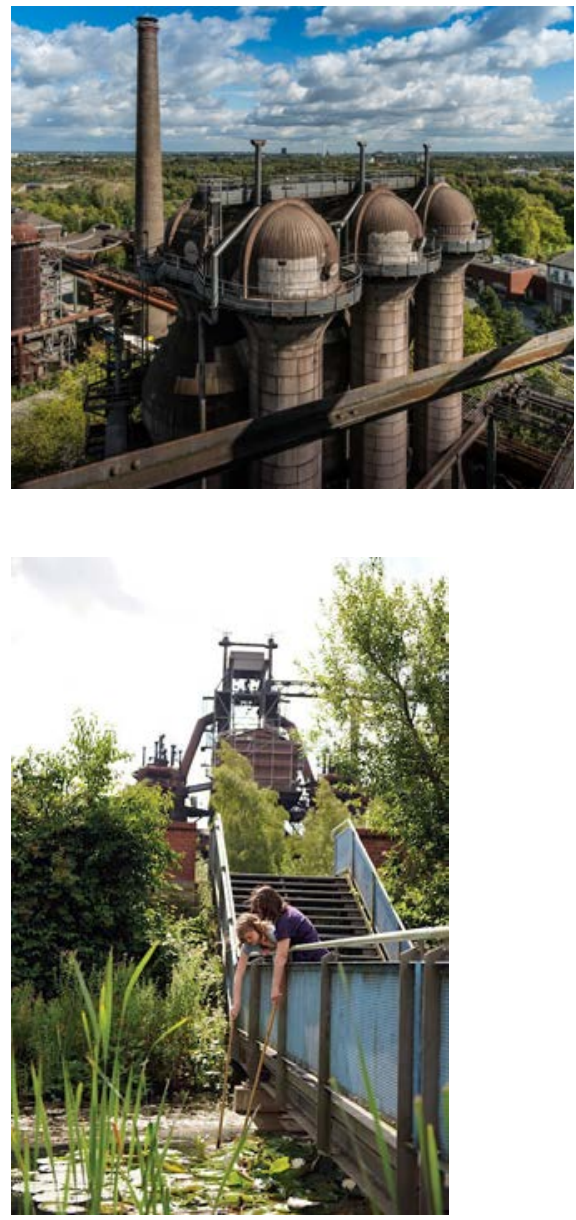

Figure 1.07 (Top): Aerial Image of Duisburg Landscape Park

Figure 1.08 (Bottom): On site Bioremedation 
To facilitate memories of earlier industrial activities, the park is designed with the intent that a grandfather, who might have worked at the plant, could walk with his grandchildren, explaining what he used to do and what the machinery had been used for. ${ }^{95}$ Specifically, many of the old structures were adaptively reused for new programming and to punctuate the new programming, certain formal elements were retained and received architectural emphasis: the concrete bunkers created a space for a series of intimate gardens, old gas tanks became pools for scuba divers, concrete walls are used by rock climbers, and the middle of the former steel mill, has been made into piazza. ${ }^{96}$

Ultimately, the existing patterns and fragments formed by previous industrial use were taken, developed and reinterpreted with a new syntax to create cohesion. As stated by Latz, "each of these spaces uses elements to allow for a specific reading of time." ${ }^{\prime 97}$

\section{Precedent B: Toronto's Distillery District}

Architects: ERA Architects

Date of Completion: 2005

Location: Toronto, Canada

Project Type: Adaptive Reuse

Current Descriptors: Cultural Landscape, Post-Industrial Landscape, Designed Landscape, Rehabilitation (Primary), Adaptive Reuse

Previous Descriptors: Evolved Relic Landscape

Toronto's Distillery District is selected as a precedent study because of its regionality, its success as an adaptive reuse project and because several city of Ottawa council members hope that the Booth Street Complex project will result in a similar destination type complex.

Michael McClelland, founding principal of ERA Architects, wrote an article in 2005 about the firm's work on the site. He states that the first step of the project was to put forward a conceptual approach for the site which went beyond its evident heritage values to encompass ideas of growth and renewal. ${ }^{98}$ This is formally accomplished by determining appropriate change, predicting how it might occur over time, facilitating this change and doing so through minimal and reversible intervention. According to McClelland:

\footnotetext{
95. lbid

96. lbid

97. Latz Partner. "Duisburg Nord Landscape Park, DE." Latz Partner: Postindustrial Landscapes.

98. McClelland, Michael. "Learning from the Distillery District." Canadian Architect, The National Review of Design and Practice, The Official Magazine of the RAIC. February 01, 2005.
}
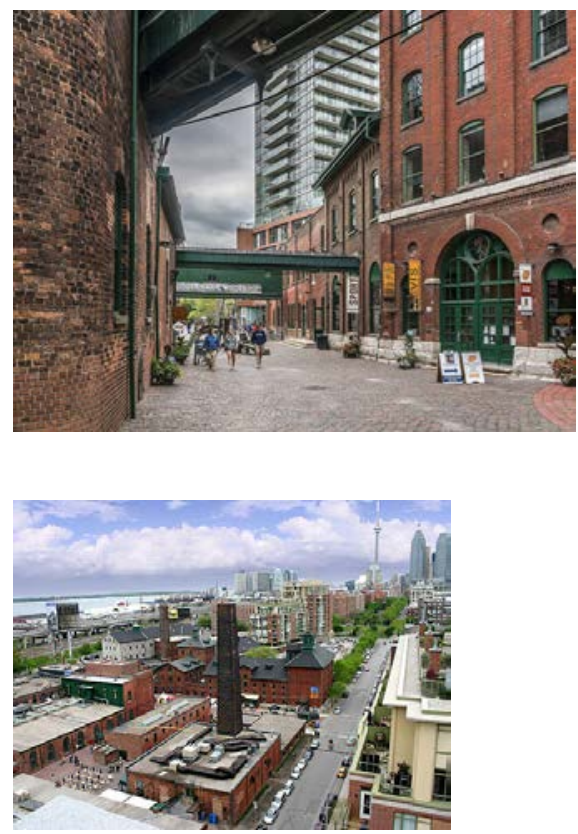

Figure 1.09 (Top): Toronto's Distillery District

Figure 1.10 (Bottom): Aerial Image of Toronto's Distillery District 
"At the Distillery, rather than formally stating issues relating to restoration, the decision was made to implicitly incorporate heritage ideals into an overall design strategy. The approach is decidedly what William Morris would have called Anti-Scrape. The buildings would not be scrubbed clean nor would they be returned to an ideal representation of a 19th-century distillery. This is important as it demonstrates the conceptual intent not to live in the past but to retain things within the present-creating a place to be experienced as a current and living entity and part of our contemporary urban environment. ${ }^{1199}$

The advantage of this anti-scrape approach is that new design elements do not need to be hidden or downplayed and it opens the opportunity for the site to continue to change over time.

\section{Precedent C: Opalis.be}

Architects: Rotor

Date of Completion: Not Applicable

Location: Brussels, Belgium

Project Type: Material Inventory

Opalis.be is an online inventory of salvaged building materials and supplies, created with the intent of helping to facilitate the use of second hand materials in construction and renovation projects around Brussels. ${ }^{100}$ Although the work is not directly architectural, the inventory indirectly has large impacts upon the system within which architecture functions and for this reason has been selected as a precedent. The inventory is compiled by a local architecture firm, Rotor a collaborative research and design firm that studies the organization of the material environment at various scales. ${ }^{101}$

As stated by Rotor: "Because we felt that the [construction] sector as a whole is realizing only a very small part of its theoretical potential, both in terms of collecting salvaged materials in the Brussels Region and in offering these materials for sale, we visited dozens of dealers in second hand building materials to gather information [and] brought the results together in an online guide"102

Opalis.be is an informative source for researching about both deconstruction practices and the organization of salvaged goods. From examining the site,

99. Ibid

100. Rotor. "Opalis.be Homepage." Opalis.

101. Rotor. "Opalis." Rotor Brussels.

102. Ibid
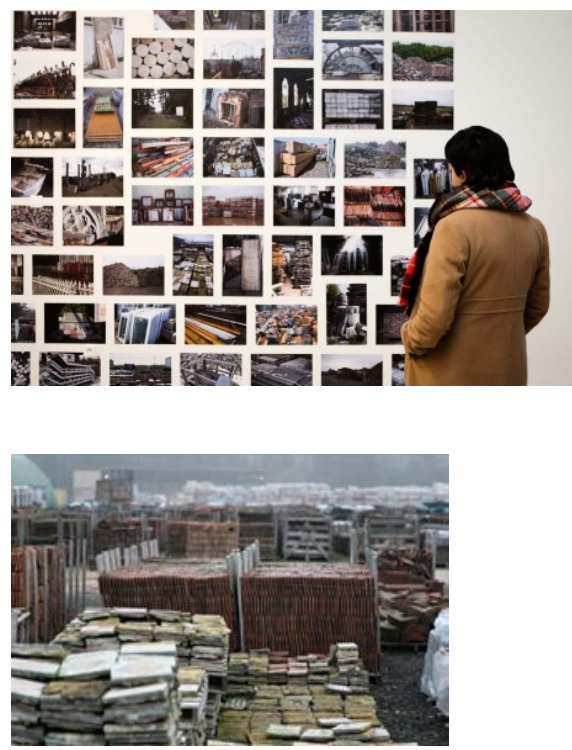

Figure 1.11 (Top): Opalis Photography Exhibit

Figure 1.12 (Bottom): One of the material yards part of Opalis 
one can see the main types of materials which emerge from deconstruction in Belgium: Steel, Wood, Masonry and Composites. These materials are of course relative to the local deconstruction and reuse economy of Belgium, but assumptions can be made to compare to the Ottawa context. The website sorts the materials into six broad categories: Site Materials, Large Openings and Envelope, Architectural Features, Finishings, Fixtures, and Ornament. ${ }^{103}$

\section{Precedent D: Sunset Park Material Recovery Facility}

Architects: Selldorf Architects

Date of Completion: 2014

Location: Brooklyn, USA

Project Type: New Construction on Brownfield Site

Current Descriptors: Industrial Landscape and Designed Landscape

Previous Descriptors: Not Applicable

Sunset Park Material Recovery Facility is selected as a precedent project because it combines an industrial recycling program with an educational program - linking the two but maintaining distinction. It is a processing center for New York City's curbside metal, glass, and plastic recyclables undertaken by Sims Municipal Recycling and the City of New York. ${ }^{104}$ Located on an 11acre waterfront pier in Sunset Park, Brooklyn, the master plan organizes the operational building and its adjacent visitor and administration buildings to support functionality and create distinct circulation systems to separate visitors from operations. ${ }^{105}$ Visitors can observe the plant interior, yet are kept at a distance.

\subsection{Chapter Conclusions}

Chapter II began by asking: What resources await secondary exploit in existing sites? How can they be accessed and reused? By discussing the environmental drivers of sustainability, the impacts of the building industry and potentials of architectural reuse, the Chapter was written with the intention to introduce the concepts which contribute to the pragmatics of architectural reuse, salvage and deconstruction. Concepts such as Embodied Energy, Preservation, Rehabilitation, Restoration, Adaptation, Interpretation, Deconstruction, Demolition, and Salvage are all described with the aim of supporting the proceeding architectural intervention posed within the thesis and creating a framework to design within.
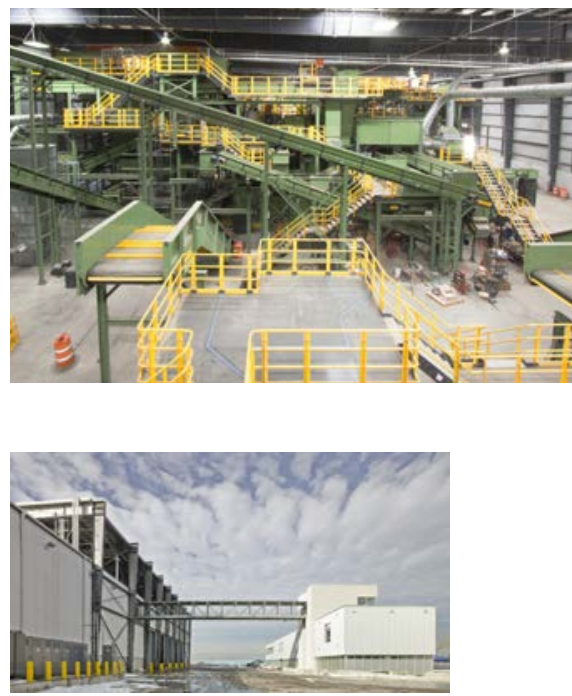

Figure 1.13 (Top): Interior of Sunset Park Material Recovery Facility

Figure 1.14 (Bottom): Administration vs. Operating Wings of Sunset Park Material Recovery Facility 


\section{Chapter III}

\section{The Industrial Heritage of the Booth Street Complex}

Themes: Territorialization, Geological Survey of Canada, Department of Mines, Department of Natural Resources, and Confederation.

The two current and historically dominant occupants of the Booth Street Complex are Canada Centre for Mineral and Energy Technology (CANMET) and the Geological Survey of Canada (GSC) - subcomponents to the larger Department of Natural Resources. Although the contemporary version of the Department of Natural Resources was only established in the year 1993, some of the department's subcomponents have long histories dating back to before Canada's confederation in 1867 - histories which ultimately led to the existence of the Booth Street Complex and which are summarized in Chapter III.

\subsection{Development of the Department of Natural Resources}

Canada's Federal Government and the organizational structure of the various departments and sectors within it, have significantly evolved and been reconfigured during the country's short history. Along with territorialization, industrialization, and the ever shifting priorities of government, the structure has been re-crafted and rearranged numerous times over. ${ }^{106}$ With new governance, came new budget dispersal and as evident within the development of the Booth Street Complex, new facilities.

The oldest portion of the current department of Natural Resources is the Geological Survey of Canada - a body which has a history dating back to its creation in 1842 via the Geological Survey of Canada Act. ${ }^{107}$ At inception, through mapping and charting the largely foreign Canadian landscape and its abundant resources, the mandate of the GSC was to promote commerce

106. Bélanger, Pierre, ed. Extraction Empire. Mit Press, 2018, 316

107. Ignatieff, Alex. A Canadian Research Heritage. Ottawa: Canadian Gov. Publ. Centre, Supply \& Services Canada, 1981, 1 
and settlement nationwide. ${ }^{108}$ Today, this is accepted as one of the initial proactive 'nation' building measures initiated by the colonial administration of the mid-19th century as the promotion of settlement ultimately supports an overarching goal of territorialization. Morris Zaslow, a historian and author of 'Reading the Rocks' supports this idea; he states:

"Geologists are not employed by governments for the primary purpose of contributing to the increase of theoretical geological knowledge; geological surveys, in Canada and elsewhere, were established with the objective of advancing the mining economy of the province and commercial endeavors. ${ }^{\prime 109}$

For a period of thirty five years, from 1842 to 1877 , the Geological Survey of Canada operated as an early form of Crown agency with its mandate occasionally renewed by Parliament. ${ }^{110}$ During this time, under the supervision of Sir William Edmond Logan and while headquartered in the original Geological Survey Building on the corner of Ottawa's Sussex and George streets, the first Geological Map of Canada was published in the year 1864. ${ }^{111}$

Soon after this premier publication, the Confederation of Canada in 1867 increased the Survey's geographic area of operations, with the addition of vast tracts of uncharted land in the west and north. During this era, the Government also moved quickly to claim the western territories, bringing the provinces of Manitoba and British Columbia into Confederation, further expanding the GSC's purview. ${ }^{112}$

As a result of the amalgamation of British Columbia and the Canadian Confederation in 1871, a new organizational structure for the government was required. Resultantly, a new 'Department of the Interior' was created in the year 1873 - once again to open up and exploit the new territories for settlement and resource development. ${ }^{113}$ In 1877, the GSC became an outside branch of the Department of the Interior and they published their first report a decade later titled: 'Production, Value, Exports and Imports of Minerals in Canada.'114

Following the Geological Survey of Canada, the Mines Branch, now titled CANMET, is the second eldest body within the current Natural Resources

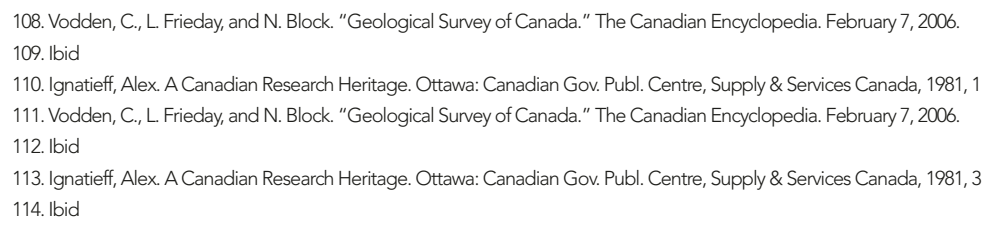


Department. According to the legislation of the Geology and Mines Act, 1907 marks the date upon which the branch was officially promulgated as the Department of Mines within its own rights; however 1901 is the unofficial inception. ${ }^{115}$ In June of 1901, Dr. Eugene Haanel was appointed 'Superintendent of Mines' in reaction to rapid increase of mining taking place across the country. ${ }^{116}$ As stated within the annual report of the Department of the Interior from that year, "the recent development of mining industries in the Yukon Territory and other sections of the country where lands are under the control of the Dominion Government [requires] the appointment of a special technical officer ... to take charge of this particular branch." ${ }^{117}$ After the creation of the Department of Mines, the GSC becomes a branch of the department alongside a sister branch named Mines Branch. ${ }^{118}$

\section{The Birth of the Booth Street Complex}

In 1908, as a result of increased territory and thereafter, the department's expansion, the government decided to begin the process of acquiring land for a departmental headquarters and testing facility. This marks the conception of the Booth Street Complex and illustrates how its existence is directly related to increasing industrial activities of the time.

From 1914 to 1918, during the period of Canada's participation in the First World War, both bodies, the Geological Survey of Canada and the Mines Branch experienced a decrease in operations due to budget cuts and staff reductions. ${ }^{119}$ Only projects with a strong economic focus continued during this time in the hopes that the work of the Department of Mines would stabilize the economy. ${ }^{120}$ The branch focused on research pertaining to the extraction of solid fuels - renovating and adding the respective laboratories at the Booth Street Complex.

Unlike the first world war, the second world war brought a level of prosperity to the Department. There were new priorities - no longer were the projects focused on increasing settlement and commerce, but about supporting the war efforts via the search for domestic sources of strategic metals and minerals. To support this, additional research laboratories and were erected at the Booth Street Complex, allowing for increased departmental employees and an increased overall productivity

117. Ibid

118. lbid

119. Ibid, 28

120. Vodden, C., L. Frieday, and N. Block. "Geological Survey of Canada." The Canadian Encyclopedia. February 7, 2006. 
Following the war, the country's growing investments in nuclear energy encouraged the GSC to explore the Canadian Shield for deposits of uranium — a project that resulted in unprecedented mapping of the Shield as well as subsequent growth within the Mines Branch. ${ }^{121}$ In 1947, a landmark oil strike in central Alberta marked the beginning of Western Canada's oil boom and an unprecedented demand for geological information about the region. ${ }^{122}$

For the following 18 years, both the GSC and the Mines Branch continued to function under the same organizational structure. During the 1950s and 1960s, two decades which showed rapid technological development, the two research bodies benefited tremendously from the government's growing willingness to fund scientific research and development; numerous buildings and laboratories were constructed, field work became more far reaching, and publications increased.

In 1967, along with the country's assortment of centennial celebrations, the organizational structure of the government was once again reconfigured. The 'Department of Energy, Mines and Resources' was crafted, which in turn gave rise to the Resources and Technical Surveys Act amending the Department of Mines and Surveys Act and charging the reorganized department with additional responsibilities. ${ }^{123}$ As a result, by the 1970s, both the GSC and the Mines Branch research had a strong environmental and land use focus. International debates on the ownership of the oceans' resources required geoscientific information from the GSC to support Canada's claims to an offshore "economic zone." 124 The extension of Canada's offshore boundaries to $371 \mathrm{~km}$ from the coast increased the already extensive 10 million $\mathrm{km} 2$ area of operations by approximately 40 per cent, and led to an expansion of offshore research capabilities. ${ }^{125}$ With this expansion, the government once again increased the body of the department and physically expanded into the William Edmond Logan Tower, a building leased to the Department in 1972.

In 1975, the Mines Branch was renamed the 'Canada Centre for Mineral and Energy Technology', commonly know as CANMET. ${ }^{126}$ A system of sectors within departments was also introduced at this time - both the GSC and CANMET were grouped into the Science and Technology Sector of the Department of Energy, Mines and Resources. ${ }^{127}$ Notably, CANMET was the last departmental body to occupy the now vacated Booth Street Complex buildings. (Figure 1.15)

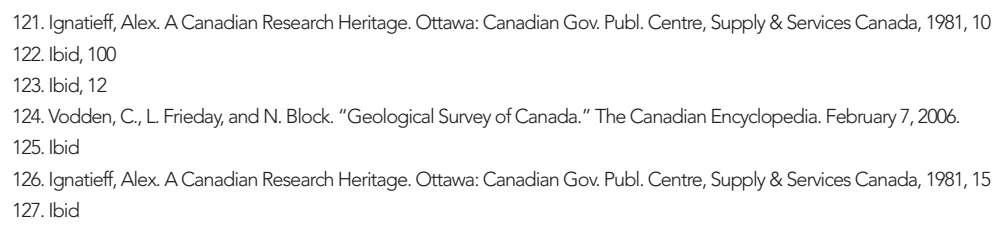


Although the contemporary Department of Natural Resources is the grandchild of legislature written with colonial priorities, the evolved version and associated mandate of the department now focuses on the country's transition to a low-carbon economy, the competitiveness of the natural resource sectors, adaptation to climate change, and the safety and security of Canadians. ${ }^{128}$

As will be explained in the coming work, the transition is not only evident within mandate changes but within the Booth Street Complex itself. The evolution of the department, the evolution of Canada's industrial landscape and that of the Booth Street Complex reacted to each other in concert.

\subsection{The State-of-the-Art}

In terms of productivity and functionality, the Department of Natural Resources can arguably be said to have peaked during the 1980s - after which, the department has been declining. In 1997, the Canadian economy slowed, causing the federal debt load to peak at 64 percent of the annual GDP. ${ }^{129}$ To counteract this, the government made numerous attempts to cut internal spending; all departmental budgets were drastically cut. The Department of Natural Resources had its expenditures reduced by about 50 percent between the years 1995 and 1998, resulting in a staff loss of about 30 percent. ${ }^{130}$

As stated within the 2005 Auditor General Report on the Department of Natural Resources, "the knowledge and expertise of the workforce are vital to the effectiveness of the department." 131 Similar to many other knowledge-based organizations, the department of Natural Resources needs to confront the issue of current and impending employment reductions if it hopes to improve productivity. In addition to the workforce decreases, it is also likely that the cuts to the departmental budget also have an impact on property maintenance. By 2015, when the process of disposal began, the vacancies and deteriorating conditions of the Booth Street Complex supported this idea. Today in 2019, there are 17 vacant buildings within the complex with 4 occupied buildings dealing with impending building issues. As stated by occupants buildings, the frequency of periodic building closures at 555, 601, 615 and 588 caused by mechanical inoperability is increasing.

\footnotetext{
128. Carr, Jim. "Natural Resources Canada 2017 - 2018 : Departmental Plan." Government of Canada Publications. 129. "Canada's Debt History." Debt Clock.

130. "Report of the Auditor General of Canada Chapter 1-Natural Resources Canada-Governance and Strategic Management." Natural

Resources Canada - Govemance and Strategic Management. April 05, 2005.

131. Ibid
} 
1842

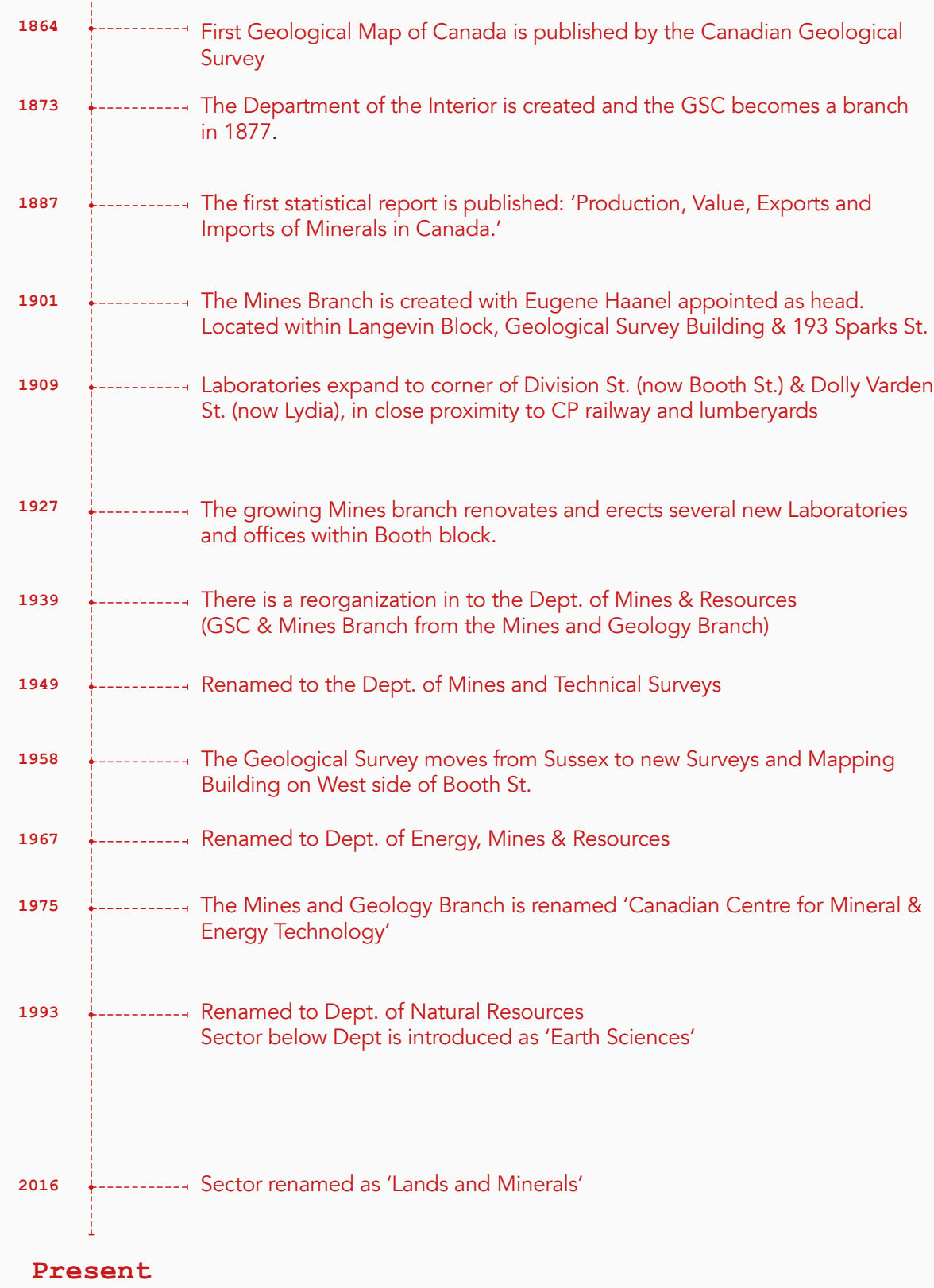

ical Survey of Canada is created with William Edmond Logan as head and headquartered at the GSC building at the corner of Sussex and George streets.

Figure 1.15: Timeline of the Department of Natural Resources (by Author) 


\section{Part 2 : Development \& Extraction}

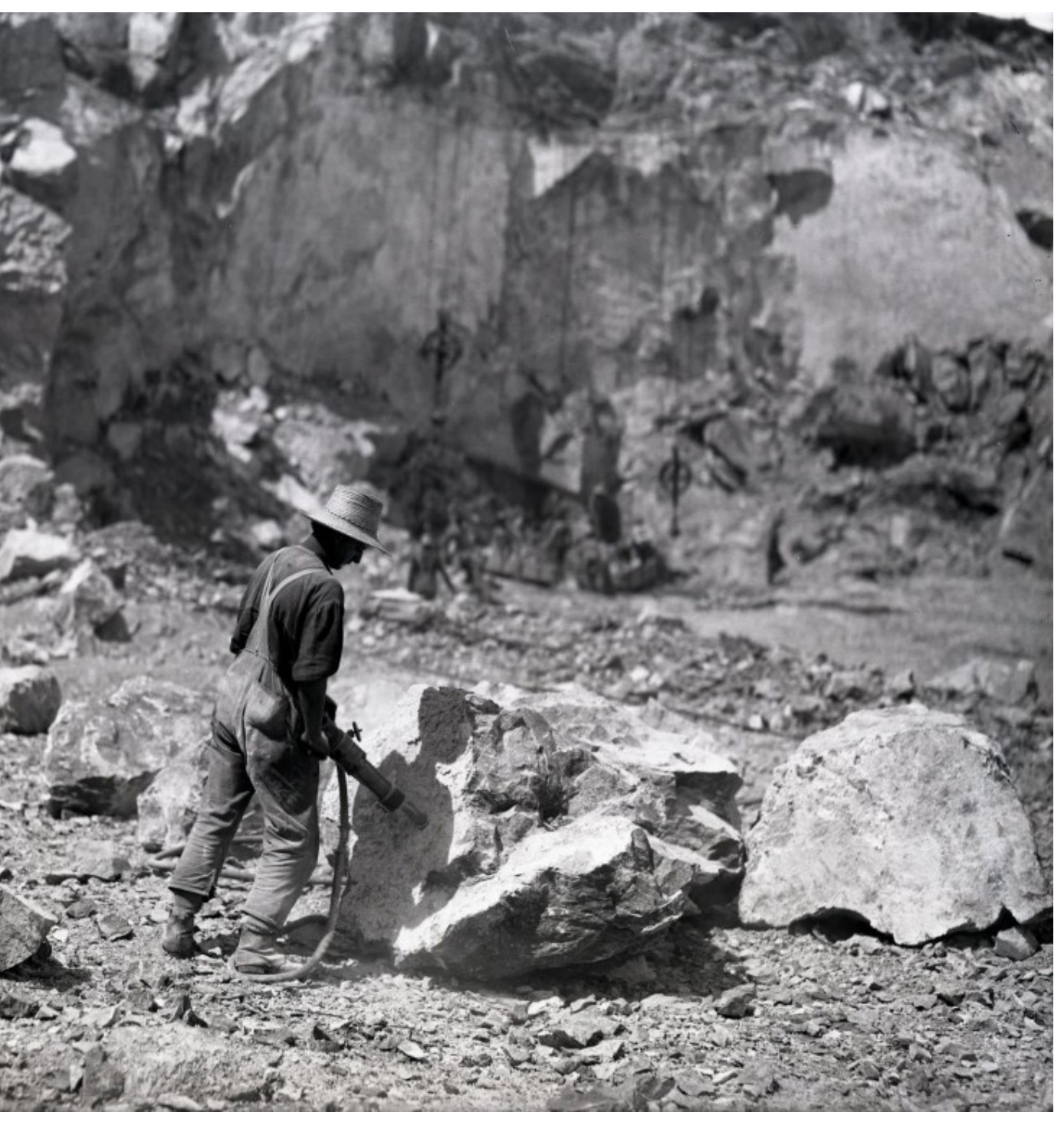

Figure 2.01: Worker at Jeffrey Mine drilling to remove asbestos ore c.1944 


\section{Chapter IV}

\section{National Implications: A Network of Industry}

Themes: Canadian Extraction, Landscape of Extraction, and Network

The current Canadian stature of research and industry within the mining and resource extraction realm is largely and undeniably due to the activities of the Federal Department of Natural Resources and its preceding bodies. These governmental bodies, officially introduced via legislature in the year 1842 were given a permanent home in the year 1908, when the federal government began to acquire land and thereafter construct laboratories, workshops, and offices on the site of Ottawa's modern Booth Street Complex. ${ }^{132}$ Chapter IV seeks to investigate and measure the complex's implications upon the national landscape.

\subsection{A Landscape of Industrial Extraction}

At the time of their construction, many of the facilities in the Booth Street Complex were state-of-the-art and were developed in response to new research needs and resource developments of the Canadian mineral and resource industry. ${ }^{133}$ The individual areas of research varied by activity and subject, but all contributed to the development of Canada as an economically prosperous country. Work focused on the exploration and subsequent mapping of the country's natural resources, their extraction and development, as well as their refining and processing. ${ }^{134}$ Numerous burgeoning Canadian industries relied on not only the cartographic endeavors of the GSC but also on the laboratories of the Mines Branch for the evaluation of sampled minerals. Should an acquired sample yield good results and possess favorable properties, the company would likely set up industry to exploit that deposit or

132. Ignatieff, Alex. A Canadian Research Heritage. Ottawa: Canadian Gov. Publ. Centre, Supply \& Services Canada, 1981, 26

133. ERA Architecture, Stantec Consulting Ltd., and Hill Knowlton Strategies. "Canada Lands Company Booth Street Redevelopment." City of Ottawa Webcast. March 28, 2018

134. Ignatieff, Alex. A Canadian Research Heritage. Ottawa: Canadian Gov. Publ. Centre, Supply \& Services Canada, 1981, 1 
reserve. Research undertaken at the Complex resulted in greater efficiencies at mining plants nationwide and encouraged Canadian industries to expand. ${ }^{135}$

Today, it is common to commend Canada's Natural Resources as a key driver of the county's economy. The mining industry in Canada employs close to 400,000 people annually, and in the year 2014, it alone contributed $\$ 57$ billion CAD to Canada's GDP. ${ }^{136}$ Not only in recent years, but for numerous decades, the exploits of the country's wealth of natural resources have stabilized and fed the Canadian economy, leading many politicians to compliment and acclaim the country's ability to 'capitalize' on its bounty. ${ }^{137}$

With regards to the extraction industry, Canada is said to have become the most active mining nation in the world, thanks in part to the unwavering support of the federal government. The activities of both domestic and foreign mining industries have ballooned since the early 19th century. Of the nearly 20,000 mining projects in the world, more than half of the operating companies are headquartered in Canada and consequently are listed on the Toronto Stock Exchange. ${ }^{138}$ As stated by the Minister of Natural Resources in 2012:

"Only five countries produce more oil than we do. Canada is the third largest producer in the world of both natural gas and hydroelectricity and the second-largest producer of uranium. Canada has over 200 active mines turning out more than 60 different minerals and metals, including more potash than anyone else. We're in the top five in aluminum, cobalt, diamonds, nickel, platinum group metals, titanium concentrate and tungsten. The Ring of Fire region in northern Ontario could make us one of the biggest producers of chromite as well. And northern Quebec has great mineral potential"139

As of January 2017, the number of active mines in Canada is actually double the disclosed figure of 2012. As illustrated in 2017's 'Principal Mineral Areas, Producing mines, and Oil and Gas Fields in Canada' map, there are 422 active mines in Canada. ${ }^{140}$ There are 249 gas or oil producing fields and 173 principal producing mines - many of which are operating on sites initially discovered by

135. ERA Architecture, Stantec Consulting Ltd., and Hill Knowlton Strategies. "Canada Lands Company Booth Street Redevelopment." City of Ottawa Webcast. March 28, 2018

136. The Canadian Chamber of Commerce. "Positions on Selected 2016 National and International Issues." Canadian Chamber of Commerce. 2016.

137. Bélanger, Pierre, ed. Extraction Empire. Mit Press, 2018, 314

138. Ibid, 7

139. Oliver, Joe. "Natural Resources: Canada's Advantage, Canada's Opportunity." Natural Resources Canada. November 06, 2015

140. Lands and Minerals Sector of Natural Resources Canada (NRCan) and the National Energy Board, comp. "Principal Mineral Areas, Producing Mines, and Oil and Gas Fields in Canada." Map. In GEOSCAN. 67th ed. "A" Series / 900A. Ottawa: Gov. of Canada, 2017. 


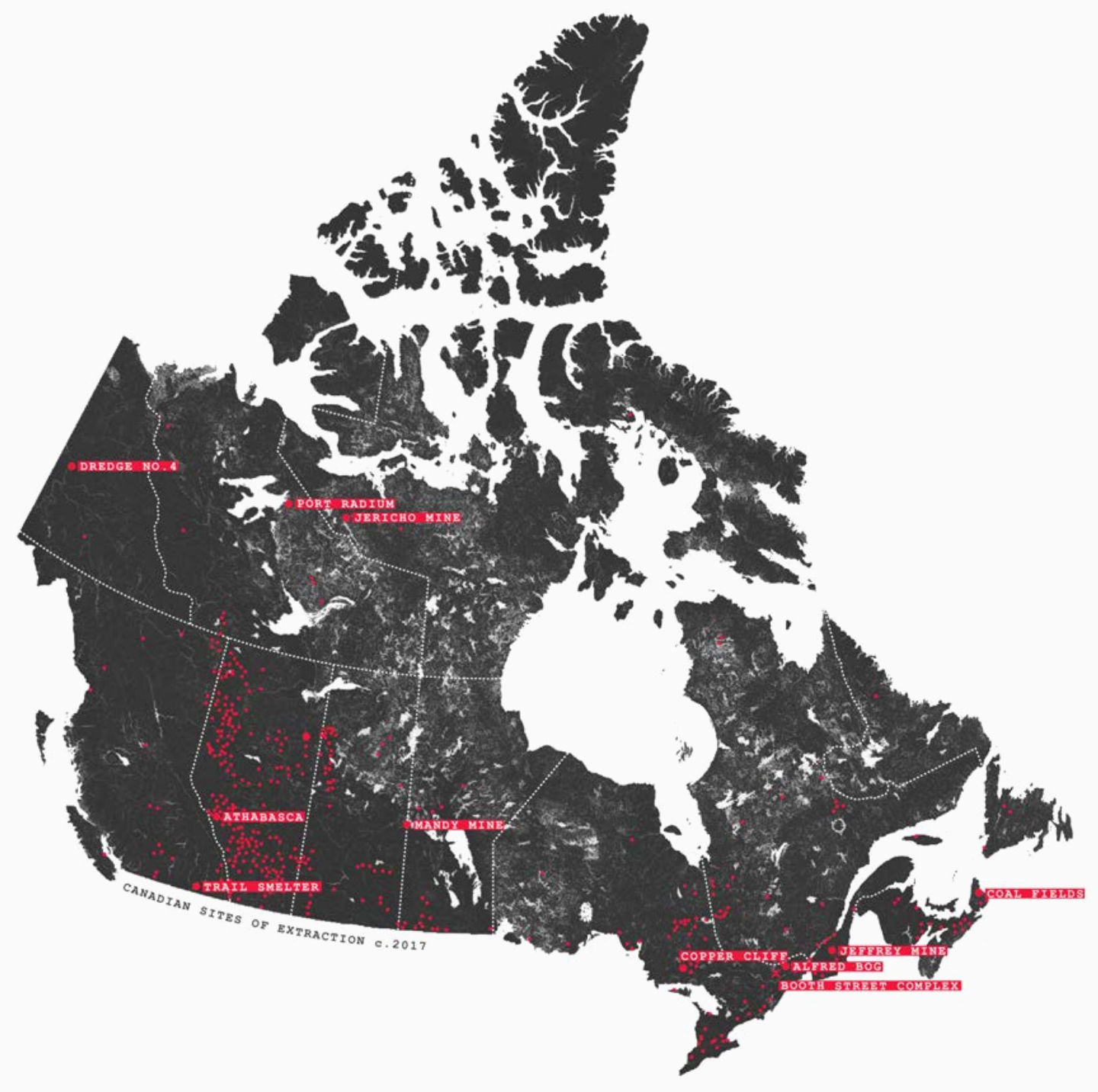

Figure 2.02: Map of 'Canadian Sites of Extraction c. 2017'

(data sourced: 2017's 'Principal Mineral Areas, Producing mines, and Oil and Gas Fields in Canada' map) (by Author) 
the geologists and scientists of Ottawa's Booth Street Complex. ${ }^{141}$ Figure 2.02 maps the 422 active extraction sites in 2017 Canada. It is difficult to imagine the shear quantity of mining sites, let alone the associated smelters, refineries, plants and mills - but these are the current objects and future artifacts of modern industrial practices.

\section{Representing Canada's Landscape of Extraction}

After a thorough examination of the development of the Department of Natural Resources, its history and the associated publishings, ten auxiliary sites to that of the Booth Street Complex have been selected for further architectural exploration within this thesis. (Figures 2.03-2.12)

The Geological Survey of Canada maps both surficial as well as bedrock geology; thus a range of stones, gas, oils and soil types are charted and illustrated. ${ }^{142}$ Likewise, the work of CANMET, the Canada Centre for Mineral and Energy Technology, also deals with a wide variety of materials - since its beginning, the branch has been leading edge with regards to research of solid fuels, hydrocarbons, base metals, industrial minerals, explosives and ceramics. ${ }^{143}$ For this reason, it was important that the selected auxiliary sites showcase a breadth of resource focus. Sorted by latitude, South to North, the selected sites are:

$\begin{array}{ll}\text { Alfred Bog, ON } & \left(45^{\circ} 29^{\prime} 33.40^{\prime \prime} \mathrm{N} 74^{\circ} 51^{\prime} 6.37^{\prime \prime} \mathrm{W}\right) \\ \text { Jeffrey Mine, QC } & \left(45^{\circ} 46^{\prime} 25.08^{\prime \prime} \mathrm{N} 71^{\circ} 57^{\prime} 15.26^{\prime \prime} \mathrm{W}\right) \\ \text { Sydney Coal Fields, NS } & \left(46^{\circ} 9^{\prime} 1.18^{\prime \prime} \mathrm{N} 60^{\circ} 11^{\prime} 22.70^{\prime \prime} \mathrm{W}\right) \\ \text { Copper Cliff Mines, ON } & \left(46^{\circ} 29^{\prime} 43.14^{\prime \prime} \mathrm{N} 81^{\circ} 3^{\prime} 15.23^{\prime \prime} \mathrm{W}\right) \\ \text { Trail Smelter, BC } & \left(49^{\circ} 6^{\prime} 16.21^{\prime \prime} \mathrm{N} 117^{\circ} 43^{\prime} 18.05^{\prime \prime} \mathrm{W}\right) \\ \text { Mandy Mine, MB } & \left(54^{\circ} 46^{\prime} 38.55^{\prime \prime} \mathrm{N} 101^{\circ} 53^{\prime} 52.70^{\prime \prime} \mathrm{W}\right) \\ \text { Athabasca Tar Sands, AB } & \left(57^{\circ} 0^{\prime} 8.52^{\prime \prime} \mathrm{N} 111^{\circ} 28^{\prime} 30.88^{\prime \prime} \mathrm{W}\right) \\ \text { Dredge No. 4, YK } & \left(63^{\circ} 56^{\prime} 36.92^{\prime \prime} \mathrm{N} 139^{\circ} 20^{\prime} 8.24^{\prime \prime} \mathrm{W}\right) \\ \text { Jericho Mine, NU } & \left(65^{\circ} 59^{\prime} 44.5^{\prime \prime} \mathrm{N} 111^{\circ} 29^{\prime} 02.4^{\prime \prime} \mathrm{W}\right) \\ \text { Port Radium, NWT } & \left(66^{\circ} 5^{\prime} 20.17^{\prime \prime} \mathrm{N} 118^{\circ} 0^{\prime} 52.06^{\prime \prime} \mathrm{W}\right)\end{array}$

By examining the life-cycles and trajectories of these auxiliary sites - which were conceived in repercussion to the research and development stemming from Ottawa's Booth Street Complex - patterns can be observed which provide insights into the likely futures of the nucleus that is the urban complex, as well as for Canada's industrial research heritage landscape as a whole.

141. Ibid

142. "Geological Survey of Canada." Geological Survey of Canada. August 08, 2018.

143. Ignatieff, Alex. A Canadian Research Heritage. Ottawa: Canadian Gov. Publ. Centre, Supply \& Senvices Canada, 1981, xi 

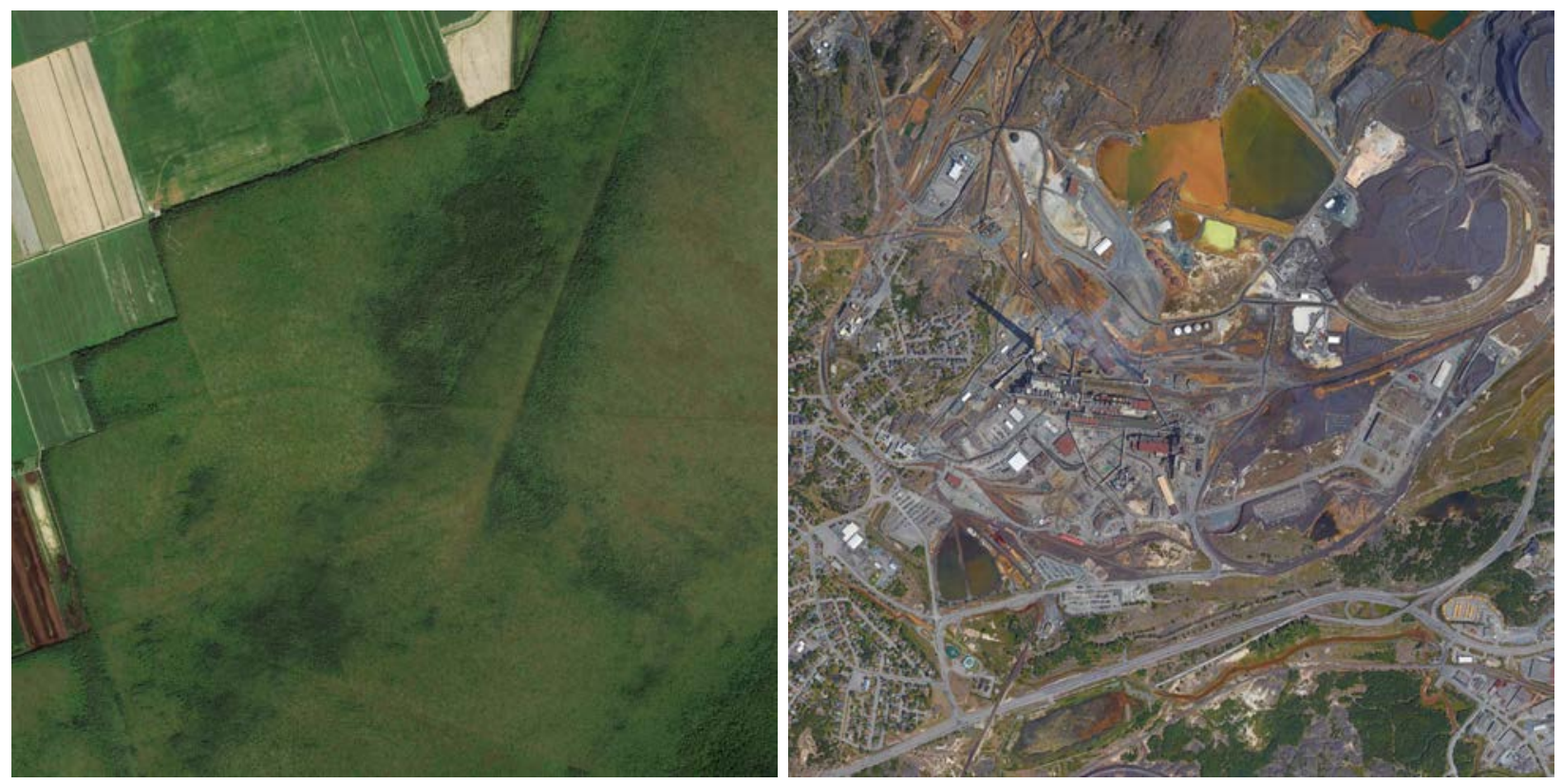

Figure 2.03 (Left): Satellite Image of Alfred Bog in Ontario c. 2018

Figure 2.04 (Right): Satellite Image of Copper Cliff Mine in Ontario c. 2018 

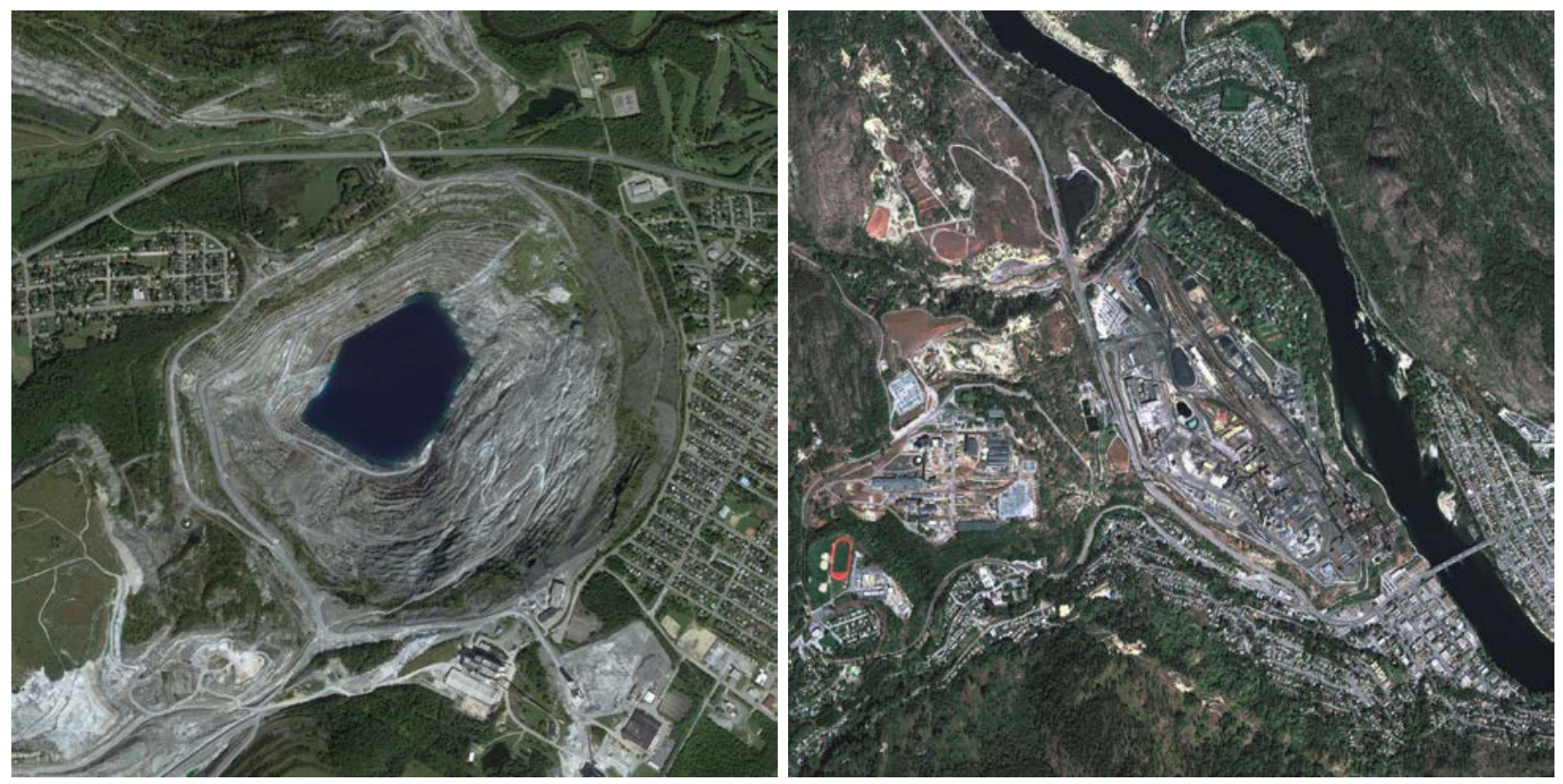

Figure 2.05 (Left): Satellite Image of Jeffrey Mine in Quebec c. 2018

Figure 2.06 (Right): Satellite Image of Trail Smelter in British Columbia c. 2018 


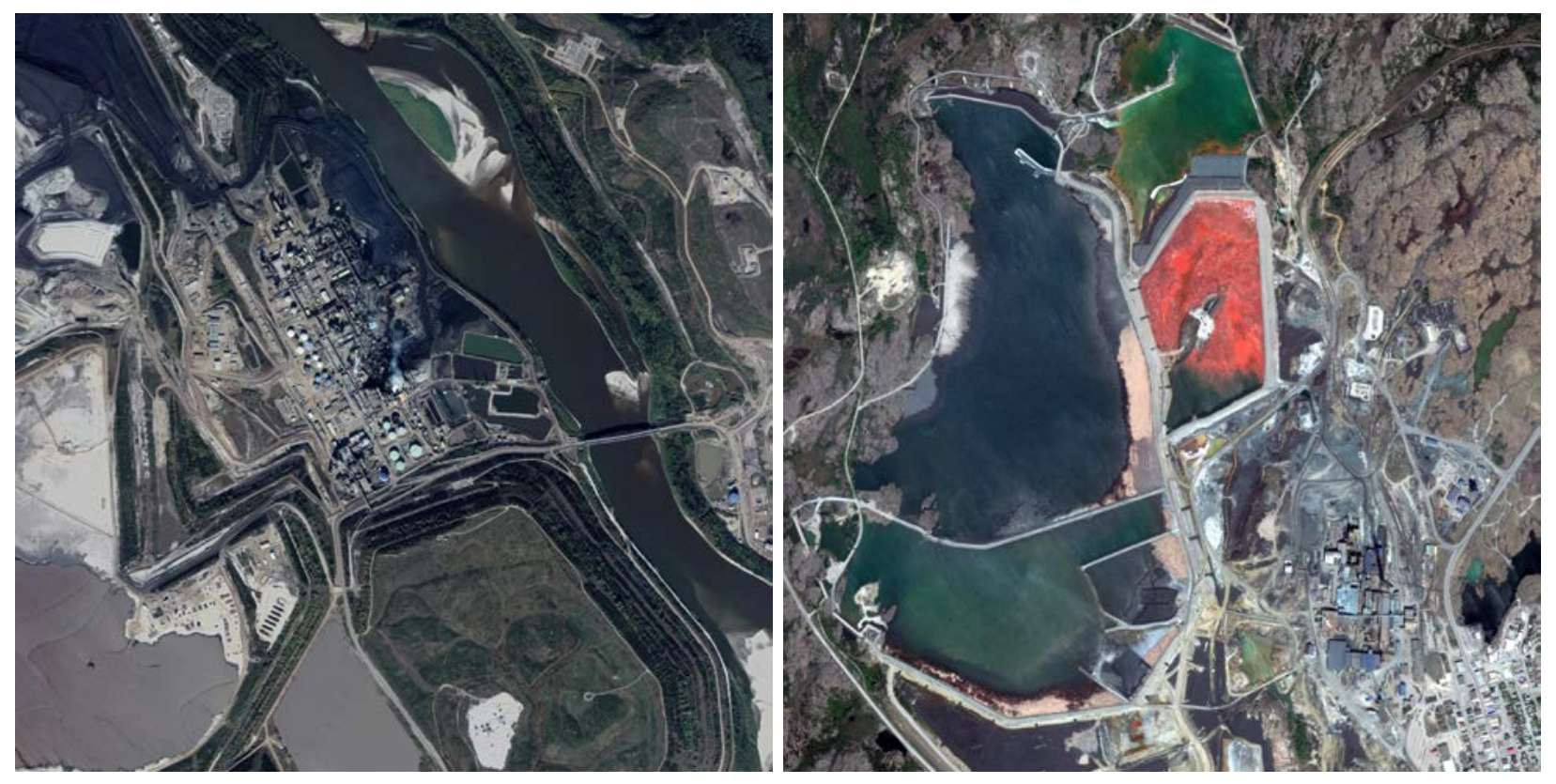

Figure 2.07 (Left): Satellite Image of Athabasca Tar Sands c. 2018

Figure 2.08 (Right): Satellite Image of Mandy Mine in Manitoba c. 2018 

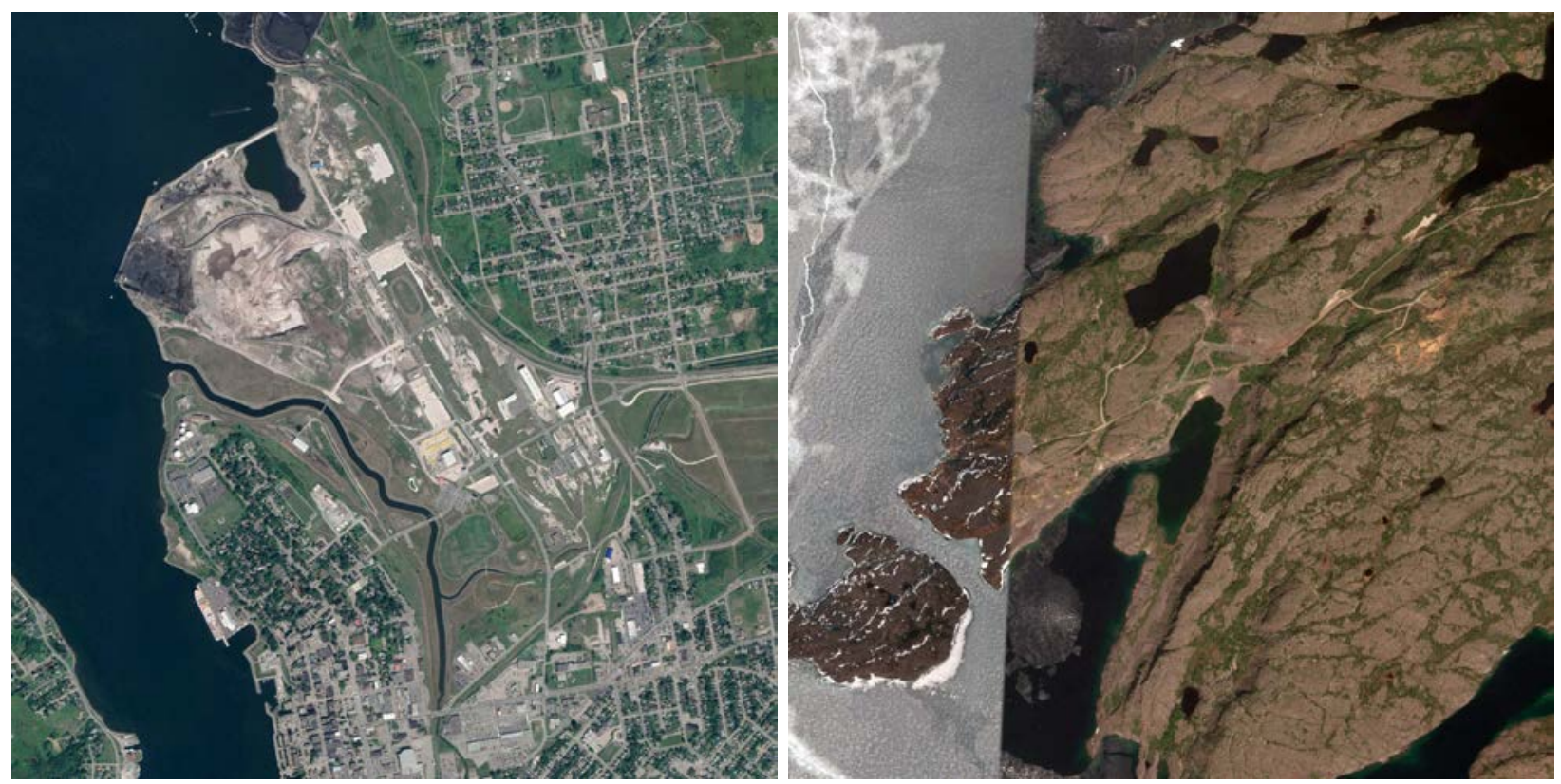

Figure 2.09 (Left): Satellite Image of Sydney Coal Fields in Nova Scotia c. 2018

Figure 2.10 (Right): Satellite Image of Port Radium in North-West Territories c. 2018 


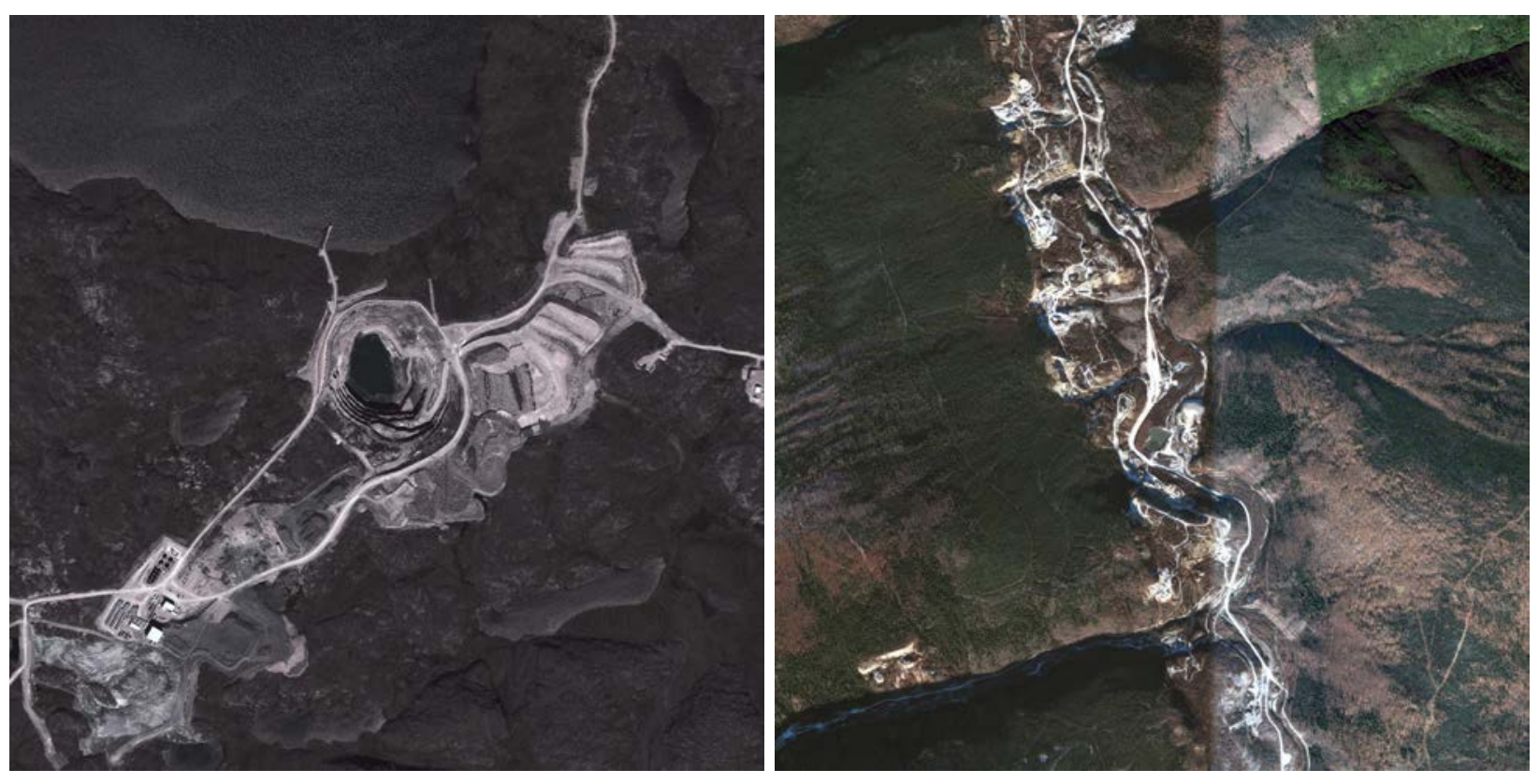

Figure 2.11 (Left): Satellite Image of Jericho Diamond Mine in Nunavut c. 2018

Figure 2.12 (Right): Satellite Image of Dredge No.4 in Yukon c. 2018 


\subsection{Auxiliary Site Analysis}

Each of the ten auxiliary extraction sites is briefly examined for its location, geology, presence of infrastructure and resource focus as well as its historical significance, contemporary significance and its evolution. Each site was then mapped to include all of said aforementioned aspects. A text report upon each site, which includes the historical and contemporary significance writings can be found in Appendix D. Following is a catalogue, compiled of site overviews and the resultant maps.

\section{Alfred Bog, ON}

$\left(45^{\circ} 29^{\prime} 33.40^{\prime \prime} \mathrm{N} 74^{\circ} 51^{\prime} 6.37^{\prime \prime} \mathrm{W}\right)$

Resource: Peat (Solid Fuel)

Historical Use: Extraction Site

Current State: Provincial Nature Reserve

Status: Decomposed

Description: The Alfred Bog is a domed peat bog located within the Canadian Shield Region in Eastern Ontario. ${ }^{144}$ With a modern area of approximately 10200 acres, the bog is located about 7 kilometers south of the town of Alfred and 70 kilometers east of the city of Ottawa.

\section{Copper Cliff Mines, ON}

(46 $\left.28^{\prime} 43.14^{\prime \prime} \mathrm{N} 81^{\circ} 3^{\prime} 15.23^{\prime \prime} \mathrm{W}\right)$

\section{Resource: Nickel (Base Metal)}

Historical Use: Mine

Current Use: Mine

Status: Operational

Description: Copper Cliff Mine is an operational underground nickel mine, located within the Canadian Shield Region in Eastern Ontario. The mine is situated within the Copper Cliff neighborhood of Sudbury, Ontario, a city with a modern population of just over 160 thousand residents.

Jeffrey Mine, QC

(4546'25.08"N 71'57'15.26"W)

Resource: Asbestos (Industrial Mineral)

Historical Use: Mine

Current Use: Not Applicable

Status: Abandoned

Description: Jeffrey Mine is an open pit asbestos mine, located within the St. Lawrence Lowlands Region in Southern Quebec. The mine shut down in 2011 
due to a lack in demand for the mineral - asbestos was deemed a carcinogenic material in the mid 1980s. ${ }^{145}$

\section{Trail Smelter, BC}

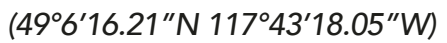

Resource: Lead and Zinc (Base Metal)

Historical Use: Smelter

Current Use: Smelter and Refinery Complex

Status: Operational

Description: The Trail Smelter, is an operative smelter which functions to extract zinc from mined ore. Now part of the TECK mining site, Trail Smelter is the third largest producer of mined zinc in the world. The full TECK complex assumes approximately 350 acres of land and is supplied by six regional mines Geographically, it smelter is adjacent to the Columbia River in the mineral rich Kootenay area, part of Canada's Cordillera region in British Columbia.

\section{Athabasca Tar Sands, AB}

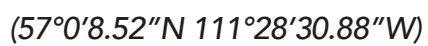

\section{Resource: Bitumen (Oil Sands)}

Historical Use: Mine

Current Use: Mine and Processing Complex

Status: Operational

Description: The Athabasca Tar Sands are large deposits of bitumen located within the Interior Plains Region of Alberta and assuming some 141,000 square kilometers. These oil deposits, found primarily in the geological McMurray Formation, consist of a mixture of crude bitumen, silica sand, clay minerals, and water. Markedly, the Athabasca deposit is the largest known reservoir of crude bitumen in the world and the largest of three major oil sands deposits in Alberta.

\section{Mandy Mine, MB}

(5446'38.55"N 101053'52.70"W)

\section{Resource: Copper}

Historical Use: Mine

Current Use: Processing Plant / Monument

Status: Operational

Description: The Mandy Mine site is located within the city of Flin Flon, which is interestingly on a correction line upon the boundary of Manitoba and 
Saskatchewan. ${ }^{146}$ Geographically the site is within the Interior Plains region of Canada and in its modern stature, is approximately 15 square kilometers in size. At a separate location within the city is a monument, erected to commemorate the first discovery of copper in Manitoba. ${ }^{147}$ The plaque was erected by the Manitoba Heritage Council within one of the city's green spaces. ${ }^{148}$

\section{Sydney Coal Fields, NS}

(46 9'1.18"N 60¹1'22.70"W)

Resource: Coal and Steel

Historical Use: Processing Plant

Current Use: Not Applicable

Status: Active Remediation

Description: The Sydney Coal Fields site is located on the north-eastern coast of the Island of Cape Breton. Situated on the southern shore of an, Atlantic estuary, Sydney Harbor, its maritime geography is characteristic of the Appalachian Region of Canada. The site is no longer home to operating mining or processing activity but remains a large tract of land - covering approximately 470 acres of land.

\section{Port Radium, NWT}

(66 5'20.17"N $\left.118^{\circ} 0^{\prime} 52.06^{\prime \prime} \mathrm{W}\right)$

Resource: Uranium and Silver

Historical Use: Mine

Current Use: Not Applicable

Status: Dismantled / Decomposed

Description: The Port Radium Mine site is located on the eastern shore of Great Bear Lake, in the Canadian Shield region of North West Territories. The site is 440 kilometers northwest of Yellowknife and 265 kilometers east of the community of Deline. At one time the area of industry was approximately 500 acres, but the site has since been dismantled and bears no artifacts of industry.

Jericho Mine, NU

(65⒌'44.5"N 111'29'02.4"W)

Resource: Diamonds

Historical Use: Mine

Current Use: Dormant Mine

Status: Paused and Decomposing

146. Davies, J., B. Bannatyne, G. Barry, and H. McCabe. "Geology and Mineral Resources of Manitoba." Province of Manitoba : Department of Mines and Minerals.

147. Goldsborough, Gordon, and Alan Mason. "Historic Sites of Manitoba: The Mandy Mine (Flin Flon)." Manitoba Historical Society.

December 8, 2013.

148. Ibid 
Description: The Jericho Diamond Mine is a dormant open pit diamond mine located in Canada's Nunavut territory. Jericho was Nunavut's first diamond mine and is located within the province's Canadian Shield region. ${ }^{149}$ In terms of its proximity to urban settlements, the mine is located $420 \mathrm{~km}$ northeast of Yellowknife, Northwest Territories and is accessible by air all year and by winter road from Yellowknife. The approximate size of the mine pit is 45 acres and has associated infrastructure which extends much further into the landscape.

\section{Dredge No. 4, YK}

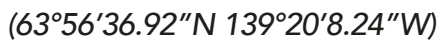

\section{Resource: Gold}

Historical Use: Dredge

Current Use: National Historic Site

Status: Preserved

Description: Dredge No. 4 is a wooden hull bucketline sluice dredge used to mine placer gold. ${ }^{150}$ The dredge lay dormant where it was decommissioned from 1959 to 992 it was moved to its current site, on Bonanza Creek in the Klondike goldfields, just outside of Dawson City, Yukon - a region which is part of Canada's Cordillera. The dredge is now preserved and operated as a national historic site by Parks Canada. ${ }^{151}$ It measures approximately $65 \mathrm{~m}$ in length and $25 \mathrm{~m}$ in height, so given its stature, the dredge could dig 17 meters below water level, and 5 meters above water level using hydraulic monitors and by washing down the gravel banks. ${ }^{152}$

149. Jakubec, Jarek, and Mike Johnson. "The Jericho Diamond Mine - What Happened?" SRK NorthAmerica - Jericho Mine.

150. "Dredge No. 4 National Historic Site of Canada." HistoricPlaces.ca - HistoricPlaces.ca.

151. Ibid

152. Ibid 


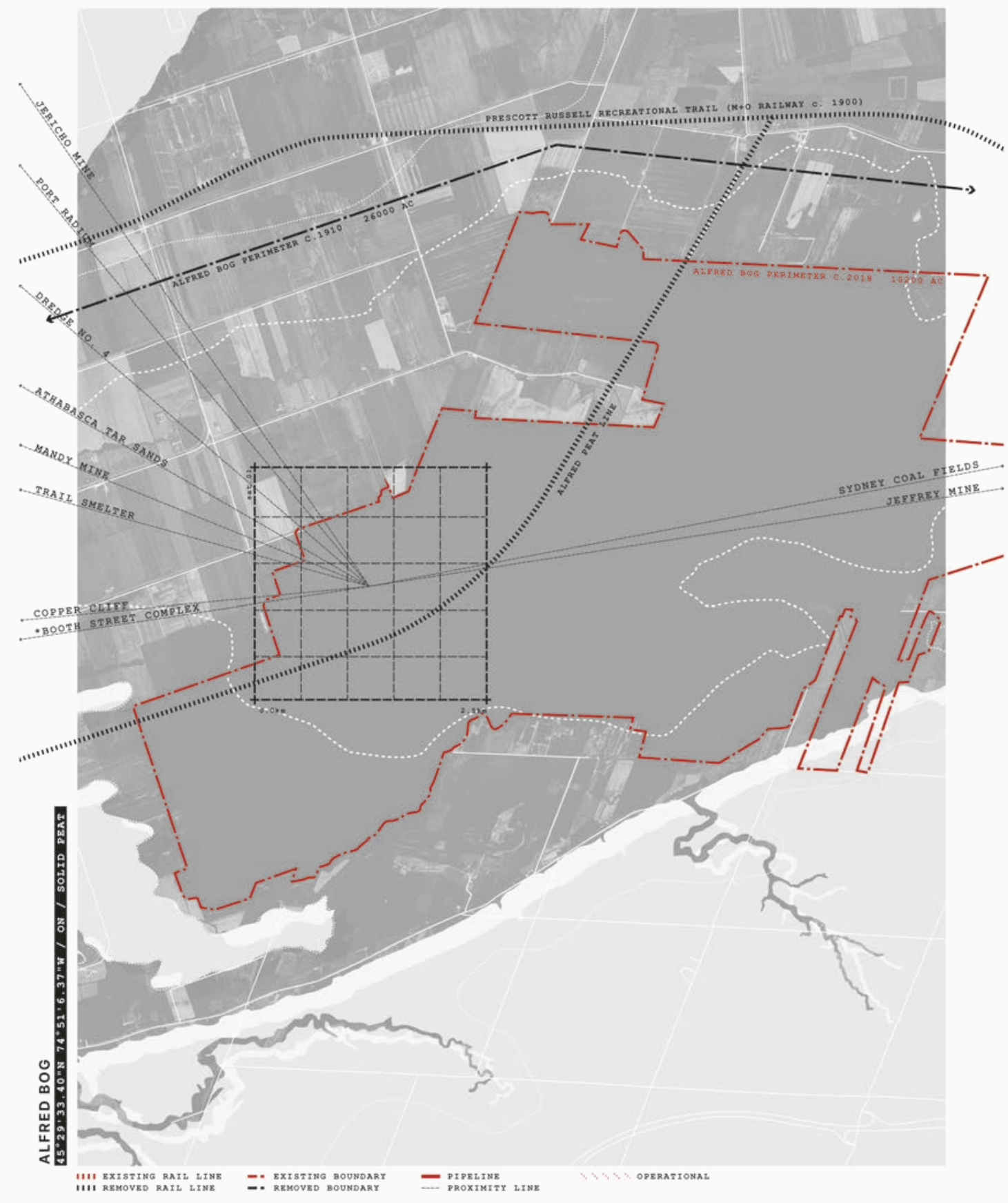

Figure 2.13: Mapped Evolution of Alfred Bog, ON (by Author) 


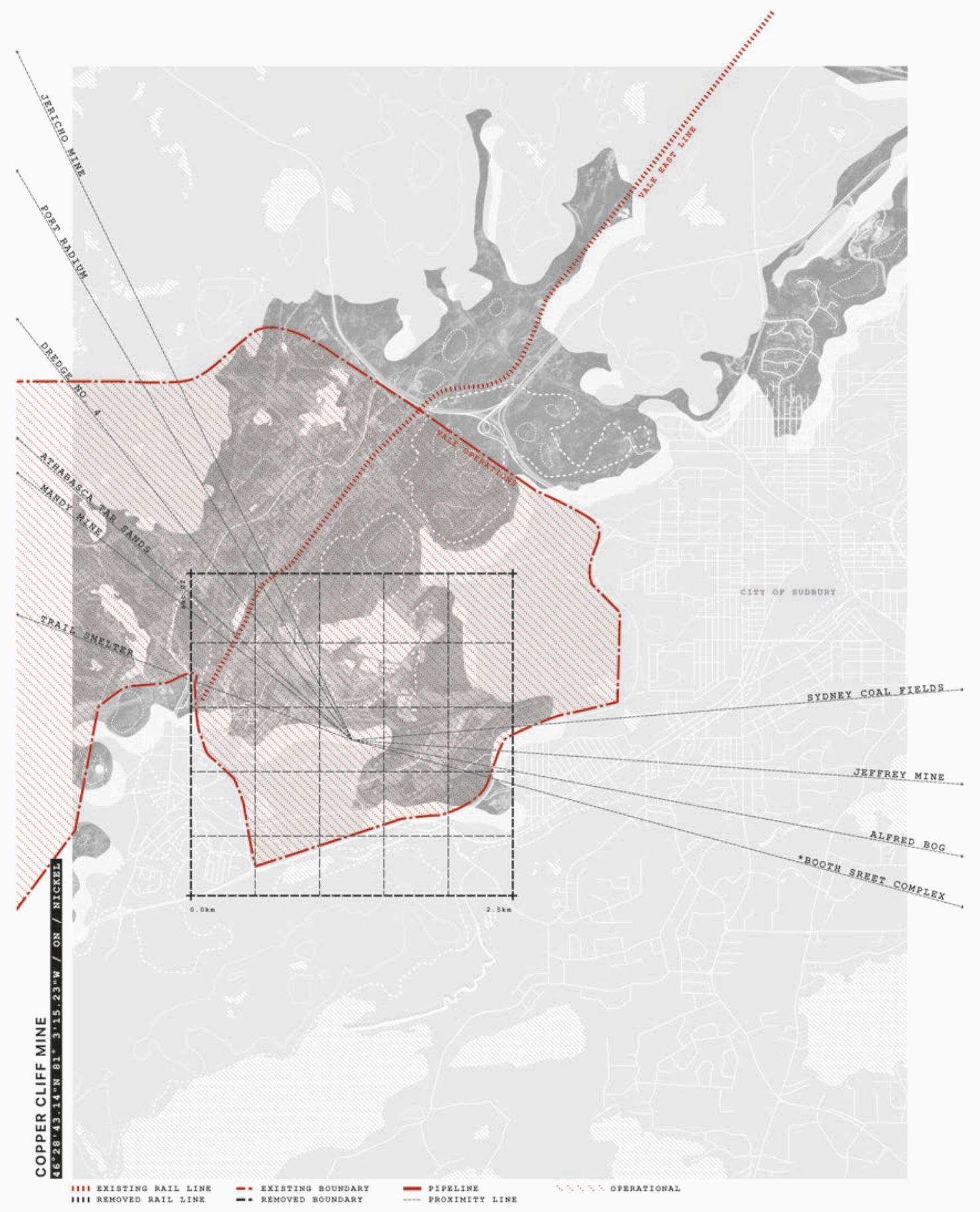

Figure 2.14: Mapped Evolution of Copper Cliff Mine, ON (by Author) 


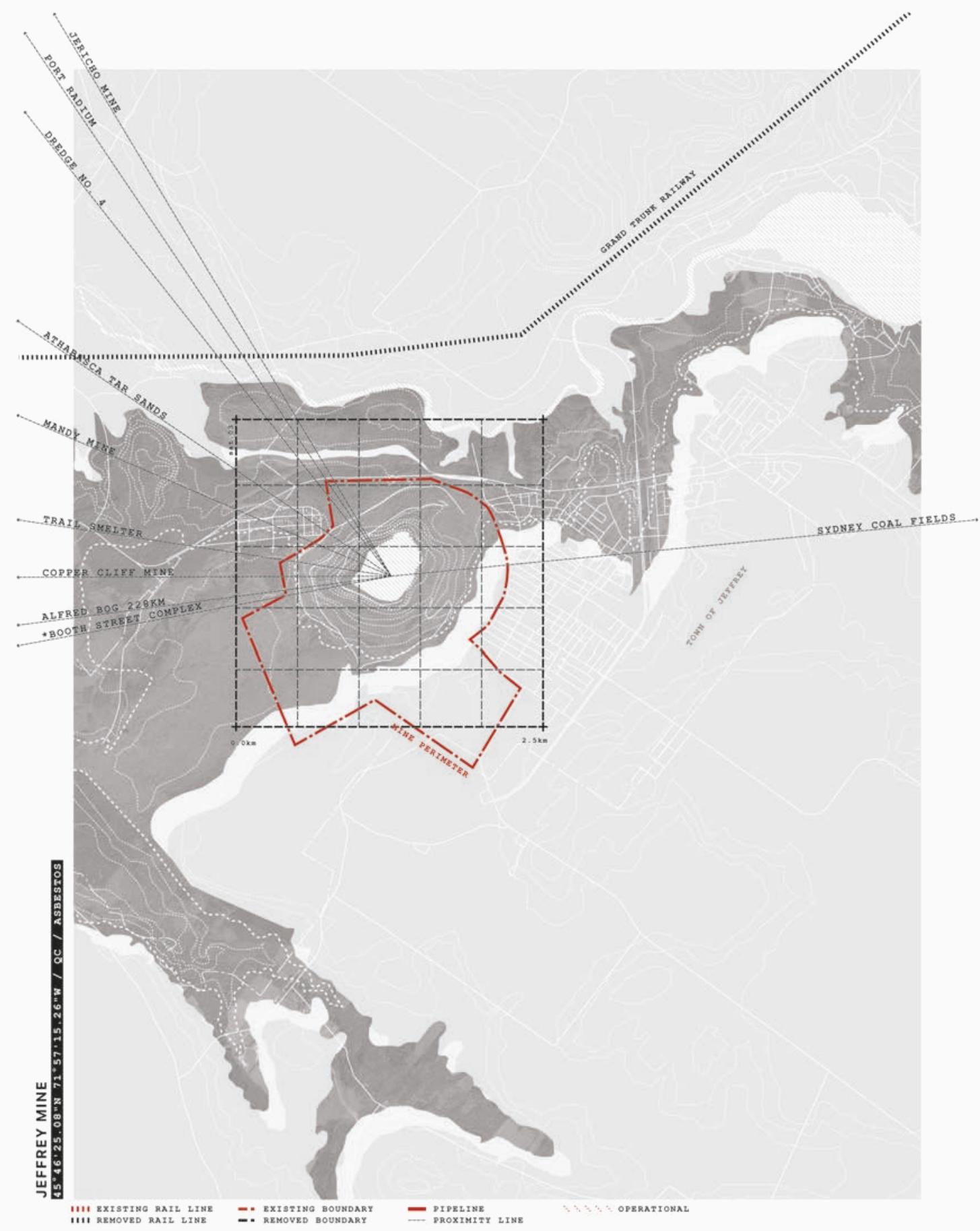

Figure 2.15: Mapped Evolution of Jeffrey Mine, QC (by Author) 


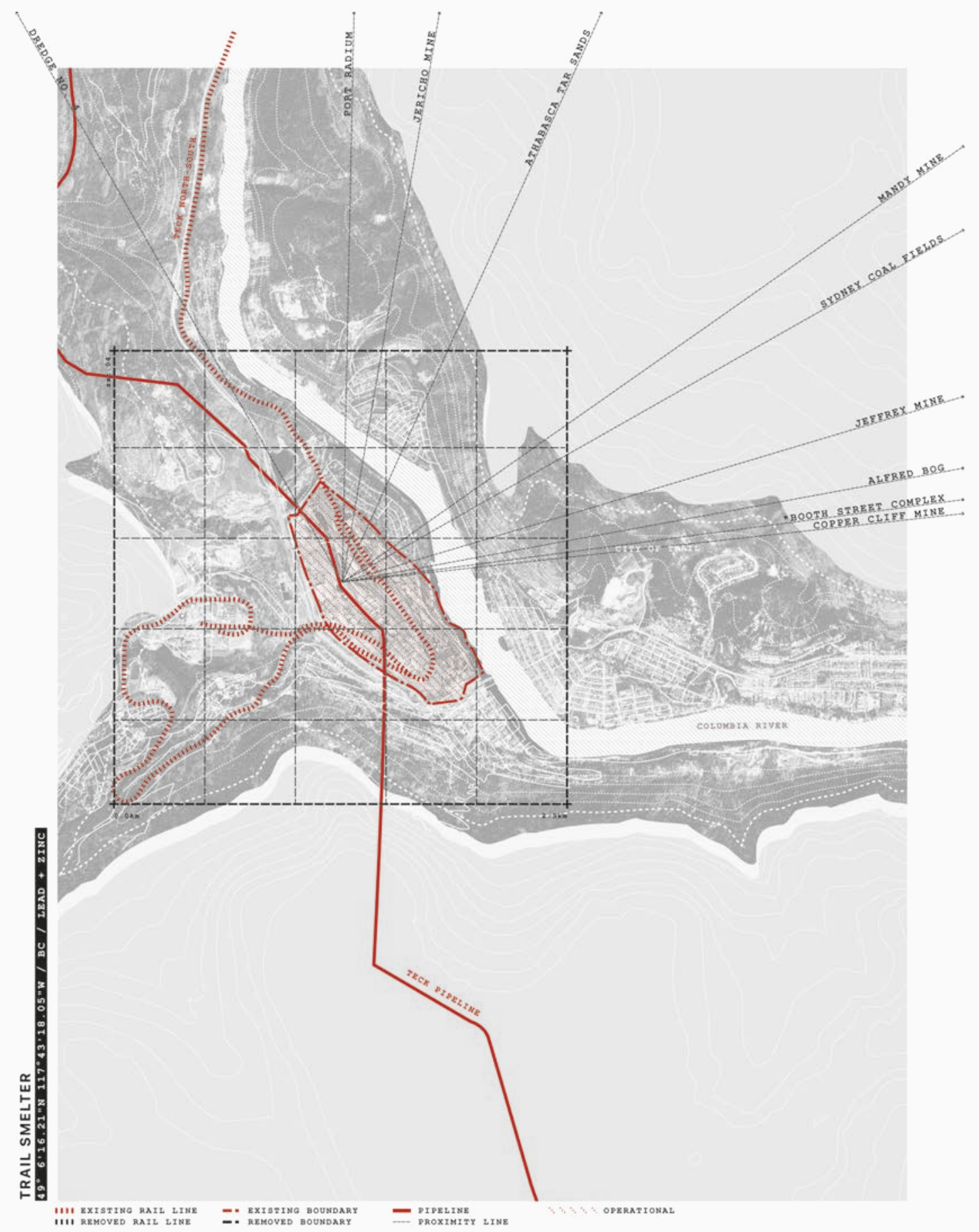

Figure 2.16: Mapped Evolution of Trail Smelter, BC (by Author) 


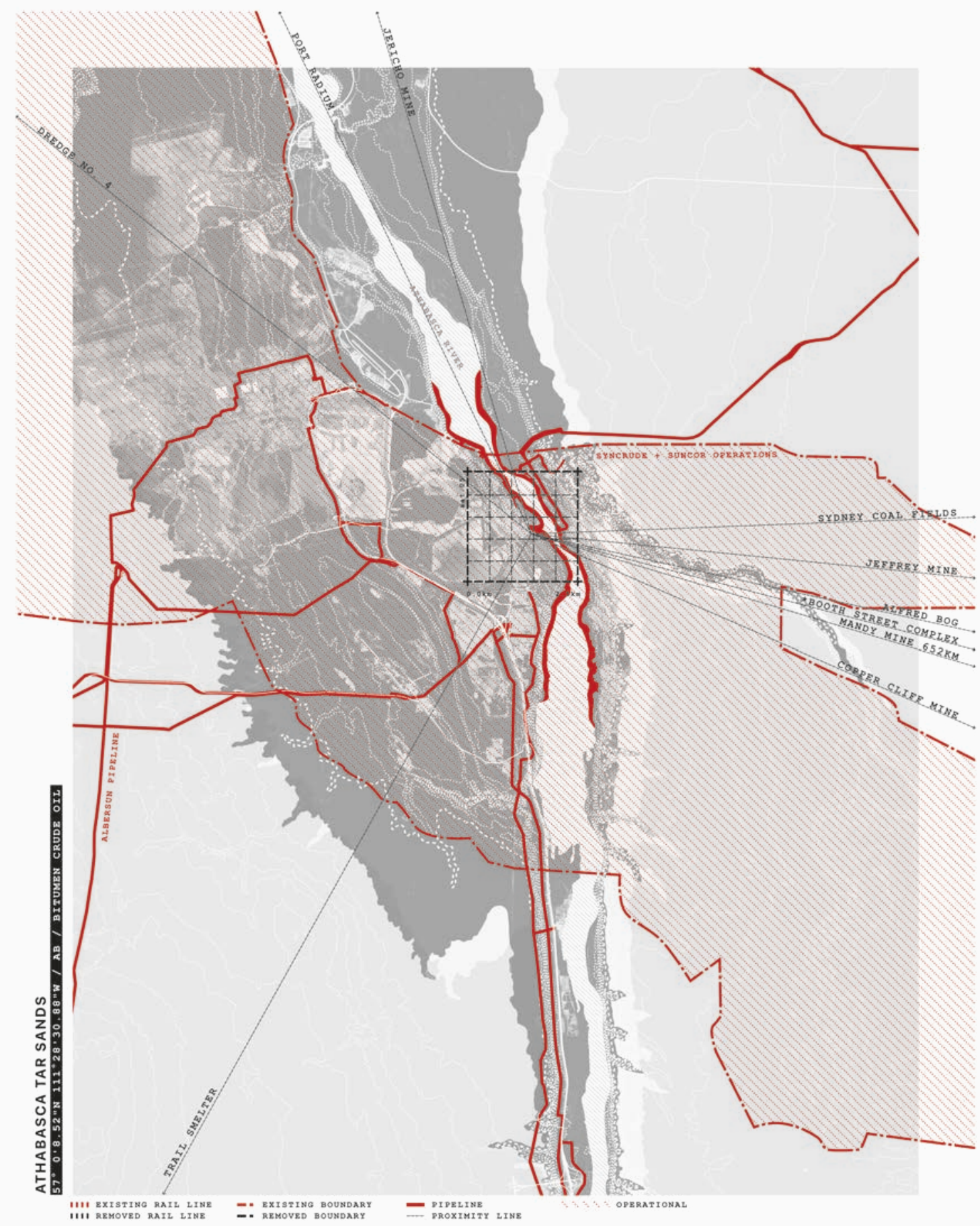

Figure 2.17: Mapped Evolution of Athabasca Tar Sands, AB (by Author) 


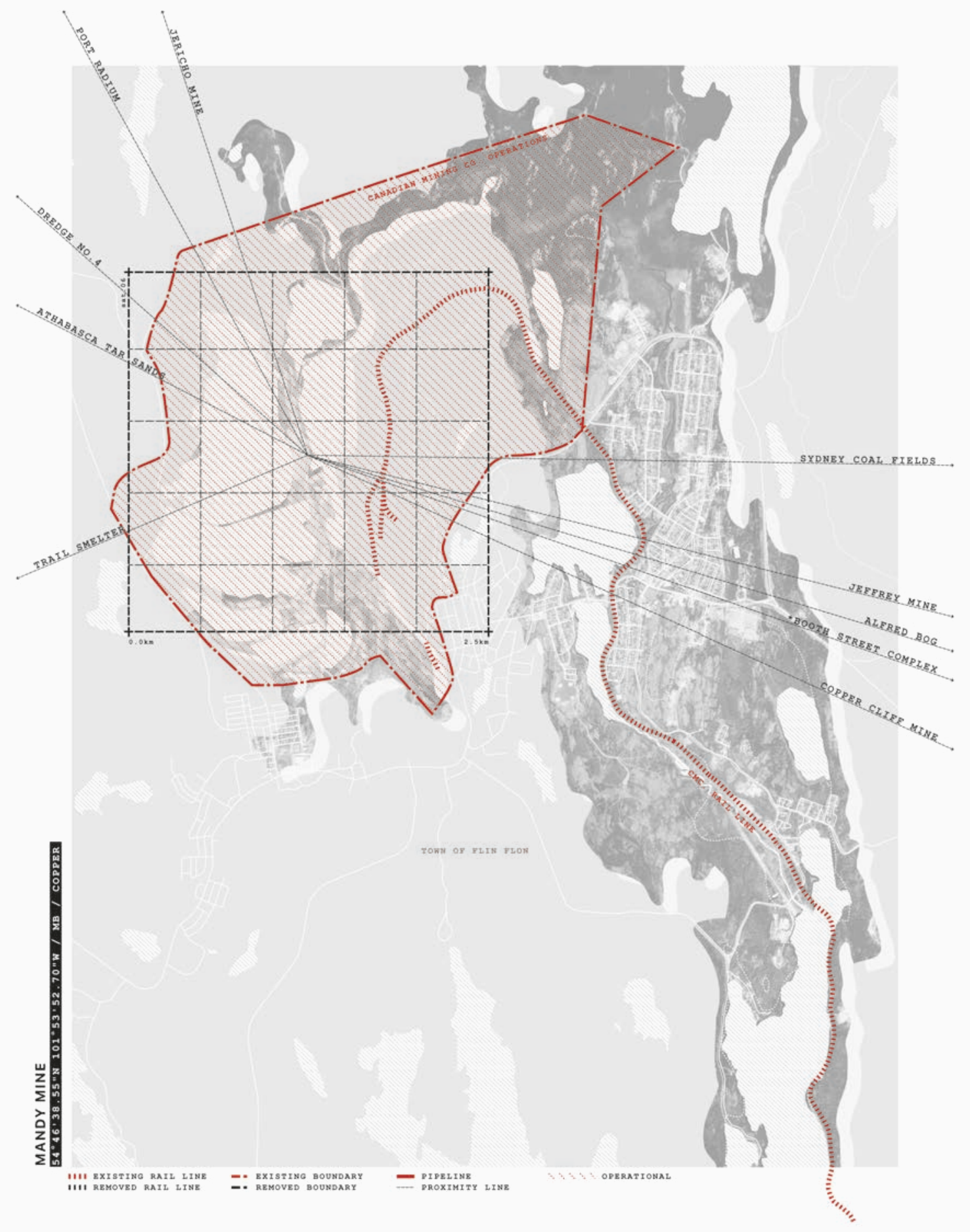

Figure 2.18: Mapped Evolution of Mandy Mine, MB (by Author) 


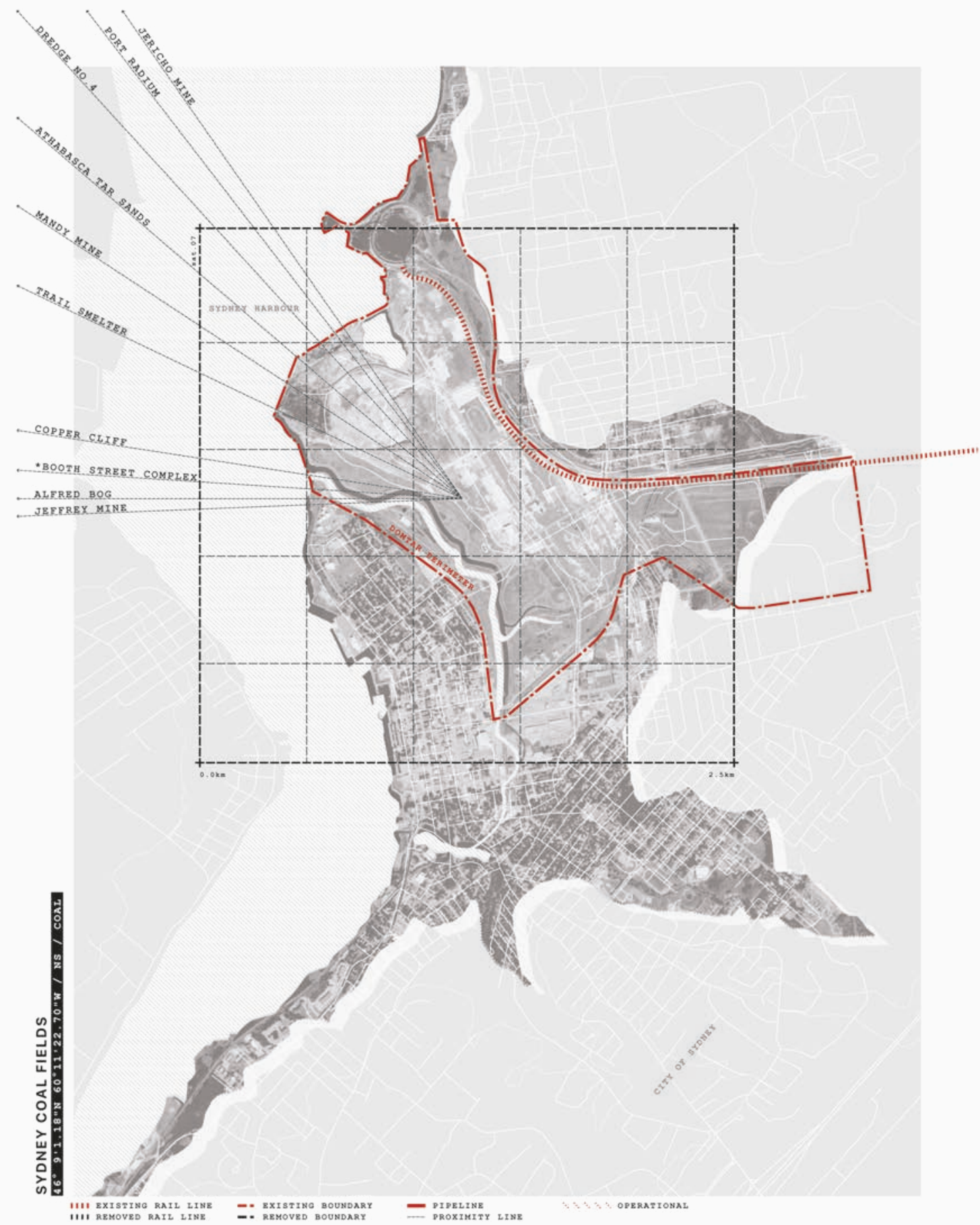

Figure 2.19: Mapped Evolution of Sydney Coal Fields, NS (by Author) 


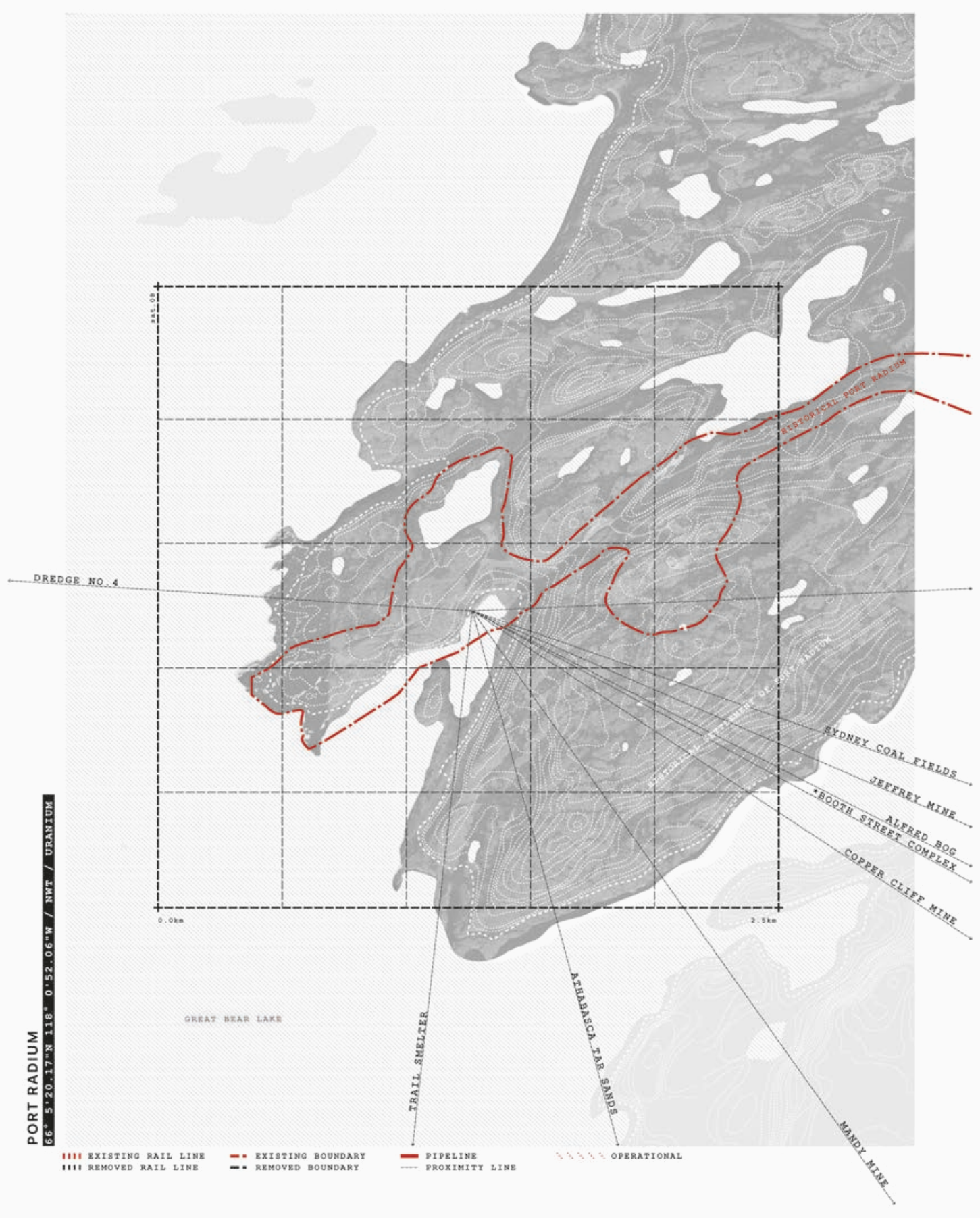

Figure 2.20: Mapped Evolution of Port Radium, NWT (by Author) 


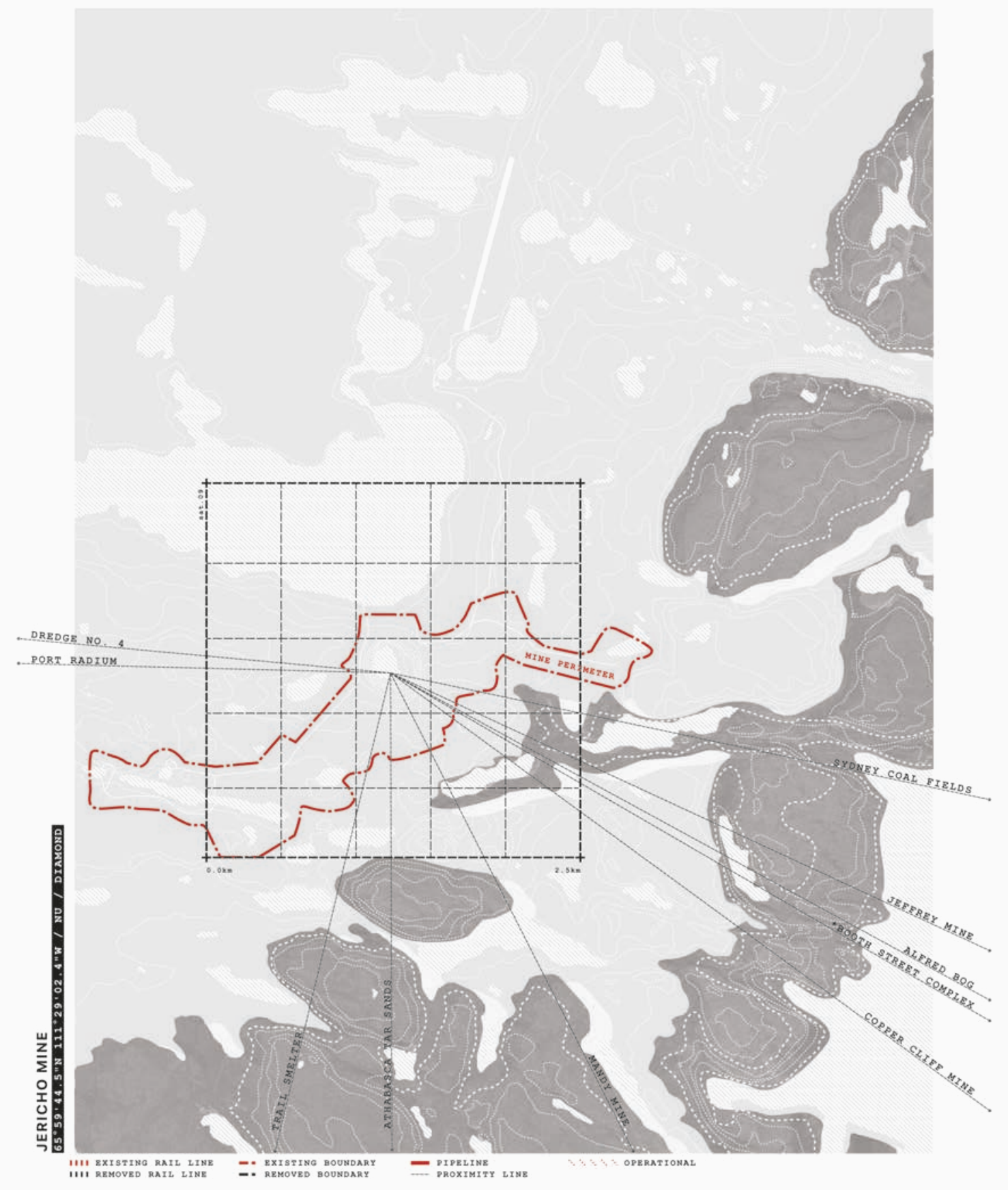

Figure 2.21: Mapped Evolution of Jericho Mine, NU (by Author) 


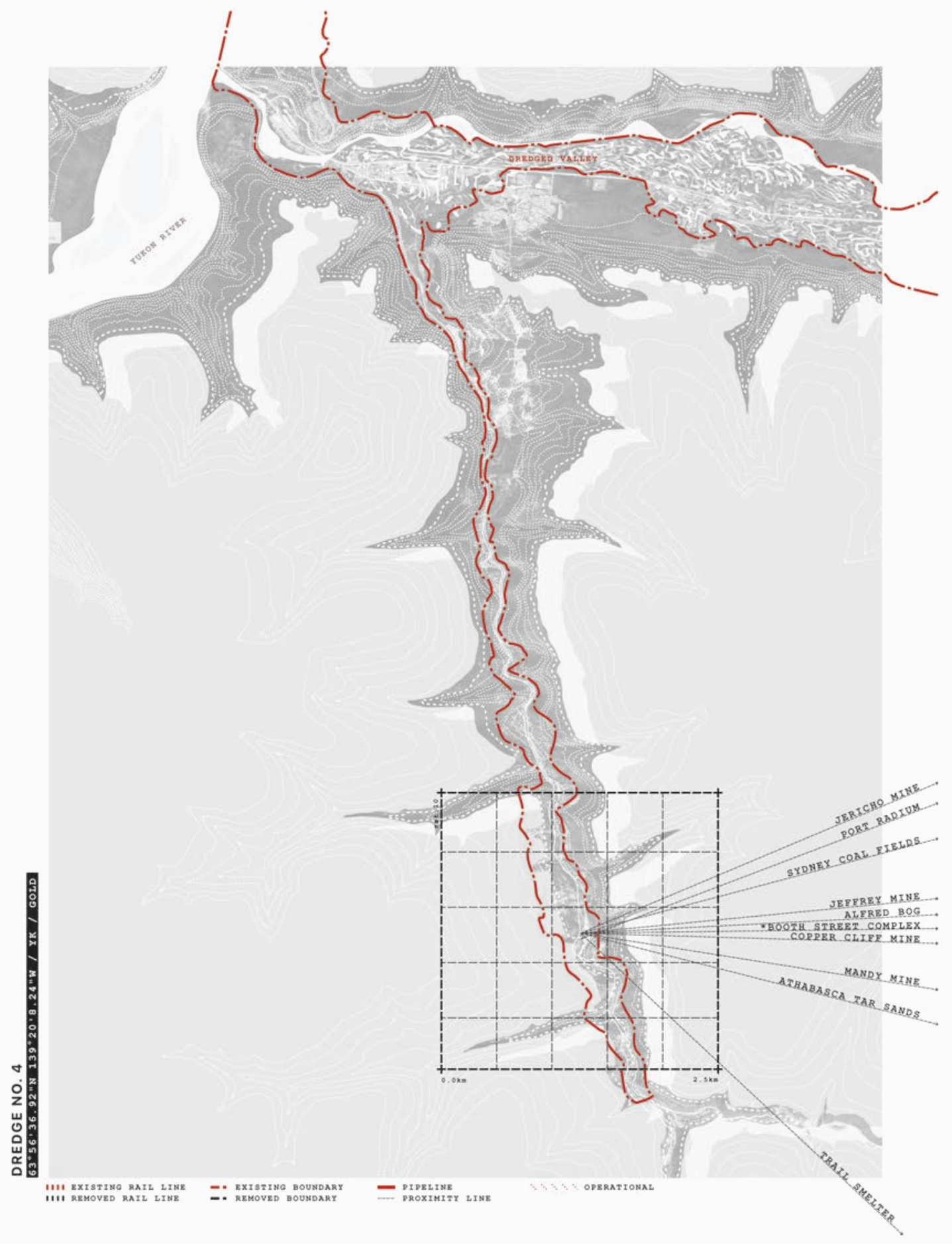

Figure 2.22: Mapped Evolution of Dredge No. 4, YK (by Author) 


\subsection{Spectrum of Existence Matrix and Results}

To measure the reactionary forces of extraction and to classify the status of each of the ten industrial sites, a radial matrix was created. (Figure 2.23) Graphically organized around the nucleus of Canadian extraction, research and development — the Booth Street Complex — the radial matrix illustrates the auxiliary site's location relative to the complex as well as its various degrees of infrastructural, connectivity and operational existence.

The matrix ranks the existence of: on site extraction, above-ground infrastructure, under-ground infrastructure, railway, on site processing, on site disposal, settlement, hydrological features and remediation. To do this, the ranking system employs: removed, operable or inoperable - each corresponding to a distinct fill - mirroring those found in the maps preceding auxiliary site maps.

Removed, graphically represented by the color white, indicates that the relative element has been either purposely or consequentially removed. Within this context 'remove' can be defined as the action of moving something from a place or position; to take away or off.

Operable, graphically represented by the color red, indicates that the relative element is currently in existence and functioning. Within this context 'operable' can be defined as the state of being able to be used.

Inoperable, graphically represented by the color black, indicates that the relative element is not operating or that was never. Within this context 'inoperable' can be defined as the state of not being able to be used. 


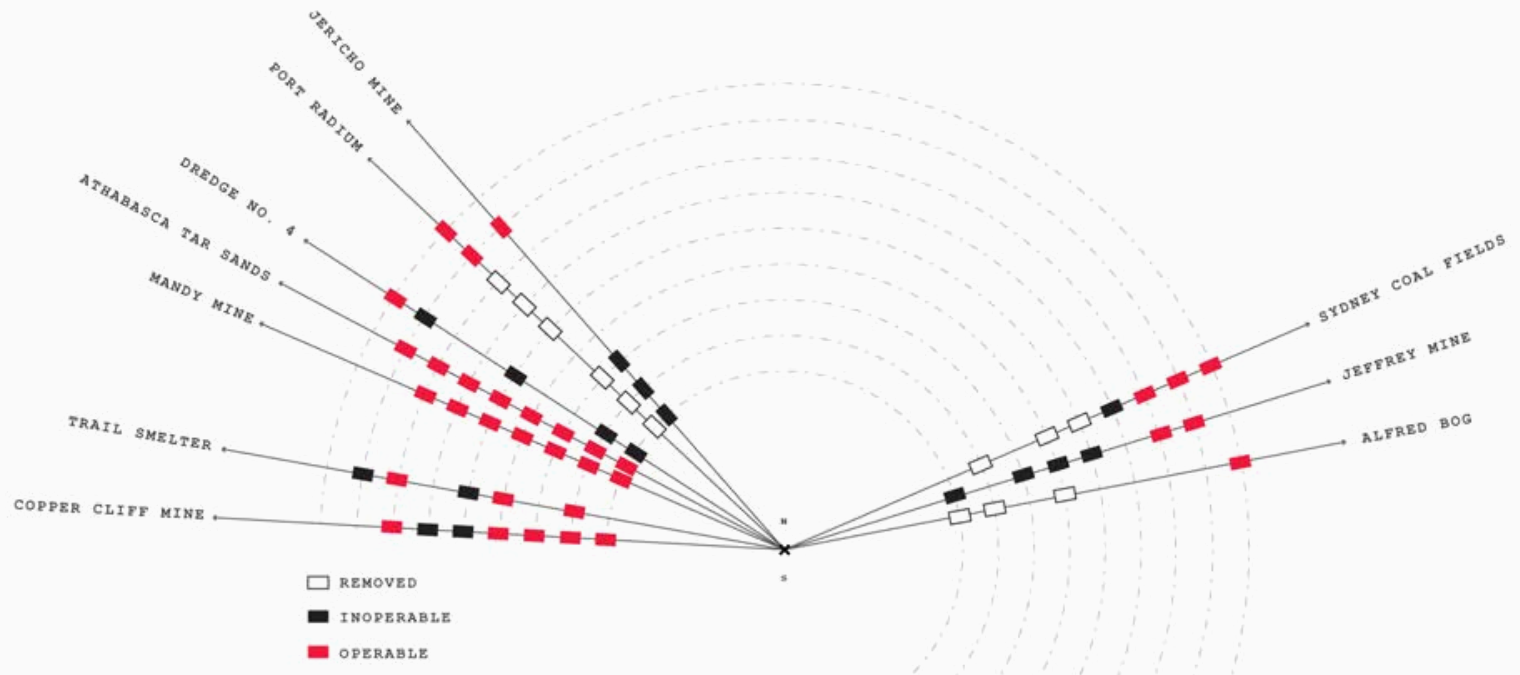

- operable

$$
\begin{array}{r}
\text { ON SITE EXTRACTION } \\
\text { ABOVE-GROUND INFRASTRUCTURE } \\
\text { UNDER-GROUND INFRASTRUCTURE } \\
\text { RATLWAY } \\
\text { ON SITE PROCESSING } \\
\text { ON SITE DISPOSAL / TAILINGS } \\
\text { SETTLEMNT } \\
\text { NEARBY HYDROLOGICAL FEATURES } \\
\text { REMEDIATION EFFORTS }
\end{array}
$$

Figure 2.23: Spectrum of Existence Radial Matrix for the Ten Selected Industrial Sites (by Author) 


\subsection{Chapter Conclusions}

Using this methodology, it becomes more evident which sites currently operate at a higher degree of productivity, which sites historically were more industrially intensive and which sites have contracted in terms of extraction actions. A site which presents mainly red indicators, such as Athabasca Tar Sands, is within a different life phase than a site which presents either black or white indicators, such as Sydney Coal Fields. These observations led to the identification of distinct industrial site life cycle phases:

1. Expanding: the site is operating at full capacity with plans to increase in magnitude, to escalate production, or to boost intensity.

2. Operating: the site is currently extracting, processing, or refining materials, with no plans to increase or decrease in magnitude. The site is stable, with plans to continue at the current performance level.

3. Dormant: the site is not operational but is minimally maintained to retain and preserve a potential for future reignited operations.

4. Abandoned: the site has been deserted with no plans for cleanup, remediation or reuse.

5. Remediated: the site is, or has, undergone cleanup to reverse environmental impacts from earlier industry. The remediation could be preparatory work for reuse or disposal.

Classifications applied to the ten auxiliary industrial sites:

1. Expanding: Copper Cliff Mines, Athabasca Tar Sands,

2. Operating: Trail Smelter, Mandy Mine

3. Dormant: Jericho Mine

4. Abandoned: Jeffrey Mine

5. Remediated: Alfred Bog, Sydney Coal Fields, Port Radium, and Dredge No. 4

Within Chapter VII, the determined phases are used to form the basis for a macro design approach for reuse of the Booth Street Complex. 


\section{Chapter V}

\section{Local Implications: The Booth Street Complex Site}

As of today, the eldest building remaining within the Booth Street Complex dates back to the year 1912; however, the complex as well as the site has a much longer and much tenured history within the landscape. Prior to the federal government's industrialization of the Booth Street Complex, the site upon which the complex now sits, underwent several transitory phases: first, the site morphed from traditional Algonquin territory to unceded European settlement, from unconsolidated colonial settlements to a municipality, and thereafter from private owner to private owner until its acquisition by the federal government in the early twentieth century. Chapter $V$ is written with the intention of not only making this layered and mosaicked history more transparent, but also to shed light onto what are perhaps some lesser recognized components.

\subsection{The Recognized and Unrecognized Layers of History}

\section{Pre Industrial Histories}

Preceding colonial settlement of the Ottawa region in the early 19th century, the land upon which the Booth Street Complex rests was occupied by Indigenous populations. Although not acknowledged in any of the federal heritage documentation, the Algonquin population lived nomadically off of the land for over 5,000 years prior to European settlement in the Ottawa region and unto the site. ${ }^{153}$ Seasonally moving throughout the area to hunt and gather, the Algonquin way of life did not result in lasting impacts unto the landscape; their lack of permanent structures and prolonged settlement negated long lasting imprints. ${ }^{154}$ With the settlement of Europeans, this first and imperative story of the place became blurred; although distinguishable in artifacts and oral histories, the original layer was metaphorically inscribed upon and written over - now largely forgotten with relevance to the site's heritage.

153. Black, Meredith Jean. "Algonquin." The Canadian Encyclopedia. September 30, 2007.

154. Ibid 
In 1788, after European settlement and the assembly of Upper Canada, the province of Quebec began creating districts and counties to serve administrative needs at the local level. ${ }^{155}$ At this time, the Ottawa area was classified as part of the Lunenburg district - a region located in central historical Quebec but there were no settlers in the vicinity of modern Ottawa until 1792, at which point an Irish family began farming. ${ }^{156}$

\section{Proto Industrial Histories}

In 1800, the overall area within which site of the complex now rests, was established as Township D - an administrative subdivision within a larger Carleton County, later to be renamed the Township of Nepean. ${ }^{157}$ In 1888, the Booth Street Complex site was annexed by the city of Ottawa from Nepean Township, classified within the historic Dalhousie Ward and became apart of the city's either ward. ${ }^{158}$ Specifically created to accommodate the growing west side of the city of Ottawa, Dalhousie Ward was spurred by southerly migrating development. Markedly, Dalhousie Ward was merged with Wellington Ward in 1994 to become Somerset Ward - the modern ward nomenclature. ${ }^{159}$

In the later 19th century, the expansion of industry along the rail lines not only meant that the city limits were expanding but that the associated and increasingly urban fabrics were becoming more formal. As evident within the fire insurance plans of the city Ottawa from 1901 and 1912, the area had already developed a significant industrial and urban presence prior to the establishment of the Booth Street Complex (Figure 2.24 - 2.25); rail and lumber yards composed a large part of the area.

155. "Early Districts and Counties 1788-1899." The Changing Shape of Ontario: Early Districts and Counties 1788-1899.

156. Taylor, John H. Ottawa, an Illustrated History. Brantford, Ont.: W. Ross MacDonald School Resource Services Library., 2008, 11

157. "Early Districts and Counties 1788-1899." The Changing Shape of Ontario: Early Districts and Counties 1788-1899.

158. ERA Architecture, Stantec Consulting Ltd., and Hill Knowlton Strategies. "Canada Lands Company Booth Street Redevelopment." City of Ottawa Webcast. March 28, 2018.

159. Taylor, John H. Ottawa, an Illustrated History. Brantford, Ont.: W. Ross MacDonald School Resource Services Library., 2008, 11 


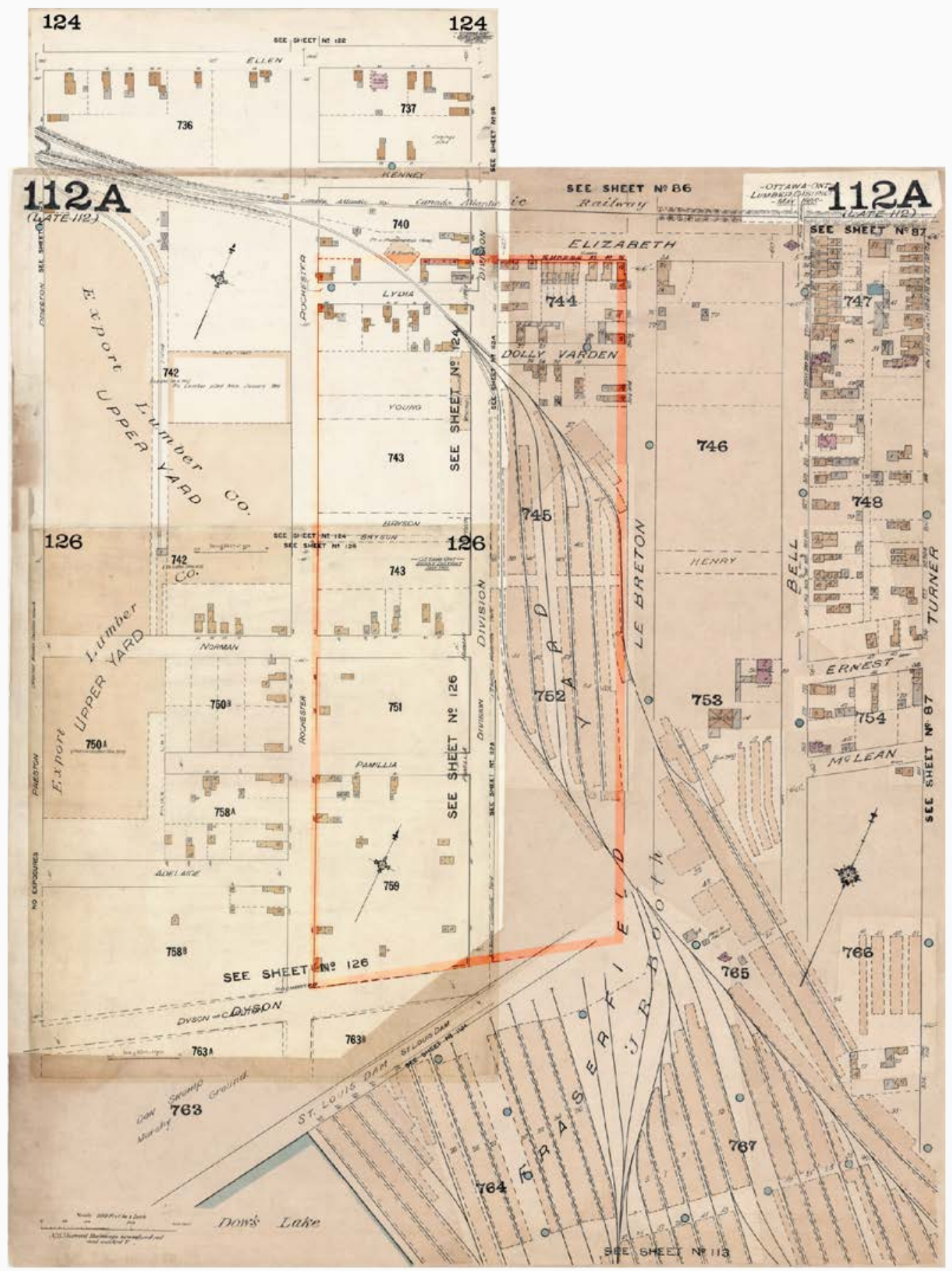

Figure 2.24: Overlaid Ottawa Fire Insurance Plans from 1901 (by Author) 


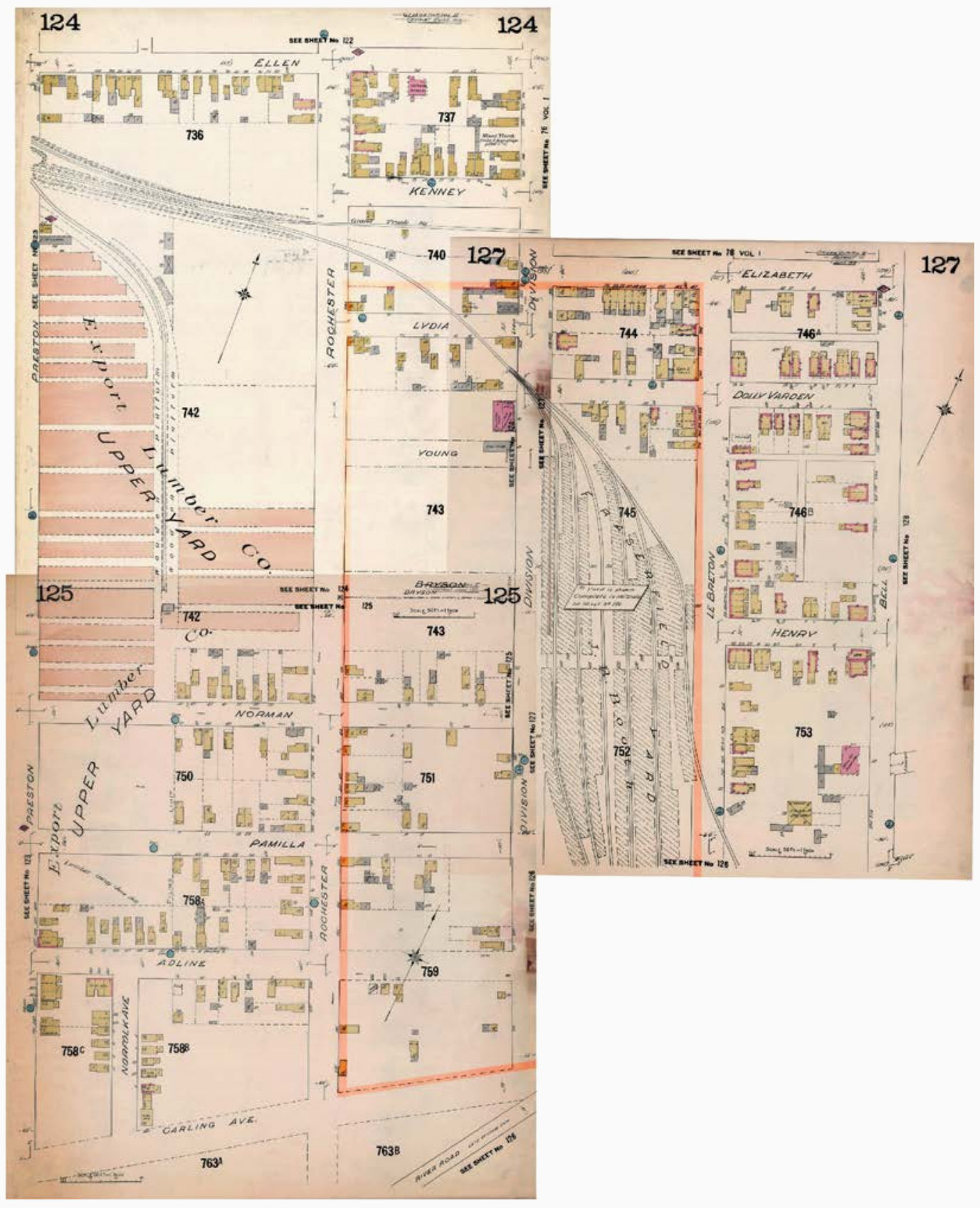

Figure 2.25: Overlaid Ottawa Fire Insurance Plans from 1912 (by Author) 


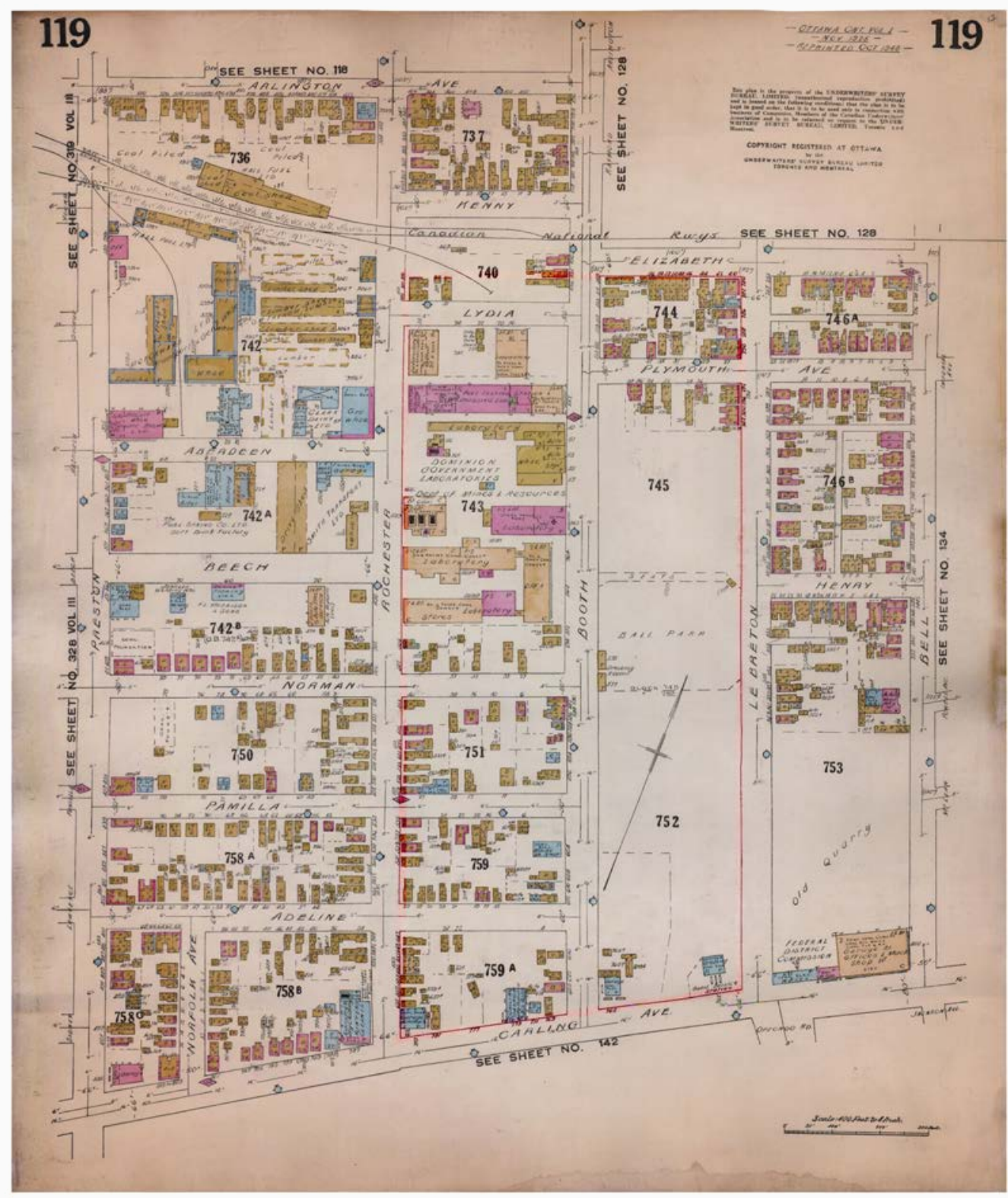

Figure 2.26: Overlaid Ottawa Fire Insurance Plans from 1948 (by Author) 


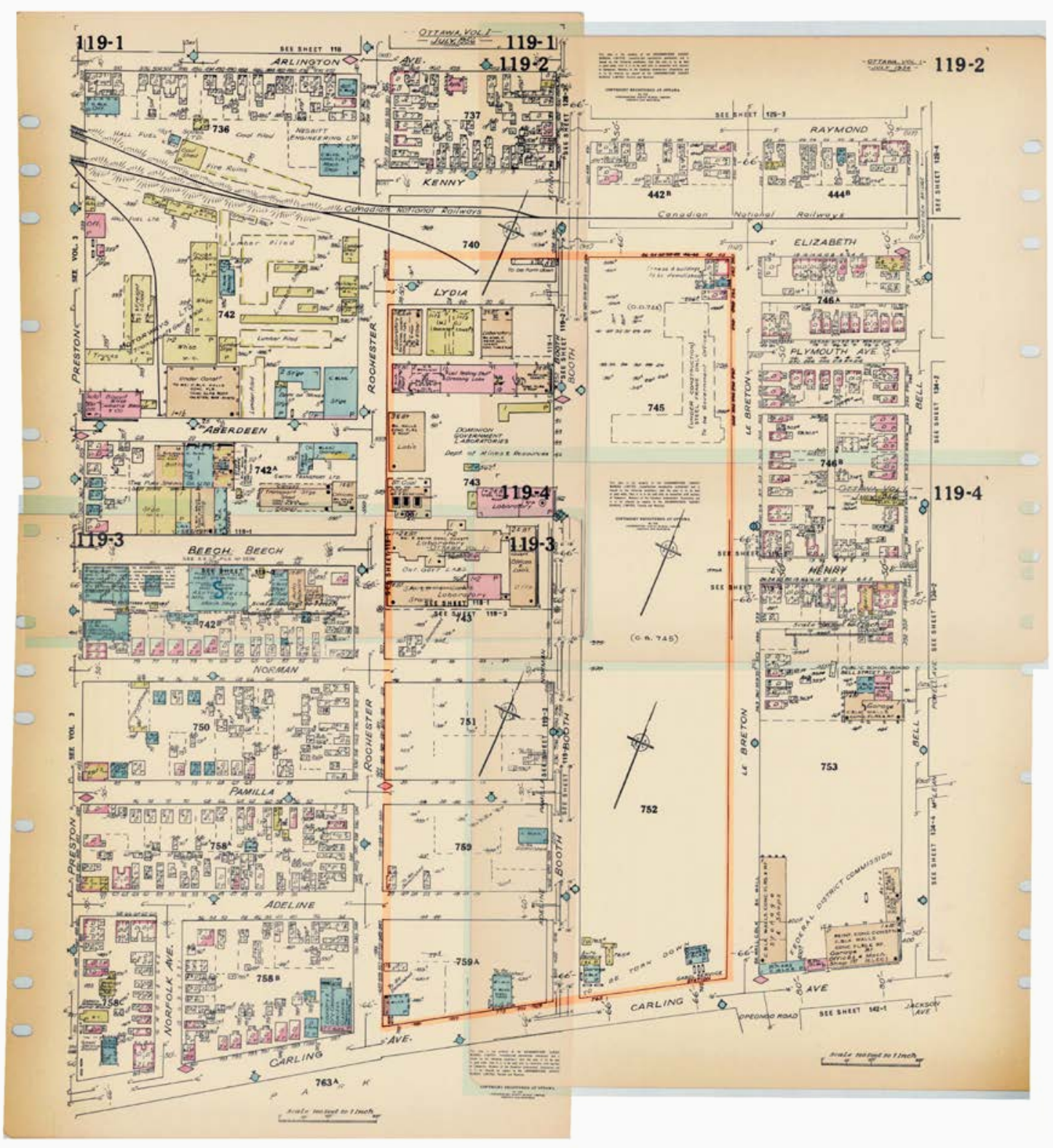

Figure 2.27: Overlaid Ottawa Fire Insurance Plans from 1953 (by Author) 


\subsection{Origins of the Booth Street Complex and Historical Uses}

\section{Land Acquisitions and Historical Fabrics}

In the year 1908, the federal government of Canada began acquiring parcels of land within the block of Division (now Booth) and Rochester streets, just south of Dolly Varden (now Orangeville) street. ${ }^{160}$ This initial land acquisition was for a single acre of land and resulted in the erection of the Department of Mines preeminent testing facility within Ottawa in 1909, the Department of Mine's Fuel Testing Station also commonly referred to as the 'Peat Works' (refer to image 2.28). ${ }^{161}$ As time progressed, the government continued to purchase adjoining land; In 1911, three more acres of land were acquired resulting in the construction of additional Mines Branch Buildings and in the earliest extant laboratory - the Ore Dressing and Metallurgical Laboratory in 1912. ${ }^{162}$ This pattern of expansion continued until 1936, by which time the entire modern complex site had been successfully acquired.

As evident in successive aerial imagery, from 1928 to 1991 (Figure 2.31), the growth of the complex was steady and significantly altered the surrounding neighborhood. Over this period, additional laboratories and offices were gradually introduced, transforming the area from a largely wooden-built residential neighborhood to an increasingly brick and concrete-built industrial and commercial area. There was also a gradual disappearance of the adjacent rail lines during this time. In 1936, with the federal department's purchase of the land east of Booth Street, the adjacent lumberyards were removed and the In their place, the department planned the Geological Survey Building, the Survey and Mapping Building as well as the Chemical and Radioactive Ores Building. (Figure 2.31)

\section{Unity of Complex Planning}

The drawn out development of the complex, over a period of 60 years, has led to an overall complex schematic which is formally and stylistically fluid while also relatively cohesive. While three distinct approaches to development are legible within the Complex, the site reads as a cohesive whole because of continuity of architectural massing, materiality and general styling.

From 1908 to 1929, the site existed as a semi-industrial assortment of informal buildings. ${ }^{163}$ Many of the original buildings were wood structures and limited to

160. Ignatieff, Alex. A Canadian Research Heritage. Ottawa: Canadian Gov. Publ. Centre, Supply and Services Canada, 1981, 27 161.Ibid

162. ERA Architecture, Stantec Consulting Ltd., and Hill Knowlton Strategies. "Canada Lands Company Booth Street Redevelopment." City of Ottawa Webcast. March 28, 2018

163. Ibid
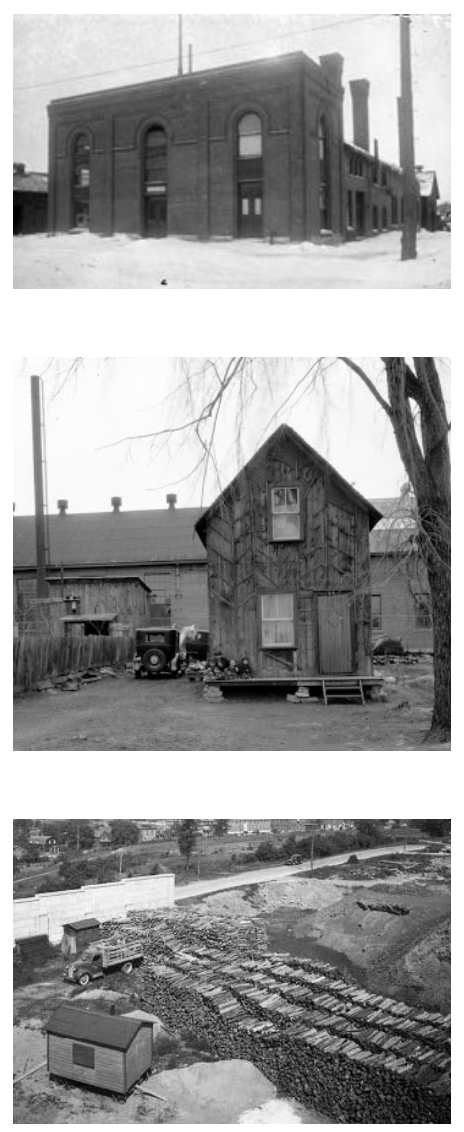

Figure 2.28 (Top): Original Fuel Testing Station c. 1912

Figure 2.29 (Mid): Wooden house, since demolished on site of current complex c. 1930

Figure 2.30 (Bottom): The Booth Lumber Yard on site of modern Geological Survey of Canada Building. Unknown Date 

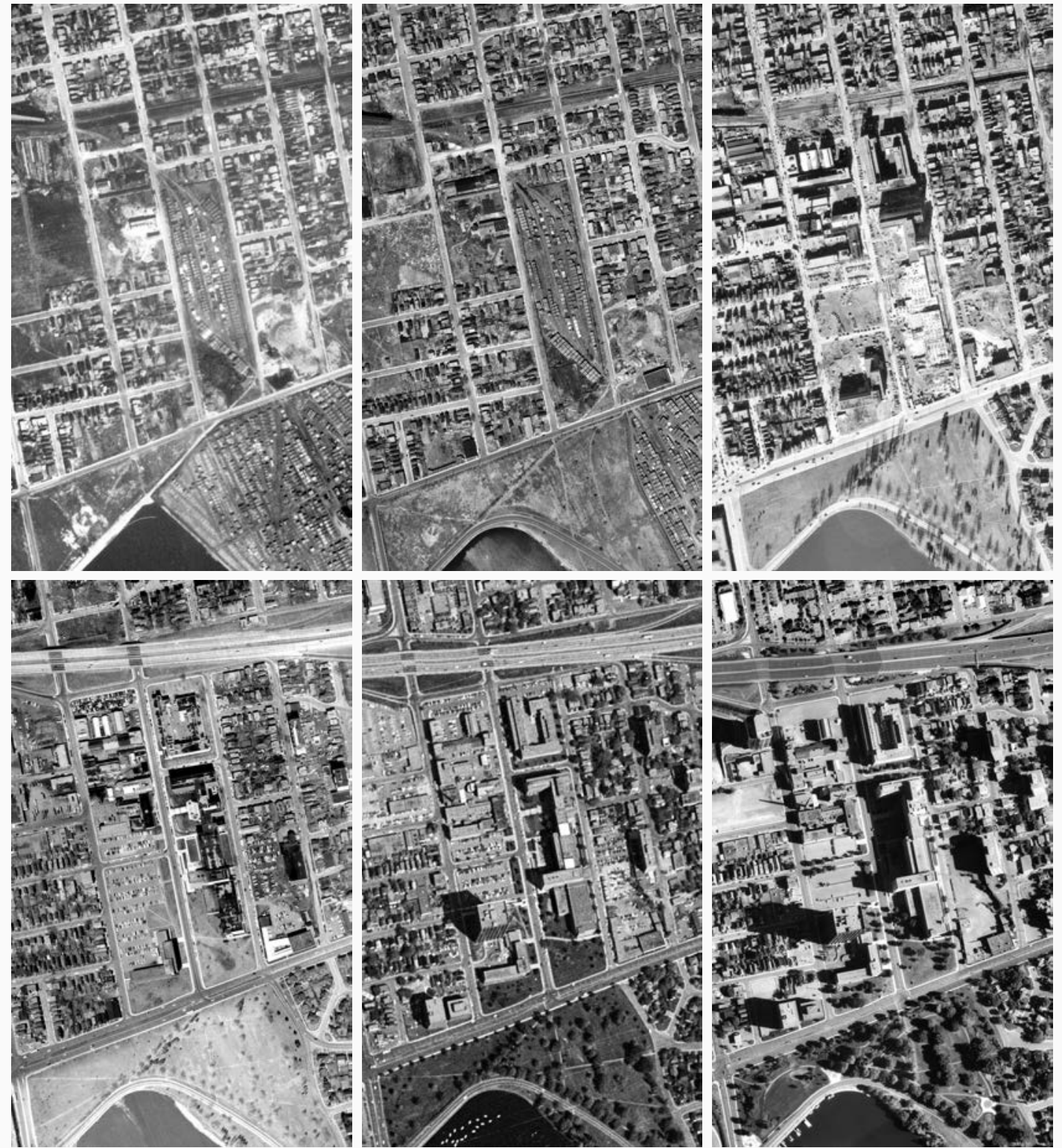
single or double storeys. Their strict utilitarian nature and sporadic construction left much to be desired regarding complex unity. Until the mid 1920s, there was no evidence of an overarching site plan or vision, but as early as 1925 the Chief Architect's Branch of the Department of Public Works produced a site plan including the proposed new Fuel Testing Laboratory. ${ }^{164}$ This, in conjunction with the already existing and proposed buildings within the plan, formed a roughly balanced grouping of structures (Figure 2.32).

A second and more formal approach to the complex's planning is evident with the further delineation of the aforementioned structure grouping, created in the 1930s and 1940s. ${ }^{165}$ In 1930, The Department of Public Works contracted Werner Ernst Noffke, one of the city's most influential and prolific architects of the early 20th century, to not only work on the complex but to propose an expanded site plan (Figure 2.33).

Within Ottawa, Noffke had gained a reputation for implementing a revivalist style unto residential, commercial and religious architectures during the 1920s, but with the falling off of the building sector during the depression years he began to take on federal government projects. ${ }^{166}$ From 1930 to 1942, Noffke designed all of the permanent buildings erected upon Booth Street Complex. This period, characterized by an accelerated building program, resulted in the construction of five additional buildings - each formally designed as a head house and with the aim of providing more publicly oriented frontage.

The design of the Noffke's final Booth Street Complex building in 1942, the Physical Metallurgy Laboratories, marks a shift to a more modernist site approach which was both typical of federal design of the period and indicative of the nature of Noffke's own approach to office design from that time. ${ }^{167}$ When the bulk of his work changed from the design of large, single-family residences to public buildings Noffke gave up the romanticism of the revivalist styles and turned toward more utilitarian interpretations. ${ }^{168}$ There was a turn from historicism to a more stripped modernism with an emphasis on the functional, which produced laboratories with more architectural flexibility.

The later buildings erected within the complex are of the International Architectural Style, and are examples of modernist architecture. They, as well as their site planning exhibit orthogonal clean lines and unadorned aesthetics.

164. Ricketts, Shannon. FHBRO Building Report 86-61: Four Structures on the EMR Complex, Booth Street, Ottawa. Ottawa, ON: Federal Heritage Buildings Review Office, 1986, 11

165. Ibid

166. Ibid, 17

167. Ibid, 19

168. Ibid
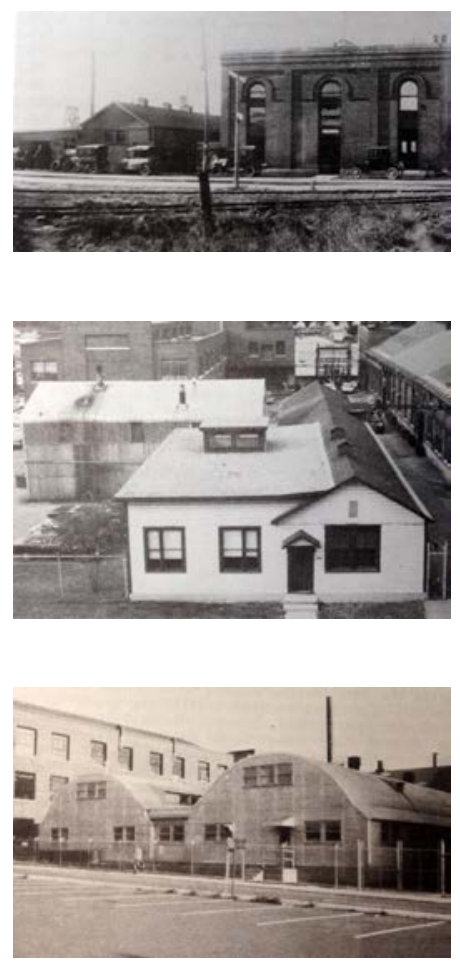

Figure 2.32 (Top): Original Fuel Testing Station and adjacent sheds c. 1912, since demolished

Figure 2.33 (Mid): Wooden and Metal Buildings, Uknown Date, since demolished or removed

Figure 2.34 (Bottom): Quonset Huts, c. 1955, since demolished or removed 

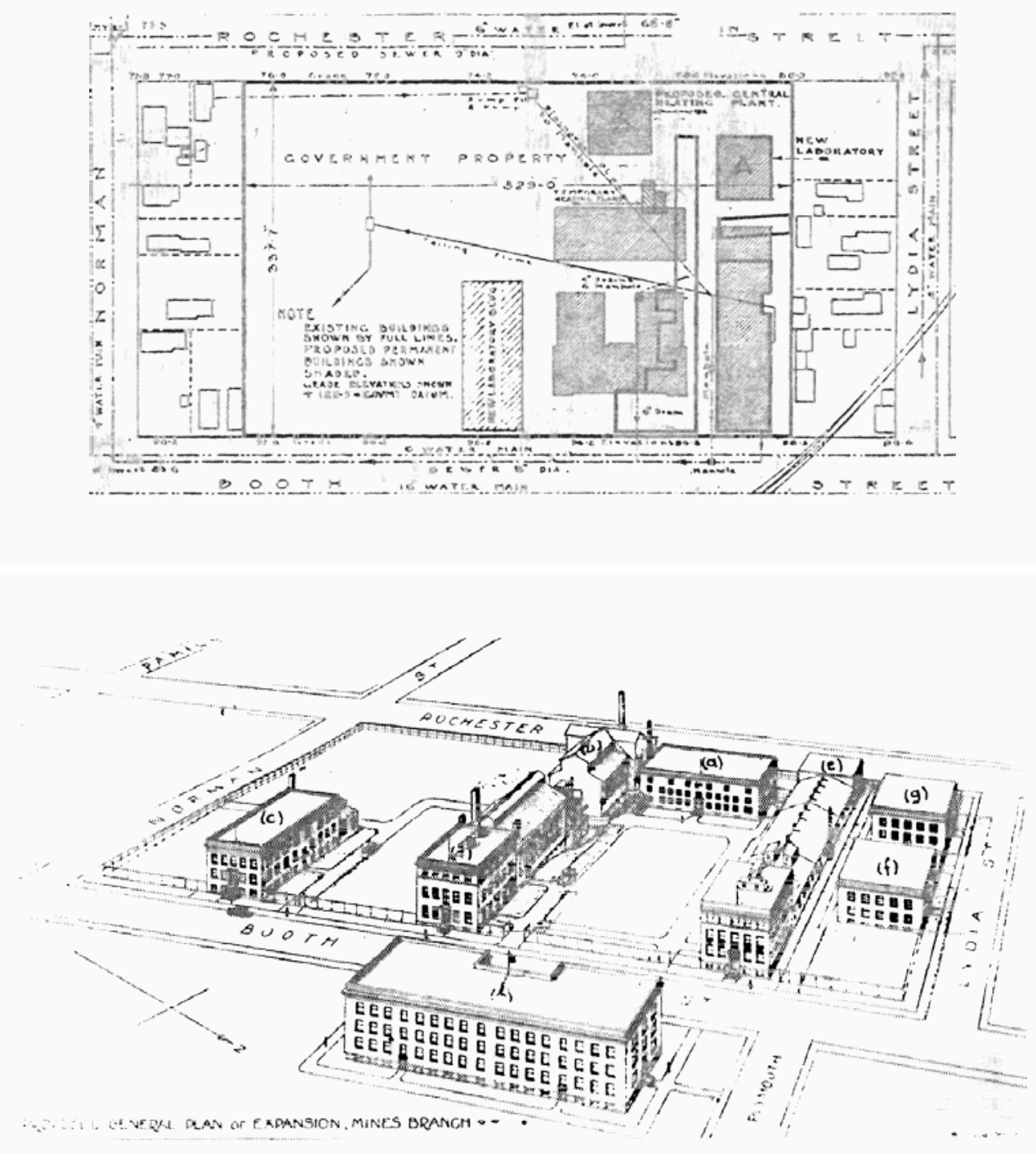

Figure 2.35 (Top): Earliest Overall Plan of Booth Complex c. 1925,

Figure 2.36 (Bottom): Proposed Complex Schematic c. 1931 by Noffke, 


\section{Existing Building Descriptions and FHBRO Heritage Designations}

Today there are sixteen buildings remaining within the Booth Street Complex; the total number of structures to have existed within the complex is unknown however there is photographic evidence to suggest that numerous were either dismantled or expanded upon beyond recognition (Figure 2.34 - 2.36). The remaining buildings on site are listed below in chronological order of initial construction and are seen in plan in figure 2.40:

1912: Ore Dressing and Metallurgical Laboratory (3b) 552 Booth St. 1925: Hydro Metallurgical Laboratory (3d) 552 Booth St.

1927: Fuel Testing Laboratory (6) 562 Booth St.

1929: Pyro Metallurgical Laboratory (3c) 552 Booth St.

1931: Ore Dressing Laboratories (2) 550 Booth St.

1931: Industrial Minerals and Ceramics Laboratories (1) 405 Rochester St.

1932: Ore Dressings and Metallurgical Laboratories (3a) 552 Booth St.

1935: Tailings Disposal Building (3e) 552 Booth St.

1942: Physical Metallurgical Research Laboratories (7a-e) 568 Booth St.

1945: Central Heating Plant (5) 558 Booth St.

1952: Mechanical Shops and Stores Building (4) 556 Booth St.

1955: Chemical and Radioactive Ores (8) 555 Booth St.

1955: Geological Survey of Canada (9) 601 Booth St.

1958: Surveys and Mapping Building (10) 615 Booth St.

1958: Administration Building (11) 588 Booth St.

1972: Sir William Logan Building (12) 580 Booth St.

Of the sixteen buildings within the complex, thirteen are recognized as federal heritage buildings (Figure 2.41) - excluding the Mechanical Shops and Stores Building (c. 1952), the Central Heating Plant (c.1945) as well as the Sir William Logan Building (c. 1972). ${ }^{169}$ Of these sixteen recognitions, there are five formal federal heritage designations which are not restricted to single building, but sometimes are for a number of structures, as many of the buildings are laboratories which developed incrementally over time. As of autumn 2018, the formerly recognized heritage buildings within the north-west quadrant had been removed from the register of FHBRO properties. Following is a summary of the Federal Heritage Buildings Review Office Heritage Character Statements for each of the recognized and designated buildings or grouping of buildings, and a more detailed date of construction. Appendix B includes a table outlining the dates of construction, architect, address and current proprietor for all of the buildings within the complex.

169. ERA Architecture, Stantec Consulting Ltd., and Hill Knowlton Strategies. "Canada Lands Company Booth Street Redevelopment." City of Ottawa Webcast. March 28, 2018.
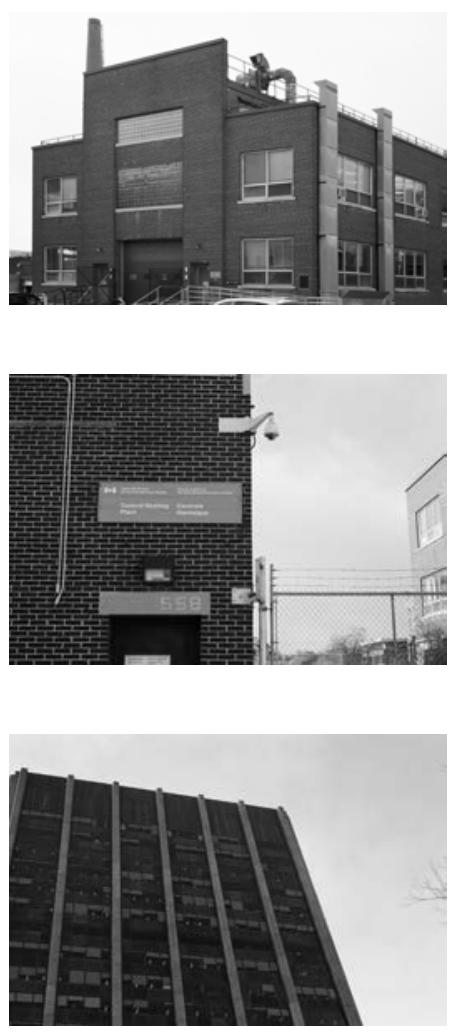

Figure 2.37 (Top): Mechanical Shops and Stores Building, c. 2018

Figure 2.38 (Mid): Central Heating Plant, c. 2018

Figure 2.39 (Bottom): William Edmond Logan Tower, c.2018 


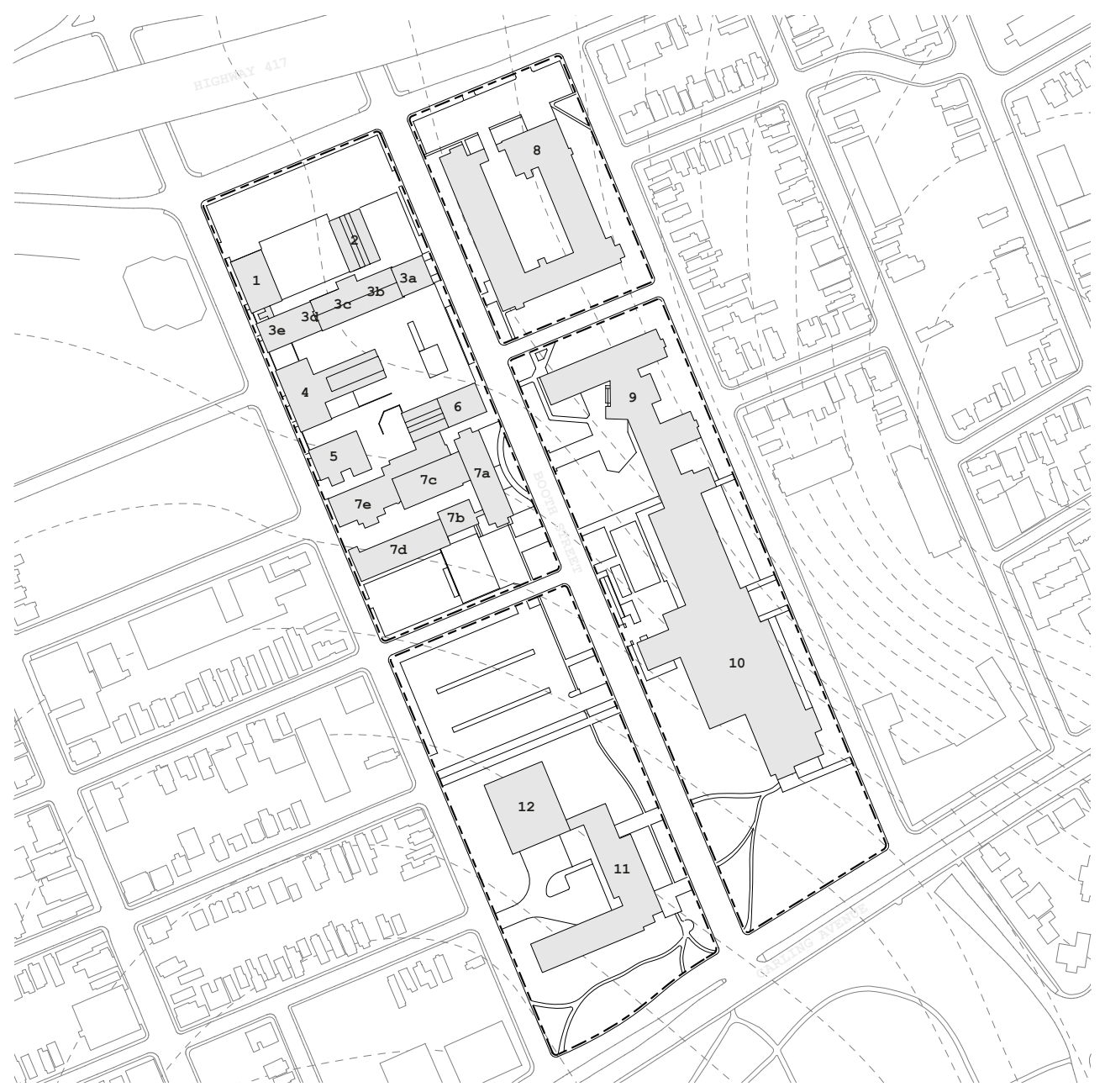

Figure 2.40: Plan View of Booth Street Complex c. 2018 (by Author)

Industrial Minerals and Ceramics Laboratories (1) Ore Dressing Laboratories (2)

Ore Dressings and Metallurgical Laboratories (3a)

Ore Dressing and Metallurgical Laboratory (3b)

Pyro Metallurgical Laboratory (3c)

Hydro Metallurgical Laboratory (3d)

Tailings Disposal Building (3e)

Mechanical Shops and Stores Building (4)

Central Heating Plant (5)

Fuel Testing Laboratory (6)

Physical Metallurgical Research Laboratories (7a-e)

Chemical and Radioactive Ores (8)

Geological Survey of Canada (9)

Surveys and Mapping Building (10)

Administration Building (11)

Sir William Logan Building (12) 


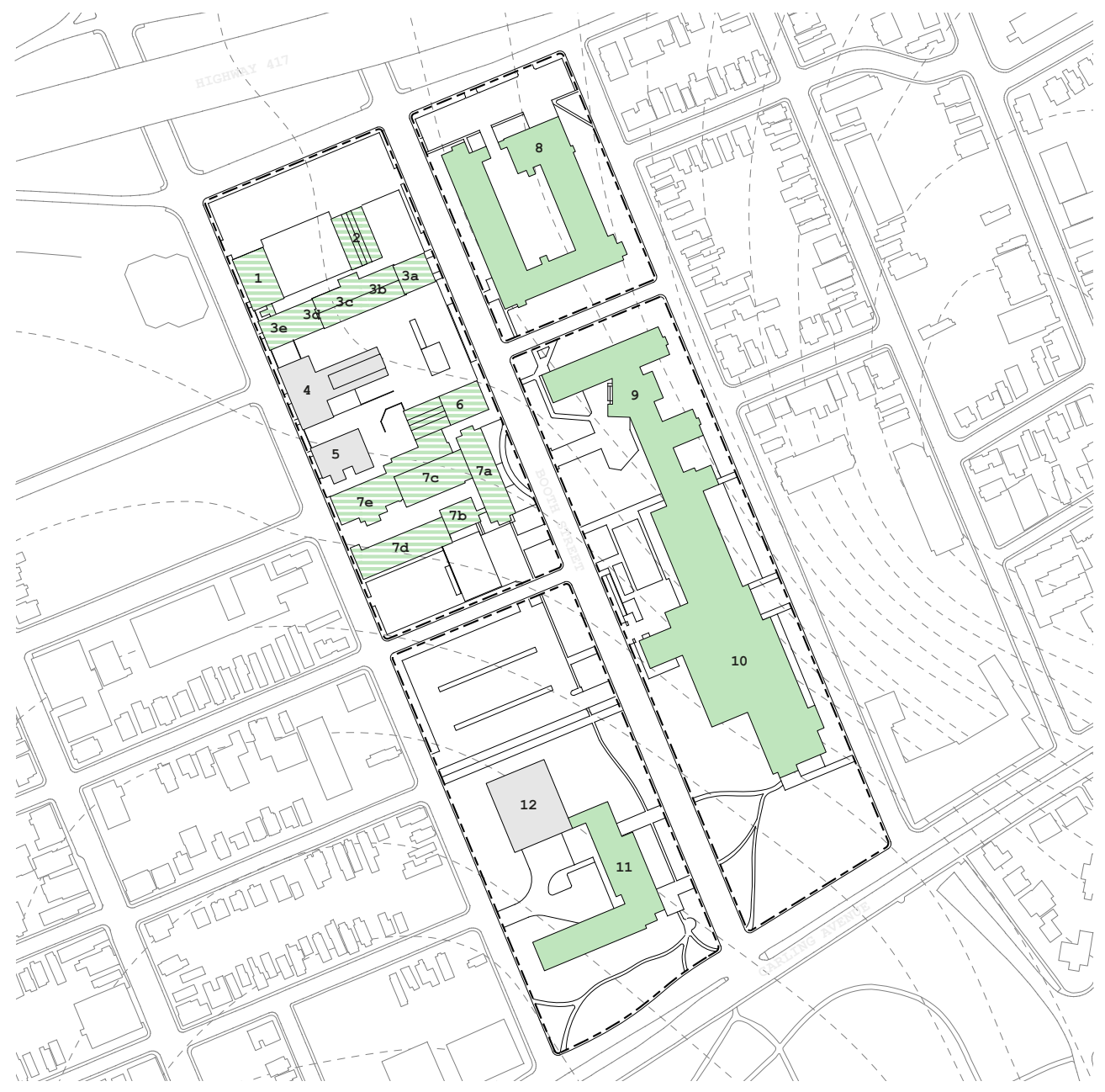

Figure 2.41: Preexisting Heritage Recognitions (by Author)

Current FHBRO Recognition Former FHBRO Recognition No Status 


\title{
Industrial Minerals and Ceramics Laboratories
}

\author{
405 Rochester Street, Ottawa, ON \\ Heritage Status: Federally Designated \\ Date of Recognition: June 6th ,1987 \\ FHBRO Number: 86-061
}

Relevant Buildings: Industrial Minerals and Ceramics Labs (c. 1931)

As stated within the Heritage Character Statement, the Industrial Minerals and Ceramics Laboratories by Noffke is designated for its historical, architectural and environmental significance. ${ }^{170}$ Historically, the building is significant for its association with the development of the Canadian mining and energy industries in general, and with research in the field of developing commercially viable methods of improving the acquisition and use of non-metallic industrial minerals and ceramics. ${ }^{171}$ The Industrial Minerals and Ceramics Laboratory is valued for its good aesthetics; classical influence can be seen in the symmetry and order of the facades and the centrally located entrance. ${ }^{172}$ Clean functional lines and durable materials speak to its industrial role. ${ }^{173}$

\author{
Ore Dressing Laboratory \\ 550 Booth Street, Ottawa, ON \\ Heritage Status: Federally Designated \\ Date of Recognition: June 16th, 1987 \\ FHBRO Number: 86-061 \\ Relevant Buildings: Ore Dressing Lab. (c. 1931)
}

As stated within the Heritage Character Statement, the Ore Dressing Laboratory by Noffke is designated for its historical, architectural and environmental significance. ${ }^{174}$ Historically, the building is significant for its association with the development of the Canadian mining and energy industries in general, and with research in the field of developing commercially viable methods of recovering metal from ores. ${ }^{175}$ It was designed to accommodate tests and investigations of the Ore Dressing and Metallurgical Division of the Department of Mines so the laboratory was strategically located next to the now removed, CNR railway corridor for easy delivery of bulk ore samples. ${ }^{176}$ Architecturally, the building's classical symmetry, clean functional lines and aesthetic compatibility with the rest of the complex contribute to its heritage
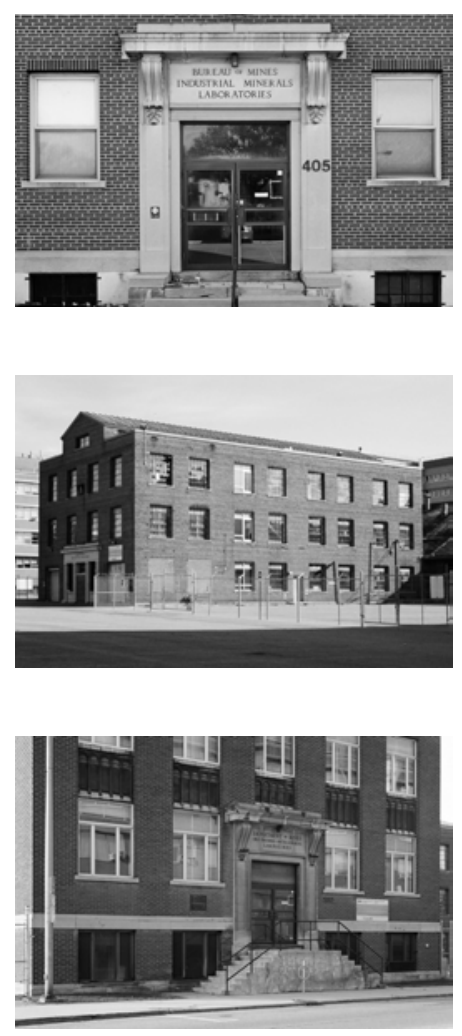

Figure 2.42 (Top): Industrial Mineral and Ceramics Laboratory c. 2018

Figure 2.43 (Mid): Ore Dressing Laboratory, c. 2018

Figure 2.44 (Bottom): Ore Dressing and Metallurgical Laboratories, $c$. 2018

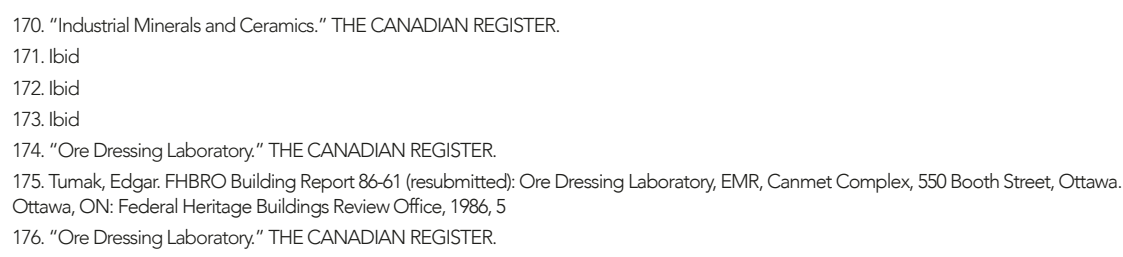


value. This building is a prominent member of the ensemble, acting as the anchor of the complex at the corner of Booth and Orangeville Streets.

\section{Ore Dressings and Metallurgical Laboratories}

552 Booth Street, Ottawa, ON

Heritage Status: Federally Designated

Date of Recognition: June 6th, 1987

FHBRO Number: 86-061

Relevant Buildings: Ore Dressings and Metallurgical Laboratories (c. 1932), Ore Dressing and Metallurgical Laboratory (c.1912), Hydro Metallurgical Laboratory (c. 1925), Pyro Metallurgical Laboratory (c.1929), Tailings Disposal Building (c. 1935)

Asstated within the Heritage CharacterStatement, the Ore Dressing Laboratories are designated for their historical and environmental significance. ${ }^{177}$ Designated specifically for its association with research in the field of commercially viable methods of recovering metals from ores, this early complex is associated with the inauguration of the Ore Dressing and Metallurgy division (1911) and the Industrial Minerals Division (1926) of the Mines Branch. ${ }^{178}$ The designation is composed of five buildings, including two frontage buildings and three inner utilitarian workshops; markedly, the eldest extant building, the Ore Dressing and Metallurgical Laboratory is apart of this grouping. ${ }^{179}$

\section{Fuel Testing Laboratory \\ 562 Booth Street, Ottawa, ON \\ Heritage Status: Federally Designated \\ Date of Recognition: June 6th, 1987 \\ FHBRO Number: 86-061 \\ Relevant Buildings: Fuel Testing Laboratory (c.1927)}

According to the Heritage Character Statement, the Fuel Testing Laboratory is designated for its historical, architectural and environmental significance. ${ }^{180}$ Designated for its association with the development of the Canadian mining and energy industries in general, and specifically for its association with research in the field of efficient use of Canadian fuels, the Fuel Testing Laboratory is one of the best examples of a structure associated with the development of the Canadian mining and energy industry during the boom period of the
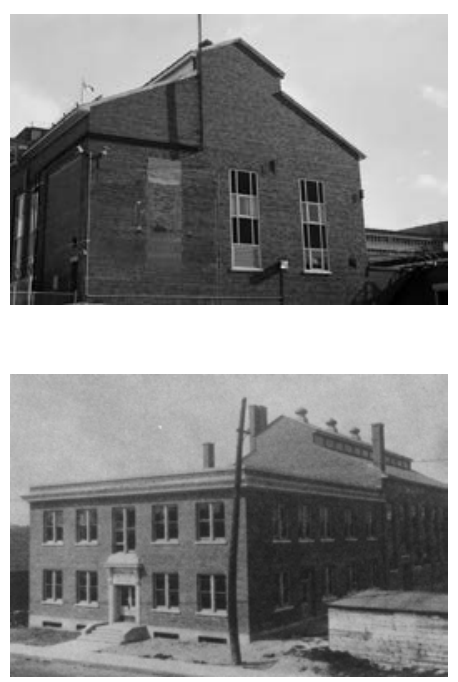

Figure 2.45 (Top): Fuel Testing Laboratory, c. 2018

Figure 2.46 (Mid): Fuel Testing Laboratory Head House, c. 1927

177. ERA Architecture, Stantec Consulting Ltd., and Hill Knowlton Strategies. "Canada Lands Company Booth Street Redevelopment." City of Ottawa Webcast. March 28, 2018

178. Ibid

179. Ibid

180. "EMR Complex: Fuel Testing Laboratory." THE CANADIAN REGISTER. 
1920s. Valued for its good aesthetics and functional qualities, the Fuel Testing Laboratory is a purpose built structure almost devoid of ornament. ${ }^{181}$ The office block has simple classical lines, while the attached laboratory is industrial in design, scale and detail. Its very good functional design can be seen in the interior layout of the laboratory, whose form was determined by the functional and safety requirements of coke testing. ${ }^{182}$ Notably, a third storey, designed by W.E. Noffke, was added to house the chemistry and physics laboratory in 1937, elevating the aesthetic of the building to match Noffke's other head houses. ${ }^{183}$

\section{Physical Metallurgy Laboratories \\ 568 Booth Street, Ottawa, ON \\ Heritage Status: Federally Designated \\ Date of Recognition: July 7th, 1988 \\ FHBRO Number: 87-108}

Relevant Buildings: Physical Metallurgical Research Labs. (c.1942-52)

According to the Heritage Character Statement, the five buildings comprising the Physical Metallurgical Research Labs by Noffke are designated because of their important historical associations and the functional quality of their design. ${ }^{184}$ The buildings are specifically associated with the significant role that the department played in the World War II war effort, which demanded new sources of energy, strategic minerals and gold. ${ }^{185}$ Architecturally, the buildings are valued for their good aesthetic and very good functional design. They are an exemplar of a restrained classicized style characteristic of institutional functionalism; the original three buildings reflect a logical division of access points, offices and various sizes of laboratories. ${ }^{186}$

\section{Chemical and Radioactive Ores Building \\ 555 Booth Street, Ottawa, ON \\ Heritage Status: Federally Recognized \\ Date of Recognition: November 27th, 1997 \\ FHBRO Number: 92-043 \\ Relevant Buildings: Chemical and Radioactive Ores (c.1955)}

Asstated within the Heritage Character Statement, The Chemical and Radioactive Ores Building by architects Allward and Gouinlock is federally recognized because of its

181. Ricketts, Shannon. FHBRO Building Report 86-61: Four Structures on the EMR Complex, Booth Street, Ottawa. Ottawa, ON: Federal Heritage Buildings Review Office, 1986, 11

182. "EMR Complex: Fuel Testing Laboratory." THE CANADIAN REGISTER. A

183. Ibid

184. "Physical Metallurgy Laboratory." THE CANADIAN REGISTER.

185. Ricketts, Shannon. FHBRO Building Report 87-108: Physical Metallurgy Laboratories, EMR Complex, Booth Street, Ottawa. Ottawa, ON:

Federal Heritage Buildings Review Office, 1987, 2

186. "Physical Metallurgy Laboratory." THE CANADIAN REGISTER.
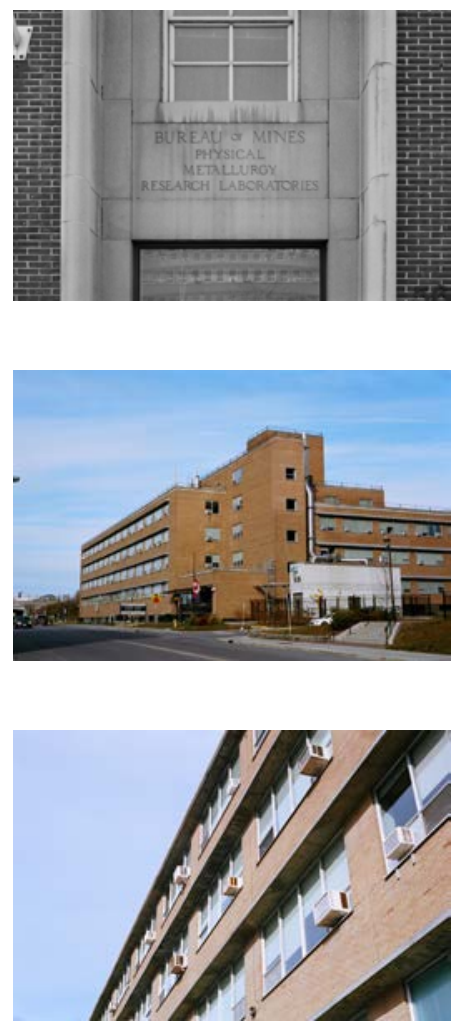

Figure 2.47 (Top): Physical Metallurgical Laboratories c. 2018

Figure 2.48 (Mid): Chemical and Radioactive Ores Building, c. 2018

Figure 2.49 (Bottom): Chemical and Radioactive Ores Building, c. 2018 
historical associations, its architectural style and its environmental significance. ${ }^{187}$ Like the Geological Survey of Canada and the Survey and Mapping Buildings, the Chemical Radioactive Ores Building is associated with the exploitation of Canada's natural resources, and of the federal government's recognition of the significance of the these activities. It is also associated with the pioneering of many new techniques in radioactivity, and with Arvid Thunaes and Dr. E. A. Brown who advanced approaches in the recovery of radioactive materials from ore samples. ${ }^{188}$ Architecturally, the building is valued for its good aesthetic qualities; strong asymmetrical massing, the open volume of the recessed entrance, and the flat roof are characteristic of the International Style. ${ }^{189}$

\section{Surveys and Mapping Building \\ 615 Booth Street, Ottawa, ON \\ Heritage Status: Federally Recognized \\ Date of Recognition: November 27th, 1997 \\ FHBRO Number: 92-044 \\ Relevant Buildings: Surveys and Mapping Bldg. (c. 1958)}

As stated within the Statement of Significance, the Surveys and Mapping Building of architects Allward and Gouinlock is recognized because of its historical associations, and its architectural and environmental value. ${ }^{190}$ The Surveys and Mapping Building is directly associated with the role of the Surveys and Mapping department in the exploration and mapping of Canada, and the federal government's recognition of the significance of the these activities. ${ }^{191}$ The building is also associated with the post-Second World War acceleration of mineral exploration and ore testing by the Canadian government and illustrates the development of the mining sector and its value to the Canadian economy. ${ }^{192}$ The Surveys and Mapping Building is valued for its very good aesthetic qualities; strong asymmetrical massing, the variation in size and form of the building's components, the open volume of the recessed entrance, and the flat roof line are characteristic of the International Style. ${ }^{193}$

\section{Geological Survey of Canada Building \\ 601 Booth Street, Ottawa, ON \\ Heritage Status: Federally Recognized \\ Date of Recognition: November 27th, 1997}
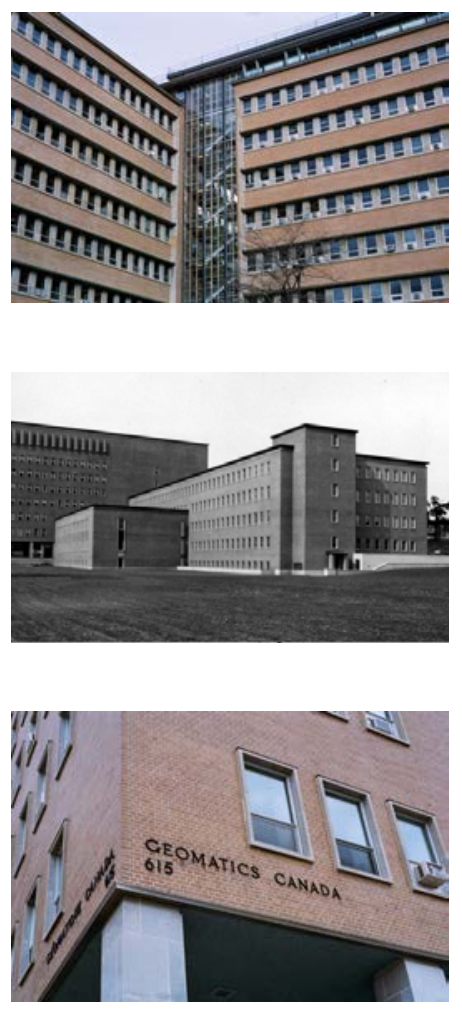

Figure 2.50 (Top): Surveys and Mapping Building, c. 2018

Figure 2.51 (Mid): Geological Survey of Canada Building, c. 1955

Figure 2.52 (Bottom): Geological Survey of Canada Building, c. 2018

187. "Chemical Radioactive Ores Building." THE CANADIAN REGISTER.

188. Ibid

189. "Chemical Radioactive Ores Building." THE CANADIAN REGISTER.

190. "Booth Street Complex, Surveys and Mapping Building." THE CANADIAN REGISTER.

191. Ibid

192. lbid

193. Ibid 
As stated within the Heritage Character Statement, The Geological Survey of Canada Building by architects Allward and Gouinlock is recognized because of its historical associations, its architectural style and its environmental significance. ${ }^{194}$ The GSC Building is directly associated with the role of the GSC department in the exploration, mapping and subsequent exploitation of Canada's natural resources, and of the federal government's recognition of the significance of the these activities. ${ }^{195}$ The building is also associated with the post-Second World War acceleration of mineral exploration and ore testing by the Canadian government and illustrates the development of the mining sector and its value to the Canadian economy. ${ }^{196}$ The Geological Survey of Canada Building is valued for its very good aesthetic qualities; strong asymmetrical massing, the variation in size and form of the building's components, the open volume of the recessed entrance, and the flat roof line are characteristic of the International Style. ${ }^{197}$

\section{Administration Building \\ 405 Rochester Street, Ottawa, ON \\ Heritage Status: Federally Recognized \\ Date of Recognition: March 5th, 1998 \\ FHBRO Number: 97-083 \\ Relevant Buildings: Administration Building (c.1958)}

As stated within the Heritage Character Statement, The Administration Building by architects Allward and Gouinlock is recognized because of its historical associations, its architectural style and its environmental significance. ${ }^{198}$ The Administration Building testifies to the post-Second World War acceleration of mineral exploration and ore testing by the federal government. ${ }^{199}$ The building was designed to accommodate the administrative functions of the Department of Mines and Technical Surveys during a period of expansion. ${ }^{200}$ Valued for its good aesthetics, the Administration Building is an example of the Intemational Style of architecture, which promoted clean lines, legible structure, asymmetrical balance in composition and a building form that expresses internal function. This style was widely used by the federal government during the period of postwar expansion and is found in the nearby GSC and Survey and Mapping Buildings. ${ }^{201}$
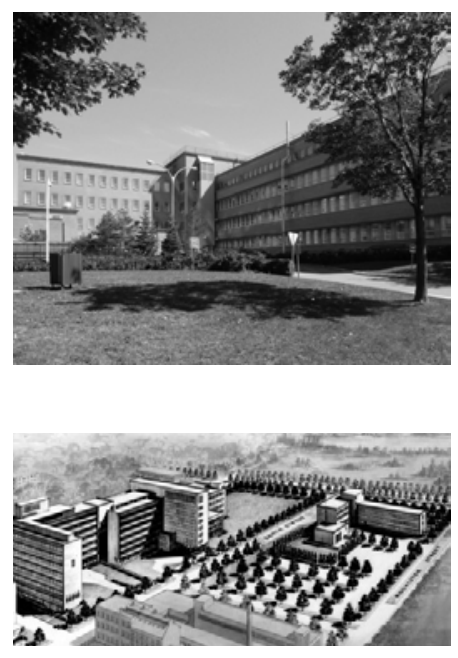

Figure 2.53 (Top): Administration Building, c. 2018

Figure 2.54 (Mid): Complex rendering, c. 1954

194. "Geological Survey of Canada Building." THE CANADIAN REGISTER.

195. Ibid

196. Ibid

197. Ibid

198. "Administration Building." THE CANADIAN REGISTER.

199. Ibid

200. Ibid

201. Ibid 


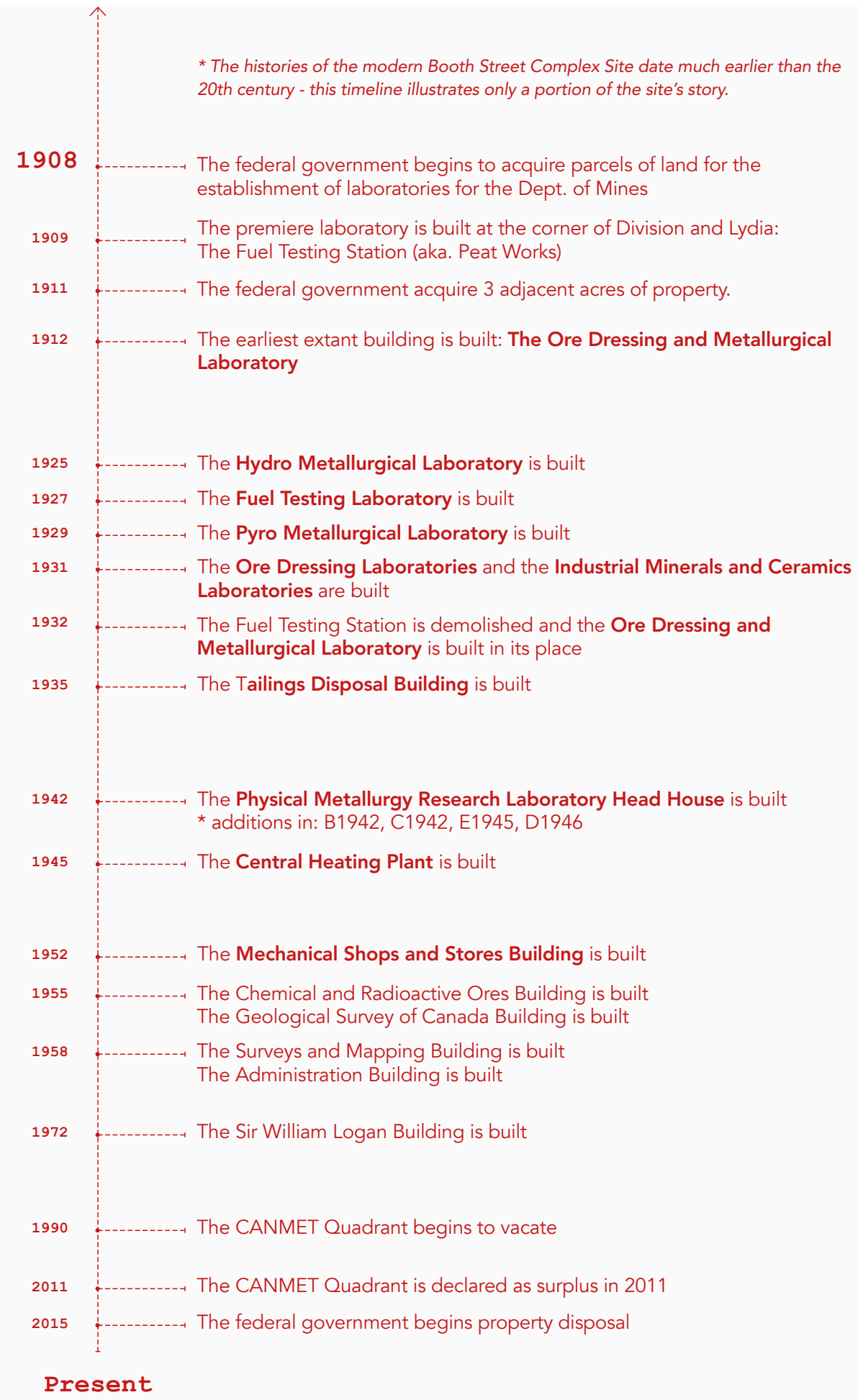

Figure 2.55: Timeline of Booth Street Complex's Development 


\section{Chapter VI}

\section{Architectural Status and Redevelopment}

A decline in growth of the federal research and development sector has lead to the vacation of numerous buildings within the Booth Street Complex; as a result, the process of federal property disposal is underway and a portion of the site is slated for redevelopment by Canada Lands Corporation.

\subsection{Future Development Plans}

For over two decades, several buildings within the CANMET quarter of the Booth Street Complex sat idle and vacant, an unfortunate event which ultimately lead to their declaration as surplus properties by the title department in 2011, consequently igniting the process of federal disposal - the governmental process through which property assets are liquidated via sale or transfer. ${ }^{202}$

\section{Federal Disposal}

According to the federal 'Guide to the Management of Real Property', there are two types of federal disposal processes - dependent upon the classification of property surplus type. The first, and logistically simpler disposal occurs when a property is deemed 'surplus routine' - a label applied when the real properties in question are those of lesser value that can be sold easily without any substantial investment. ${ }^{203}$ The second, and more complex disposal occurs when a property is classified as 'surplus strategic' - a label applied to sites with potential for significantly enhanced value, those that are highly sensitive, or a combination of these factors. ${ }^{204}$ When a site is deemed 'surplus strategic' the crown corporation, Canada Lands Corporation Limited (CLC), enters the picture as a third party entity who handles the proceedings of required remediation, heritage designations, zoning amendments and property maintenance. ${ }^{205}$

202. Butler, Don. "Redevelopment Process Set to Begin on Former NRCan Booth Street Property." Ottawa Citizen. June 15, 2016. 203. Office of the Comptroller General. "Guide to the Management of Real Property." Treasury Board of Canada Secretariat. October 24, 2011. 204. Ibid 205. Ibid 
In 2011, a portion of the Booth Street Complex - the block bound by Booth, Orangeville, Norman and Rochester streets - was designated as a 'surplus strategic' property, leading to its transfer to CLC in October of 2015.206

Adding a layer of complexity to the disposal of the Booth Street Complex are the numerous buildings on the property, recognized or designated as federal heritage properties. There are eleven individual buildings within the CANMET quadrant, seven of which are protected under three designations, and two of which are recognized.

The 'Guide to the Management of Real Property' states that when the title department wishes to liquidate heritage properties, there should be consultation with the Federal Heritage Buildings Review Office (FHBRO) on heritage conservation measures as early as possible. ${ }^{207}$ The federal government recognizes that using heritage buildings on an ongoing basis is the best way of ensuring their long-term survival, so the guide requires that custodian departments make 'best efforts' to find appropriate alternative uses. ${ }^{208}$

With respect to arranging for appropriate alternative uses for surplus federal heritage buildings, the Guide to the Management of Real Property states that 'best efforts' means, at a minimum:

- for a Classified federal heritage building, taking steps to protect the building's heritage character and specifying the nature and level of protection in the sales agreement - protection could mean a heritage covenant, easement, or servitude registered on title that specifies the conservation requirements; 209

- for a Recognized federal heritage building, exploring options and deciding whether to continue to protect its heritage character; and when applicable, specifying the nature of any heritage protection in the sales agreement. If a decision is made not to protect the heritage character, this decision must be justified and documented. ${ }^{210}$

206. ERA Architecture, Stantec Consulting Ltd., and Hill Knowlton Strategies. "Canada Lands Company Booth Street Redevelopment." City of Ottawa Webcast. March 28, 2018.

207. Federal Heritage Buildings Review Office. "Processes: Disposal." Parks Canada - History and Culture. April 01, 2017.

208. Ibid

209. Ibid

210. Ibid 
Transfer of the North-West Quadrant of the complex to Canada Lands Corporation was ultimately the Department of Natural Resources making the required best efforts however there are issues of operation and maintenance best efforts which still beg to be asked. If best efforts were applied, should federally recognized heritage buildings present such significant levels of deterioration? Why weren't they deemed as surplus earlier, before the decay took place?

\section{The Canada Lands Corporation Proposal}

On March 29th of 2018, after a thirty month-long project, Canada Lands Corporation submitted a Zoning By-law Amendment and an Official Plan Amendment to the city of Ottawa council which included:

- Combined Application Summaries

- Planning Rationale

- Site Plan

- Servicing and Storm-water Management Report

- Survey

- Wind Study

- Species at Risk Assessment

- Wildlife Management Plan

- Phase 1 Environmental Site Assessment

- Phase 2 Environmental Site Assessment

- Urban Design Panel Formal Review Submission

- Ontario Heritage Act Designation Report

On March 6th of 2019 both amendments were approved by Ottawa city council, meaning that the project will continue as proposed. ${ }^{211}$ Of most relevance to this thesis are the Planning Rationale, the Environmental Site Assessments and the Ontario Heritage Act Designation Reports.

The Planning Rationale submitted by CLC is a 98 page document compiled by Stantec Consulting Ltd, ERA Architecture and Hill and Knowlton Strategies. It addresses the existing site conditions, neighborhood contexts, transportation infrastructure, socioeconomic conditions, the planning context, the public consultation process, and the site heritage. ${ }^{212}$ As a result of its analysis, the planning rationale concludes by presenting a proposed concept plan, a design brief and proposed amendments to the official plan and zoning by-laws.

211. "City of Ottawa Development Applications." Development Application Search.

212. ERA Architecture, Stantec Consulting Ltd., and Hill Knowlton Strategies. "Canada Lands Company Booth Street Redevelopment." City of Ottawa Webcast. March 28, 2018. 
The proposed concept plan is largely presented as a design which creates a distinct sense of place and integrates sustainability, but ultimately, the driver of the proposal is the introduction of significant residential density and commercial programming to the area. ${ }^{213}$ With a combined total of 102 storeys of residential infill, the proposal seems motivated by the opportunity to turn a revenue for the government. (Figure 2.55) Not only is this motivation evident within the proposed programming, but also within the treatment of the existing heritage buildings and within the surface level sustainability approaches.

As part of the design brief, the illustrations suggest the complete demolition of 5 existing buildings and extensive alterations to the remaining. ${ }^{214}$ While the vision of the design brief states that the "heritage building will be restored," the design proposal suggests a treatment more akin to facadism. As defined by the 'Standards and Guidelines for the Conservation of Historic Places in Canada', restoration involves "accurately revealing, recovering or representing the state of an historic place or individual component as it appeared at a particular period in its history, while protecting its heritage value". ${ }^{215}$ The treatment must be based on clear evidence and detailed knowledge of the earlier forms and materials being recovered. ${ }^{216}$ As per the official Parks Canada definition, it seems like the 'restoration of heritage buildings' proposed within the planning rationale falls short. Within the rationale, only alterations to the exteriors of the existing heritage buildings will require approval from city committees inferring that the value of the existing heritage buildings lay only within their exterior architecture. This is more aligned with the ideals of rehabilitation a valid and recognized conservation approach. As explained within Chapter II, rehabilitation is a more flexible intervention that allows for thoughtful and appropriate architectural change to accommodate new programming.

With respect to the 'green infrastructure' proposed within the planning rationale, the strategies seem minimally integrated. Although the proposed elements such as permeable pavers, green roofs and large tree canopies are undeniably beneficial, there were some larger sustainable strategies that were missed. ${ }^{217}$ The planning rational is only a preliminary tool, being used by the city to rationalize plan and zoning changes, but none the less, it overlooked some major sustainable potentials of the site:

\footnotetext{
213. Ibid

214. Ibid

215. Standards and Guidelines for the Conservation of Historic Places in Canada. 2nd ed. Canada's Historic Places and Parks Canada, 2010, 16

216. Ibid

217. ERA Architecture, Stantec Consulting Ltd., and Hill Knowlton Strategies. "Canada Lands Company Booth Street Redevelopment." City of Ottawa Webcast. March 28, 2018.
} 

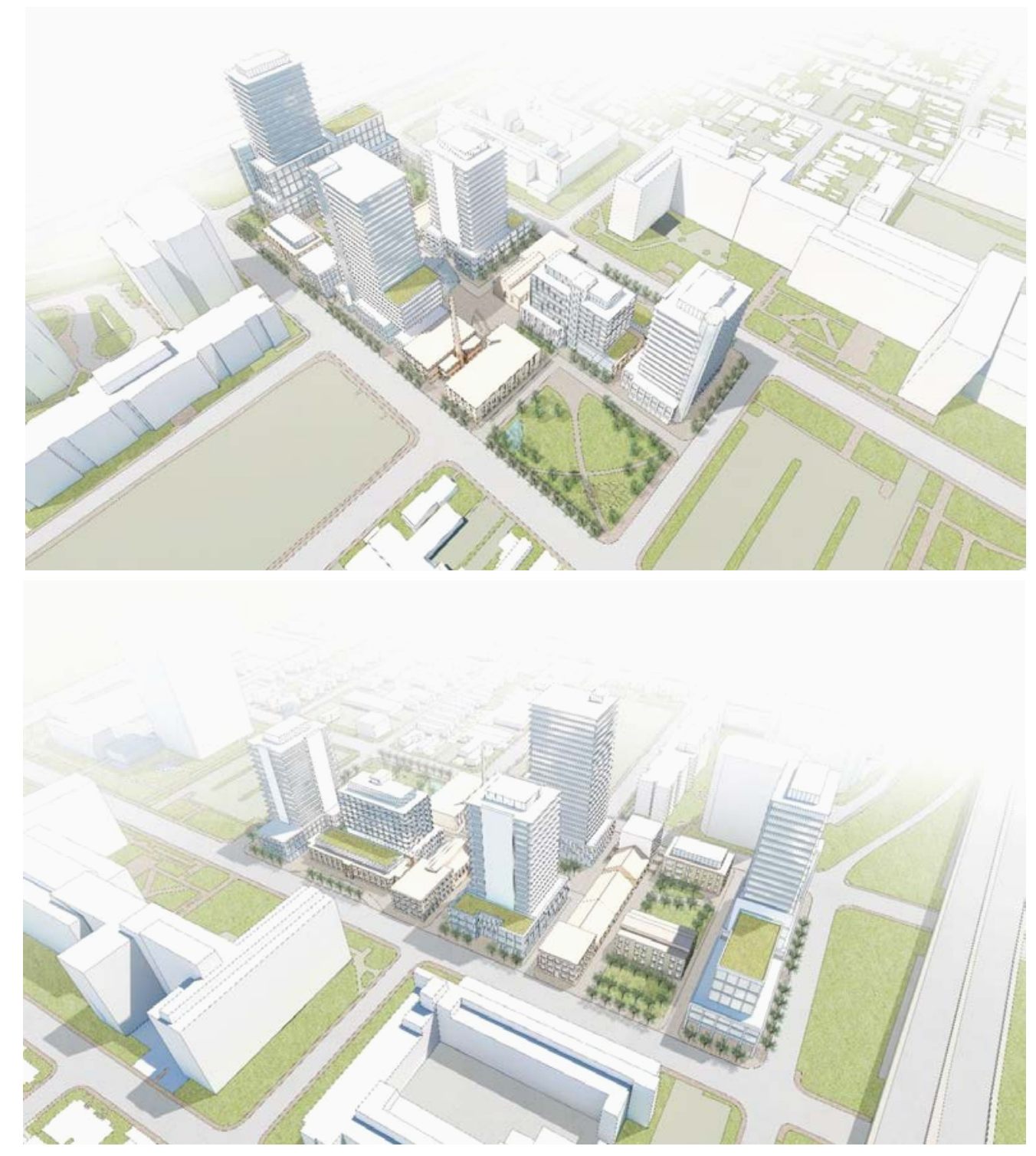

Figure 2.56 (Top): Massing Proposal by Canada Lands Corp - Rendering looking North-East Figure 2.57 (Bottom): Massing Proposal by Canada Lands Corp - Rendering looking South-West 
1. There is an existing central heating plant which historically serviced the entirety of the Booth Street Complex - this existing infrastructure could have been integrated into a district heating strategy for the CANMET property.

2. On-site reuse of materials or existing components is not mentioned as part of the green strategy.

3. Reuse of Existing Buildings is proposed within an aesthetic and planning approach only.

4. The proposal makes no reference to reconciling the embodied energies of the buildings caused by their prolonged vacancies or abandonment.

\section{Provincial Heritage Designation Proceedings}

On February 11th and 28th of 2019, a report presented to the city of Ottawa's Built Heritage Sub-Committee as well as the Planning Committee respectively, proposed the provincial designation of the a portion of the Booth Street Complex as a designated complex under Part IV of the Ontario Heritage Act. ${ }^{218}$ The portion at the subject of this report is the north-west quadrant, formerly occupied by CANMET, currently owned by Canada Lands Corporation.

As a 'designated complex', the entire parcel would be protected, however, because the Statement of Cultural Heritage Value excludes certain buildings and additions to existing buildings from the designation, demolition of these buildings and additions would not require approval under the Ontario Heritage Act. ${ }^{219}$ Similarly, the construction of new freestanding structures within the Complex would not require approval under the Act but alterations to the structures identified in the Statement of Cultural Heritage Value would. ${ }^{220}$ The structures identified in the statement are as follows:

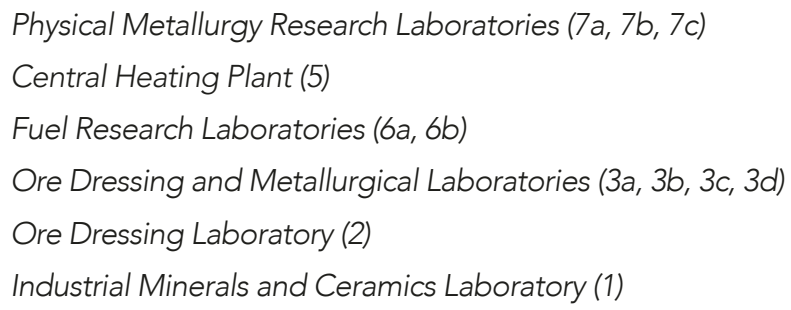

Excluded from the Statement of Cultural Heritage Value and therefore those buildings which are not being suggested for protection are:

218. Sally Coutts, and Court Curry. Report to Ottawa's Built Heritage Sub Comittee. 2011, 2

219. Ibid, 6

220. Ibid, 2 


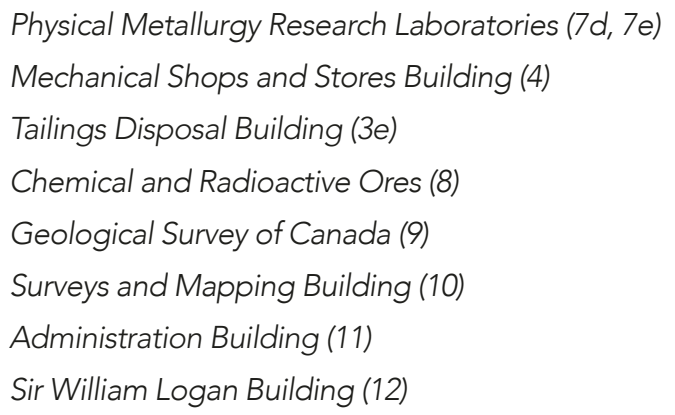

Most of the buildings excluded from this designation are either not under the ownership of Canada Lands Corporation and therefore not undergoing the process of federal disposal, or are those which were not previously recognized by the Federal Heritage Buildings Review Office. Moreover, because these buildings are still under ownership of the federal government, provincial designation is not possible. As an exception, the later additions to the Physical Metallurgy Research Laboratories, additions $D$ and $E$ are excluded without justification but are pending municipal recognition. ${ }^{221}$

Amongst the buildings up for disposal, it is interesting to note that the city is proposing an additional Part IV designation to those recognized by the review office. In response to public consultation, the complex's Central Heating Plant and its accompanying smokestack has been described as a contextual landmark, therefore of local value. ${ }^{222}$

\subsection{Complex Documentation}

Although thorough site documentation was beyond the scope of this thesis due to limited site access, documentation was compiled from afar. Documentation via research and photography, were the main methodologies through which it was accomplished. Photographs were taken by the author to document character defining elements and exterior site conditions. Additionally, earlier photographs of the interiors of select buildings were attained to highlight interior elements - taken by Michelle McKenna, a 2016 graduate of the M.Arch program at Carleton University.

\section{Character Defining Elements}

The character defining elements of each building within the CANMET quadrant are listed in the following chart. Photographs highlighting major elements can be found in Figures 2.60 - 2.64. 


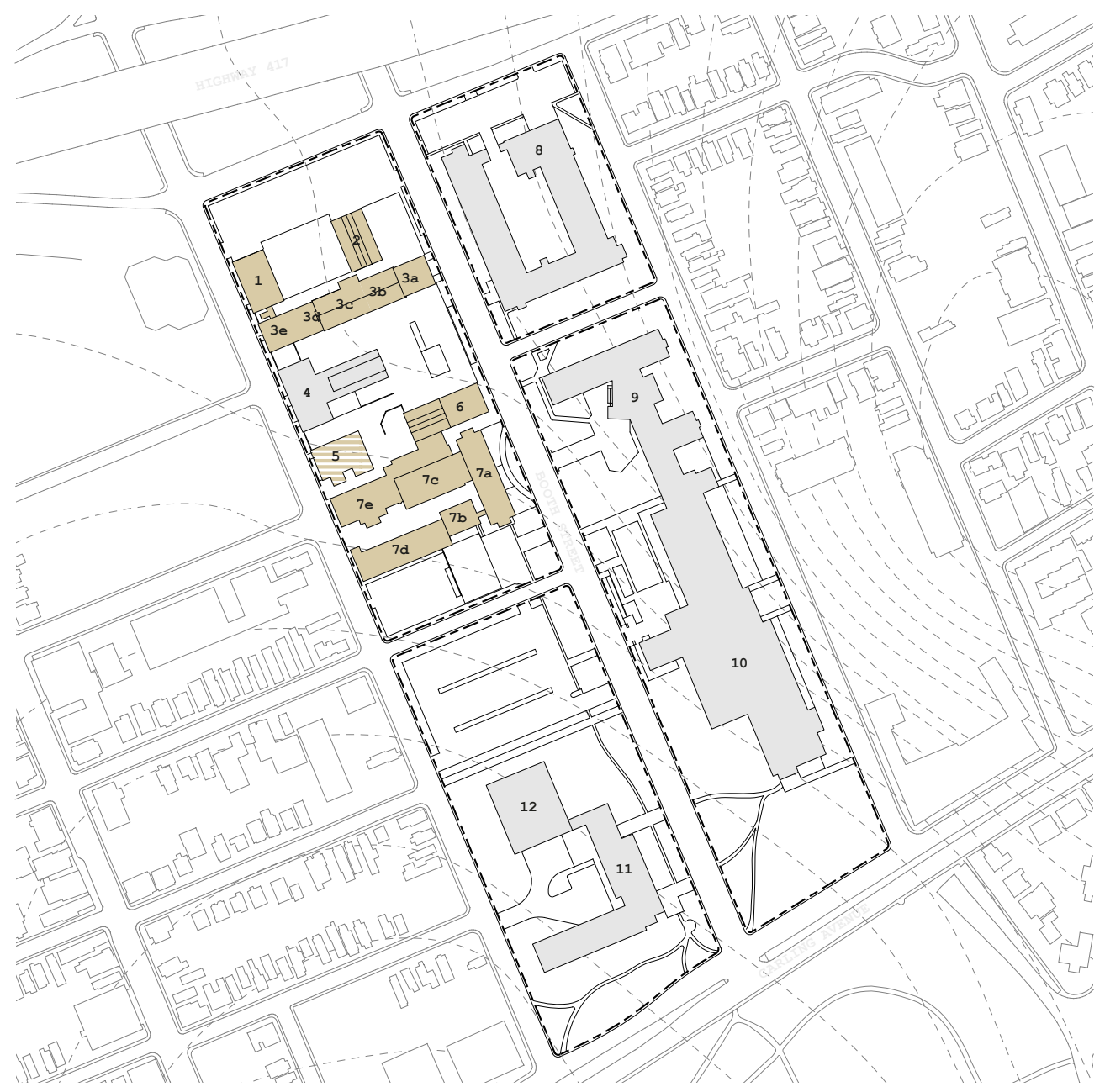

Figure 2.58: Ontario Heritage Act Recognitions c. 2019

Ontario Heritage Act Designations of Pre-Recognized Property

Ontario Heritage Act Designations of Formerly Un-Recognized Property

No Status Ontario Heritage Act Designations 


\begin{tabular}{|c|c|c|}
\hline Building & CDE (Materials and Form) & CDE (other) \\
\hline Ore Dressing Laboratory & $\begin{array}{l}\text { Bricked in Alterations, Bracketed Decorative } \\
\text { Entablature around Main Entrance, Symmetrical } \\
\text { Facade, Gabled Monitor Roof, Central Floor-plate } \\
\text { Puncture, Partition Walled Rooms, Large Service } \\
\text { Elevator, Exposed Structure }\end{array}$ & $\begin{array}{l}\text { Complex compatibility via: } \\
\text { massing, materials and } \\
\text { design }\end{array}$ \\
\hline $\begin{array}{l}\text { Industrial Minerals and } \\
\text { Ceramics Laboratory }\end{array}$ & $\begin{array}{l}\text { Common Bond Brickwork Pattern, Bracketed } \\
\text { Decorative Entablature around Main Entrance, } \\
\text { Symmetrical Facade, Glazed Interior Brickwork, } \\
\text { Metal Switchback Staircase }\end{array}$ & $\begin{array}{l}\text { Complex compatibility via: } \\
\text { massing, materials and } \\
\text { design }\end{array}$ \\
\hline $\begin{array}{r}\text { Ore Dressing } \\
\text { and Metallurgical } \\
\text { Laboratories }\end{array}$ & $\begin{array}{l}\text { Bracketed Decorative Entablature around Main } \\
\text { Entrance, Parapet Entablature, Metal Facade Panels, } \\
\text { Low Gable Roof, Twin Sash Windows, Arched } \\
\text { Radiating Voussoirs, Upper Casement Windows, } \\
\text { Large Fixed Windows with Grid Mullions, Bricked- } \\
\text { In Alterations, Exposed Structure, Large Skylights, } \\
\text { Punctured Floor Plates, Architectural Roof Vents, } \\
\text { Common Brick Bond }\end{array}$ & $\begin{array}{l}\text { Complex compatibility via: } \\
\text { massing, materials and } \\
\text { design }\end{array}$ \\
\hline $\begin{array}{r}\text { Tailings Disposal } \\
\text { Building }\end{array}$ & $\begin{array}{l}\text { Large Wood Swing Doors with Transom, Exposed } \\
\text { Services, Common Brick Bond }\end{array}$ & $\begin{array}{l}\text { Complex compatibility via: } \\
\text { massing, materials and } \\
\text { design }\end{array}$ \\
\hline $\begin{array}{r}\text { Fuel Research } \\
\text { Laboratories }\end{array}$ & $\begin{array}{l}\text { Bracketed Decorative Entablature around Main } \\
\text { Entrance, Large Fixed Windows with Grid Mullions, } \\
\text { Bricked-In Alterations, Gabled Monitor Roof }\end{array}$ & $\begin{array}{l}\text { Complex compatibility via: } \\
\text { massing, materials and } \\
\text { design }\end{array}$ \\
\hline $\begin{array}{r}\text { Mechanical Shops and } \\
\text { Stores Building }\end{array}$ & $\begin{array}{l}\text { Expansive Interior Volumes, Large Sliding Lift, Glass } \\
\text { Block Facade Elements, Symmetrical Front Facade, } \\
\text { Garage Doors }\end{array}$ & $\begin{array}{l}\text { Complex compatibility via: } \\
\text { massing, materials and } \\
\text { design }\end{array}$ \\
\hline $\begin{array}{r}\text { Physical Metallurgy } \\
\text { Research Laboratories }\end{array}$ & $\begin{array}{l}\text { Symmetrical Front Facade, Decorative Molding } \\
\text { around Main Entrance, Double-Height Interior } \\
\text { Volumes }\end{array}$ & $\begin{array}{l}\text { Complex compatibility via: } \\
\text { massing, materials and } \\
\text { design }\end{array}$ \\
\hline Central Heating Plant & $\begin{array}{l}\text { Large Fixed Windows with Grid Mullions, } \\
\text { SmokeStack }\end{array}$ & $\begin{array}{l}\text { Complex compatibility via: } \\
\text { massing, materials and } \\
\text { design }\end{array}$ \\
\hline
\end{tabular}

Figure 2.59: Table of Exemplary Character Defining Elements for the Booth Street Complex c. 2019 

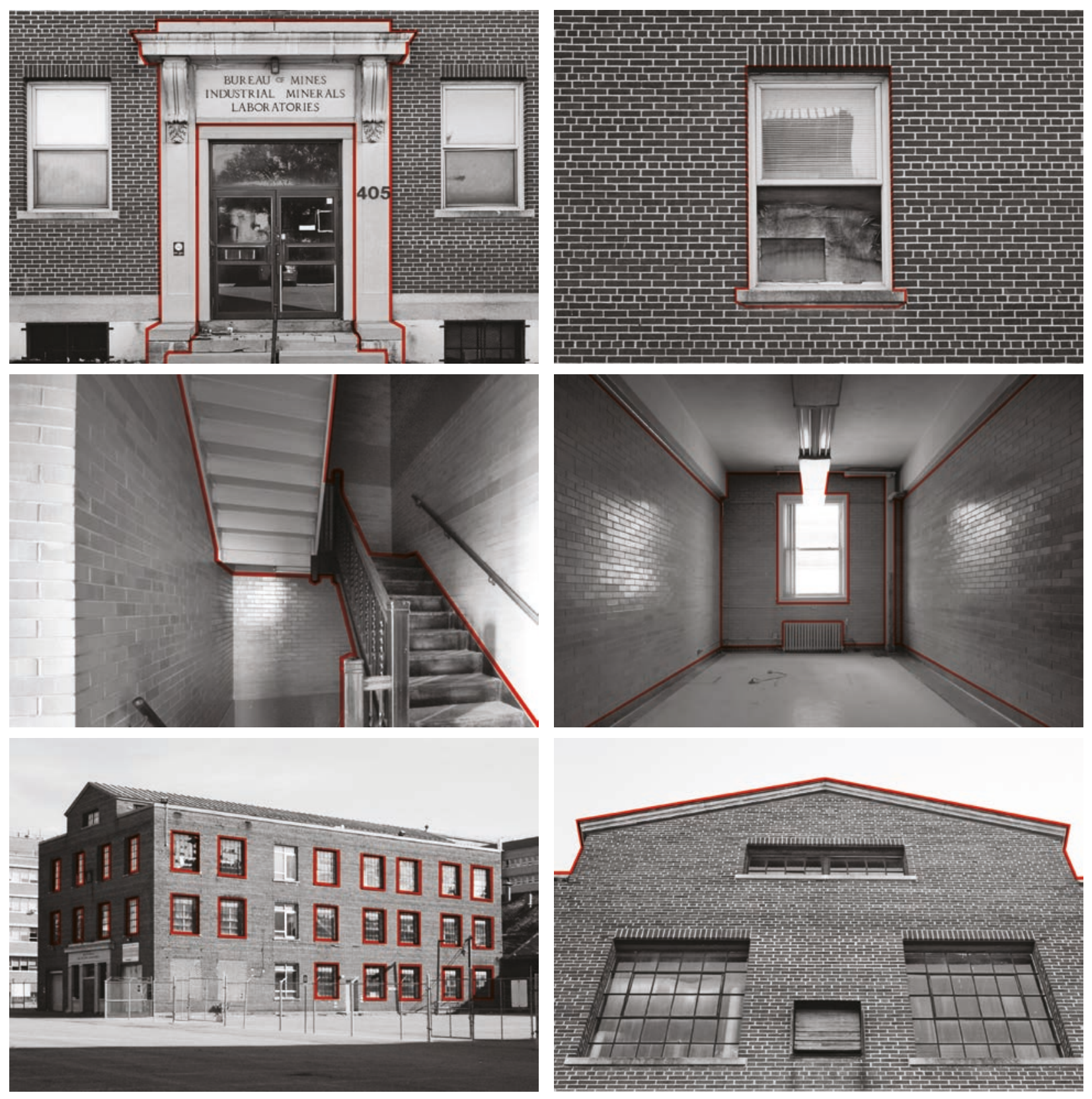

Figure 2.60: Character Defining Elements of The Industrial Minerals and Ceramics Laboratories (1) at 405 Rochester St. and The Ore Dressing Laboratories (2) at 550 Booth St. 

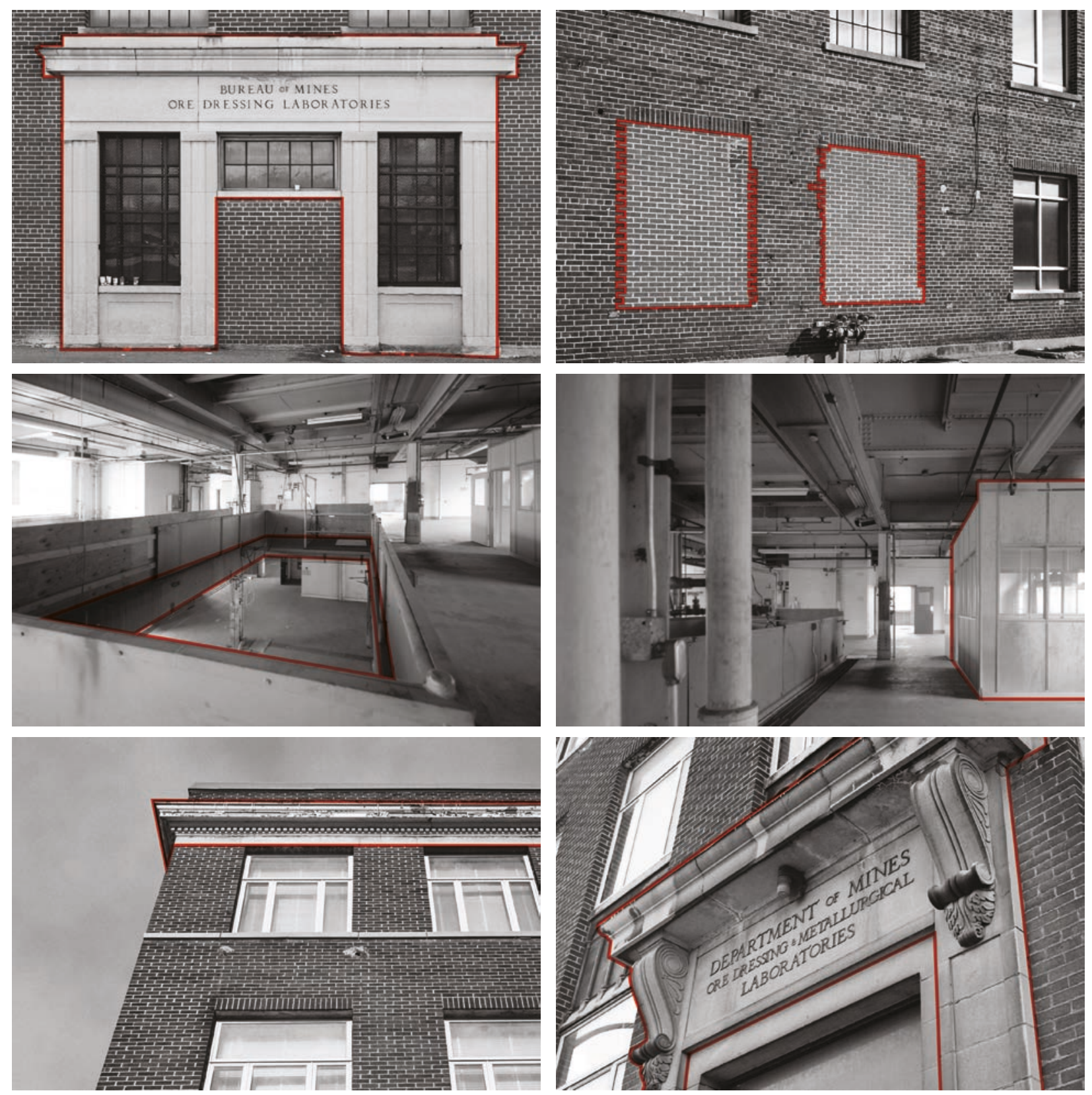

Figure 2.61: Character Defining Elements of The Ore Dressing Laboratories (2) at 550 Booth St. and The Ore Dressing and Metallurgical Laboratories (3a-e) at 552 Booth St 

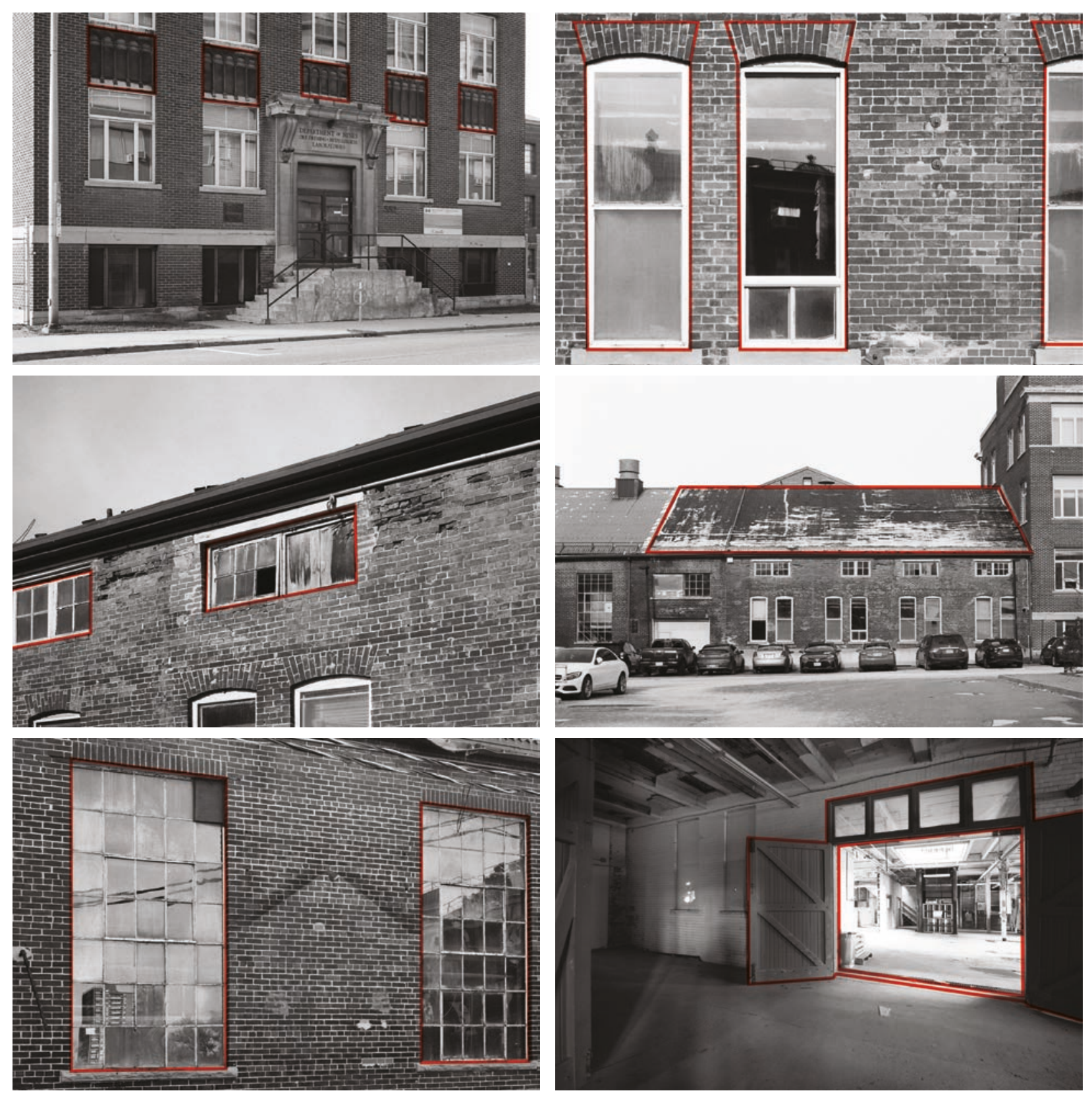

Figure 2.62: Character Defining Elements of The Ore Dressing Laboratories (3a-e) at 552 Booth St. 

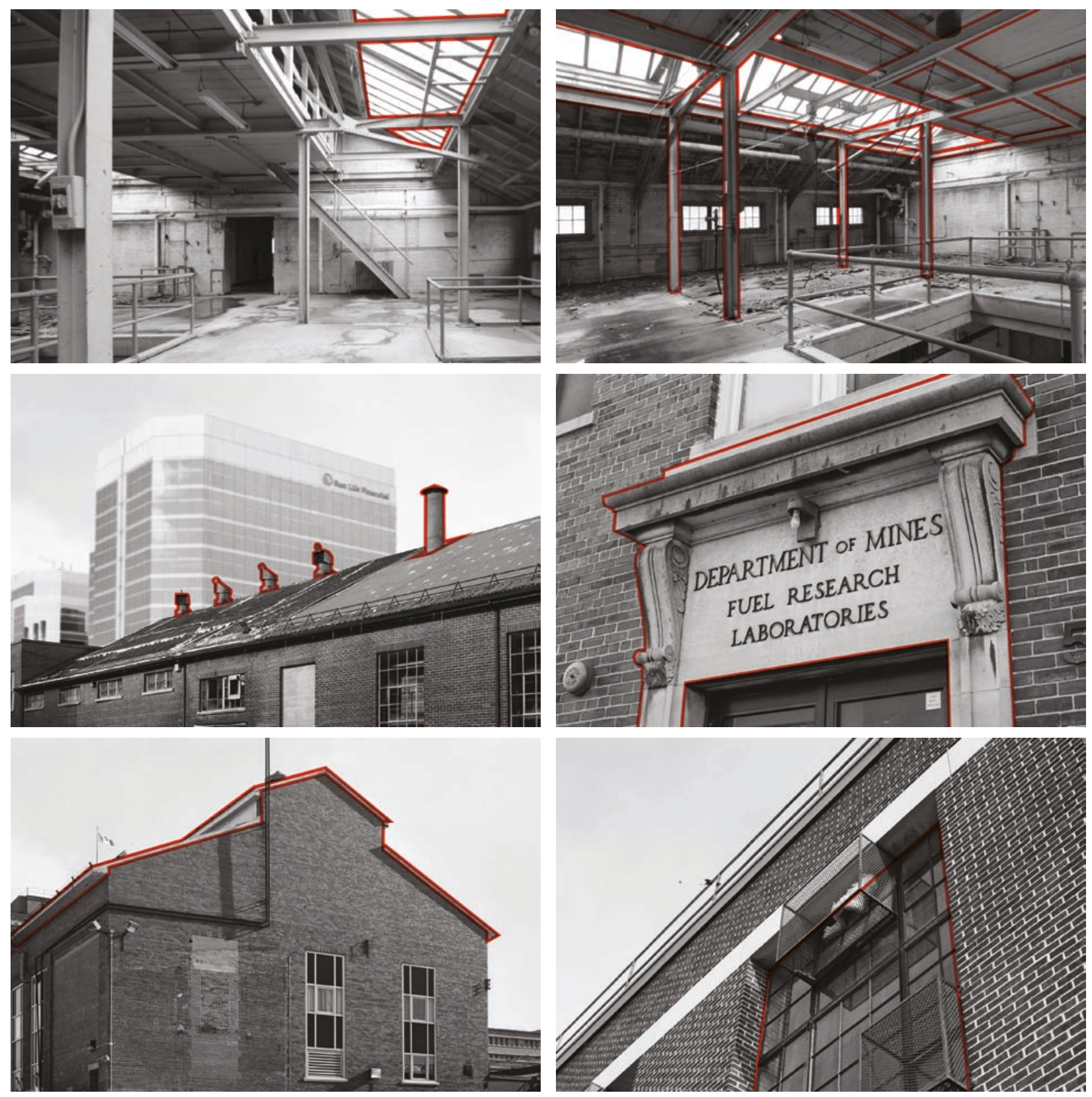

Figure 2.63: Character Defining Elements of The Ore Dressing Laboratories (3a-e) at 552 Booth St., The Fuel Testing Laboratory (6) at 562 Booth St. and the Central Heating Plant (5) at 558 Booth St. 

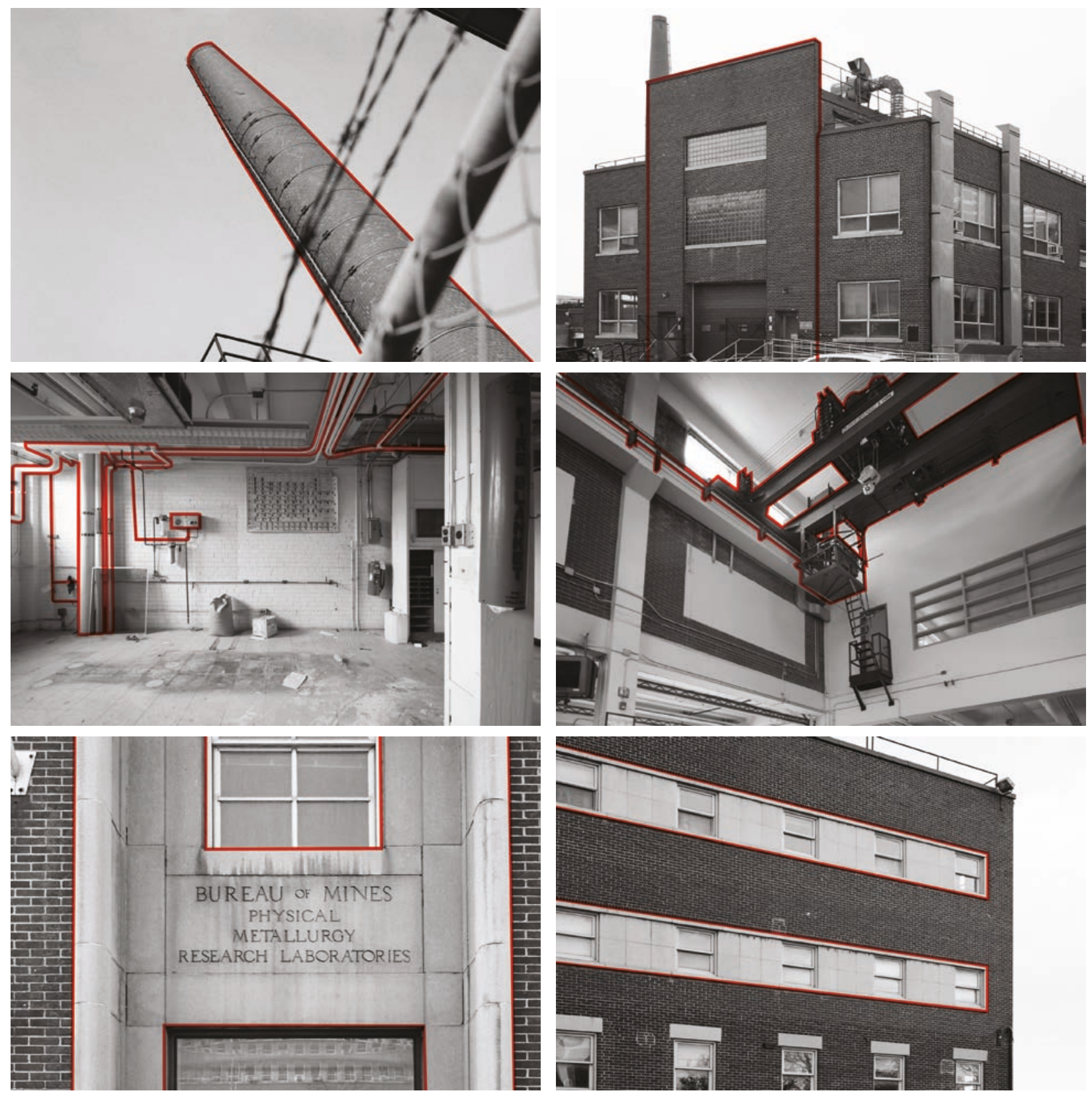

Figure 2.64: Character Defining Elements of The Central Heating Plant (5) at 558 Booth St., The Mechanical Shops and Stores Building (4) at 556 Booth St. and the Physical Metallurgy Laboratories (7a-e) at 568 Booth St. 


\section{Contamination Overview}

Within the documents submitted to the city by CLC in March of 2018, there were two Environmental Site Assessments (ESA) : Phase 1 and Phase 2. Like the other CLC documents, they pertain only to the CANMET quadrant of the complex, but provide in depth information about this area's contamination.

The preliminary Phase $1 \mathrm{ESA}$, a report done with the objective of determining the need for further site investigation, resulted in the conclusion that there were seventeen areas of potential environmental concern (APEC) within the quadrant - all of which showed the potential for soil and ground water contamination. ${ }^{23}$ The APECs are a result of former use, chemical storage or machinery wastes. ${ }^{224}$

The Phase 1 ESA report also summarizes a designated substances surveys report which was conducted in 2002. At the time of inspection, all of the buildings within the CANMET quadrant presented a degree of contamination. The substances identified in the survey were: acrylonitrile, arsenic, asbestos, benzene, mercury, silica, vinyl chloride and lead. ${ }^{225}$

The Phase 2 ESA report - the result of soil and groundwater sampling concluded that indeed all of the APEC did return results which exceeded the acceptable limits of petroleum hydrocarbons, metals, volatile organic compounds and polycyclic aromatic hydrocarbons. ${ }^{226}$

In conclusion, there will need to be further site documentation and testing before CLC sells any parcels of land in order to satisfy the required 'records of site conditions'. ${ }^{227}$ Partial soil remediation took place between the years of 2011 and 2012 with final remediation efforts to be undertaken in 2019.

A soil remediation strategy has not been created as part of this thesis work because the selected programming and overall conceptual objectives do not align with the required intensive soil remediations. If the project were to be realized, the likely suggested remediation strategy would be off-site phytoremediation, however the conceptual gesture of removing material does not bode well in terms of reconciling industrial extraction.

223. Golder Associates Ltd. Phase One Environmental Site Assessment. Ottawa: Golder, 2018, iii

224. Ibid

225. Ibid, 14

226. Ibid, 3

227. Ibid, 4 


\subsection{An Extrapolated Future}

In 2008, it was predicted that not only the CANMET quadrant of the Booth Complex Site would become surplus, but that the entire complex, including 555, 580, 588, 601, and 615 Booth Street would be designated surplus by the end of 2013. ${ }^{228}$ This has yet to happen, but all signs point to impending disposal or worse, demolition.

Although, the speculation alone is reason for concern, there is other evidence pointing in the same direction:

- As of late, there is a distinct pattern of federal property liquidation.

- There are currently rumors that the Geologic Survey of Canada will be relocated to a shared 'Scientific Research Centre' in East Ottawa.

- There have been other local federal buildings, which have also been FHBRO designated and which have undergone disposal and demolition. (In 2014, the demolition of Ottawa's Sir John Carling building went ahead against public protest and a FHBRO designation)

- Amongst increasing mechanically faulted building closures, there have not been any major renovation projects undertaken within the past decade.

- Increasing privatization has lead to drops in departmental staff - resulting in a decrease in building occupancy.

What will happen to the remainder of the complex's quadrants once the entire site becomes surplus? Will the CLC undertake the impending adjacent project? Since the department of Natural Resources waited two decades to list the CANMET buildings as surplus, does the same fate await the rest of the complex? Perhaps the government is treating the impending redevelopment as a pilot project.

228. Spears, Tom. "Booth Street Site in Critical Condition." Ottawa Citizen. June 2, 2011. 


\section{Part 3 : Processing and Refining}

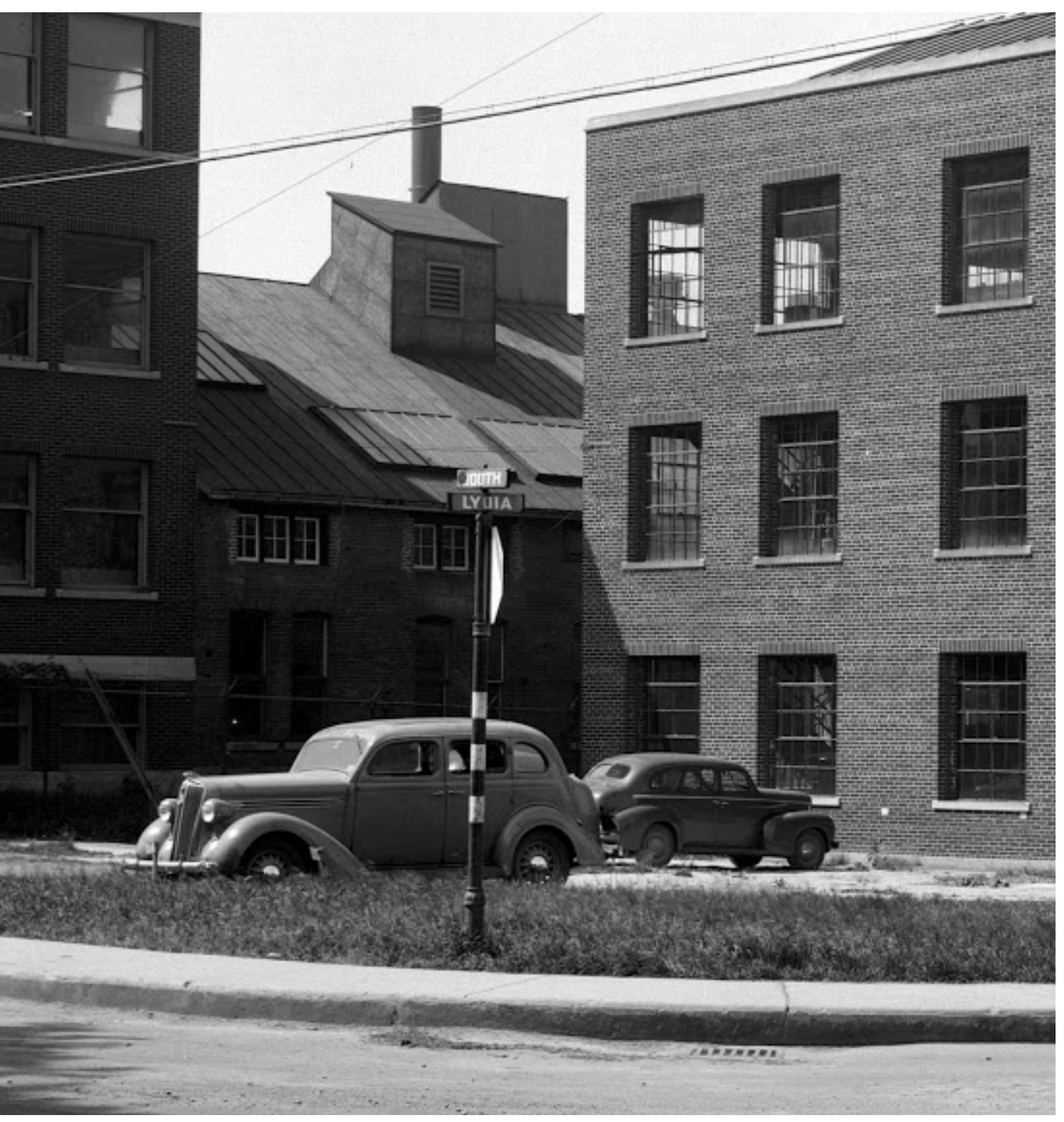

Figure 3.01: Photograph at Corner of Booth St and Lydia (Orangeville) St, c. 1940 


\section{Chapter VII}

\section{Macro Design Approach: Site as Landscape}

Although the 26 acre site of Ottawa's Booth Street Complex is minute in comparison to the magnitude of the greater Canadian Industrial Landscape, as the preceding Chapters prove, the Booth Street Complex site has played a critical role in the development of this greater landscape and thus, is a valid participant and component.

Mainly referencing the research completed within Chapter I and the work undertaken within Chapters IV and V, Chapter VII stands as their synthesis presenting the resultant macro design approach, from the perspective of 'site as landscape'. The concept of crafting a macro design approach — site as landscape - ultimately involves considering the whole of the complex as part of a larger network. In the case of this work, the larger network is the greater Canadian landscape of industry and extraction.

\subsection{Classification of the Booth Street Complex Landscape}

As presented within Chapter I, there are numerous classifications and subclassifications for landscapes - defined by their inception, use, evolution and current state.

Ottawa's Booth Street Complex, can be principally classified as a cultural landscape, as it is directly and indirectly a result of the intermingling of man and of nature. The fundamental function of the complex is directly consequential to nature - focusing on the sourcing, mapping, extraction, processing and refining of Canada's natural resources. Moreover the complex is located on the modern site because of successive patterns of use - driven by geographic proximities. The complex was built in close proximity to the adjacent lumber yards and railways, which in turn were built in close proximity to the Ottawa River. 
Under the umbrella classification of 'cultural landscape' as defined within Chapter I, the complex - as a compilation of parts - can also be defined as the following:

- Industrial Landscape

- Post-Industrial Landscape

- Evolved Landscape

- Relic Landscape

- Continuing Landscape

Although each quadrant can undeniably be described as an evolved landscape, there are evident contradictions within the other classifications. How can a landscape be industrial and post-industrial at the same time? How can it be a relic evolved landscape and a continuing evolved landscape simultaneously?

These contradicting classifications are justifiable because the Booth Street Complex site, in its 2019 state, is segmented and fractured. It is no longer a unified whole, but instead a composition of distinct parts.

After decade long building vacancy, the north-west quadrant of the complex - the properties formally occupied by CANMET and the Department of Mines - were deemed 'surplus' to the department of natural resources in 2011. This ignited the process of federal disposal and subsequent transfer to Canada Lands Corporation.

The segmentation from the remaining active areas of the larger complex, resulted in distinct sub-functions, uses and building conditions within the complex. While the once productive laboratory typologies now sit abandoned and obsolete, the large office buildings are slowly degrading, remaining partially occupied and semi-operable. For this reason, the quadrants can be classified into their respective landscape categories as follows:

North-West Quadrant: Post-Industrial Landscape / Relic Landscape North-East Quadrant: Post-Industrial Landscape / Continuing Landscape South-West Quadrant: Industrial Landscape / Continuing Landscape South-East Quadrant: Industrial Landscape / Continuing Landscape

These classifications inform the proposed macro design approach by supporting the rationale behind the life-cycle phase application designation discussed in the next section. 


\subsection{Life-Cycle Phase Application}

\section{Existing and Projected Site Phases}

Applying the life-cycle phase classifications, as derived from the study of auxiliary sites of extraction, onto the Booth Street Complex results in similar contradictions as those just previously discussed. Recalling the identified industrial site life-cycle phases as per the generated 'Radial Matrix' upon page 70, the five derived phases are:

1. Expanding: the site is operating at full capacity with plans to increase in magnitude, to escalate production, or to boost intensity.

2. Operating: the site is currently extracting, processing, or refining materials, with no plans to increase or decrease in magnitude. The site is stable, with plans to continue at the current performance level.

3. Dormant: the site is not operational but is minimally maintained to retain and preserve a potential for future reignited operations.

4. Abandoned: the site has been deserted with no plans for cleanup, remediation or reuse.

5. Remediated: the site is, or has, undergone cleanup to reverse environmental impacts from earlier industry. The remediation could be preparatory work for reuse or disposal.

Applied at the scale of the complex quadrants, the classifications are:

\begin{tabular}{|c|c|}
\hline \multicolumn{2}{|c|}{ Dated 2011 (Pre-Disposal) } \\
\hline North-West Quadrant: & Abandoned \\
\hline North-East Quadrant: & Operating \\
\hline South-West Quadrant: & Operating \\
\hline South-East Quadrant: & Operating \\
\hline \multicolumn{2}{|c|}{ Dated 2019 (Mid-Disposal) } \\
\hline North-West Quadrant: & Dormant \\
\hline North-East Quadrant: & Operating \\
\hline South-West Quadrant: & Operating \\
\hline South-East Quadrant: & Operating \\
\hline
\end{tabular}




\section{Dated 2030 (Projected - Post Disposal) \\ North-West Quadrant: Expanding \\ North-East Quadrant: Dormant \\ South-West Quadrant: Dormant \\ South-East Quadrant: Remediated}

These classifications, which are both based on reality and hypothesized, prove to be problematic in that they are merely broad overlays. The scale of the quadrants abstracts the reality of each building or structure. To correct this, Figures 3.02 - 3.04 depict the same phase applications at the scale of each building. Arguably, even applying the phases at the building scale is an abstraction from the conditions of the material constituents, however in searching for a overarching site approach — the quadrant and building scales are more appropriate than the material scale.

\section{Objective and Updates of Terminology}

In proposing a viable site plan for the Booth Street Complex, the primary objective is to ensure longevity of site use. As explained by Brad Guy within his resource hierarchy and as discussed within Chapter II, continued use is the preliminary and most impactful method to reducing the environmental footprint of the built environment. ${ }^{229}$ Moreover, retention of existing architecture carries with it existing values and memories, both positive identity crafting aspects.

Longevity as a proposal objective speaks directly to the main ambition of this thesis work: to propose an impactful and sustainable interpretation of the entirety of the Booth Street Complex. To achieve this, the proposal argues that by considering the existing trajectories of auxiliary industrial sites, a realistic, forward thinking and compatible intervention approach is possible. In utilizing the derived pattern evolutions of sample industrial and post-industrial sites, the future of the Booth Street Complex could be more successfully managed. Taking into consideration likely life-cycle phases assumes certain patterns of decay, obsolesce, perseverance and continuation - ultimately of evolution.

Upon overlaying multiple iterations of possible phase mappings, it was realized that not all phases are going to work in the favor of complex longevity and the phase terminology also needed to be redefined.

229. Guy, Brad. "Towards a Broader Culture of Reuse: US Perspective." Lecture, Heritage in Reverse Symposium, Carleton University, Ottawa, October 27, 2018 


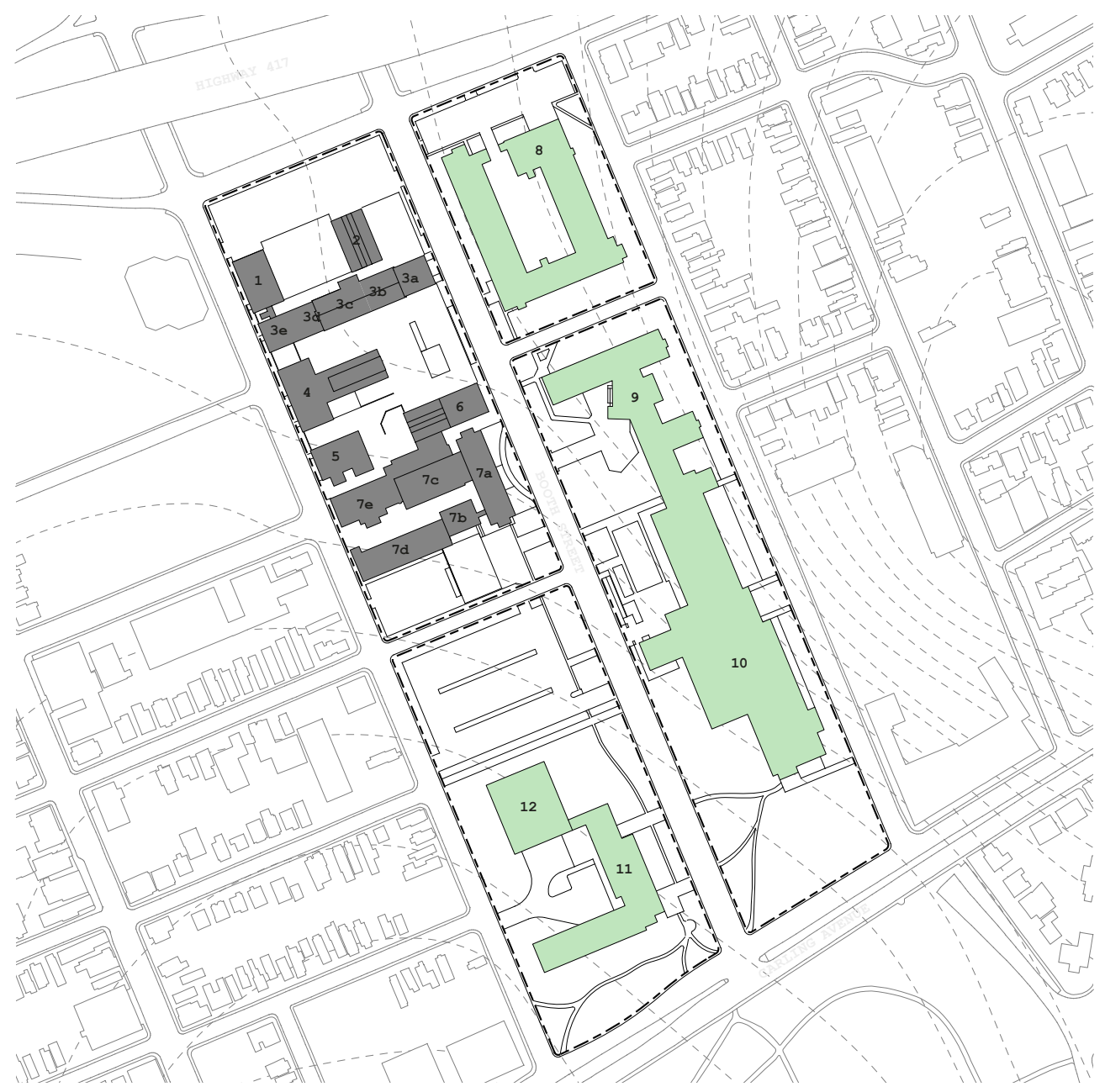

Figure 3.02: Pre-Disposal Life-Cycle Phase c. 2011

(by Author)

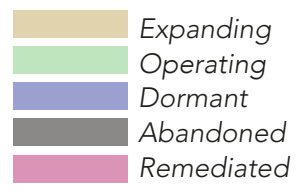




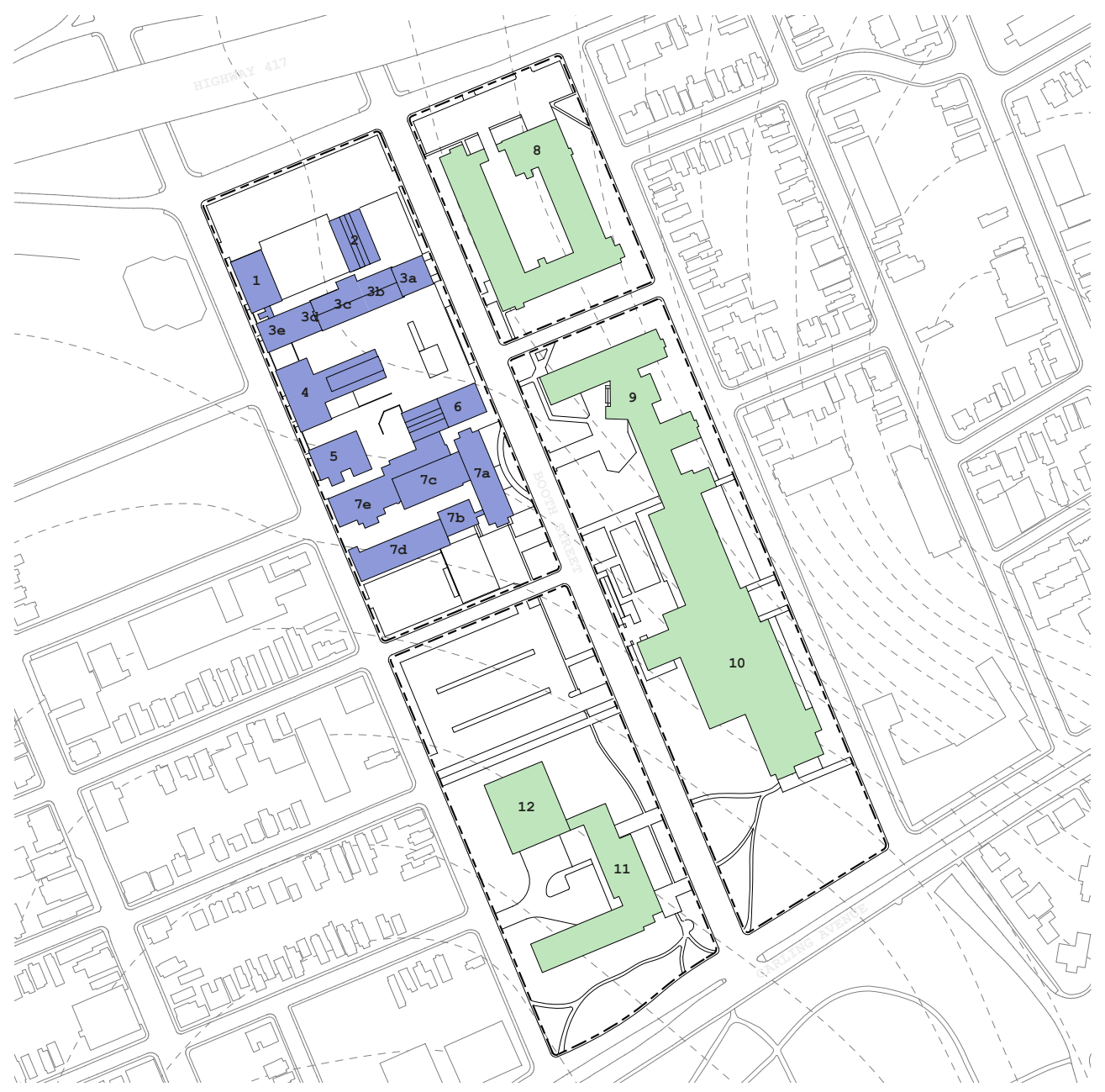

Figure 3.03: Mid-Disposal Life-Cycle Phase c. 2019

\begin{tabular}{|l|}
\hline Expanding \\
\hline Operating \\
\hline Dormant \\
Abandoned \\
Remediated
\end{tabular}




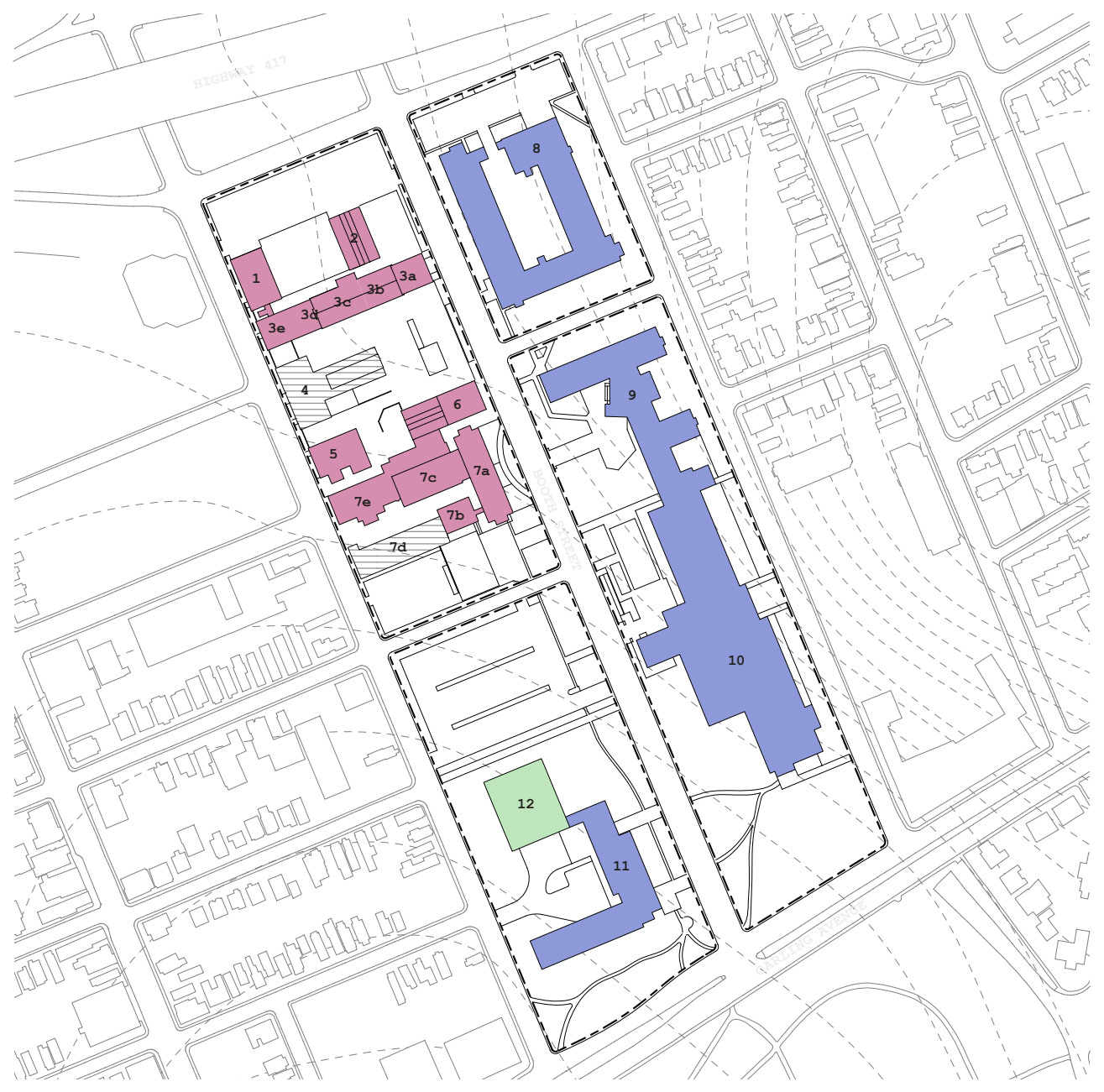

Figure 3.04: Projected Post-Disposal Life-Cycle Phase c. 2030

\begin{tabular}{|l|}
\hline Expanding \\
\hline Operating \\
\hline Dormant \\
Abandoned \\
Remediated
\end{tabular}


Firstly, the phase of 'abandonment' is in no way a sustainable concept. Although in several ways the status is better than the idea of demolition, by definition, abandonment suggests a lack of maintenance, and correlated losses of function and desirability. As per the derived definition: abandonment means that there are no plans for cleanup, remediation or reuse, inferring that there are high probabilities of degradation and pollution. Moreover, while abandoned, the building or structure is not contributing to justifying its embodied energy. For these reasons, it was decided that the phase of 'abandoned' was not an appropriate status and would therefore not be applied within the proposal.

The application of the phase titled 'dormant' also presented some issues. Like abandonment, prolonged dormancy increases the risk of degradation and also increases the justification period of embodied energy. If the site or building is not frequently monitored, it is likely that some type of mechanical or performance issue will arise. To correct this issue, within the proposal's phases, the status of operating and dormant have been merged. A rotational period of dormancy will allow an operating building to undergo routine maintenance, repair and ideally continual rehabilitation. Dependant upon building size and function, there might be a variety of rotational time frames. In laboratory type buildings, with constant technological advancements, the dormant period would have to be more frequent than that of an office building - for example.

'Remediated' was also decidedly not the appropriate phase term. To remediate is the action of remedying something, or of reversing or stopping environmental damage. To many people this would suggest preexisting contamination, pollution or decay - conditions which may or may not be present. To remove preconceptions, 'Remediated' has been replaced with the term 'adapted'. Adapted is understood as modified but with a purposeful and beneficial outcome. Within the scope of this thesis - adapted encapsulates a variety of treatments: preservation, restoration, and rehabilitation as well as all their sub-treatments.

After refinement, the phase descriptions were updated to:

1. Expanding: the site [or building] is operating at full capacity with plans to increase in magnitude, to escalate production, or to boost intensity [in similar activities].

2. [A] Operating: the site [or building] is currently extracting, processing, or refining materials [occupied and productive], with no plans to increase or decrease in magnitude. The site is stable, with 
plans to continue at the current performance level.

2. [B] Dormant: the site is not operational but is [either, regularly] maintained to retain and preserve a potential for future reignited operations [or is paused is operation to allow for periodic rehabilitation]

4. Abandoned: the site has been deserted with no plans for cleanup, remediation or reuse.

5. Remediated [Adapted]: the site is, or has, undergone eleanup to reverse envirenmentalimpacts from earlierindustry. Theremediation eould be preparatery work for reuse or disposal. [a transformation with the objective of reestablishing operations, facilitating new use, or accommodating required change]

\subsection{The Macro Site Proposal}

Taking into consideration, the extrapolated future of the Booth Street Complex, its current material conditions and its potential for reuse, figure 3.05 illustrates the proposed application of the life-cycle phases.

As presented, the north-west quadrant, currently undergoing property disposal and awaiting redevelopment, has been highlighted with an overall approach of adaption. The other three quadrants, the north-east, south-east and southwest, have been highlighted with an overall approach of operational and dormant meaning the latter design interventions — described within Chapters VIII and IX — takes place within the 'adapted' north-western quadrant only.

Not only has the methodology of rationalizing subsequent intervention via this type of relative landscape research shown to support tangible site longevity, but the methodology has also supported the interpretation of the complex. By examining the larger body of places which, in tandem with the Booth Street Complex, generate the industrial and post-industrial landscape of Canada, a deeper understanding of the heritage place has been acquired. Interpretation resurfaces as a point of discussion within Chapter VIII. 


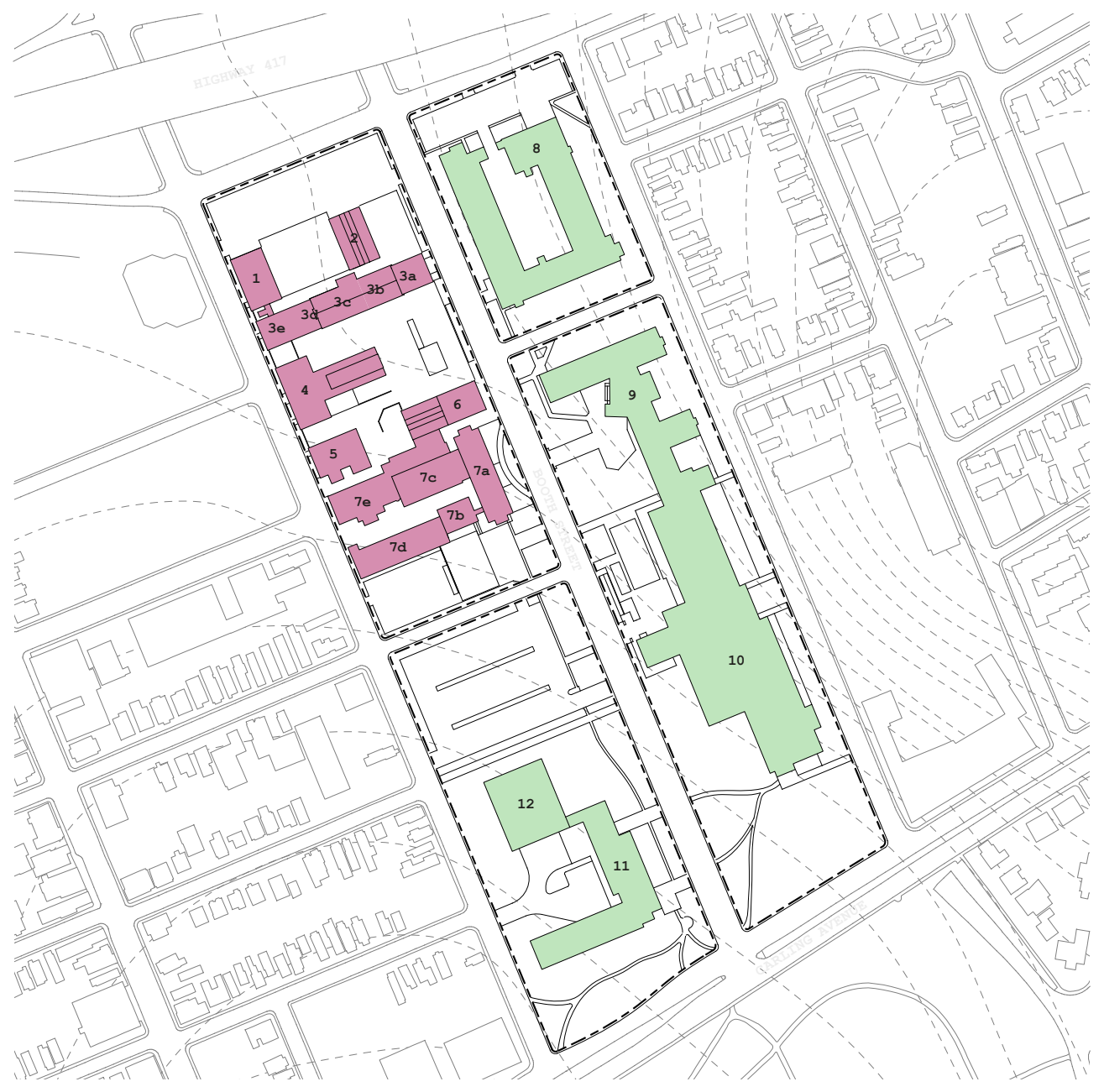

Figure 3.05: Proposed Life-Cycle Phase Landscape Design Approach

Expanding

Operating + Dormant

Adapted 


\section{Chapter VIII}

\section{Mezzo Design Approach: Site as Post-Industrial Complex}

Chapter VIII is written with the intention of resolving the proposal of 'Secondary Exploits' to the scale of the complex - the deliberate grouping of buildings and structures which, with purposeful organization and partnership, constitute the architectural complex.

This complex-scaled resolution of the proposal is referred to as the mezzo design approach. Found between the concept of macro and micro, mezzo as a term refers to the middle territory. With respect to architectural design, the term mezzo indicates an idea grounded at the resolution of a building grouping rather than a landscape or an individual material component. In addressing this, the mezzo design approach of the Booth Street Complex considers site programming, interpretation and building organization for the portions of the site labeled as 'adapted' within the macro proposal for the north-west quadrant.

\subsection{Overall Design Objectives and Approaches}

At the outset of the design plan, there were four primary objectives set in response to the site's history, use, and associations; set to conceptually guide the proposal:

i. To reconcile the environmental impacts of:

+ Prolonged building vacancy

+ The associated extraction industry

ii. To create stewardship for post-processed materials

iii. To extend the life-cycles for the existing architecture

iv. To disseminate skills and knowledge about sustainability and heritage to project users. 
To achieve this, the following complex-scaled approaches were adopted:

i. Allow for the secondary and post-industrial exploit of:

+ Embedded material value

+ Embedded heritage value

ii. Maintain integrity of the architecture and plan new use according to existing conditions

iii. Comply with the Dublin Principles:

\subsection{Program Proposal}

\section{Alignment of Design Objectives and Programming}

As a counterproposal to the mixed-use development posed by Canada Lands Corporation, this thesis poses a more sustainable, historically sensitive, compatible and functionally appropriate alternative. As opposed to the suggested retail and residential programming, the proposal of 'Secondary Exploits' is an architectural salvage yard and a material restoration complex, which together work in tandem to create a place of material and knowledge sharing. By maintaining the semi-industrial nature of the complex, there will be a smooth architectural transition and a close lineage to historical use.

The programming of a salvage yard and restoration complex align seamlessly with the predetermined primary objectives as previously listed, and is a compatible new use.

Programming as an architectural salvage yard and restoration complex contributes to the first objective - a reconciliation of the environmental impacts of prolonged building vacancy and the associative extraction industry - in a twofold manner.

Industrial extraction is a societal process which involves the forceful removal and relocation of naturally occurring resources. Conceptually, this process can be countered and reconciled by the action of replenishing and reinstating said exploits. Within an architectural salvage yard, it is argued that these reconciling actions equate the stockpiling, collecting and mending of architectural building components. By storing the discarded but valuable materials on site, the yard itself becomes the antithesis to the original extraction site. The salvage yard is the site of secondary extraction ... of tertiary extraction and so on. Where it cannot reverse the initial extractive action, it can prolong the material's functionality and negate the need for another primary site of extraction. 
The second objective: to create stewardship for post-processed materials also aligns with the proposed programming. Unlike the previous objective, the salvage yard programming achieves this in a much more pragmatic way. By facilitating material reuse through salvage and restoration, the idea of an architectural salvage yard is ideal. Within the general region of Ottawa, there are no architectural salvage yards which operate at the same scale nor which are designed to accommodate similar material intakes. There are numerous smaller-scale operations which accept either lightweight elements or heavy materials individually, but none can accommodate both. The lack of post-use material reuse infrastructure not only creates a gap in the larger reuse system but limits the ability for Ottawa's construction field to transition to a more circular economy. Ultimately, 'Secondary Exploits' and its program is posed as a solution to this obstacle.

Extending the life-cycles for the existing in-situ architecture was an additional objective. Moreover, it was not only a desire to extend their life, but to do so in a manner which is appropriate in terms of the heritage of the complex. The Dublin Principles state that finding a new use which is compatible with the existing fabric is paramount. Compatibility allows for a less invasive intervention and improves the place's successful interpretation potential. By proposing a new program which takes advantage of existing conditions and context, a conservation treatment of rehabilitation was selected, therefore extending the life-cycle of the existing architecture.

An architectural salvage yard is a compatible program to be applied to the Booth Street Complex in that the spatial conditions and relationships already in place easily transition from the original function to the proposed function. The mix of industrial workspaces in combination with the dispersed office programming is architecturally co-operative.

The final objective: to disseminate skills and knowledge about sustainability and heritage to project users, also aligns with the proposed programming of an architectural salvage yard and restoration complex in that both elements include an educational overlay, pertaining to ideas such as reuse, recycling, embodied energy, and the circular economy.

\section{Determining Program Elements}

Every city has a micro-economy of material reuse dependent upon the existing reuse infrastructure and the available resources within the local building stock. To determine the materials most common within the Ottawa material economy would be a significant undertaking and was beyond the scope of this 
thesis, however, based upon the composition of the surrounding built fabric, assumptions were made. It is assumed that because the predominant building materials nearby are brick, wood, steel, and concrete, these materials will be the main constituents of the salvage yard.

Based upon this assumption, the preexisting organizational scheme of opalis (precedent c) and the known historical uses of individual buildings within the Booth Street Complex, the proposed material categorizations are:

- Structural and Dimensional Elements

- Masonry and Ceramic Units

- Large Architectural Features

- Large Ornament

- Cladding

- Envelope Features

The salvage yard will therefore be able to intake, process, store and disperse materials in these categories.

Given the existing spatial arrangement of the complex, the materials are grouped on site for processing into: Masonry, Wood, Steel, and Plastics and Ceramics. Figure 3.09 illustrates the designated complex areas for each of these material types. In terms of the logistical program needs, the following requirements were set:

Architectural Salvage Yard:

- Retail Outdoor Lot

- Retail Indoor Lot

- Retail Semi-Protected Lot

- $\quad$ Large Drop-Off Zone

- Small Drop-Off Zone

- Sorting Areas

- Disposal Zone

- Staff Facilities

Educational Programming:

- Exhibit Space

- Lecture Room

- Classrooms x2

- Work Area

- Observation Deck

- Material Archives

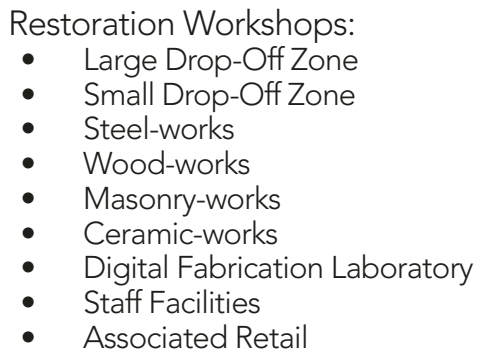

- Associated Retail

Artisan Complex:

- Rental Studios

- Material Storage

- Exhibit Space

- Supply Storage

- Material Disposal

These program requirements are a broad overview; the full program resolution and spatial interplay can be seen in figures 3.10 - 3.18. 


\subsection{Interpretation}

To take full advantage of the educational and cultural enrichment potential of the Booth Street Complex, and to ensure its appreciation, a thorough interpretation schematic was developed to help support overall design decisions and the architectural intervention.

Recalling the ICOMOS definition and principles of interpretation, as a concept which refers to the full range of activities intended to heighten public awareness and enhance understanding of the cultural heritage site, this thesis employs numerous interpretation techniques. Within the design proposal, via the selected conservation treatments, the inclusion of interpretive infrastructure and purposeful presentation, both the heritage of the Booth Street Complex as well as its proposed sustainability initiatives are shared, displayed and imparted to site visitors.

\section{Interpretation via Rehabilitation, Adaptive Reuse, and Deconstruction}

Given the large scale and prominence of the Booth Street Complex within its direct context as well as its visibility from Carling Avenue and from the adjacent 417 highway, the site has the potential to present itself to many passersby. By implementing a primary conservation treatment of rehabilitation, which embraces the new programming, through adaptive reuse and deconstruction, the site's sustainability objectives are architecturally displayed.

Both techniques, adaptive reuse, and deconstruction are visually evident treatment types - likely techniques that the community members and site visitors will take note of. By drawing the visitors attention to the fact that the property is being reused, the message of building retention and heritage conservation is indirectly presented. Likewise, the visible presence of building deconstruction will spark curiosity. To do this, the proposal retains as much historical architectural fabric as possible, adjusting the new interventions around existing elements and distinguishing between existing and new components.

Adaptive Reuse is employed within this thesis with a primary motivation of extending the complex's functionality by way of not only rehabilitation but also as a part of the site's overall interpretation scheme. As a design strategy, it can be used to point out change. By presenting architectural change through distinguished materiality or form, adaptive reuse makes visitors aware of the sites histories - it alludes to what was in existence before and contributes to a deeper understanding of site. 
Building deconstruction is being employed within this thesis with two driving motivations. The first motivation is to ignite the programming of the salvage yard by sourcing materials in-situ. As evident in figure 3.18, there are four areas of building partial building deconstruction within this proposal. The site prominence of the partial deconstruction reinforces the concept of material re-usability and conveniently supports the programming function.

A second motivation of both treatments was to provide a teaching opportunity for on-site education, focused on material restoration, assembly repair, building deconstruction and overall material conservation. Visitors will be able to see first hand how buildings are 'un-built', how certain material assemblies are preserved, and how the deconstructed materials can be salvaged.

Although these treatment types do not speak directly to interpretation by way of direct dissemination, they do boldly convey the site's heritage and new message of reconciliation and sustainability - critical messages relevant to understanding and appreciating uniqueness.

\section{Interpretive Infrastructure}

With the intention of facilitating on-site education about deconstruction, extraction and the site's heritage, as well as to increase the public accessibility of the complex, interpretive infrastructure is introduced by way of catwalks, terraces, storefront conditions, and exhibition spaces with the specific intention of knowledge dissemination.

The steel catwalks proposed within the design, draw inspiration from those already in existence within the complex. There are existing catwalk conditions within the central heating plant and several buildings within the Ore Dressing and Metallurgy Laboratories. These preexisting conditions were not only maintained, but they were enhanced by reinstating functionality.

Publicly accessible terrace and mezzanine conditions are introduced across the complex to provide viewing areas from which visitors can see the ongoings of the main outdoor salvage lot. This allows visitors to better understand the operations necessary for material reuse and enhances the overall educational experience of the design.

Lastly, storefront conditions and public exhibition spaces are introduced to draw visitors into the complex and spark curiosity. Aligned to Rochester Street, this move improves the site's conceptual accessibility. 


\section{Presentation akin to Double Exposures}

As a somewhat early exercise within the thesis research and documentation of site history, a series of 'double exposure' photographs were crafted (Figures 3.06 - 3.08). The photos combine analogue contemporary film photography and composite historical images archivally sourced.

Although they are not true double exposures, in that both images are not photographed upon the same negative film frame, the resultant composite images capture two distinct subjects in a single image. The intent of the exercise was to illustrate the significance of the Booth Street Complex by depicting contrast between the complex's conditions and the conditions of the related industrial landscape of Canada.

The first 'double exposure' (Figure 3.06), contrasts the architectural magnitude Geological Survey and Mapping Building with the realities of the department's field surveyors during a Northern Expedition. The archival image is dated 1904, where the contemporary photograph was taken in 2018.

The second double exposure (Figure 3.07), depicts the Booth Street Complex's Ore Dressing Laboratory, sited upon the parcel of land initially acquired by the government for the since-demolished original, Fuel Testing Station. The archival image, dated 1923, of manual laborers along the shores of the Athabasca River. Upon their backs are bags of sand saturated with bitumen, likely to be sent for testing, perhaps to the Booth Street Complex.

Lastly, the third double exposure (Figure 3.08) contrasts the decorative main entrance to the Ore Dressing Laboratory with the mechanized lifts in use at Jeffrey Mine c. 1934.

The double exposure photographs were not only a useful exercise within the scope of this thesis, but because they convey the associative value of the Booth Street Complex, they would also be a useful method of interpretive presentation. For this reason, within the proposal, it is suggested that similar models of presentation be integrated into public spaces such as exhibit spaces, and catwalk infrastructure. Similar applications could be displayed according to location, context, and setting, to illustrate the history associated with a particular place within the complex. 


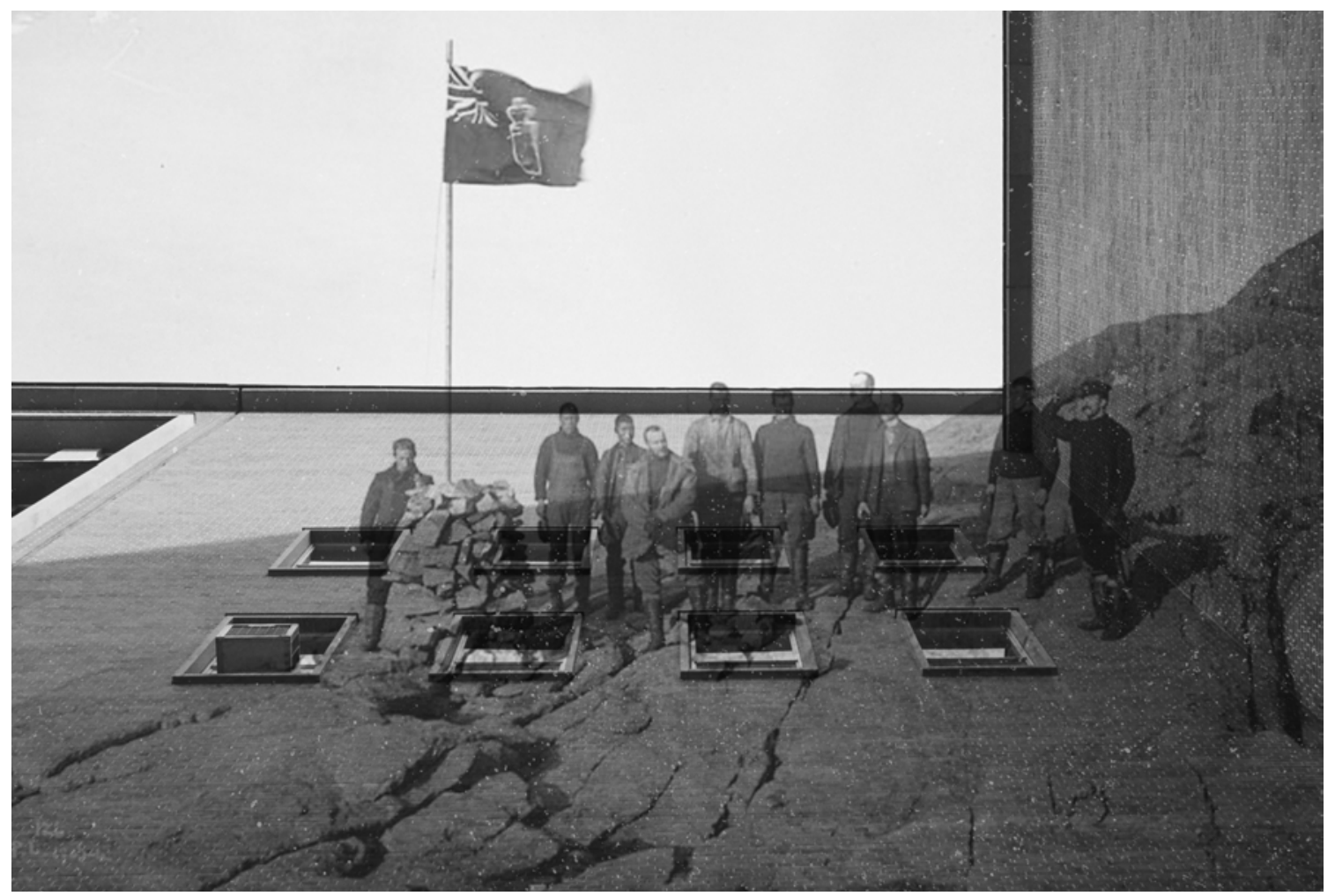

Figure 3.06: Double Exposure 1 - Geological Survey of Canada 


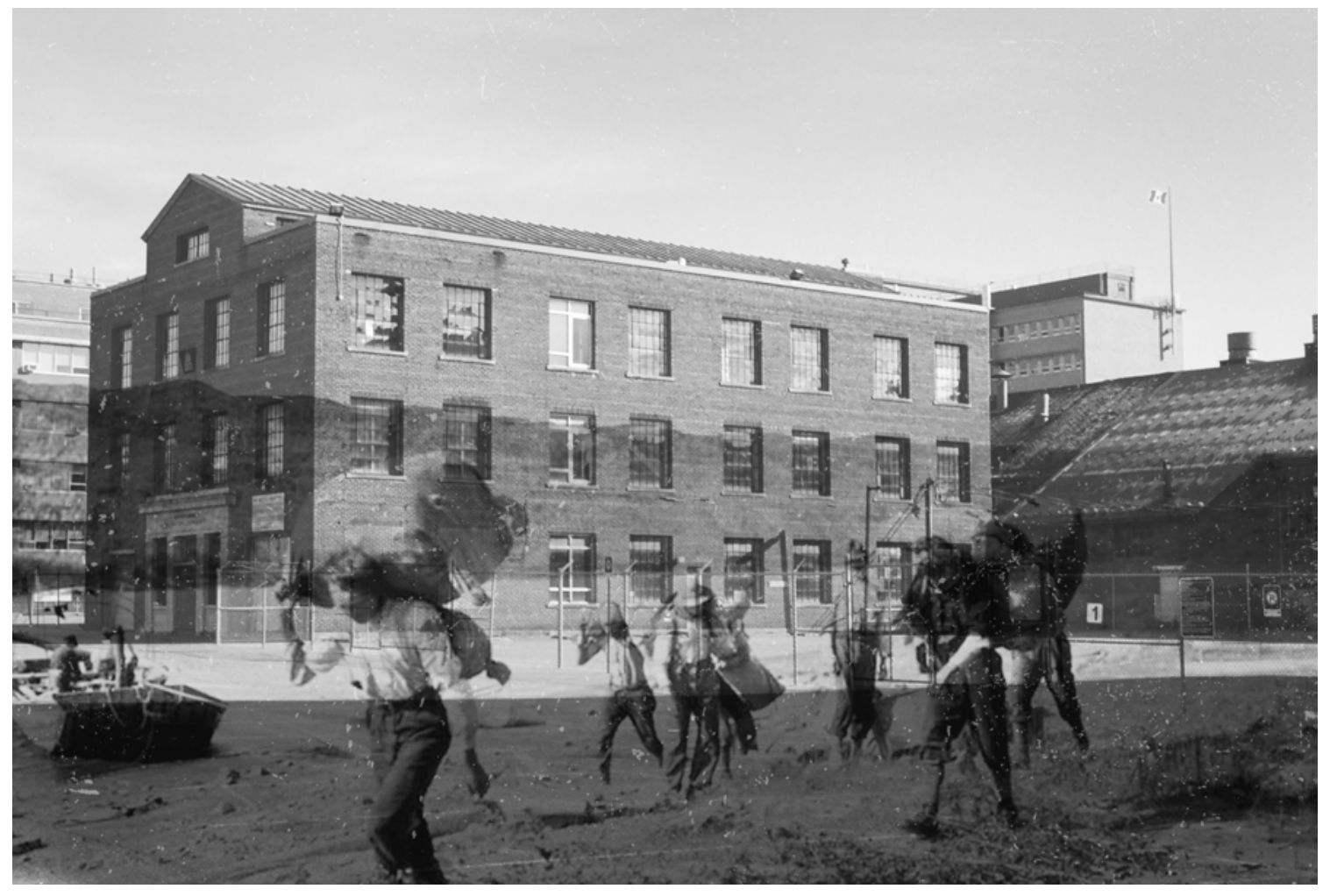

Figure 3.07: Double Exposure 2 - Fuel Testing Division 


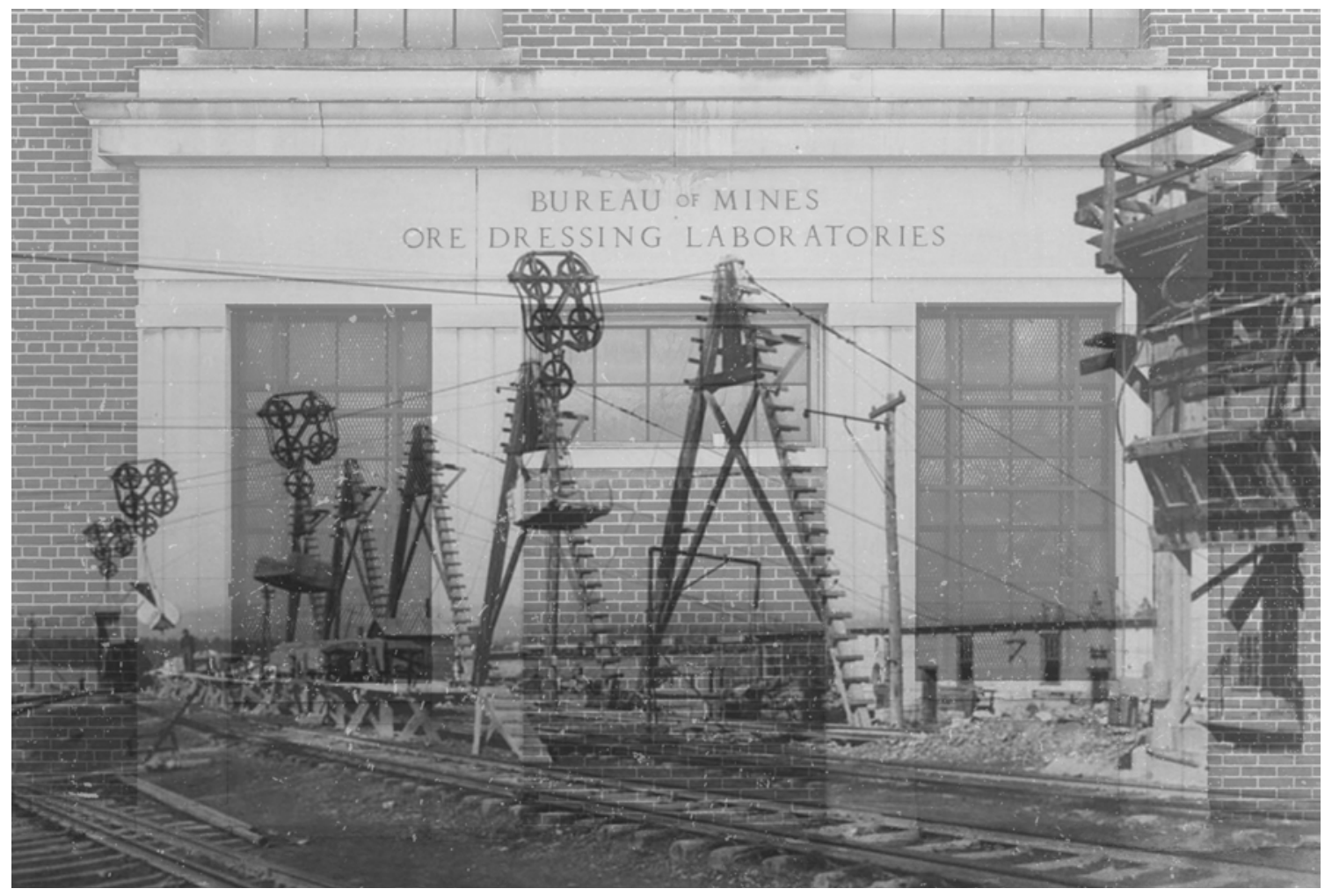

Figure 3.08: Double Exposure 3 - Ore Lifting and Dressing 


\subsection{Building Organization and Architectural Gestures}

There are three main architectural ideas which dictated a majority of the architectural intervention details:

1. To increase vehicular circulation to facilitate salvage yard function

2. To improve East-West site permeability

3. To create a central Salvage Lot Zone (Outdoor/Covered/Indoor)

After this overarching logic had been configured, the program was sorted within the complex - each building being roughly dedicated to a single material or purpose. The general organization is as follows:

Ore Dressing Laboratory:

Architectural Salvage Yard + Restoration Workshops

Industrial Minerals and Ceramics Laboratory:

Architectural Salvage Yard + Restoration Workshops

Ore Dressing and Metallurgical Laboratories:

Architectural Salvage Yard + Restoration Workshops + Education

Fuel Research Laboratories:

Restoration Workshops

Mechanical Shops and Stores Building:

Architectural Salvage Yard + Education

Physical Metallurgy Research Laboratories:

Architectural Salvage Yard + Education + Artisan Complex

Central Heating Plant :

Education

Site Infill:

Architectural Salvage Yard + Public Domain

\subsection{Architectural Drawings}

Following are the architectural plan drawings which convey the site organization. (refer to figures 3.10 - 3.18) 


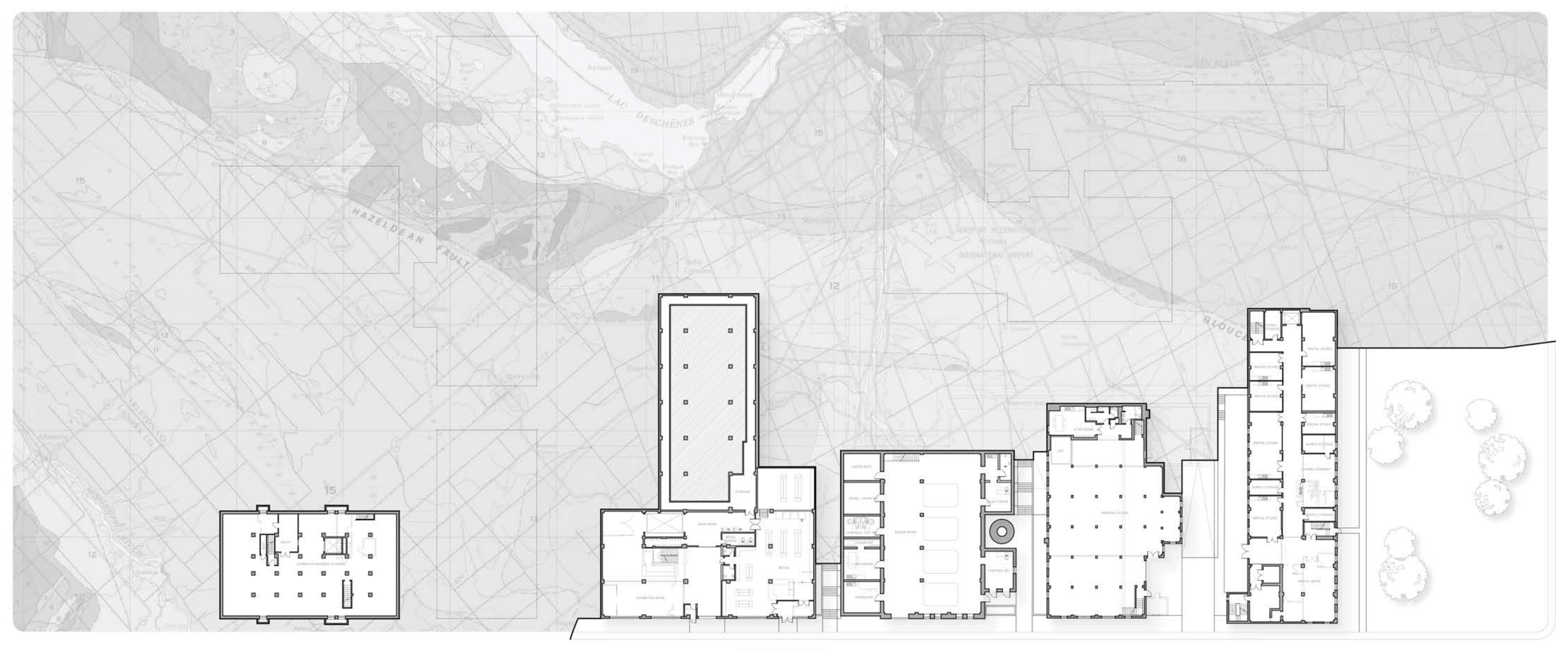




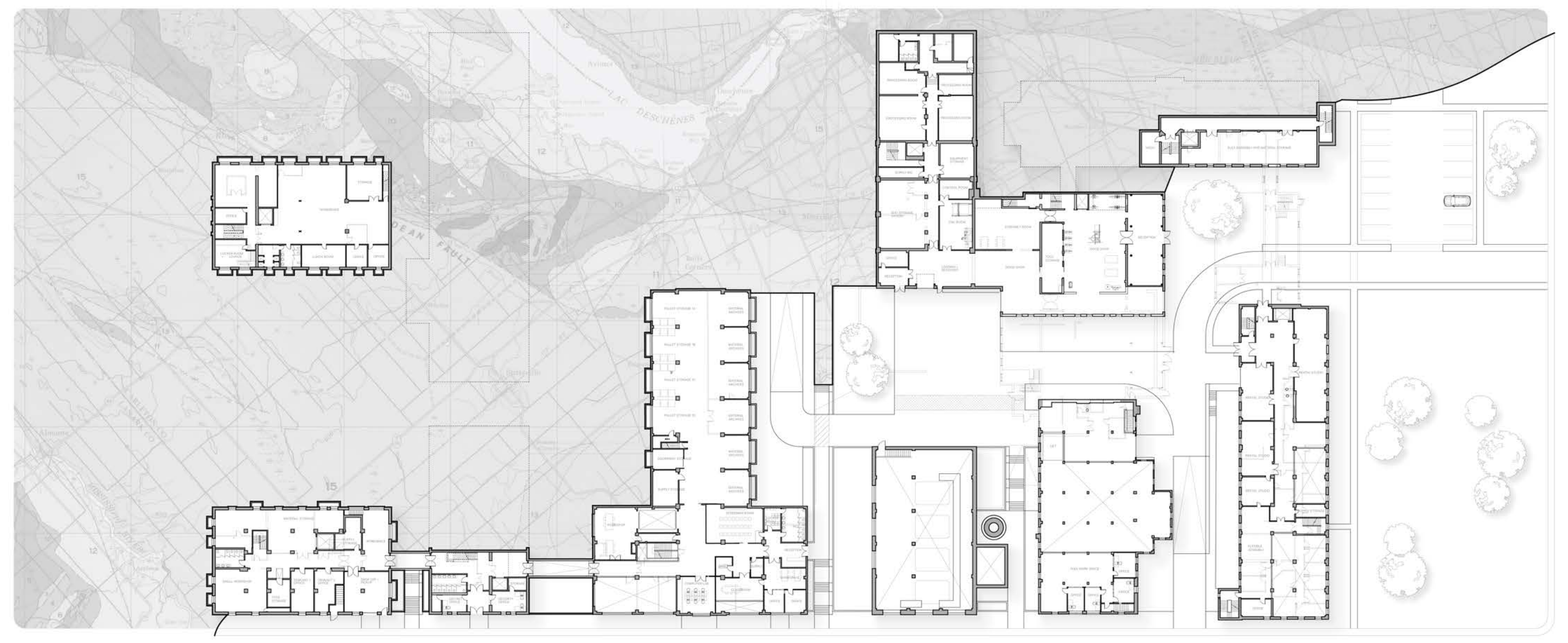




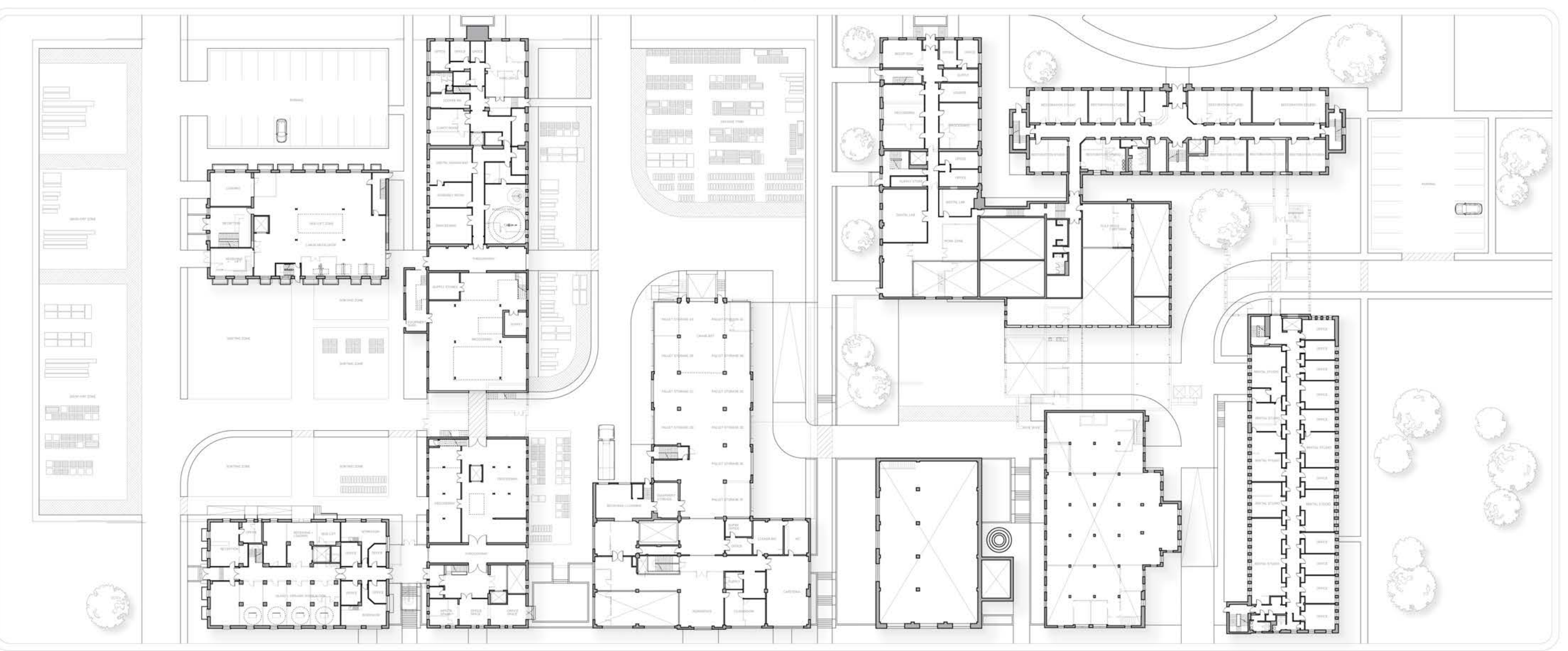



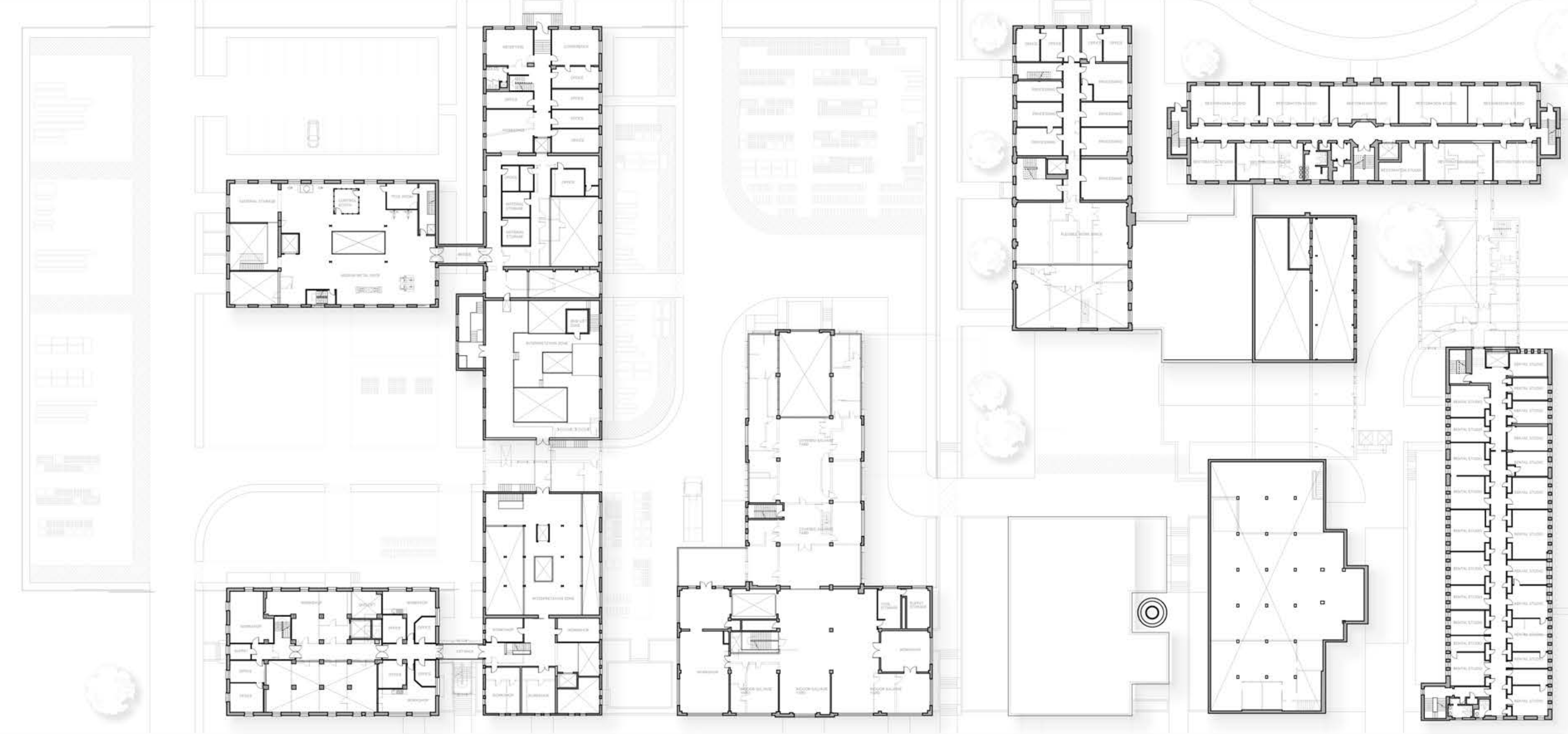


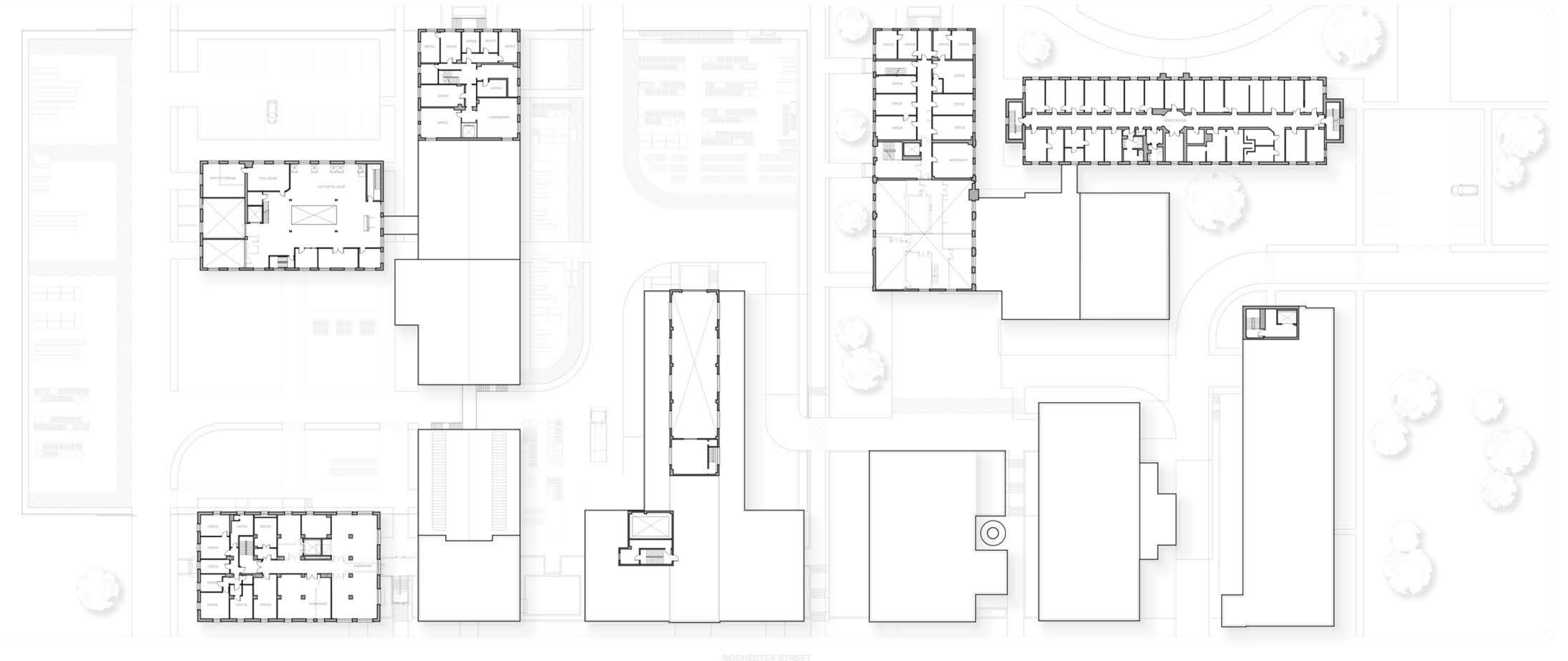




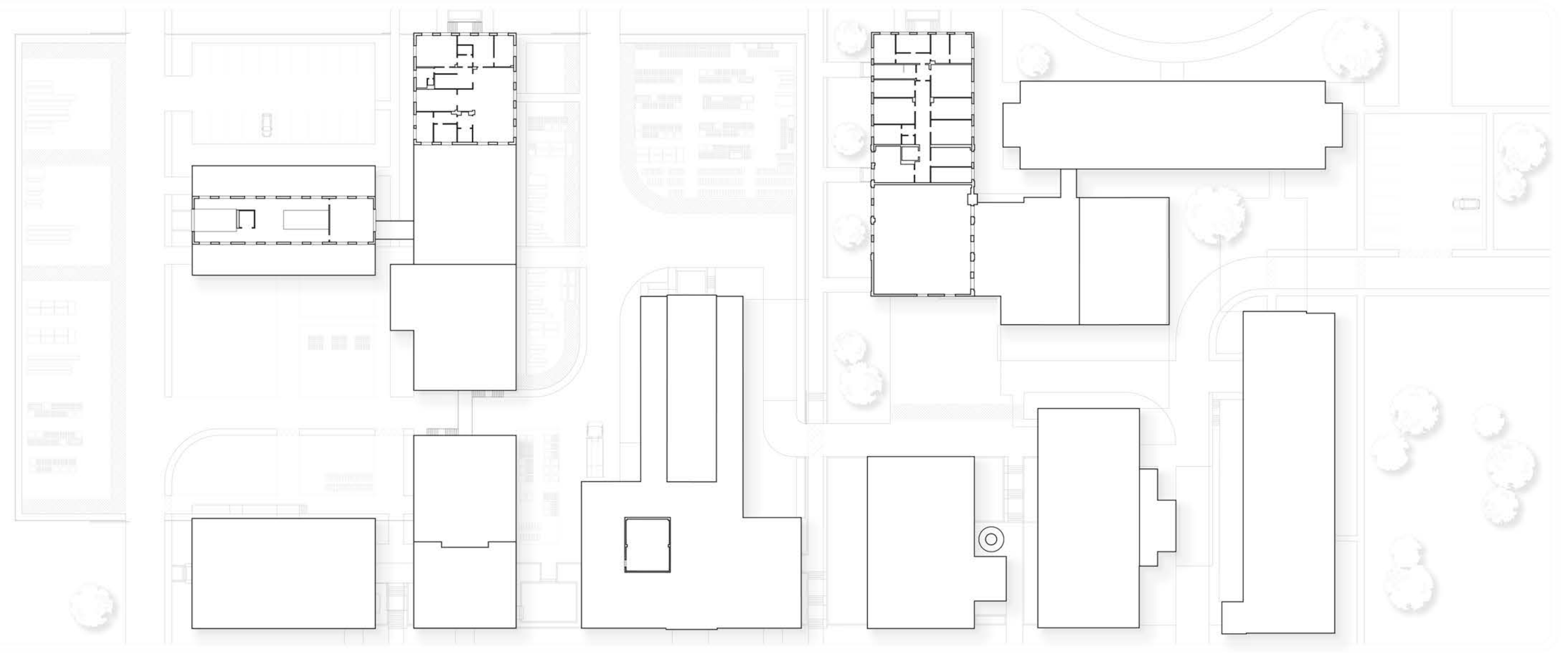




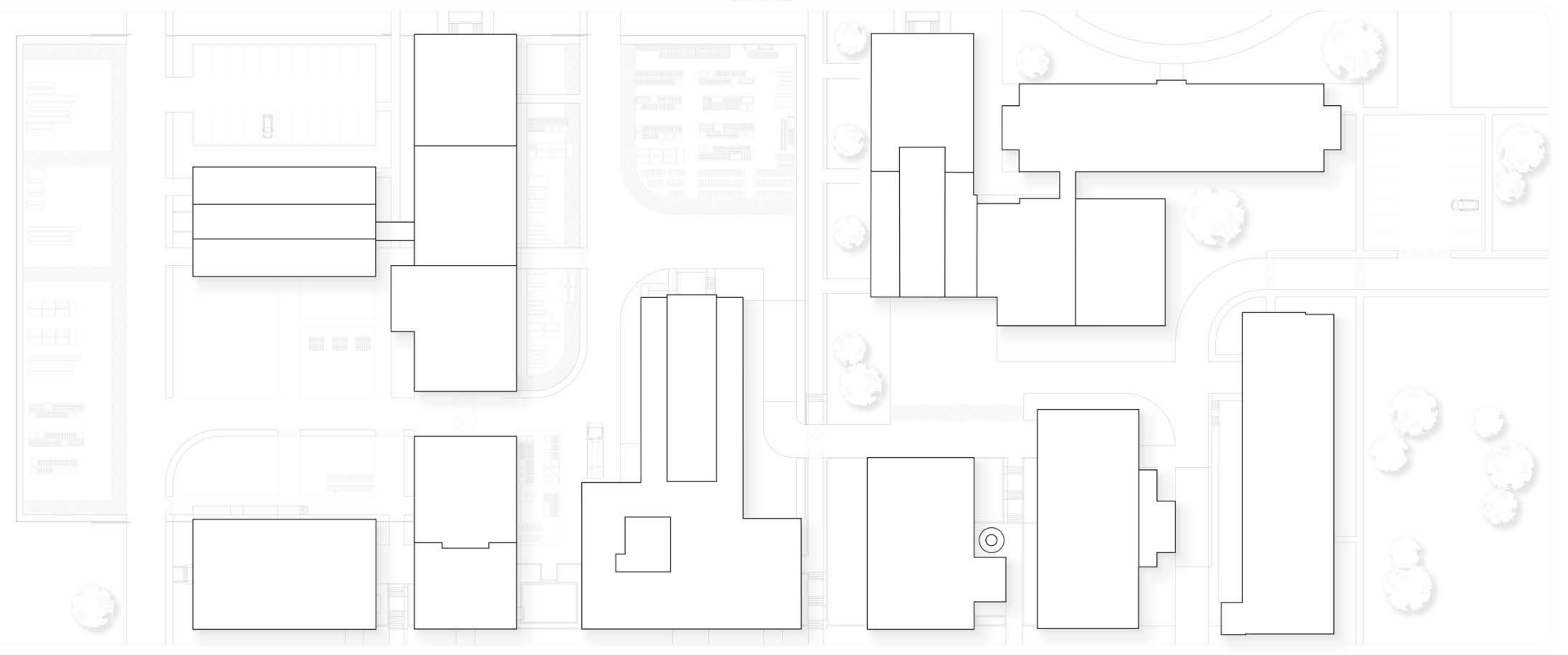




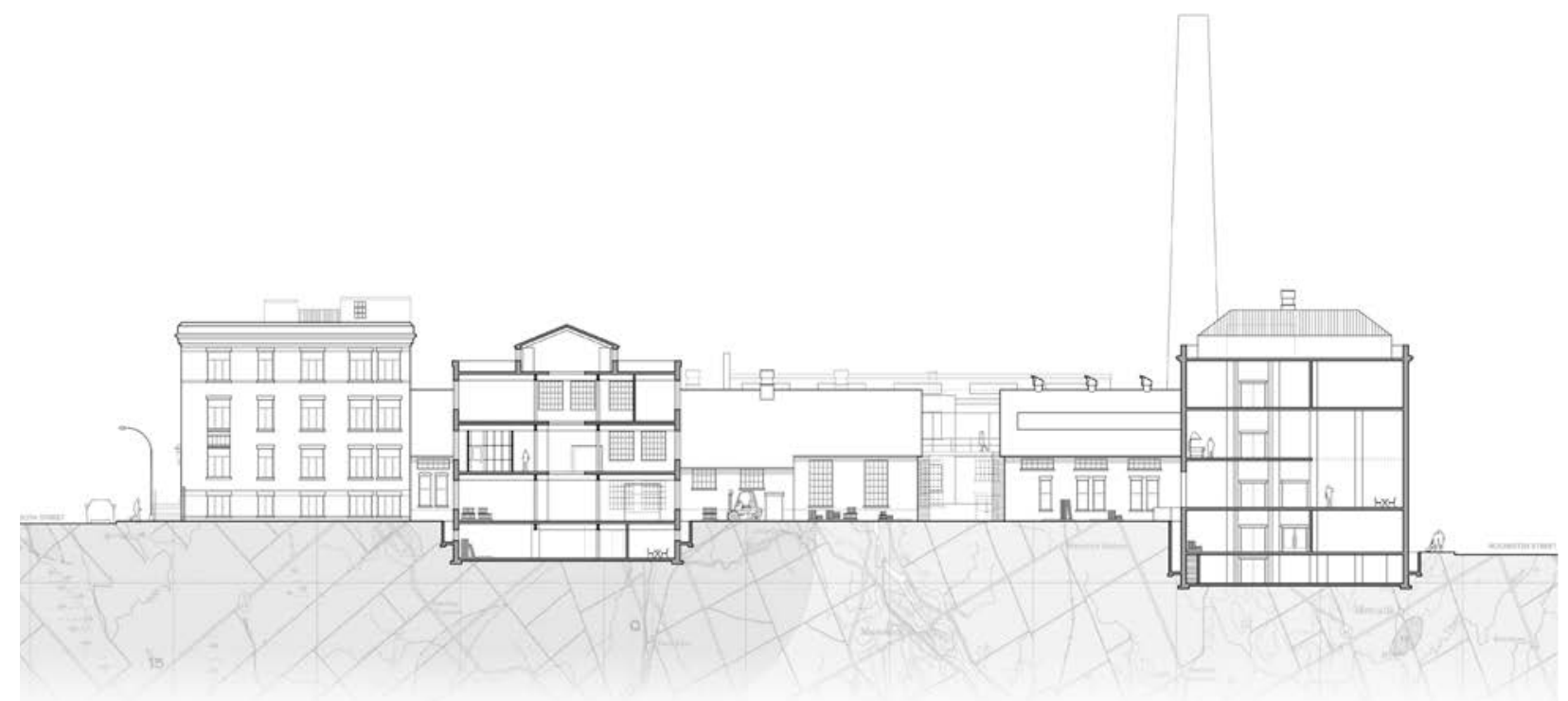

Figure 3.16: Section Drawing A

1:750 


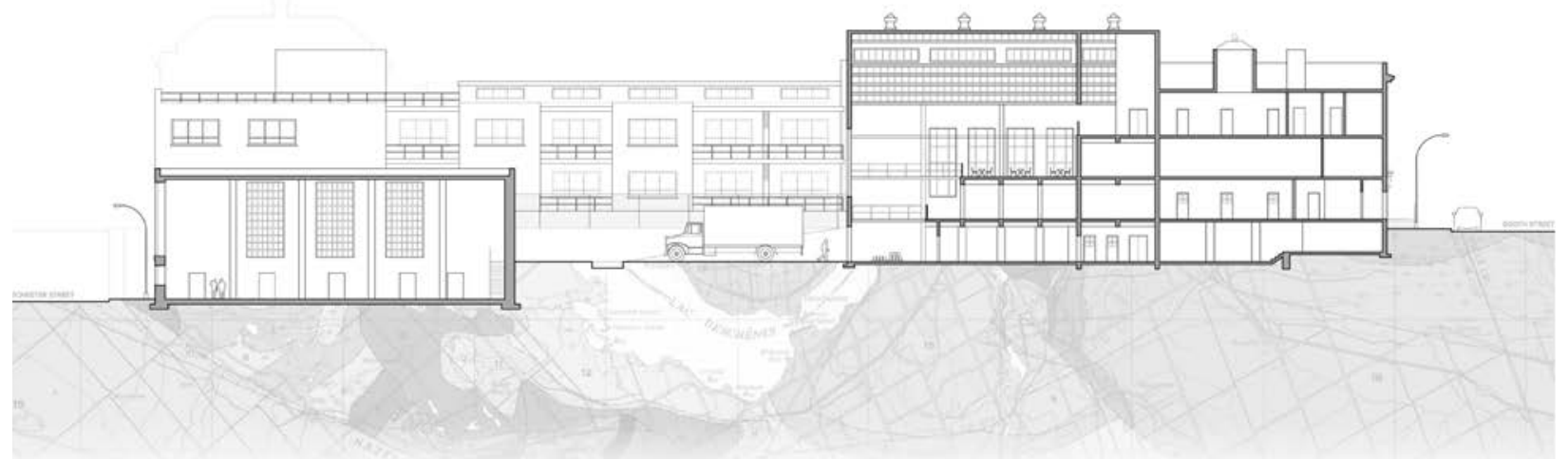

Figure 3.17: Section Drawing B

$1: 750$ 


\section{Chapter IX}

\section{Micro Design Approach: Site as Material Assembly}

Chapter IX is written with the intention of resolving the proposal of 'Secondary Exploits' at the scale of a material assembly and refers mainly to concepts discussed within Chapter II.

This material-scaled resolution of the proposal is referred to as the micro design approach and therefore focuses upon, deconstruction, material quantifications, material cycles and material treatments. The approach answers questions such as: How are the existing assemblies being retained, maintained or enhanced? Where do the deconstructed materials end up? What happens to the surplus materials? What parts of the design intervention are original, which are new?

As highlighted in earlier Chapters, the primary conservation treatment type of the proposal is rehabilitation - a treatment associated with minimal architectural interventions which are only introduced when necessary to allow reuse. Minimal intervention, which suggests material stabilization and mandatory assembly upgrades is most commonly employed within the design, but in favor supporting and facilitating the salvage yard operations, deconstruction is posed as an alternative to demolition. This will be the focus of this Chapter.

\subsection{Rationale of Deconstruction}

Second to assembly, stabilization, and reuse, deconstruction is a prominent material approach within the 'Secondary Exploits' design proposal. Of the 17 existing buildings within the north-west quadrant, the design proposal suggests three partial buildings to be fully deconstructed and one building to be slowly deconstructed overtime.

Deconstruction is a controversial idea within the realm of architectural conservation because it involves the removal of existing fabric and the 
fragmentation of possible heritage value. That being said, deconstruction still presents itself as a beneficial endeavor compared to demolition, in the face of heritage loss. As Chapter II describes, deconstruction is a way of exploiting the existing material stock rather than destroying it. Deconstruction as a material treatment also strengthens the conceptual basis for the entire project with regards to functionality and interpretation.

Heritage loss is a reality faced by many federal buildings located upon prime urban property. The Canadian government is increasingly furthering itself from property ownership. By increasingly disposing of departmentally owned buildings and transitioning to lease agreements, the government is liquidating its assets and disposing of heritage properties.

In the case of the Booth Street Complex, whether it will be caused by redevelopment and gentrification or demolition by neglect, heritage loss is likely inevitable for the site. In addition to those buildings already slated for removal within the CLC planning rationale for the north-western quadrant, it is probable that the buildings of 555, 588, 601, and 615 Booth Street will face similar fates. Given its central location and low density, the government is actively trying to capitalize on its asset; labeled as a 'strategic disposal', the motivation of the complex's rezoning is to turn top profits in sale.

Chapter $\mathrm{VI}$ explains the recent proceedings regarding the formal heritage protection for a portion of the Booth Street Complex under the Ontario Heritage Act. It is important to note that although the north-west quadrant is protected as a 'designate complex', there are only specific buildings within which, that are recognized as having heritage value and furthermore, that it is only the exteriors of said buildings which will be protected.

The counter design proposal of 'Secondary Exploits' takes the existing heritage designations into consideration, recognizes the overall site character, and examines the quadrant's flexibility to accommodate future uses within the design and ultimately proposes one of the same removals as the CLC planning rationale, alters the location of another, and retains a building otherwise slated for demolition. The buildings to be fully, partially or gradually deconstructed with the design proposal are illustrated in figure 3.24. Portions of the Physical Metallurgical Research Laboratories will be fully deconstructed to improve site circulation and accessibility; a portion of the Hydro Metallurgical and Pyro Metallurgical Laboratories will deconstructed for the same the reason; and the eastern portion of the Mechanical Shops and Stores Building will be gradually deconstructed over several years. 


\subsection{Reclaimed Materials for Salvage}

In addition to the four locales of deconstruction within the Booth Street Complex, any altered building interiors will also be deconstructed, generating a significant amount of reusable materials. Figure 3.18 represents the estimated salvage material quantities sourced from the project itself as well as 'how much' and 'what' is being reused on site versus that which will be placed in the salvage yard for repair and resale.

Generously funding the initial material stock for the on site salvage yard and the restoration facilities, the deconstruction also provides a plentiful stock of materials to be used directly within the proposal's intervention. Wherever possible, the design proposed reuses fixtures and baseline dimensions in new interventions, favoring reuse within the same building first, then reuse within the complex second.

Within the architectural drawings included within the previous Chapter, the deconstructed components are illustrated along with the existing conditions and intervention. (Figures 3.10 - 3.18)

\section{Material Cycles}

Following the construction of the proposed thesis design, the Booth Street Salvage Complex would intake salvage and reclaimed materials from other regional sites in addition to stockpiling the deconstructed materials from insitu. There will therefore be four possible material flows through the complex assuming regular rehabilitation and a period of rotational dormancy.

- Materials Sourced On-site and Reused in design of 'Secondary Exploits'

- Materials Sources Off-Site and Reused in design of 'Secondary Exploits'

- Materials Sourced On-site and placed into Salvage Yard

- Materials Sourced Off-site and placed in Salvage Yard

To source on-site and reuse on-site without drastic transformation is the most favoured material flow in that there is the least amount of energy required to transport the materials and that a higher degree of associative heritage value is retained. The less favoured material flow would be to source-off site and reuse off-site with major transformations because this equates the most amount of energy required, and a likelihood that heritage value would be diminished. 


\begin{tabular}{|c|c|c|}
\hline INDUSTRIAL MINERAL \& CERAMICS LABORATORY & ORE DRESSING LABORATORY & ORE DRESSING \& METALLURGICAL LABORATORIES \\
\hline $\begin{array}{l}\text { Concrete Block: } \\
103.4 \mathrm{n} . \mathrm{ft}=1005 \text { units - } 10 \text { pallets }\end{array}$ & Concrete Block: & Concrete Block: \\
\hline $\begin{array}{l}\text { (Glazed) Brick: } \\
561.0 \text { in.ft }=45800 \text { units }=92 \text { pallets }\end{array}$ & $\begin{array}{l}\text { Brick: } \\
263.0 \text { in.ft }=21460 \text { units }=43 \text { pallets }\end{array}$ & $\begin{array}{l}\text { Brick: } \\
658.8 \text { in.ft }=53760 \text { units }=107 \text { pallets }\end{array}$ \\
\hline $\begin{array}{l}\text { windows: } \\
2\end{array}$ & $\begin{array}{l}\text { Windows: } \\
2\end{array}$ & $\begin{array}{l}\text { Windows: } \\
4\end{array}$ \\
\hline $\begin{array}{l}\text { Doors: } \\
9 \text { Right-swing, } 16 \text { Left-swing, } 5 \text { Double } \\
\text { Doors, I Sliding, S } 1 \text { Double-swing } \\
\text { Other: Elevator }(1.6 \mathrm{~m} \times 1.6 \mathrm{~m})\end{array}$ & $\begin{array}{l}\text { Doors: } \\
3 \text { Right-swing, of } 4 \text { Left-swing } \\
\text { Other: Wood Panels }=35 \mathrm{ln}, \mathrm{ft}\end{array}$ & $\begin{array}{l}\text { Doors: } \\
\text { 11 Right-swing, } 28 \text { Left-swing, \& } 9 \text { Double } \\
\text { Doors } \\
\text { Other: Wood Pane1s }=120 \mathrm{ln} \text {.ft }\end{array}$ \\
\hline MECHANICAL SHOPS AND STORES & CENTRAL HEATING PLANT & ESTIMATED COMPLEX SALVAGE TOTALS \\
\hline Concrete Block: & $\begin{array}{l}\text { Concrete Block: } \\
0\end{array}$ & $\begin{array}{l}\text { BRICK: } \\
1035 \text { pallets }\end{array}$ \\
\hline 1325 in.ft $=105985$ units $=211$ pallets & BFICK: & 210 pallets reused \\
\hline $\begin{array}{l}\text { Windows: } \\
29\end{array}$ & Windows: & -104450 units \\
\hline $\begin{array}{l}\text { Doors: } \\
\text { 10 Right-swing, } 26 \text { Left-swing, B Double } \\
\text { Doors, \& I Sliding }\end{array}$ & $\begin{array}{l}\text { Doors: } \\
0\end{array}$ & $\begin{array}{l}\text { CONCRETE BLOCK: } \\
19 \text { pallets }\end{array}$ \\
\hline FUEL RESEARCH LABORATORIES & PHYSICAL METALLURGY RESEARCH LABORATORIES & \\
\hline Concrete slock: & Concrete Block: & $\begin{array}{l}\text { DOORS: } \\
236 \text { pieces }\end{array}$ \\
\hline & 93.8 ln.ft $=911$ units -9 pallets & 59 pieces reused \\
\hline $\begin{array}{l}\text { Brick: } \\
675 \mathrm{ln} . \mathrm{ft}=53920 \text { units }=107 \text { pallets }\end{array}$ & $\begin{array}{l}\text { Brick: } \\
2970 \text { in.ft }=237600 \text { units }=475 \text { pallets }\end{array}$ & \\
\hline windows: & Windows: & \\
\hline & & WINDOWS: \\
\hline $\begin{array}{l}\text { Doors: } \\
\text { 10 Right-swing, } 7 \text { Left-swing, \& } 15 \text { Double } \\
\text { Doors }\end{array}$ & $\begin{array}{l}\text { Doors: } \\
\text { 32 Right-swing, } 28 \text { Left-swing, } 7 \text { Double } \\
\text { Doors, } 55 \text { sliding }\end{array}$ & $\begin{array}{l}110 \text { pieces } \\
26 \text { pieces reused }\end{array}$ \\
\hline
\end{tabular}

Figure 3.18: Salvaged Material Quantification and Reuse Graphic 
Material Treatments: New vs. Old

An important architectural conservation principle is to distinguish between the existing and new architectures, to ensure authenticity and historical legibility. Within the 'Secondary Exploits' proposal, this is accomplished not through new materiality but rather form, construction and tagging.

As outlined within standards ten through twelve of Parks Canada's Standard's and Guidelines for the Conservation of Historic Places, rehabilitation entails specific practices in terms of material authenticity and integrity:

\section{Repair rather than replace character-defining elements.}

Where character-defining elements are too severely deteriorated to repair, and where sufficient physical evidence exists, replace them with new elements that match the forms, materials and detailing of sound versions of the same elements. Where there is insufficient physical evidence, make the form, material and detailing of the new elements compatible with the character of the historic place.

11. Conserve the heritage value and character-defining elements when creating any new additions to an historic place or any related new construction. Make the new work physically and visually compatible with, subordinate to and distinguishable from the historic place.

12. Create any new additions or related new construction so that the essential form and integrity of an historic place will not be impaired if the new work is removed in the future.

Due to the fact that there is abundant on-site reuse of materials, fixtures and architectural components, it would be almost impossible for alterations and interventions to be materially distinguishable. For this reason, the assemblies, construction methodologies and archive tags of the materials will be what differentiates new from old.

As an example of distinguishable assemblies and constructions, the brickwork of the intervention will reuse bricks salvaged from on-site but will not reconstitute any historical bond patterns with the objective of differentiating the form and aesthetic of new interventions. The bond pattern will be evidently differentiated by the absence of header courses. This is only a single example of how the logic would be applied, but the straightforward change in 
assemblage illustrates the overall on-site material reuse methodology.

Archive Tags are a second, and more programatically intensive methodology for distinguishing 'new' materials versus those already in use. Given that the integral function of the project proposal is to salvage architecture, materials and heritage, the program incorporates as much material reuse on site as possible. To ensure historical legibility, not just within the complex but within the greater context of Ottawa's reuse economy, a selection of the material types which filter through and from the Booth Street Complex will be 'tagged' and archived, thereafter creating a lineage of the elements use. Materials falling into the categories of: Structural and Dimensional Elements, Large Architectural Features, Large Ornament, and Envelope Features, are those upon which the tags would be applied.

Information such as original building, date of constructions, date of deconstruction and treatments will be archived and applied to the material or component by way of a scannable bar-code - akin to an ISBN code.

Given the facilities on site, each material type could be appropriately marked - strategically located and applied in such a manner as to make the marking visible but not have it detract from the value of the piece. The associated data will be compiled within the on-site material archive and thereafter tracked.

The following enlarged plan drawings (Figures 3.19 - 3.23), illustrate to what extent the interiors of the Mechanical Shops and Store's building has been altered as part of its rehabilitation. The existing, deconstructed and new elements are distinguished by gray fill, dashed lines and no fill respectively. Given the limitations enforced via restricted site access, the drawings are as detailed as possible within the context of this project. 


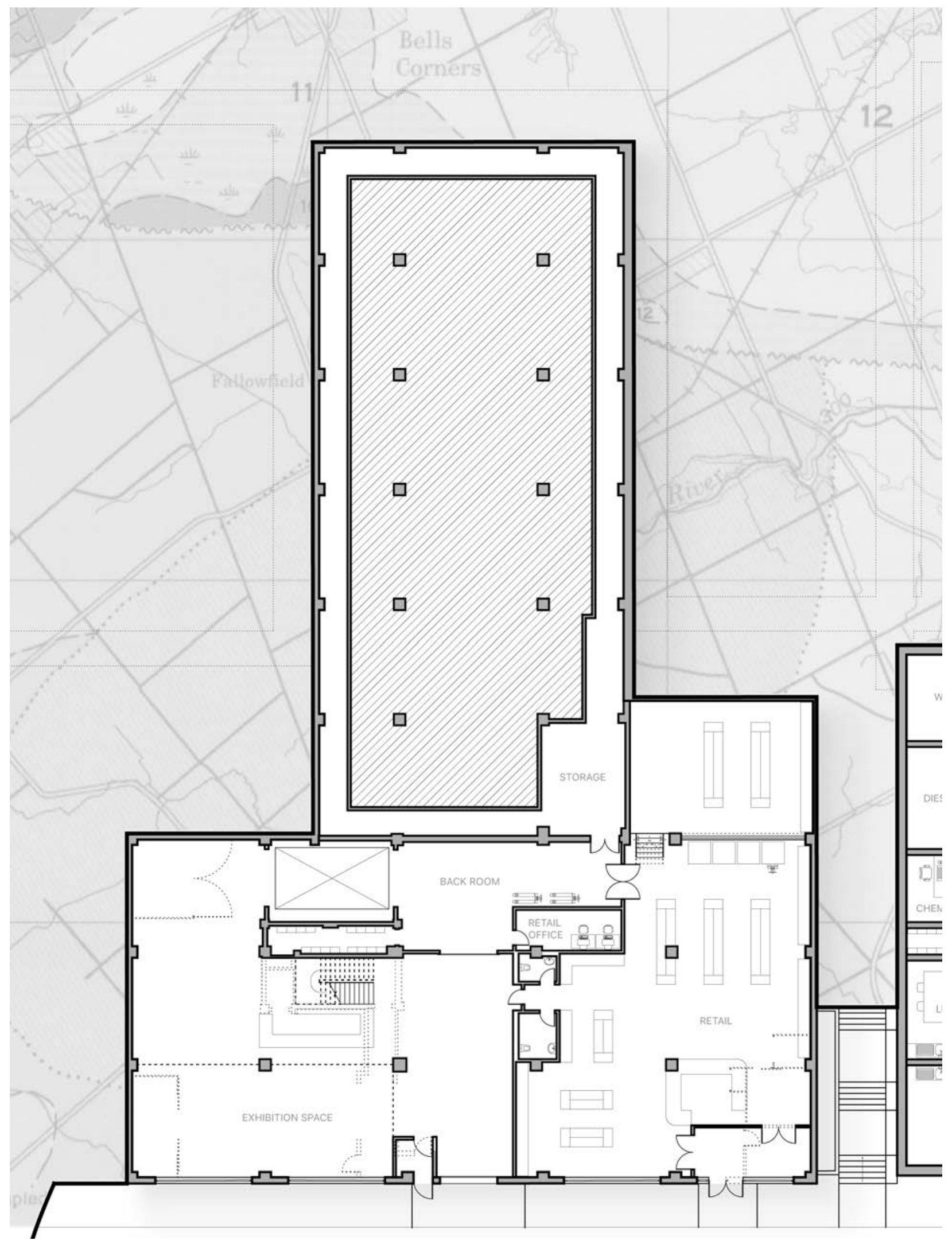

Figure 3.19: Mechanical Shops and Stored Building: Level -1 Plan 1:300 


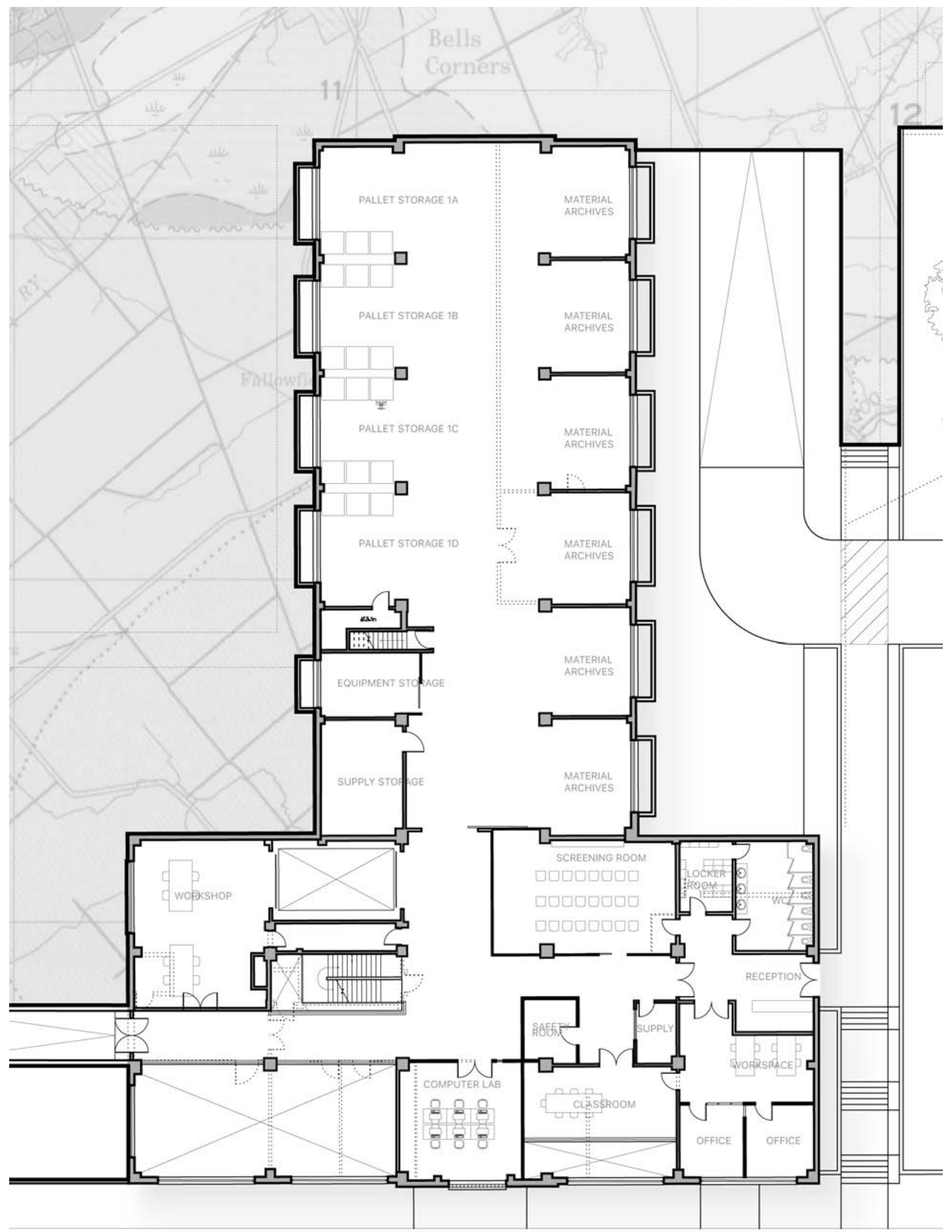

Figure 3.20: Mechanical Shops and Stored Building: Level 0 Plan $1: 300$ 


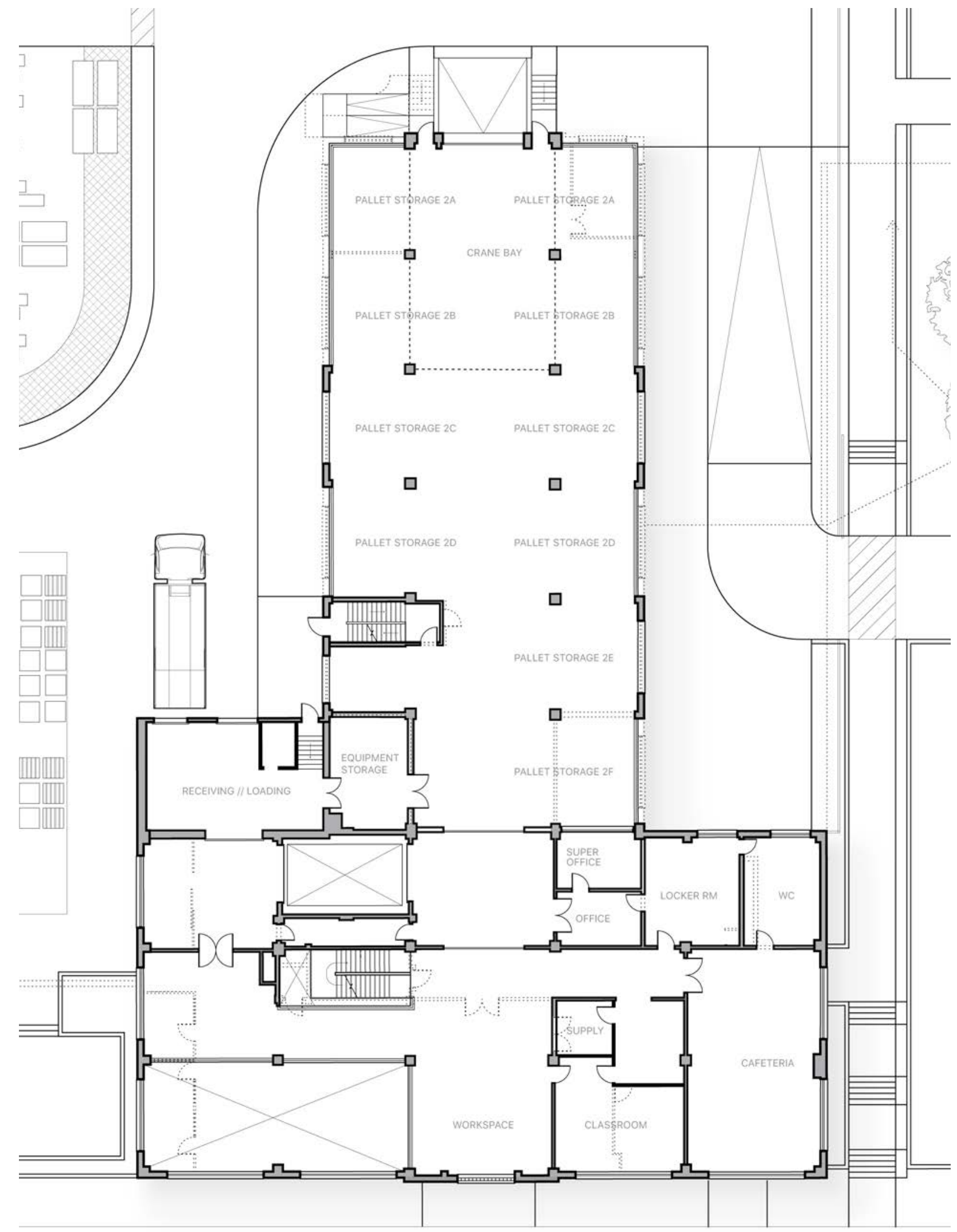

Figure 3.21: Mechanical Shops and Stored Building: Level 1 Plan 1:300 


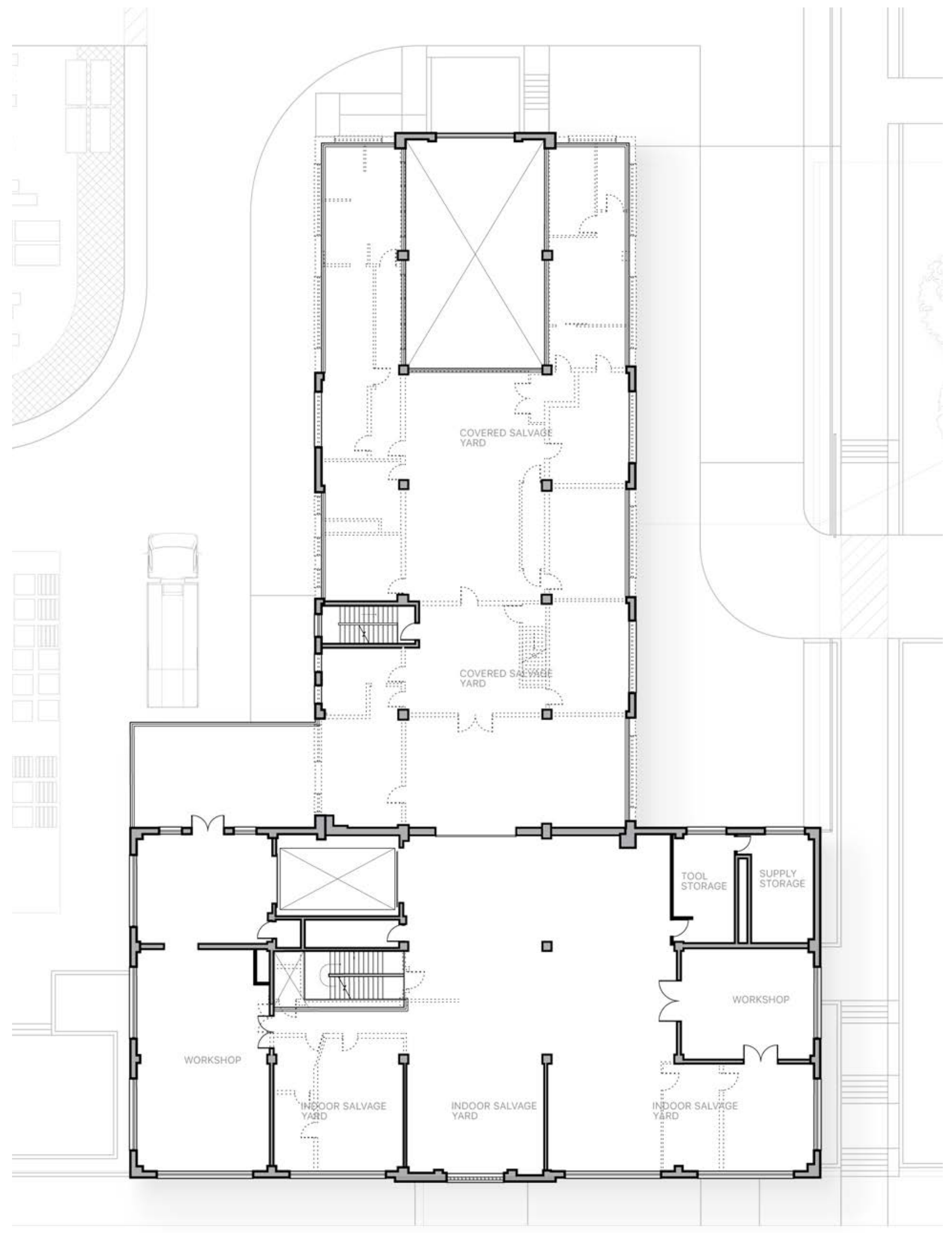

Figure 3.22: Mechanical Shops and Stored Building: Level 2 Plan 1:300 


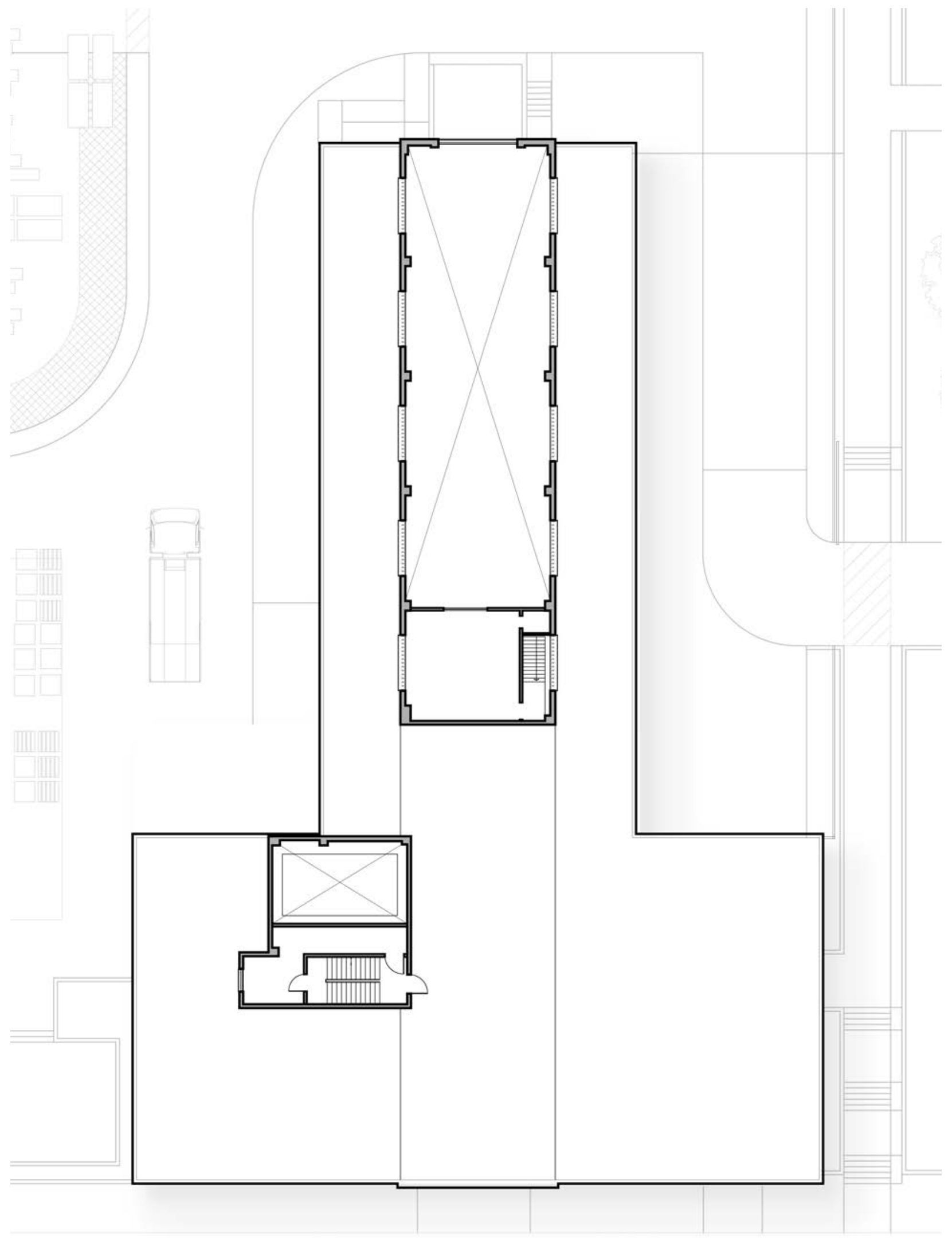

Figure 3.23: Mechanical Shops and Stored Building: Roof Plan 1:300 


\section{Chapter X}

\section{Conclusions and Post Project Reflections}

At the beginning of this thesis, the following question was posed:

Can a post-industrial urban society capitalize on the potential

of embodied material and societal wealth found within existing

architecture, via secondary sourcing, extracting and processing?

Response to Thesis Question: Ultimately, the Booth Street Complex, the epicenter of this thesis, manifest in existing built form, through future heritage interpretation and as a physical site, is itself, the site of secondary exploit the resources of which are rich and plentiful.

Throughout the process of this thesis, as well as within the resultant architectural proposal, the Booth Street Complex has served as a resource for education, story telling, research and documentation as well as one of material, energy and architectural abundance. Where tangibly, the architectural proposal crafted within this project, cannot reverse the initial extractive action, it proposes a prolonged material and societal functionality, thus negating the need for any additional primary sites of extraction. In a similar manner, the proposal extends the intangible and associate existing values, thereafter contributing to cultural sustenance via thorough heritage interpretation and the continuation and sharing of knowledge.

Secondary sourcing is realized via the decision to adapt and to conserve the existing site; extraction, via the tangible exploit of materials and the intangible exploit of heritage; and processing, via the material reconstitution and heritage interpretation. Together, these actions constitute an evaluation and thereafter a secondary exploitation through architectural reuse and salvage, in turn, fostering the notion of a circular economy via re-exploitation of materials, and of cultural continuity via heritage interpretation. 
Reflections upon Methodology: The methodology employed within this thesis was directly influenced by the thesis question itself. Posed as one which questions a the possibility of a process, the thesis question drew upon the following quote of Alex Ignatieff within 'A Canadian Research Heritage':

"The exploitation of mineral resources requires three distinct steps - geological exploration and mapping, mining and extraction ... and the processing and refining of these materials of geological origin. ${ }^{\prime 1}$

In reaction, the thesis question thereafter pondered the possibility that the same actions could be used to secondarily exploit the values and resources of the existing building stock. For this reason, not only did the work explore this process, as applied onto architectural reuse but also onto a thesis project. Although the course of work was iterative, the general process for completing the thesis work was Step 1: Sourcing via exploration and mapping of existing site conditions and histories, Step 2: Mining and extraction of archival and contemporary information, Step 3: Processing and refining of said information into an architectural proposal. This was not only a successful methodology for organizing the thesis, but it also added a layer of complexity and nuance to the work in its thematic compatibility with the site's history.

Grounding the exploratory work in a tangible site - Ottawa's Booth Street Complex - not only established a framework to work within, but enhanced the research by providing a contextual setting and specific site details. In depth analysis of the complex revealed repercussive impacts onto the greater Canadian landscape, which thereafter resulted in an increased magnitude of resource extraction as well as an increased presence of current industrial heritage nationwide. Through an examination of the statuses and evolutions of a selection of associated sites, a model of cyclical existence was derived, thereafter utilized to inform interpretation of the local architectural proposal.

Reflections upon Approach: By applying a macro, mezzo and micro logic to the interpretive architectural proposal, the thesis work is resolved to three coexisting scales: site as landscape, site as complex, and site as materials. This scalar approach allows for speculation at the macro level while also including a degree of technical design on the micro level. This proved to be a worthwhile endeavor as the final proposal addresses multiple types and scales of conditions.

At the macro level: site as landscape, the proposal is able to address the direct landscape of the complex as well as the indirect, greater landscape

1. Ignatieff, Alex. A Canadian Research Heritage. Ottawa: Canadian Gov. Publ. Centre, Supply \& Services Canada, 1981. 
of Canada's post-industrial and research sites. By evaluating the select ten industrial extraction or processing sites across Canada, which were noticeably associated with the Booth Street Complex, assumptions were made regarding the greater landscape as a whole - assumptions which were then overlaid upon the Booth Street Complex site in order to anticipate a cyclical evolution.

At the mezzo level: site as complex, the proposal is able to address formal organizations, programmatic layouts, pedestrian and vehicular circulation and site permeability.

At the micro level: site as materials, the proposal is able to address conservation treatments, material flows, the necessary degree of intervention and salvage material quantifications.

Areas for Further Development: Given the opportunity to further the resolution and outcome of this thesis work, there are certain aspects of the project which might benefit from an expansion of study or further development:

- The resolution to which the material-scale approach is developed could be improved upon by an in-depth condition assessment and a follow-up inventorying exercise.

- The regional specificity of the salvage yard programming proposal could be refined upon a study of Ottawa's material economy.

- The proposed interpretative infrastructure and presentation schematics could be expanded upon to more provocatively consider the future role of the department of natural resources upon Canadian extraction industries.

Post-Project Conclusions: This thesis project has sought to employ adaptive reuse architecture and heritage conservation with the fundamental purpose of improving the natural and built environment, specifically with regards to degradations as a result of rapid urbanization and climate change. It proposes a sustainable interpretation of the entirety of the Booth Street Complex - an interpretation which maintains existing value and promotes architectural and environmental longevity through appropriate treatment, reuse and salvage, proposing a model for encouraging the circular economy and comprehensive heritage interpretation. This being said, whilst suggesting both tenable and speculative solutions, ultimately, the thesis work represents only a cursory exploration into a much larger conservation about the contrasting roles of architectural reuse and industrial extraction in the desire for environmental and cultural sustainability. It will not be an architectural thesis which inevitably finds a solution to the widespread issues; however, work such as this must continue to support that pursuit. 


\section{Appendices}
A. Glossary
B. Site Building Information Tables
C. Photographic Documentation
D. Auxiliary Site Reports
E. The Dublin Principles
F. Thesis Defense Information
G. Reference List 


\section{Appendix A: Glossary}

Adaptation A modification of a place, intended to suit the existing use or a proposed use.

Artifact An object made by a human being, typically an item of cultural or historical interest

Brownfield A former industrial or commercial site where future use is affected by real or perceived environmental contamination

Ceramics A ceramic is a solid material comprising an inorganic compound of metal, non-metal or metalloid. Common examples are earthenware, porcelain, and brick.

Circular Economy A circular economy is an economic system aimed at minimizing waste and making the most of resources.

Cradle-to-Cradle A life-cycle trajectory that mimics the regenerative cycle of nature in which waste is reused.

Cradle-to-Grave A life-cycle trajectory from resource extraction to use phase, to disposal phase.

Cultural Landscape A property which and represents the "combined works of nature and of man"

Decomposed A state of separation or disintegration into constituent parts or elements

Deconstruction The selective dismantlement or removal of materials from buildings for primarily reuse or secondarily recycling

Degrade To physically or chemically break down

Embodied Energy The energy expenditure associated with the construction and the acquisition of new raw materials which comprise existing buildings 
Federal Disposal The process through which the Canadian Federal Government liquidates property asset via transfer or sale

Industrial Heritage An interdisciplinary method of studying all the evidence, material and immaterial, of documents, artifacts, stratigraphy and structures, human settlements and natural and urban landscapes, created for or by industrial processes.

Industrial Minerals The geological materials which are mined for their commercial value, which are not fuel (and are not sources of metals but are used in the industries based on their physical and/or chemical properties

Inoperable The state of being non-functioning

Interpretation The full range of activities intended to heighten public awareness and enhance understanding of the cultural heritage site

The physical installations, facilities, and areas at, or connected with a cultural heritage site that may be specifically utilized for the purposes of interpretation and presentation.

Metallurgy The branch of science and technology concerned with the properties of metals and their production and purification

Operable The state of being functioning

Ore A naturally occurring solid material from which a metal or valuable mineral can be profitably extracted

Post-Industrial That which no longer relies on heavy industry.

Presentation The carefully planned communication of interpretive content through the arrangement of interpretive information, physical access, and interpretive infrastructure at a cultural heritage site

Rehabilitation The sensitive adaptation of an historic place or individual component for a continuing or compatible contemporary use.

Salvage The reusable materials saved during the process of dismantlement 


\section{Appendix B: Building Information Table}

\begin{tabular}{|c|c|c|c|c|c|c|c|c|c|}
\hline Plan No. & Building Title & Quadrant & Address & $\begin{array}{l}\text { Date of } \\
\text { Construction }\end{array}$ & $\begin{array}{l}\text { Dates of Renovation } \\
\text { or Addition }\end{array}$ & Architect & FHBRO Status & OHA Status & 2019 Proprietor \\
\hline 1 & Industrial Minerals and Ceramics Laboratories & North-West & 405 Rochester St. & 1931 & .. & Noffke & Formerly Recognized & Designated & Canada Lands Corporation \\
\hline 2 & Ore Dressing Laboratories & North-West & 550 Booth St. & 1931 & - & Noffke & Formerly Recognized & Designated & Canada Lands Corporation \\
\hline за & Ore Dressings and Metallurgical Laboratories & North-West & 552 Booth St. & 1932 & -- & Noffke & Formerly Recognized & Designated & Canada Lands Corporation \\
\hline $3 b$ & Ore Dressing and Metallurgical Laboratory & North-West & 552 Booth St. & 1912 & -- & R.C. Wright & Formerly Recognized & Designated & Canada Lands Corporation \\
\hline 3c & Pyro Metallurgical Laboratory & North-West & 552 Booth St. & 1929 & -- & R.C. Wright & Formerly Recognized & Designated & Canada Lands Corporation \\
\hline $3 d$ & Hydro Metallurgical Laboratory & North-West & 552 Booth St. & 1925 & -- & R.C. Wright & Formerly Recognized & Designated & Canada Lands Corporation \\
\hline 3е & Tailings Disposal Building & North-West & 552 Booth St. & 1935 & -- & T. W. Fuller & Formerly Recognized & Designated & Canada Lands Corporation \\
\hline 4 & Mechanical Shops and Stores Building & North-West & 556 Booth St. & 1952 & -- & C. Gustave Brault & No Status & No Status & Canada Lands Corporation \\
\hline 5 & Central Heating Plant & North-West & 558 Booth St. & 1945 & -- & Noffke & No Status & Designated & Canada Lands Corporation \\
\hline 6 & Fuel Testing Laboratory & North-West & 562 Booth St. & 1927 * & 3rd FIr. 1937 & R.C. Wright \& Noffke & Formerly Recognized & Designated & Canada Lands Corporation \\
\hline 7a-e & Physical Metallurgical Research Laboratories & North-West & 568 Booth St. & $1942 *$ & $\begin{array}{l}\text { a1942, b1942, c1942, } \\
\text { d1946, e1945 }\end{array}$ & Noffke & Formerly Recognized & Designated & Canada Lands Corporation \\
\hline 8 & Chemical and Radioactive Ores Building & North-East & 555 Booth St. & 1955 & -- & Allward and Gouinlock & Recognized & No Status & Natural Resources Canada \\
\hline 9 & Geological Survey of Canada Building & South-East & 601 Booth St. & 1955 & -- & Allward and Gouinlock & Recognized & No Status & Natural Resources Canada \\
\hline 10 & Surveys and Mapping Building & South-East & 615 Booth St. & 1958 & -- & Allward and Gouinlock & Recognized & No Status & Natural Resources Canada \\
\hline 11 & Administration Building & South-West & 588 Booth St. & 1958 & -- & Allward and Gouinlock & Recognized & No Status & Natural Resources Canada \\
\hline 12 & Sir William Edmond Logan Building & South-West & 580 Booth St & 1972 & -. & unknown & No Status & No Status & Public Services and Procurement Canada \\
\hline
\end{tabular}




\section{Appendix C: Photographic Documentation}

Photographer: Kathleen Coulthart

Media: Kodak Portra 400 with Nikon FE2

Date: October 2018
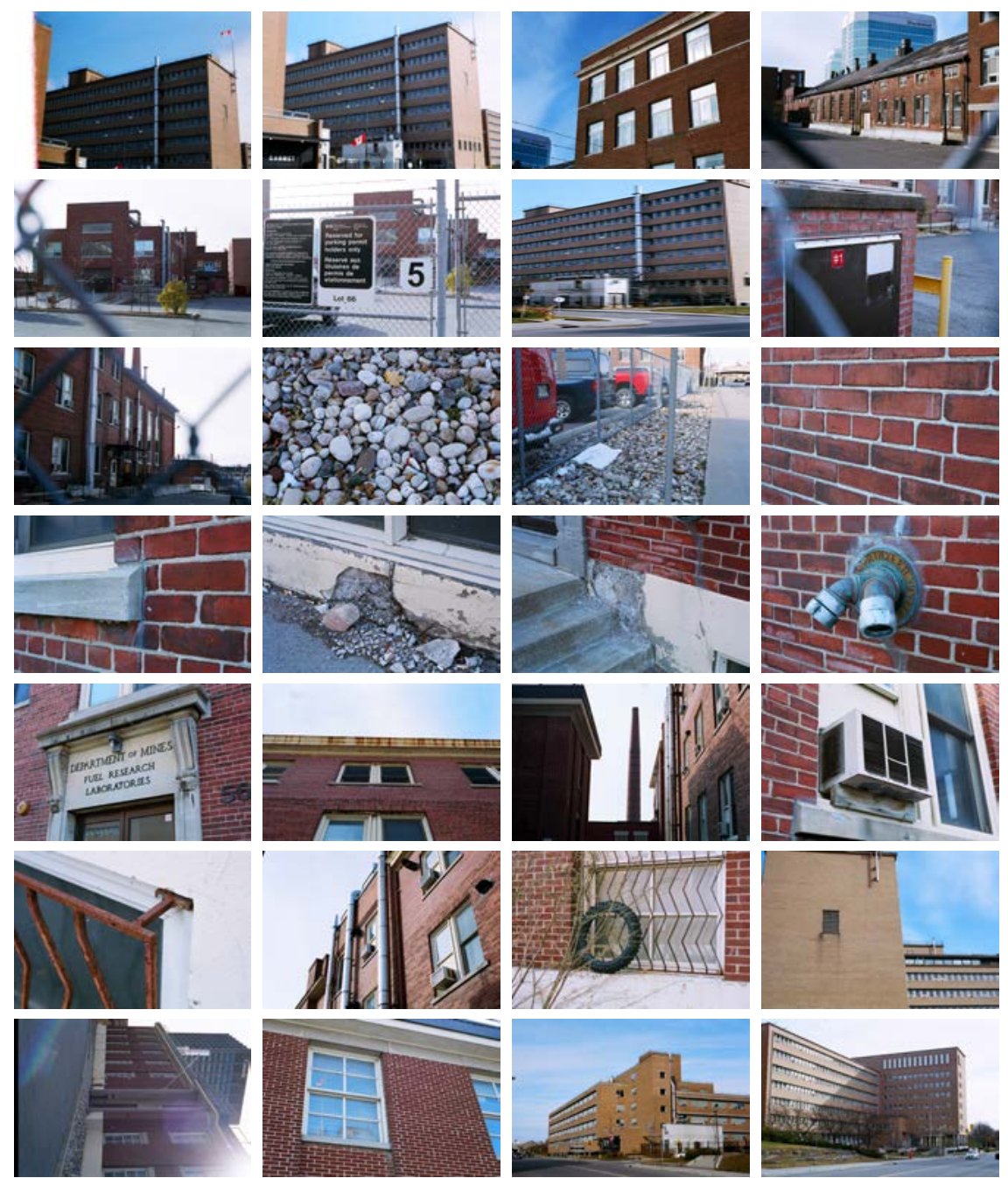


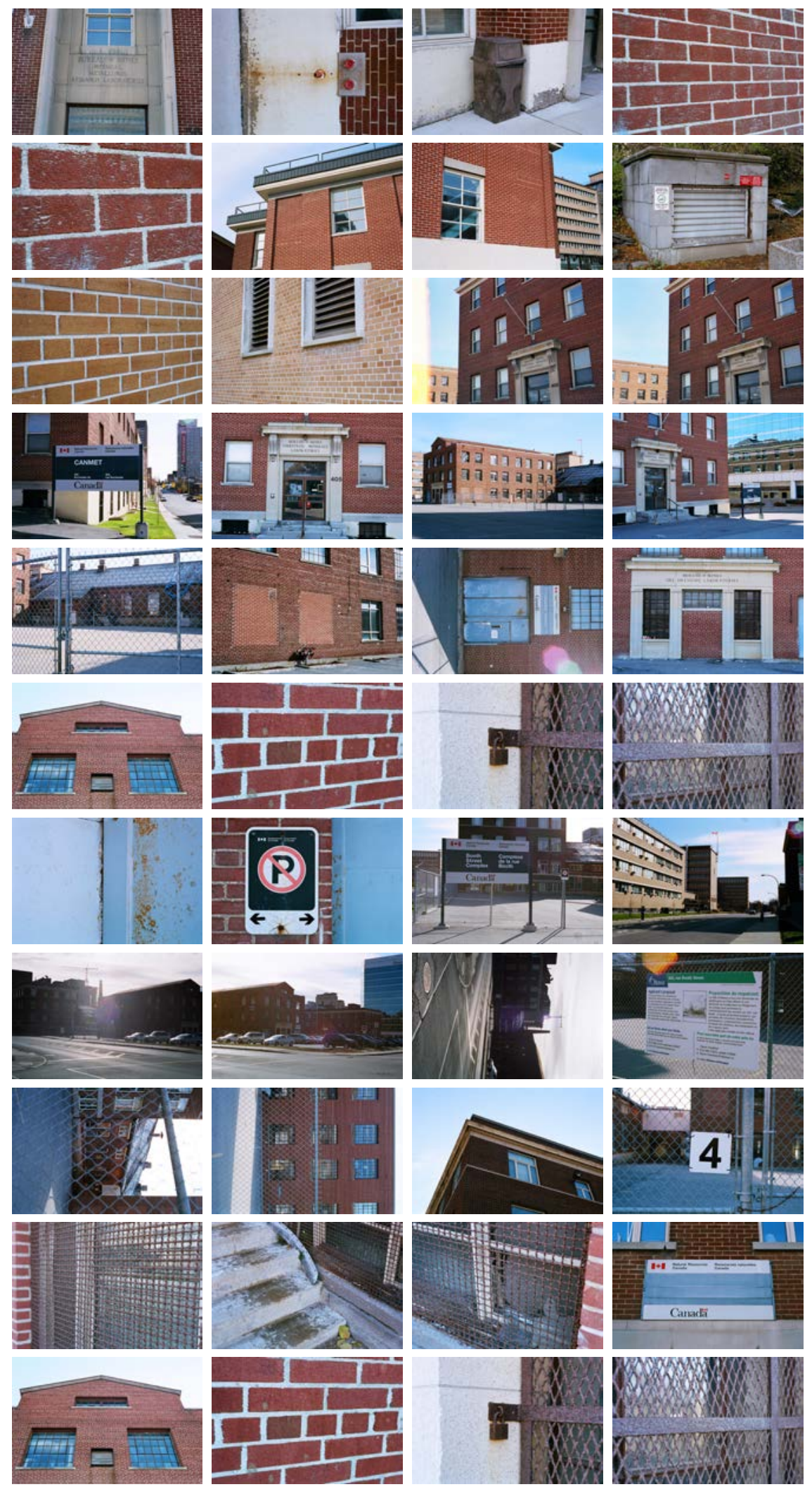




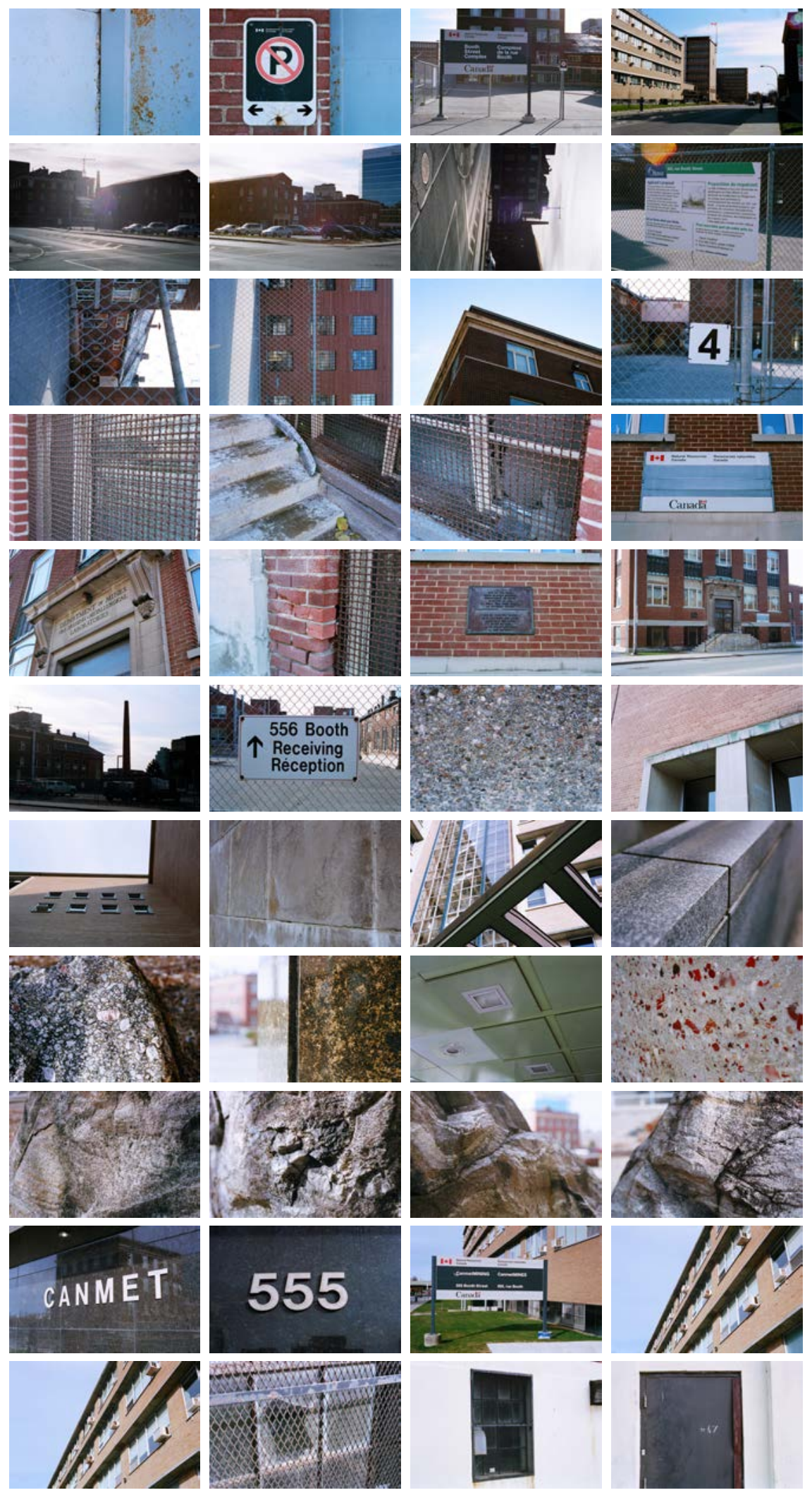



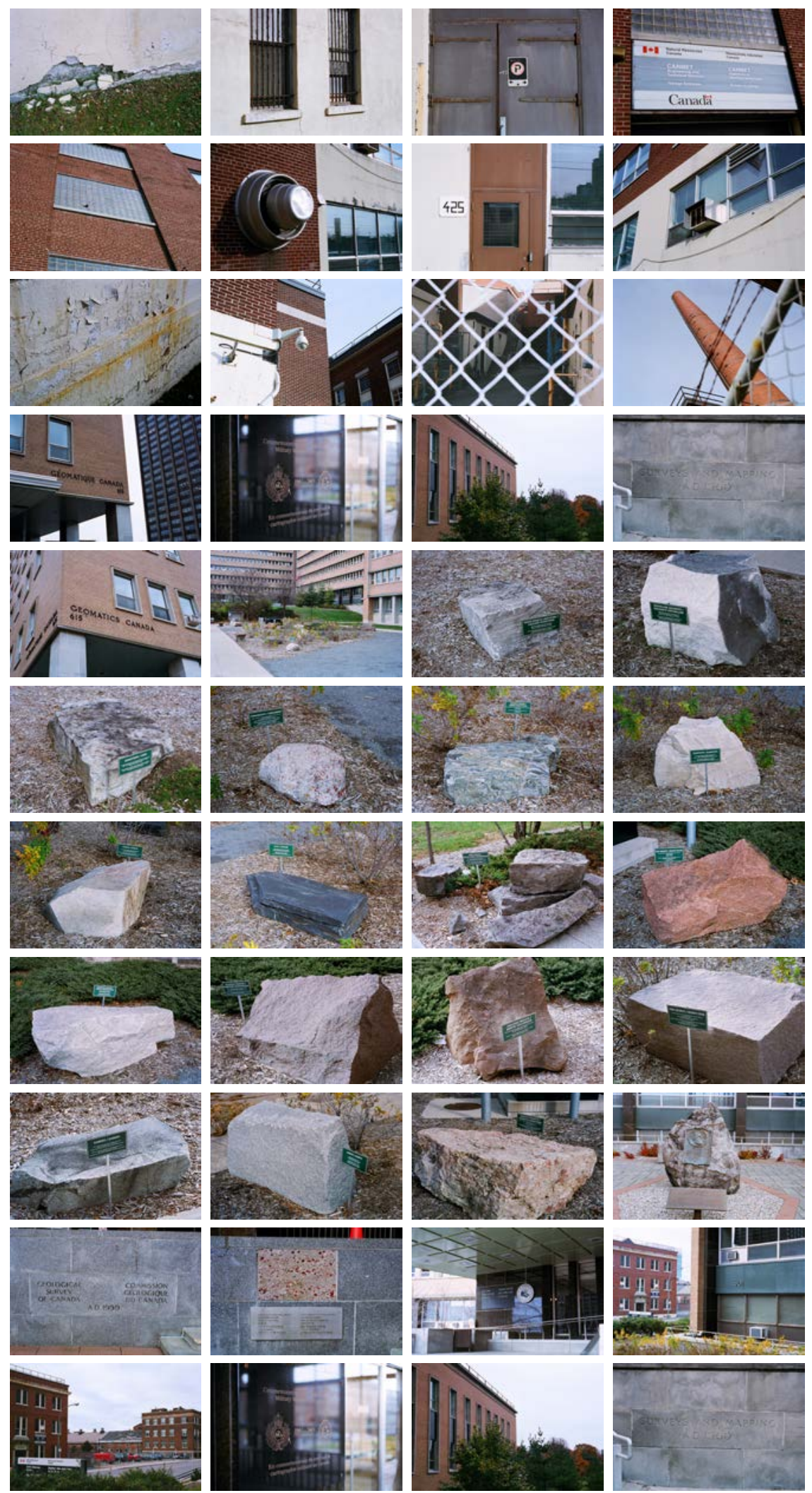


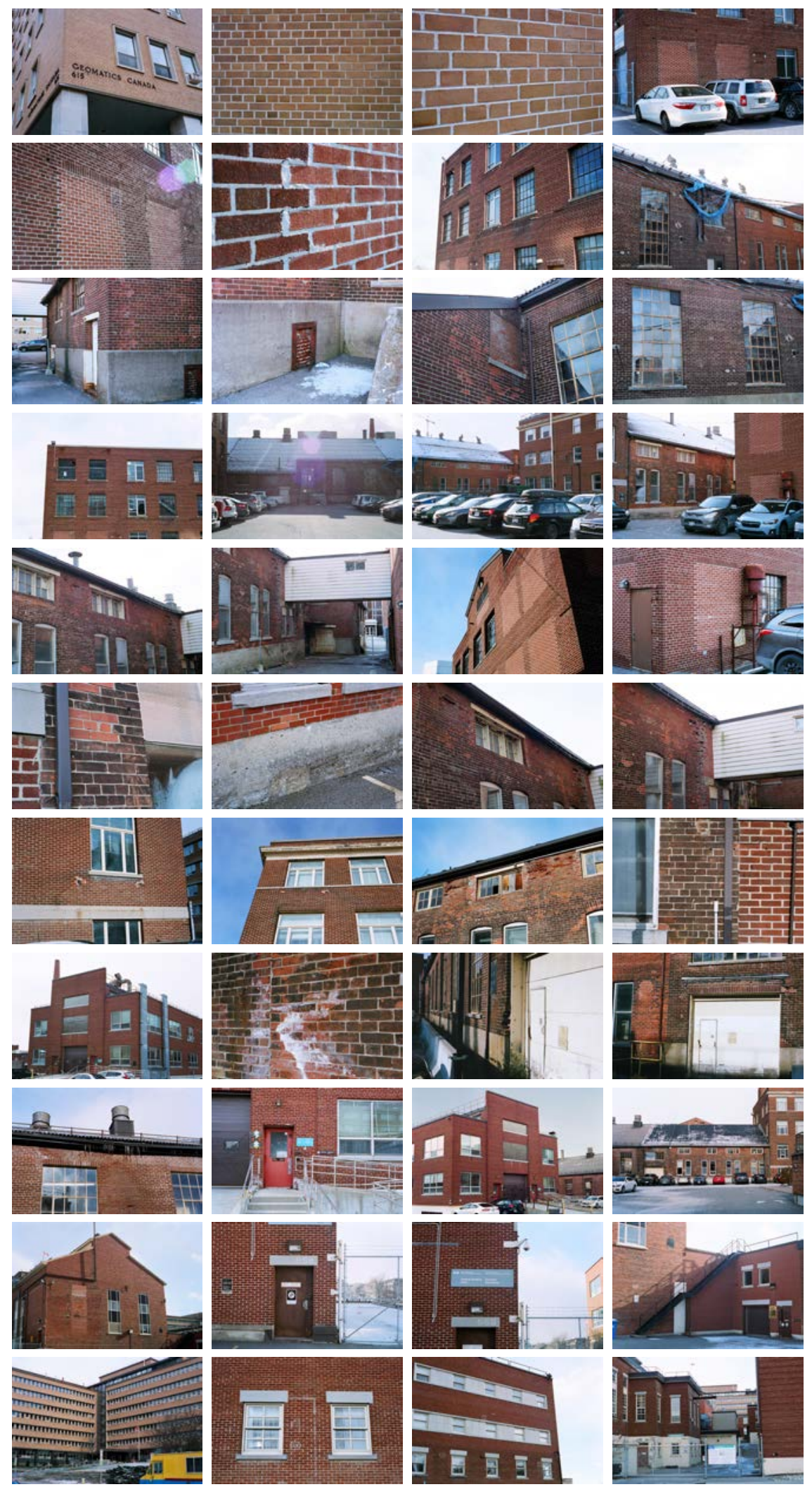




\section{Appendix D: Auxiliary Site Reports}

\section{Alfred Bog, ON}

Historical Significance: In the early 20th century, the Canadian government encouraged commercial peat extraction because peat could serve as an alternative fuel source to coal. ${ }^{1}$ Championed by Dr. Eugene Haanel, the first head of the Department of Mines around 1910, significant research was done on the viability of peat as a major source of energy. Given the magnitude of the Alfred Bog, its relative proximity to the Booth Street Laboratories and the quality of the bog ecology, extraction of peat at the site began in $1911 .^{2}$ Shortly after the initial extractions, a narrow gauge railway was built to facilitate extraction, as well as separate rail siding along the Montreal-Ottawa line for shipping. ${ }^{3}$

Contemporary Significance: The modern area of the bog is approximately 10200 acres or 41 square kilometers. It is considered the largest high quality bog in Southem Ontario. ${ }^{4}$ Environmental Conservation efforts began in 1981 when zoning changes were proposed to allow new peat harvesting development - to counteract these changes, environmentalists lobbied to protect the delicate ecology of the bog. As a result the site was designated by the Ontario Ministry of Natural Resources as a 'Class 1 Wetland' and an 'Area of Natural and Scientific Interest (ANSI)' in 1984. Although the conservation partners retain title to properties within the Bog, it is now managed by Ontario Parks as a Provincial Nature Reserve. Markedly, since its designation, the protected land has grown incrementally through the purchase of parcels of land from commercial and private owners. The Alfred Bog is recognized today as a recreational site - "the $273 \mathrm{~m}$ boardwalk lets you relish the beauty of the bog. "

Evolution: In the early 19th century, the Alfred Bog covered about 26000 acres - an area which is more than twice its present size. ${ }^{6}$ Human development of agriculture and peat extraction since then greatly reduced the bog. By 1945, the bog was reduced to 5000 acres but since its ecological conservation, has rebounded in size to 10000 acres. As a

1. Ignatieff, Alexis. A Canadian Research Heritage. Ottawa: Canadian Gov. Publ. Centre, Supply \& Services Canada, 1981

2. Ignatieff, Alexis. A Canadian Research Heritage. Ottawa: Canadian Gov. Publ. Centre, Supply \& Services Canada, 1981.

3. Churcher, Colin. "The Alfred Peat Bog Railway." Railways in Canada. December 2008.

4. Scaverley. "Alfred Bog Walk, Alfred, Ontario." South Nation Conservation Authority. October 03, 2013.

5. "Alfred Bog." OFNC. November 2017.

6. Ignatieff, Alexis. A Canadian Research Heritage. Ottawa: Canadian Gov. Publ. Centre, Supply \& Services Canada, 1981

7. "Alfred Bog." OFNC. November 2017. 
result of the peat removal, the bog is generally between 1 and 2 meters higher than the surrounding farmland. Periodic burns and presence of drainage ditches have also changed the natural conditions of the remaining bog. Although the narrow gauge railway has been removed, its path is still evident in aerial photography.

\section{Copper Cliff Mines, ON}

Historical Significance: The Copper Cliff Mine began operations in 1887 at a site now within the town of Copper Cliff and was the first major mine to be developed in the Greater Sudbury area. ${ }^{8}$ The site was preeminently discovered and was determined to have potential by two surveyors of the GSC in 1856 . ${ }^{9}$ Both surveyors were running lines throughout the territory and noticed "considerable local attraction" on their compasses meaning there was a presence of magnetic metal. ${ }^{10}$ Noting this, industry was surprisingly not developed however, until thirty years later when the Canadian Copper Company was established. ${ }^{11}$ With the demand for nickel generated by the First and Second World Wars, the mining operations in Sudbury prospered. ${ }^{12}$ The post war metals market did not sink into the disastrous recession which followed World War l; there were new demands for nickel in the automobile industry and although the world was temporarily at peace, the United States was increasing its defense stockpiles.

Contemporary Significance: The city of Sudbury's economy remains very dependent on the mining industry..$^{13}$ Recent production shutdowns of many months duration have left little doubt about the need to diversify its industrial activity. Today Copper Cliff Mine is operated by Vale, a global mining company which employs approximately 300 employees at the Copper Cliff Site and 4000 employees within Sudbury. ${ }^{14}$ In March of 2018, the company announced a plan for expansion; the current underground structure extends $1500 \mathrm{~m}$ deep and $6 \mathrm{~km}$ laterally, but the aim of the planned expansion is to increase this by 30 percent. ${ }^{15}$

Evolution: The magnitude of the mining operations within the site as well as the whole of the city of Sudbury have drastically ballooned. With the increased industry came increased construction on the site. What once was a single mine shaft puncturing the landscape some $700 \mathrm{~m}$, the same mining site houses two vertical shafts reaching over twice the original depth. ${ }^{16}$ Moreover, Vale now has plans to extend the northern shaft to almost $2 \mathrm{~km}$. The site is also now home to an associated smelter, refinery, mill and tailings pond. ${ }^{17}$

8. Turner, Bob, Marianne Quat, Ruth Debicki, and Phil Thurston. "Natural Resources Canada and Ontario Geological Survey 2015 . Copper Cliff, Greater Sudbury: A Driving Tour of Greater Sudbury's Mining Industry; GeoTours Northern Ontario Series." Science North. 2015.

9. Ignatieff, Alexis. A Canadian Research Heritage. Ottawa: Canadian Gov. Publ. Centre, Supply \& Services Canada, 1981.

10. Jewiss, Tom. "The Mining History of the Sudbury Area." Earth Sciences Museum. October 09, 2013.

11. Jewiss, Tom. "The Mining History of the Sudbury Area." Earth Sciences Museum. October 09, 2013.

12. Ignatieff, Alexis. A Canadian Research Heritage. Ottawa: Canadian Gov. Publ. Centre, Supply \& Services Canada, 1981.

13. Jewiss, Tom. "The Mining History of the Sudbury Area." Earth Sciences Museum. October 09, 2013.

14. "Sudbury." Vale Communities. Accessed November 15, 2018. http://wnw.vale.com/canada/EN/aboutvale/communities/sudbury/Pages/ default.aspx.

15. "Vale Says No New Jobs to Come with \$760M Copper Cliff Mine Expansion." CBC News. March 08, 2018

16. Turner, Bob, Marianne Quat, Ruth Debicki, and Phil Thurston. "Natural Resources Canada and Ontario Geological Survey 2015 . Copper Cliff, Greater Sudbury: A Driving Tour of Greater Sudbury's Mining Industry; GeoTours Northern Ontario Series." Science North. 2015.

17. Turner, Bob, Marianne Quat, Ruth Debicki, and Phil Thurston. "Natural Resources Canada and Ontario Geological Survey 2015 . Copper Cliff, Greater Sudbury: A Driving Tour of Greater Sudbury's Mining Industry; GeoTours Northern Ontario Series." Science North. 2015. 


\section{Jeffrey Mine, QC}

Historical Significance: At one point, the Jeffrey Mine was the top asbestos producing mine in Canada. Technically referred to as an open pit chrysotile asbestos mine, at its largest, the pit reached a diameter of $2 \mathrm{~km}$ and a depth of $350 \mathrm{~m} .{ }^{18}$ Mining began in 1879 when the land was acquired by John Mansville. Notably, in 1969 the mine pit was expanded, requiring the relocation of the adjacent town. The town of Jeffrey, which had grown alongside the mine, was home to many of the mine's workers. At one point the mine employed upwards of 2000 people.

Contemporary Significance: Today the pit is arguably seen a monument to the town's prosperous mining history. The mine has been abandoned since the year 2011 but has been inactive since 2001, leaving many of the town's residents unemployed. ${ }^{19}$ In addition to a loss of jobs, numerous residents of Jeffrey and former employees of the mine have developed mesothelioma and other respiratory conditions, likely caused from working with the asbestos fibers for so many years in industry. ${ }^{20}$

Evolution: During its operational lifetime, the open pit mine significantly grew in diameter and depth. Markedly, the town of Asbestos, which had grown in conjunction with the mine slowly lost acreage as the mine expanded. ${ }^{21}$ Since its abandonment in 2011, the mine has remained empty - void of activity but not void of life. According to residents of the town, nature is slowly regaining its territory - vegetation is growing on the upper levels, the underground facilities are now filled with water and algae and bird species have taken habitat.22

\section{Trail Smelter, BC}

Historical Significance: According to the Trail History Society, the discovery of base metal ore on the face of Red Mountain in 1890 was the single most important event in the history of the city of Trail.23 Thereafter, several mines began operations and settlement in the area increased. ${ }^{24} \ln 1895$, the smelter was constructed to treat the extracted ores and was quickly sold to the Cominco Republic of Mining - the mother company for today's TECK. ${ }^{25}$ In 1905, the newly formed federal Department of Mines investigated the region of Kootenay and published a strategic report on improving mining efficiency and smelting concentrations for lead-zinc metals. ${ }^{26}$ This undeniably provided aid to the Trail Smelter, both directly and indirectly. In the 1920s, Cominco expanded its Trail operations and increased its production of lead and zinc. ${ }^{27}$ With expansion of the smelter operations, the city prospered. The population increased as the demand for workers at the smelter grew and this resulted in many civic improvements.

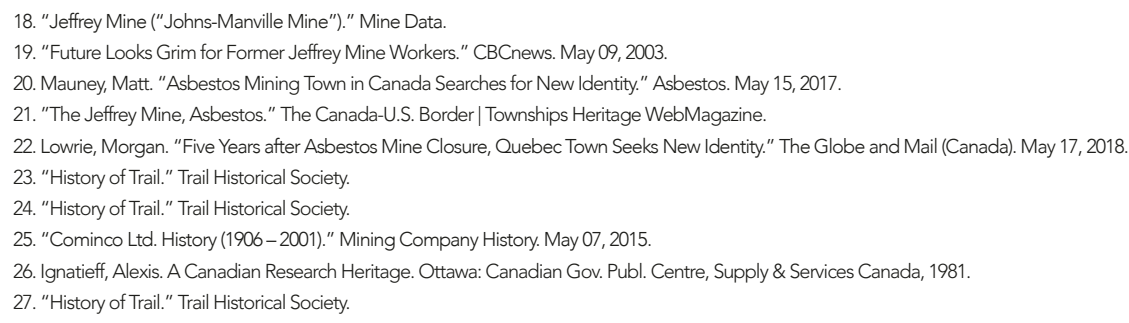


Contemporary Significance: Continuing the historical pattern, the TECK operations currentlyemployee approximately2000 people-making itthe region's largestemployer. ${ }^{28}$ The local economy is undeniably supported by the TECK corporation yet as of late, there have been concerns about the smelters other regional impacts. In 2014, nearby residents and the American EPA filed a lawsuit against the TECK, claiming that the site has been leaching toxic pollutants from the smelter into the Columbia River. ${ }^{29}$ Specifically, the lawsuit claims that between the years 1930 and 1995, the Trail Smelter discharged at least 9 million tonnes of slag containing zinc, lead, copper, arsenic cadmium, barium, antimony, chromium, cobalt, manganese, nickel, selenium and titanium into the river. ${ }^{30}$

Evolution: The Trail smelter has slowly expanded in the magnitude of operations since its opening. Its success has benefited the local economy, causing the surrounding settlements to prosper, but the site has also increased its environmental footprint. As claimed within the 2014 lawsuit, industrial pollutants have leaked into the adjacent river and in repercussion potentially caused unknowable detriment to local ecologies. As a result of the legal action, Teck has spent more than a billion dollars on improvements to the Trail operation's sustainability. ${ }^{31}$ The company says that post improvements, metals from the smelter are lower than levels that occur naturally in the river. Additionally, the company has also spent millions in remediating the area in and around the smelter. ${ }^{32}$

\section{Athabasca Tar Sands, AB}

Historical Significance: Although significant reconnaissance work on the tar sands in Athabasca was done prior to the creation of the Department of Mines, the recognized 'Father of the Oil Sands' was Sidney Ells - an engineer who joined the Mines Branch as Assistant to the Director in the year $1913 .{ }^{33}$ Ells launched a field party that year to begin a detailed survey of the oil sands in the Athabasca River valley and during his first survey of the area, collected 200 core samples. ${ }^{34}$ Notably, Ells dedicated his career to the tar sands. ${ }^{35}$ In 1936, the Dept of Mines published a comprehensive report detailing his evaluation of the deposits - the report remains the best overall reference of this resource. ${ }^{36}$ Ells work also led to the development of more efficient drills and drums. ${ }^{37}$ Once the potential value of the Athabasca Tar Sands became known, more and more extraction activity began. The resource gave way to increased settlement by way of Fort McMurray and became the driver of the regional economy.

Contemporary Significance: Today the Athabasca Tar Sands are a very controversial subject. On one hand, the Canadian economy is benefiting greatly from the extraction

\footnotetext{
28. Teck Resources Limited. "Every Day : 2016 Annual Report." TECK.

29. Moore, Dene. "Teck Smelter Lawsuit Alleges Toxins Caused Breast Cancer." HuffPost. February 19, 2014.

30. Moore, Dene. "Teck Smelter Lawsuit Alleges Toxins Caused Breast Cancer." HuffPost. February 19, 2014

31. Moore, Dene. "Teck Smelter Lawsuit Alleges Toxins Caused Breast Cancer." HuffPost. February 19, 2014.

32. Moore, Dene. "Teck Smelter Lawsuit Alleges Toxins Caused Breast Cancer." HuffPost. February 19, 2014

33. Hein, Frances. "Historical Ovenview of the Fort McMurray Area and Oil Sands Industry in Northeast Alberta." Alberta Energy and Utilities Board. May 2000.

34. Hein, Frances. "Historical Ovenview of the Fort McMurray Area and Oil Sands Industry in Northeast Alberta." Alberta Energy and Utilities Board. May 2000.

35. Ignatieff, Alexis. A Canadian Research Heritage. Ottawa: Canadian Gov. Publ. Centre, Supply \& Services Canada, 1981.

36. Ignatieff, Alexis. A Canadian Research Heritage. Ottawa: Canadian Gov. Publ. Centre, Supply \& Services Canada, 1981.

37. Ignatieff, Alexis. A Canadian Research Heritage. Ottawa: Canadian Gov. Publ. Centre, Supply \& Services Canada, 1981.
} 
endeavors via employment and foreign investment but the sites have also become notoriousfornegativeenvironmental effects. Notably, themain concerns ofenvironmental engineers are: pollution via tailing pond leakage, greenhouse gas emissions generated by extraction and processing, water depletion caused by injection and steam processes, air pollution from machinery operations and deforestation via expansion. ${ }^{38}$

Evolution: Great Canadian Oil Sands opened the first large-scale mine in 1967 but the Tar Sands did not experience large growth until the year 2000.39 After 2000, the price of oil began to climb, and investment in oil sands became profitable; this caused existing mines to expand and new mining operations to emerge. ${ }^{40}$ Markedly, this trend of growth is likely to continue - permits have been approved to expand several mines in the region. With the expansion of industry came the growth of regional urbanization.

\section{Mandy Mine, MB}

Historical Significance: Established in 1916, Mandy Mine became the first productive copper mine in Manitoba. ${ }^{41}$ Discovered in 1915 by F. C. Jackson, an experienced prospector, the mine was quickly developed by Mandy Mining Company, a subsidiary of the Tonopah Mining Company of Nevada. ${ }^{2}$ With support of the federal Mines Branch, the development used, for the first time in Canada, a diamond drill; this allowed for quicker cuts, less dust and flexibility in drilling locations. ${ }^{43}$ Between 1916 and 1920, over 17,000 tons of ore were transported to Trail Smelter in British Columbia for processing. ${ }^{44}$ With the prosperity of the copper mine, the mining town expanded into a small city.

Contemporary Significance: Today, the Mandy Mine site is home to a processing plant. Owned and operated by Canadian mining company, Hudbay, the Mandy Mine site is home to the primary ore concentrator in Manitoba. ${ }^{45}$ Although the mine itself is no longer in use, the processing operations have taken over and now supports the regional economy. The Hudbay complex includes significant areas of tailings ponds which have been accused of polluting local water sources.

Evolution: The Mandy Mine site has been host to a change in use - from copper mining to processing - and has evolved along side. With the change a processing plant only site, the plant adopted three tailings ponds, a paste backfill plant and additional support structures for maintenance shops and laboratories. ${ }^{46}$ Markedly, in 2010, the Mandy Mine site closed its smelting operations, leaving the residents of Flin Flon nervous for a potential closure of the rest of the processing plant. ${ }^{47}$ This nervousness illustrates the continued economic dependency of the city upon the sites prosperity.

\footnotetext{
38. Dyer, Simon. "Environmental Impacts of Oil Sands Development in Alberta." Resilience.

39. "World of Change: Athabasca Oil Sands." NASA.

40. "World of Change: Athabasca Oil Sands." NASA.

41. "Manitoba Heritage Council Commemorative Plaques." Historic Resources Branch : Historic Placques.

42. "Manitoba Heritage Council Commemorative Plaques." Historic Resources Branch : Historic Placques.

43. "Diamond-core Drilling." Blast Hole Drilling | Boring.

44. Goldsborough, Gordon, and Alan Mason. "Historic Sites of Manitoba: The Mandy Mine (Flin Flon)."

45. "Flin Flon Processing : Concentrator." Hudbay Minerals.

46. "Flin Flon Processing : Concentrator." Hudbay Minerals.

47. Graham, lan. "Little Change since Flin Flon's Closure." Thompson Citizen. September 16, 2014
} 


\section{Sydney Coal Fields, NS}

Historical Significance: In 1899, Sydney Nova Scotia was selected as a favorable location for the processing of Steel by industry investors. ${ }^{48}$ That same year, the Dominion Iron and Steel Company Limited began construction of a major steel works plants upon the Sydney Coal Fields site. The mill opened in 1901 and was sold to the Dominion Tar and Chemical Company Ltd (DOMTAR) in 1903.49 During the early years, samples of coal, iron and steel were frequently shipped to the federal Mines Branch Laboratories for testing - in return the department supplied the operations with information regarding their product's ductility, strength and quality..$^{50}$ By 1912, the plant was producing more than 800,000 tonnes of pig iron and 900,000 tonnes of crude steel - nearly half of Canada's steel production - and was the largest steel producer in the country. The steel mill, and the nearby coal mines that fueled it, operated for nearly a century under a variety of owners and largely supported the local economy until its closure. In 1967, Domtar ceased operations in Sydney and abandoned its storage tanks, waste disposal lagoons, pipes, buildings and equipment. ${ }^{51}$ Domtar conducted little or no clean up of the site leaving the site as an urban brownfield. ${ }^{2}$

Contemporary Significance: In 2004, as a joint venture between the federal and provincial governments, a remediation plan was proposed for the Sydney Coal Fields Site. ${ }^{53}$ As outlined in the plan's report, significant soil contamination had occurred during the site's operation life - An estimated 560,000 tonnes of soil on the Coke Ovens is contaminated with petroleum hydrocarbons, polycyclic aromatic hydrocarbons, and metals. ${ }^{54}$ An additional 1,300 tonnes of hydrocarbons contaminated sediment is present in the nearby Coke Ovens Brook and 25,000 tonnes of contaminated soil is present in the in-ground tar cell..$^{55}$ Because of this pollution, the site has been considered one of Canada's most toxic industrial waste sites. ${ }^{56}$ Post remediation, the significance of this site has changed. As part of the remediation strategy, surface restoration and site landscaping were undertaken, thereafter bringing the sites potential for hosting recreational activities.

Evolution: After the abandonment of the site and during the modern remediation efforts in 2004, the site went through strategic redevelopment. Some of the strategies implemented involved the removal of contaminants, treatment of contaminants in-situ, the creation of water controlling diversions and surface restoration..$^{77}$ Although some of the major topographical characteristics have not been altered, as evident in aerial photography, much of the site has been re-vegetated.

\footnotetext{
48. Frost, Louis. "Description of Sydney Coal Field." The Louis Frost Notes. January 5, 1998.

49. Frost, Louis. "Description of Sydney Coal Field." The Louis Frost Notes. January 5, 1998.

50. Ignatieff, Alexis. A Canadian Research Heritage. Ottawa: Canadian Gov. Publ. Centre, Supply \& Services Canada, 1981.

51. Sydney Tar Ponds Agency. "Last of the Domtar Tank Contents Destroyed." Government of Nova Scotia, Canada. November 27, 2006.

52. Sydney Tar Ponds Agency. "Last of the Domtar Tank Contents Destroyed." Government of Nova Scotia, Canada. November 27, 2006.

53. AMEC Earth \& Environmental A Division of AMEC Americas Limited. "REMEDIATION OF THE SYDNEY TAR PONDS AND COKE OVENS

SITES." Tar Ponds Cleanup. December 2004.

54. AMEC Earth \& Environmental A Division of AMEC Americas Limited. "REMEDIATION OF THE SYDNEY TAR PONDS AND COKE OVENS

SITES." Tar Ponds Cleanup. December 2004.

55. AMEC Earth \& Environmental A Division of AMEC Americas Limited. "REMEDIATION OF THE SYDNEY TAR PONDS AND COKE OVENS SITES." Tar Ponds Cleanup. December 2004.

56. "Toxic Timeline |CBC News." CBCnews. June 25, 2010.

57. AMEC Earth \& Environmental A Division of AMEC Americas Limited. "REMEDIATION OF THE SYDNEY TAR PONDS AND COKE OVENS SITES." Tar Ponds Cleanup. December 2004.
} 


\section{Port Radium, NWT}

Historical Significance: The Port Radium mine was built to excavate a vein of pitchblende ore that was originally staked by the Geological Survey of Canada's Gilbert Labine in 1930. ${ }^{58}$ Shortly after the discovery, in 1931, 20 tonnes of high-grade material was sent from Port Radium to the Booth Street Complex for hydro-metallurgical treatment and testing ${ }^{59}$ In 1932, after favorable results were found, commercial shipping from the sites first mine, Eldorado Gold Mines Ltd, began and were sent to the Trail Smelter in British Columbia. ${ }^{60}$ From the ore, not only could silver, copper, and iron be extracted, but for the first time in Canada, the mine was capable of producing radium and uranium. ${ }^{61}$ In 1942, the American government asked to purchase sixty tons of Canadian uranium oxide for use in the Manhattan Project, a task force working to develop new, extremely powerful nuclear weapons. ${ }^{62}$ In response, the Canadian government decided to purchase a controlling share of Labine's Eldorado Gold Mines Ltd., rename it Eldorado Mining and Refining Ltd. and reopen the Port Radium site as a Crown corporation. ${ }^{63}$ Afterwards, the Eldorado Mine at Port Radium continued to produce uranium ore until 1960, when it closed down again. In 1964, it reopened as a silver mine but was shut down for the final time in 1982. During its operation, many of the mines workers were from the indigenous community of Deline and were employed in positions which involved close and frequent contact with the radioactive materials. ${ }^{64}$

Contemporary Significance: Today the Port Radium Site is seen by many as a negative endeavor during Canadian History. The site is associated with the radioactive contamination of Great Bear Lake, with having detrimental health impacts unto its workers as well as with playing a role in the American nuclear bombings of World War II. Caused by the site's pollution, arise in cancer cases among the Deline population became noticeable after the mine closed in the 1980s and as a result, the community pressured the Canadian government to undertake responsibility for cleanup..$^{65}$ The resultant federal report listed twenty-six recommendations for remediation and reconciliation - a majority of which have been completed. Markedly, the thorough environmental cleanup is fraught with tension: many indigenous community elders dislike that barrels of waste are being buried on-site, rather than transported elsewhere for disposal. ${ }^{66}$ Moreover, many people still desire compensation for the cancer deaths that they attribute to radiation exposure on the land. ${ }^{67}$

Evolution: As of today, the Port Radium Site has been significantly remediated. There

58. Bothwell, Robert. "Gilbert LaBine." The Canadian Encyclopedia. November 29, 2007.

59. Ignatieff, Alexis. A Canadian Research Heritage. Ottawa: Canadian Gov. Publ. Centre, Supply \& Services Canada, 1981.

60. Ignatieff, Alexis. A Canadian Research Heritage. Ottawa: Canadian Gov. Publ. Centre, Supply \& Senvices Canada, 1981.

61. Silke, Ryan. "The Operational History of Mines in the Northwest Territories, Canada." Mining North. 2009.

62. Keeling, Arn, and John Sandlos, eds. Mining and Communities in Northern Canada: History, Politics and Memory. Calgary: University of

Calgary, 2015.

63. Keeling, Arn, and John Sandlos, eds. Mining and Communities in Northern Canada: History, Politics and Memory. Calgary: University of

Calgary, 2015.

64, Keeling, Arn, and John Sandlos, eds. Mining and Communities in Northern Canada: History, Politics and Memory. Calgary: University of Calgary, 2015.

65. Keeling, Arn, and John Sandlos, eds. Mining and Communities in Northern Canada: History, Politics and Memory. Calgary: University of Calgary, 2015.

66. Keeling, Arn, and John Sandlos, eds. Mining and Communities in Northern Canada: History, Politics and Memory. Calgary: University of Calgary, 2015.

67. Keeling, Arn, and John Sandlos, eds. Mining and Communities in Northern Canada: History, Politics and Memory. Calgary: University of Calgary, 2015. 
are no remaining artifacts on site - In 2007, the government dismantled the remaining buildings and filled in the mining shafts. ${ }^{68}$ The only evidence of past settlement and industrial activity is are dirt roads and an air strip, visible in aerial photography.

\section{Jericho Mine, NU}

Historical Significance: The Jericho Diamond Mine was Nunavut's first diamond mine, and the first mine to open in the province after joining Canada in 1999, thus making it the first mine studied by the Geological Survey of Canada in that province..$^{69}$ The mine was operational between the 2006 to 2008 but became dormant due to a slump in the global diamond market.70 In 2010, Shear Diamonds, a diamond exploration company focused within the Nunavut region, announced its purchase of the Jericho Diamond Mine and its plan to restart the operations within the year - that year came and went and the mine remained dormant. ${ }^{71}$

Contemporary Significance: The Jericho Diamond Mine has now been in a state of dormancy for a decade-resulting in frustration within the NunavutCommunity. Members of the nearby communities are worried about pollution caused by deteriorating infrastructure and neglect. ${ }^{72}$

Evolution: Since the sites abandonment, there have been no remediation efforts nor further developments. As reported by individuals living with the community, there is deterioration of the site and although no studies have been made, pollution is likely occurring. ${ }^{73}$

\section{Dredge No. 4, YK}

Historical Significance: Dredge No. 4 was built during the summer and winter of 1912 for the Canadian Klondike Mining Company on Claim 112 Below Discovery on Bonanza Creek. $^{74}$ It commenced operations in May of 1913, and dug its way upstream in the Klondike Valley into what was known as the "Boyle Concession," sinking there in 1924.75 In 1927, it was re-floated and continued to operate from the Klondike Valley to Hunker Creek. The ground at the mouth of Hunker Creek was so rich the dredge produced as much as 800 ounces of gold in a single day. ${ }^{76}$ It operated until 1940, when the operating company, the Yukon Consolidated Gold Company shut down; the Second World War brought increased wages, and a fixed price of gold which eventually took its toll on the company's profitability. ${ }^{77}$ Markedly, and all dredging activity within the Yukon ceased by $1966^{78}$

\footnotetext{
68. "Cleanup Starts on N.W.T.'s Port Radium | CBC News." CBCnews. July 30, 2007.

69. Jakubec, Jarek, and Mike Johnson. "The Jericho Diamond Mine - What Happened?" SRK NorthAmerica - Jericho Mine. 70. "New Estimates Could Double Diamond Potential for Nunavut Mining Project|CBC News." CBCnews. November 30, 2017.

71. Murray, Nick. "Nunavut Community Frustrated after Deserted Exploration Site Left to Rot|CBC News." CBCnews. April 07, 2017.

72. Murray, Nick. "Nunavut Community Frustrated after Deserted Exploration Site Left to Rot|CBC News." CBCnews. April 07, 2017.

73. Murray, Nick. "Nunavut Community Frustrated after Deserted Exploration Site Left to Rot |CBC News." CBCnews. April 07, 2017.

74. "Klondike National Historic Sites." Parks Canada. May 30, 2018.

75. "Dredge No. 4 National Historic Site of Canada." HistoricPlaces.ca - HistoricPlaces.ca.

76. "Dredge No 4." Yukon River - Background Information and Map.

77. "Dredge No 4." Yukon River - Background Information and Map.

78. "Dredge No 4." Yukon River - Background Information and Map.
} 
Contemporary Significance: Dredge No. 4 was designated as a National Historic Site by the Govemment ofCanada on Sept22nd 1997. ${ }^{79}$ According to the designationstatement : "Dredge No. 4 is commemorated because it represents the importance of dredging operations in the Yukon between 1899 and 1966. Dredges were brought to the Yukon in 1899 as a very efficient means of mining for Klondike gold. Corporate mining played a major role in the viability of the community of Dawson City and the Yukon Territory." ${ }^{\prime \prime 0}$ In addition to the values just previously stated, the Dredge has additional value today with regards to tourism - during the summer season, Parks Canada offers daily site tours.

Evolution: Since its initial construction, Dredge No. 4 has been dismantled and reconstructed. In 1940, the dredge was disassembled when paying gravels ran out in 1940, later to have all of its major mechanical components refurbished by the Yukon Consolidated Gold Corporation. ${ }^{81}$ After refurbishment, the Company encased the equipment in a new wooden hull and superstructure built-the dredge structure currently residing on Bonanza Creek. From September 1941 to the fall of 1958 it mined Bonanza Creek. It sank on its present site in 1959 and has since been preserved as a National Historic Site of Canada. ${ }^{82}$

79. "Dredge No. 4 National Historic Site of Canada." HistoricPlaces.ca - HistoricPlaces.ca.

80. "Klondike National Historic Sites." Parks Canada. May 30, 2018.

81. "Dredge No 4." Yukon River - Background Information and Map.

82. "Dredge No 4." Yukon River - Background Information and Map. 


\section{Appendix E: The Dublin Principles}

\section{ICOMOS and TICCIH Principles for the Conservation of Industrial Heritage Sites, Structures, Areas and Landscapes}

(1) Definition: The industrial heritage consists of sites, structures, complexes, areas and landscapes as well as the related machinery, objects or documents that provide evidence of past or ongoing industrial processes of production, the extraction of raw materials, their transformation into goods, and the related energy and transport infrastructures. Industrial heritage reflects the profound connection between the cultural and natural environment, as industrial processes - whether ancient or modern - depend on natural sources of raw materials, energy and transportation networks to produce and distribute products to broader markets. It includes both material assets - immovable and movable - , and intangible dimensions such as technical know-how, the organization of work and workers, and the complex social and cultural legacy that shaped the life of communities and brought major organizational changes to entire societies and the world in general.

(2) Industrial heritage sites are very diversified in terms of their purpose, design and evolution over time. Many are representative of processes, technologies as well as regional or historical conditions while others constitute outstanding achievements of global influence. Others are complexes and multiple site operations or systems whose many components are interdependent, with different technologies and historical periods frequently present. The significance and value of industrial heritage is intrinsic to the structures or sites themselves, their material fabric, components, machinery and setting, expressed in the industrial landscape, in written documentation, and also in the intangible records contained in memories, arts and customs.

I - Document and understand industrial heritage structures, sites, areas and landscapes and their values

(3) Researching and documenting industrial structures, sites, landscapes and the related machinery, equipment, records or intangible aspects is essential to their identification, conservation, and the appreciation of their heritage significance and value. Human skills and knowledge involved in old industrial processes are a critically important resource in conservation and must be considered in the heritage evaluation process. 
(4) Researching and documenting industrial heritage sites and structures must address their historical, technological and socio-economical dimensions to provide an integrated base for conservation and management. It requires an interdisciplinary approach supported by interdisciplinary research and educational programmes to identify the significance of industrial heritage sites or structures. It should benefit from a diversity of sources of expertise and information including site surveys and recording, historical and archaeological investigation, material and landscape analysis, oral history and/or research in public, corporate or private archives. Research and preservation of documentary records, company archives, building plans, and specimens of industrial products should be encouraged. The evaluation and assessment of documents should be undertaken by an appropriate specialist in the industry to which they relate to determine their heritage significance.

(5) Thorough knowledge of the industrial and socioeconomic history of an area or country or their links to other parts of the world is necessary to understand the significance of industrial heritage sites or structures. Single industry context, typological or regional studies, with a comparative component, aimed at key industrial sectors or technologies are very useful in recognizing the heritage values inherent in individual structures, sites, areas or landscapes. They should be accessible and searchable by the public, scholars as well as managers.

II - Ensure effective protection and conservation of the industrial heritage structures, sites, areas and landscapes

(6) Appropriate policies, legal and administrative measures need to be adopted and adequately implemented to protect and ensure the conservation of industrial heritage sites and structures, including their machinery and records. These measures have to address the close relation between the industrial heritage, industrial production and the economy, in particular with respect to rules for corporations and investments, trades or intellectual property such as patents, and standards applicable to active industrial operations.

(7) Integrated inventories and lists of structures, sites, areas, landscapes their setting and associated objects, documents, drawings and archives or intangible heritage should be developed and used as part of these effective management and conservation policies and protection measures. These should benefit from a legal recognition, adequate conservation and management to ensure that their significance, integrity and authenticity are maintained. In the case of industrial heritage identified through fortuitous discovery, temporary protection should be granted to allow time necessary for proper heritage documentation and research.

(8) In the case of active industrial structures or sites of heritage significance, it must be recognized that their continued use and function might carry some of their heritage significance and provide adequate conditions for their physical and economic sustainability as a living production or extraction facilities. Their specific technical characteristics and features need to be respected while implementing contemporary 
regulations such as building codes, environmental requirements or risk reduction strategies to address hazards of natural or human origin.

(9) Protection measures should apply to buildings and their contents since completeness or functional integrity is especially important to the significance of industrial heritage structures and sites. Their heritage value may be greatly jeopardized or reduced if machinery or other significant components are removed, or if subsidiary elements which form part of a whole site are destroyed. Legal and administrative frameworks should be developed to enable authorities to respond quickly to the closure of operating industrial heritage sites and complexes to prevent removal or destruction of significant elements such as machinery, industrial objects or related records

III - Conserve and maintain the industrial heritage structures, sites, areas and landscapes

(10) Appropriate original or alternative and adaptive use is the most frequent way and often the most sustainable way of ensuring the conservation of industrial heritage sites or structures. New uses should respect significant material, components and patterns of circulation and activity. Specialist skills are necessary to ensure that the heritage significance is taken into account and respected in managing the sustainable use of these industrial heritage sites and structures Building codes, risk mitigation requirements, environmental or industrial regulations, and other standards should be implemented in an adapted way to take heritage dimensions into account when they are enforced through physical interventions.

(11) Wherever possible, physical interventions should be reversible, and respect the age value and significant traces or marks. Changes should be documented. Reverting to a previous known state may be acceptable under exceptional circumstances for educational purposes, and must be based on thorough research and documentation. Dismantling and relocating are only acceptable in extraordinary cases when the destruction of the site is required by objectively proved overwhelming economic or social needs.

(12) In case of prospective redundancy, decommissioning, and/or adaptation of industrial heritage sites or structures, the processes should be recorded including, for example, where components have to be demolished and machinery has to be removed. Their material form as well as their functioning and location as part of the industrial processes should be exhaustively documented. Oral and / or written stories of people connected with work processes should also be collected.

N-Present and communicate the heritage dimensions and values of industrial structures, sites, areas and landscapes to raise public and corporate awareness, and support training and research

(13) The industrial heritage is a source of learning which needs to be communicated in its multiple dimensions. It illustrates important aspects of local, national and international history and interactions over times and cultures. It demonstrates the inventive talents related to scientific and technological developments, as well as social and artistic 
movements. Public and corporate awareness and understanding for the industrial heritage are important means for its successful conservation.

(14) Programmes and facilities such as visits of active industrial heritage sites and the presentation of their operations as well as the stories and intangible heritage associated with their history, machinery and industrial processes, industrial or city museums and interpretation centres, exhibitions, publications, websites, regional or trans-boundary itineraries should be developed and sustained as means to raise awareness and appreciation for the industrial heritage in the full richness of its meaning for contemporary societies. These should ideally be located at the heritage sites itself where the process of industrialisation has taken place and can be best communicated. Wherever possible, national and international institutions in the field of research and conservation of heritage should be empowered to use them as educational facilities for the general public and the professional communities. 


\section{Appendix F: Thesis Defense Information}

Date: April 17th, 2019

Location: The Lightroom Gallery, Carleton School of Architecture

Defense Committee: Victoria Angel (External), Prof. Sheryl Boyle

(Departmental), Prof. Ozayr Saloojee (Chair), Prof. Mariana Esponda (Advisor),

Prof. Susan Ross (Advisor)

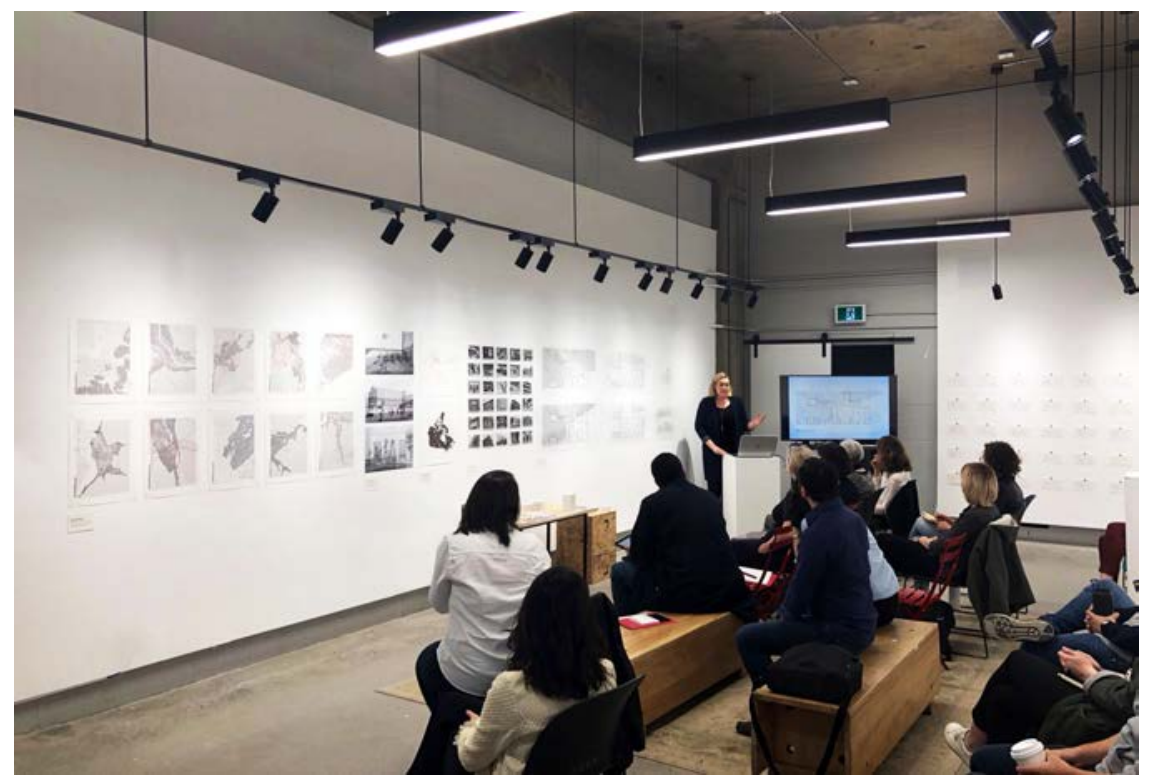

Photograph by: Liane Lanzar, Carleton University 


\section{Appendix G: Reference List}

Addis, Bill, and Owen Jenkins. "Briefing: Design for Deconstruction." Waste and Resource Management 161 (February 2008): 9-13. Accessed March 9, 2019. doi:10.1680/warm.2008.161.1.9.

Addis, Bill. Building with Reclaimed Components and Materials: A Design Handbook for Reuse and Recycling. Routledge, 2012.

Alfrey, Judith. INDUSTRIAL HERITAGE: Managing Resources and Uses. Place of Publication Not Identified: Routledge, 2016.

Ammon, Francesca. "Bulldozer: Demolition and Clearance of the Postwar Landscape." Lecture, Herb Stovel Memorial Lecture, Azrieli School of Architecture and Urbanism, Ottawa, August 20, 2018.

Ammon, Francesca. Bulldozer: Demolition and Clearance of the Postwar Landscape. John Hopkins University Press, 2016.

Arlotta, Allison Iris. "Locating Heritage Value in the Reciprocal Relationship between Preservation and Waste Reduction." Master's thesis, Columbia University, 2018. September 25, 2018. Accessed March 9, 2019. https:// academiccommons.columbia.edu/doi/10.7916/D8JM3THO.

Bélanger, Pierre. Extraction Empire: Undermining the Systems, States, \& Scales of Canadas Global Resource Empire. Cambridge, MA: MIT Press, 2018

Berger, Marcus, Liliane Wong, Damian White, and Ernesto Aparicio. Int AR: Interventions, Adaptive Reuse. Basel: Birkhauser Va, 2014.

Brandt, Mark. Conservation and Development of Canada's Industrial Heritage. ICOMOS, 1999.

Butler, Don. "Redevelopment Process Set to Begin on Former NRCan Booth StreetProperty." Ottawa Citizen. June 15, 2016. Accessed March 17, 2019. https://ottawacitizen.com/news/local-news/redevelopment-processset-to-begin-on-former-nrcan-booth-street-property.

Cameron, Christina. World Heritage Sites of Conscience and Memory. UNESCO, 2011.

Campbell, Claire Elizabeth. Nature, Place, and Story: Rethinking Historic Sites in Canada. Montreal Et Kingston; London; Chicago: McGill-Queens University Press, 2017.

Carroon, Jean. Sustainable Preservation: Greening Existing Buildings. Hoboken: Wiley, 2010.

Casella, Eleanor Conlin., and James Symonds. Industrial Archaeology: Future Directions. New York: Springer, 2005

Clark, Kate. Informed Conservation: Understanding Historic Buildings and Their Landscapes for Conservation. London: English Heritage, 2003.

Corboz, Andre. The Land as Palimpsest. Diogenes, 1983.

Corner, James. Mappings: The Agency of Mapping: Speculation, Critique and Invention. Edited by Denis Cosgrove. Reaktion Books, 2000.

Cossu, R., and I. D. Williams. "Urban Mining: Concepts, Terminology, Challenges." Current Neurology and Neuroscience Reports. November 2015. Accessed December 15, 2018. https://unw.ndbi.nlm.nih.gov/ pubmed/26505691.

Crowther, Philip. Developing an Inclusive Model for Design for Deconstruction. Queensland University of Technology, 2001.

De Silva, Megan, and Jane Henderson. "Sustainability in Conservation Practice." Journal of the Institute of 
Conservation 34, no. 1 (March 2011). doi:10.1080/19455224.2011.566013.

Dept. Energy, Mines \& Resources, comp. Facts from Canadian Maps. Ottawa: Information Canada, 1972.

Douet, James. Industrial Heritage Re-tooled: The TICCIH Guide to Industrial Heritage Conservation. London: Routledge, 2016.

Edensor, Tim. Industrial Ruins: Space, Aesthetics and Materiality. Oxford: Berg Publishers, 2005.

ERAArchitecture, Stantec Consulting Ltd., and Hill Knowlton Strategies. "Canada Lands Company Booth Street Redevelopment." City of Ottawa Webcast. March 28, 2018. Accessed November 15, 2018. http:// webcast.ottawa.ca/plan/All_Image Referencing_OPAmendmentApplication_Image Reference_2018_07_18 Planning Rationale-D01-01-18-0003.PDF

Falser, Michael. Industrial Heritage Analysis: World Heritage List and Tentative List: Is Industrial Heritage Underrepresented on the World Heritage List? UNESCO World Heritage Centre - Asia-Pacific Region, 2001.

Federal Heritage Buildings Review Office. "Processes: Disposal." Parks Canada - History and Culture. April 01, 2017. Accessed March 18, 2019. https://hww.pc.gc.ca/en/culture/beefp-fhbro/process/alienation-disposal.

Fessenden, Marissa. "The Rise and Fall of the Wrecking Ball." Smithsonian.com. January 08, 2016. Accessed March 09, 2019. https://uww.smithsonianmag.com/smart-news/rise-and-fall-wrecking-ball-180957752/.

Golder Associates Ltd. Phase One Environmental Site Assessment. Ottawa: Golder, 2018

Golder Associates Ltd. Phase Two Environmental Site Assessment. Ottawa: Golder, 2018.

Greider, Thomas, and Lorraine Garkovich. Landscapes: The Social Construction of Nature and the Environment. University of Kentucky, 1994.

Grima, Reuben, and JoAnn Cassar. Approaches to Industrial Heritage: What Works? Malta: University of Malta, 2013.

Grundhauser, Eric. "The Indestructible Appeal of the Wrecking Ball." Atlas Obscura. February 29, 2016 Accessed March 09, 2019. https://uww.atlasobscura.com/articles/the-indestructible-appeal-of-the-wreckingball.

Guy, Brad. "Towards a Broader Culture of Reuse: US Perspective." Lecture, Heritage in Reverse Symposium, Carleton University, Ottawa, October 27, 2018. Accessed March 9, 2019. https://youtu.beNAdO9awGFYk.

Harison, Rodney. Heritage: Critical Approaches. London: Routledge, 2013.

Ignatieff, Alex. A Canadian Research Heritage. Ottawa: Canadian Gov. Publ. Centre, Supply and Senvices Canada, 1981

Jeffrey, Colin. Construction and Demolition Waste Recycling: A Literature Review. Halifax, NS: Dalhousie University, 2011

Julian Smith and Associates, and Contentworks Inc. Definition and Assessment of Cultural Landscapes of Heritage Value on NCC Lands. National Capital Commission, 2004

Kalman, Harold. Heritage Planning: Principles and Process. New York: Routledge, 2014.

Kirkwood, Niall. Manufactured Sites: Rethinking the Post-industrial Landscape. London: Taylor and Francis, 2011

Knights, Paul. "Cultural Landscapes, Ecological Restoration and the Intergenerational Narrative." The International Library of Environmental, Agricultural and Food Ethics, 2014, 93-108. doi:10.1007/978-3-31907683-6_6.

Latz Partner. "Duisburg Nord Landscape Park, DE." Latz Partner: Postindustrial Landscapes. Accessed March 12, 2019. https://mww.latzundpartner.de/en/projekte/postindustrielle-landschaften/landschaftspark-duisburgnord-de/.

Liu, Jing. "Landscape Architectural Approaches to Post-Industrial Sites." Master's thesis, The University of Georgia, 2013

Lores, Luis. "Post-Industrial Landscapes: Dereliction or Heritage?" Lecture, WSEAS International Conference on Landscape Architecture, Los Angeles. Accessed January 4, 2019.

Mah, Alice. Industrial Ruination, Community, and Place: Landscapes and Legacies of Urban Decline. Toronto: University of Toronto Press, 2013.

Mah, Alice. Industrial Ruination, Community, and Place: Landscapes and Legacies of Urban Decline. Toronto: University of Toronto Press, 2013.

Maitland, Leslie, and Graham, Fern. FHBRO Building Report 92-43, 92-45a, 92-45b: Chemical and Radioactive Ores Building (now CANMET), Geological Survey of Canada Building, Surveys and Mapping Building, 555, 601 and 615, Booth Street, Ottawa. Ottawa, ON: Federal Heritage Buildings Review Office, 1992.

Mattie, Joan. FHBRO Building Report 97-83: Administration Building, Natural Resources Canada, 588 Booth Street, Ottawa. Ottawa, ON: Federal Heritage Buildings Review Office, 1997. 
McClelland, Michael. "Learning from the Distillery District." Canadian Architect, The National Review of Design and Practice, The Official Magazine of the RAIC. February 01, 2005. Accessed March 12, 2019. https://uww. canadianarchitect.com/features/learning-from-the-distillery-district.

Meeks, Stephanie, and Kevin C. Murphy. The past and Future City: How Historic Preservation Is Reviving Americas Communities. Washington D.C: Island Press, 2016.

Meinig, Donald W. The Beholding Eye: Ten Versions of the Same Scene.

Meinig, Donald W. The Interpretation of Ordinary Landscapes: Geographical Essays. New York, NY: Oxford University Press, 1979.

Meryman, Helena. "Strutural Materials in Historic Restoration." APT Bulletin 36, no. 4, 31-38. Accessed February 11, 2019. https://umw.jstor.org/stable/40003161.

New Life for Historic Cities: The Historic Urban Landscape Approach Explained. Paris: UNESCO, 2013.

O'Connor, Jennifer. Survey on Actual Service Lives for North American Buildings. Vancouver, BC: Forintek Canada, 2004 .

Office of the Comptroller General. "Guide to the Management of Real Property." Treasury Board of Canada Secretariat. October 24, 2011. Accessed March 18, 2019. https://mww.tbs-sct.gc.ca/rpm-gbi/doc/gmrp-ggbi/ gmrp-ggbi07-eng.asp.

Pill, Jaan. "Burra Charter Offers a Guideline for Adaptive Reuse of Heritage Buildings." Preserved Stories. June 29, 2013. Accessed March 09, 2019. http://preservedstories.com/2013/06/29/the-burra-charter-is-sometimescited-as-a-guideline-for-adaptive-reuse-of-heritage-buildings/.

Podner, Alice. "North Duisburg Landscape Park." ALL CHANGE: 'DARC' - Designing the New World: Developing Architectural Education in Response to Climate Change. Accessed March 12, 2019. https:// rmitallchange.weebly.com/north-duisburg-landscape-park.html.

Pollutech Geoenvironmental. "Phase I \& II Environmental Site Assessments." Pollutech Group of Companies. Accessed March 18, 2019. http://www.pollutechgroup.com/page/5666/0-1/phase i and ii environmental assessments.aspx

Poulios, loannis. The Past in the Present: A Living Heritage Approach. Ubiquity Press, 2014.

Reevely, David. "Ottawa Hospital Looks for Ways to Salvage Heritage at Sir John Carling Site." Capital Modern. March 06, 2018. Accessed March 09, 2019. http:///mw.capitalmodern.ca/news/ottawa-hospital-looksways-salvage-heritage-sir-john-carling-site/.

Ricketts, Shannon. FHBRO Building Report 86-61: Four Structures on the EMR Complex, Booth Street, Ottawa. Ottawa, ON: Federal Heritage Buildings Review Office, 1986

Ricketts, Shannon. FHBRO Building Report 87-108: Physical Metallurgy Laboratories, EMR Complex, Booth Street, Ottawa. Ottawa, ON: Federal Heritage Buildings Review Office, 1987.

Ross, Susan. "A Bibliography on Demolition Waste and Deconstruction." Discard Studies, November 27, 2017. https://discardstudies.com/2017/11/27/a-bibliography-on-demolition-waste-and-deconstruction/.

Ross, Susan. Heritage in Reverse: Material Values, Waste and Deconstruction. Carleton University, School of Indigenous \& Canadian Studies, 2018

Rotor. "Opalis." Rotor Brussels. Accessed March 12, 2019. http://rotordb.org/project/2012_opalis.

Rotor. "Opalis.be Homepage." Opalis. Accessed March 12, 2019. https://opalis.be/fr.

Sally Coutts, and Court Curry. Report to Ottawa's Built Heritage Sub Comittee. 2011.

SelldorfArchitects. "Sunset Park Material Recovery Facility." Selldorf Architects - New York. Accessed March 13, 2019. https://uww.selldorf.com/projects/sunset-park-material-recovery-facility.

Smith, Laurajane, and Natsuko Akagawa, eds. Intangible Heritage. Routledge, 2009.

Snyder, John W. "Historic Preservation and Hazardous Waste: A Legacy of the Industrial past." APT Bulletin 24, no. 1/2 (1992): 67-73. Accessed February 11, 2019. doi:10.2307/1504312.

Soares, Liliana, and Fatima Pombo. Interpretation as a Design Method. Portugal and Polytechnic Institute of Viana Do Castelo, 2010

Spears, Tom. "Booth Street Site in Critical Condition." Ottawa Citizen. June 2, 2011. Accessed March 17, 2019. https://umw.pressreader.com/canada/ottawa-citizen/20110602/285065570708493

Standards and Guidelines for the Conservation of Historic Places in Canada. 2nd ed. Canada's Historic Places and Parks Canada, 2010.

Sugden, Evan. "The Adaptive Reuse of Industrial Heritage Buildings: A Multiple-Case Studies Approach." Master's thesis, University of Waterloo, 2017. January 09, 2018. Accessed March 9, 2019. https://uwspace. uwaterloo.ca/handle/10012/12823. 
Szczepanowska, Hanna M. Conservation of Cultural Heritage: Key Principles and Approaches. London: Routledge, 2013.

Taylor, John H. Ottawa, an Illustrated History. Brantford, Ont: W. Ross MacDonald School Resource Senvices Library., 2008, 11

Taylor, Ken. "Landscape and Memory." Lecture, 16th ICOMOS General Assembly and International Symposium, Quebec. Accessed January 4, 2019. http://openarchive.icomos.org/139/.

The ICOMOS Charter for the Interpretation and Presentation of Cultural Heritage Sites. Quebec, QC: ICOMOS, 2008

Tilden, Freeman, and R. Bruce. Craig. Interpreting Our Heritage. Chapel Hill: Univ. of North Carolina Press, 2008

Tumak, Edgar. FHBRO Building Report $86-61$ (resubmitted): Ore Dressing Laboratory, EMR, Canmet Complex, 550 Booth Street, Ottawa. Ottawa, ON: Federal Heritage Buildings Review Office, 1986.

Valenzuela, Karen. "Sunset Park Material Recovery Facility / SelldorfArchitects." ArchDaily. May 27, 2014. Accessed March 13, 2019. https://www.archdaily.com/509387/sunset-park-material-recovery-facility-selldorfarchitects.

Wright, Helena E., and Robert M. Vogel, eds. Industrial Heritage '84 Proceedings. Vol. 2. Society for Industrial Archaeology.

Yeheyis, Muluken. An Overview of Construction and Demolition Waste Management in Canada: A Lifecycle Analysis Approach to Sustainability. Springer, 2012.

Yost, Peter. "Deconstruction versus Demolition." Green Building Advisor. August 10, 2018. Accessed March 09, 2019. https://www.greenbuildingadvisor.com/article/deconstruction-versus-demolition.

Zaslow, Moris. Reading the Rocks: The Story of the Geological Survey of Canada, 1842-1972. Ottawa: Macmillan Company of Canada in Association with the Dept. of Energy, Mines and Resources, 1975.

"Administration Building." THE CANADIAN REGISTER. Accessed March 18, 2019. https://umw.historicPlaces. ca/en/rep-reg/place-lieu.aspx?id=11137\&pid=0

"Booth Street Complex, Surveys and Mapping Building." THE CANADIAN REGISTER. Accessed March 18 2019. https://umw.historicPlaces.ca/en/rep-reg/place-lieu.aspx?id=10145\&pid=0

"Chemical Radioactive Ores Building." THE CANADIAN REGISTER. Accessed March 18, 2019. https://unw. historicPlaces.ca/en/rep-reg/place-lieu.aspx?id=9828\&pid=0

"City of Ottawa Development Applications." Development Application Search. Accessed March 18, 2019. https://app01.ottawa.ca/postingplans/home.jsf?lang=en.

"Dublin Principles." The International Committee for the Conservation of the Industrial Heritage. 2011 Accessed January 04, 2019. http://ticcih.org/about/about-ticcih/dublin-principles/.

"Dublin Principles." TICCIH. Accessed March 10, 2019. http://ticcih.org/about/about-ticcih/dublin-principles/.

"Early Districts and Counties 1788-1899." The Changing Shape of Ontario: Early Districts and Counties 17881899. Accessed March 18, 2019. http://www.archives.gov.on.ca/en/maps/ontario-districts.aspx.

"EMR Complex: Fuel Testing Laboratory." THE CANADIAN REGISTER. Accessed March 18, 2019. https:// unw.historicPlaces.ca/en/rep-reg/place-lieu.aspx?id=4666

"Geological Survey of Canada Building." THE CANADIAN REGISTER. Accessed March 18, 2019. https://uww. historicPlaces.ca/en/rep-reg/place-lieu.aspx?id=11135\&pid=0

"Industrial Minerals and Ceramics." THE CANADIAN REGISTER. Accessed March 18, 2019. https://uww. historicPlaces.ca/en/rep-reg/place-lieu.aspx?id=4671\&pid=0.

"Materials." Opalis. Accessed March 10, 2019. https://opalis.be/fr.

"Ore Dressing Laboratory." THE CANADIAN REGISTER. Accessed March 18, 2019. https://unw. historicPlaces.ca/en/rep-reg/place-lieu.aspx?id=4665

"Physical Metallurgy Laboratory." THE CANADIAN REGISTER. Accessed March 18, 2019. https://umw. historicPlaces.ca/en/rep-reg/place-lieu.aspx?id=4698\&pid=0

"Solid Waste Diversion And Disposal." Canada.ca (Environmental Indicators). December 20, 2018. Accessed March 09, 2019. https://uww.canada.ca/en/environment-climate-change/services/environmental-indicators/ solid-waste-diversion-disposal.html.

"The Nizhny Tagil Charter For The Industrial Heritage." The International Committee for the Conservation of the Industrial Heritage. 2011. Accessed January 04, 2019. http://ticcih.org/about/charter/ 